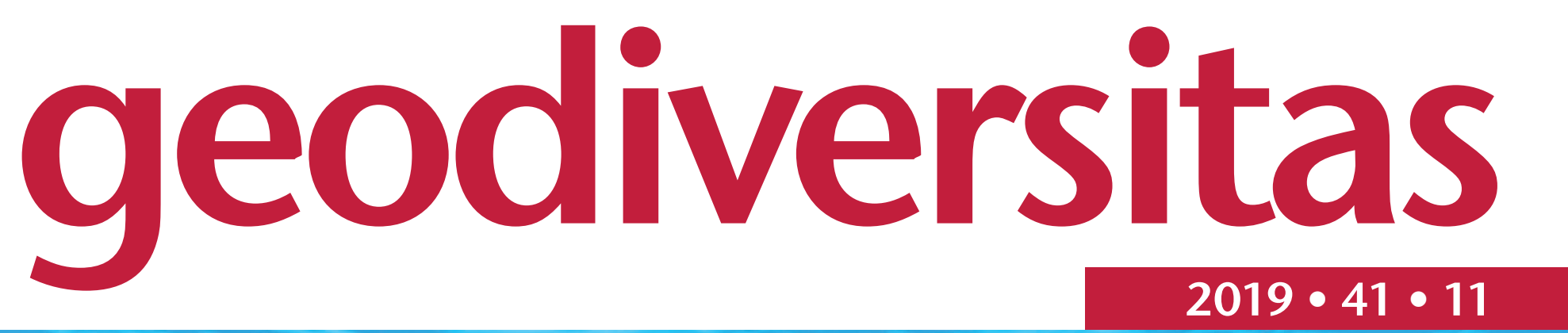

Mystacodon selenensis, the earliest known toothed mysticete (Cetacea, Mammalia) from the late Eocene of Peru: anatomy, phylogeny, and feeding adaptations

Christian de MUIZON, Giovanni BIANUCCI, Manuel MARTÍNEZ-CÁCERES \& Olivier LAMBERT 
DiRECTEUR DE LA PUBLICATION: Bruno David,

Président du Muséum national d'Histoire naturelle

RÉdACTEUR EN CHEF / EDITOR-IN-CHIEF: Didier Merle

ASSISTANTS DE RÉDACTION / AsSISTANT EDITORS: Emmanuel Côtez (geodiv@mnhn.fr); Anne Mabille

MISE EN PAGE / PAGE LAYOUT: Emmanuel Côtez

COMITÉ SCIENTIFIQUE / SCIENTIFIC BOARD:

Christine Argot (MNHN, Paris)

Beatrix Azanza (Museo Nacional de Ciencias Naturales, Madrid)

Raymond L. Bernor (Howard University, Washington DC)

Alain Blieck (chercheur CNRS retraité, Haubourdin)

Henning Blom (Uppsala University)

Jean Broutin (UPMC, Paris)

Gaël Clément (MNHN, Paris)

Ted Daeschler (Academy of Natural Sciences, Philadelphie)

Bruno David (MNHN, Paris)

Gregory D. Edgecombe (The Natural History Museum, Londres)

Ursula Göhlich (Natural History Museum Vienna)

Jin Meng (American Museum of Natural History, New York)

Brigitte Meyer-Berthaud (CIRAD, Montpellier)

Zhu Min (Chinese Academy of Sciences, Pékin)

Isabelle Rouget (UPMC, Paris)

Sevket Sen (MNHN, Paris)

Stanislav Štamberg (Museum of Eastern Bohemia, Hradec Králové)

Paul Taylor (The Natural History Museum, Londres)

COUVERTURE / COVER

Life reconstruction of Mystacodon selenensis (painting by Alberto Gennari), showing this early toothed mysticete feeding along the seafloor off the coast of nowadays southern Peru.

Geodiversitas est indexé dans / Geodiversitas is indexed in:

- Science Citation Index Expanded (SciSearch ${ }^{\circledR}$ )

- ISI Alerting Services ${ }^{\circledR}$

- Current Contents ${ }^{\circledR}$ / Physical, Chemical, and Earth Sciences ${ }^{\circledR}$

- Scopus ${ }^{\circledR}$

Geodiversitas est distribué en version électronique par / Geodiversitas is distributed electronically by:

- BioOne ${ }^{\circledR}$ (http://www.bioone.org)

Les articles ainsi que les nouveautés nomenclaturales publiés dans Geodiversitas sont référencés par /

Articles and nomenclatural novelties published in Geodiversitas are referenced by:

- ZooBank ${ }^{\circledR}$ (http://zoobank.org)

Geodiversitas est une revue en flux continu publiée par les Publications scientifiques du Muséum, Paris Geodiversitas is a fast track journal published by the Museum Science Press, Paris

Les Publications scientifiques du Muséum publient aussi / The Museum Science Press also publish:

Adansonia, Zoosystema, Anthropozoologica, European Journal of Taxonomy, Naturae, Cryptogamie sous-sections Algologie, Bryologie, Mycologie.

Diffusion - Publications scientifiques Muséum national d'Histoire naturelle

CP $41-57$ rue Cuvier F-75231 Paris cedex 05 (France)

Tél. : 33 (0)1407948 05 / Fax: 33 (0)14079 3840

diff.pub@mnhn.fr / http://sciencepress.mnhn.fr

(C) Publications scientifiques du Muséum national d'Histoire naturelle, Paris, 2019

ISSN (imprimé / print): 1280-9659/ ISSN (électronique / electronic): 1638-9395 


\title{
Mystacodon selenensis, the earliest known toothed mysticete (Cetacea, Mammalia) from the late Eocene of Peru: anatomy, phylogeny, and feeding adaptations
}

\author{
Christian de MUIZON \\ CR2P (CNRS, MNHN, Sorbonne Université), \\ Département Origines et Évolution, Muséum national d'Histoire naturelle, \\ case postale 38, 57 rue Cuvier, F-75231 Paris cedex 05 (France)
}

muizon@mnhn.fr

Giovanni BIANUCCI

Dipartimento di Scienze della Terra, Università di Pisa, Via S. Maria 53, 56126 Pisa, Italy. bianucci@dst.unipi.it

Manuel MARTíNEZ-CÁCERES

CR2P (CNRS, MNHN, Sorbonne Université),

Département Origines et Évolution, Muséum national d'Histoire naturelle, case postale 38, 57 rue Cuvier, F-75231 Paris cedex 05 (France)

Olivier LAMBERT

D.O. Terre et Histoire de la Vie, Institut royal des Sciences naturelles de Belgique, 29 rue Vautier, 1000 Brussels (Belgium) olambert@naturalsciences.be

Submitted on 3 December 2018 | accepted on 20 February 2019 | published on 30 May 2019

urn:Isid:zoobank.org:pub:10C821A5-943E-41A0-8FFF-5D5169223126

Muizon C. de, Bianucci G., Martínez-Cáceres M. \& Lambert O. 2019. - Mystacodon selenensis, the earliest known toothed mysticete (Cetacea, Mammalia) from the late Eocene of Peru: anatomy, phylogeny, and feeding adaptations. Geodiversitas 41 (11): 401-499. https://doi.org/10.5252/geodiversitas2019v41a11. http://geodiversitas.com/41/11

\begin{abstract}
Mystacodon selenensis Lambert, Martínez-Cáceres, Bianucci, Di Celma, Salas-Gismondi, Steurbaut, Urbina \& Muizon, 2017 is a toothed mysticete that represents the earliest member of the suborder in the current state of knowledge. Its holotype is a relatively complete skeleton from the upper Eocene (early Priabonian, c. $36.4 \mathrm{Ma}$ ) Yumaque Member of the Paracas Formation from the southern coast of Peru. The thorough description of this specimen is presented here and reveals numerous similarities with the contemporaneous basilosaurids including the retention of an innominate that originally articulated to the unpreserved hind limb. However, several characters of $M$. selenensis clearly relate this taxon to the mysticetes, such as the large palate with a dorsoventrally flattened rostrum, the posterior extension of the palate with an infraorbital plate of the maxilla, the shortening of the premaxillary part of the rostrum, the zygomatic process of the squamosal being closely apposed to the postorbital process of the frontal, and the humeral head being oriented more proximally than posteriorly. A parsimony analysis retrieves Mystacodon as the earliest diverging branch of the Mysticeti with no close phylogenetic relationship with Llanocetus the second oldest known mysticete (c. 34.2 Ma). The dental formula of M. selenensis is that of basilosaurids (I 3/3, C 1/1, P 4/4, M 2/3). The anterior teeth (incisors and canine) are distinctly proportionally smaller than in basilosaurids, whereas the cheek teeth are very close in relative length, but are relatively larger than in most other toothed mysticetes (except Coronodon). The large cheek teeth of Mystacodon suggest a raptorial feeding strategy, probably assisted with some
\end{abstract}


KEY WORDS

Cetacea

toothed mysticete

late Eocene,

Peru,

phylogeny,

anatomy,
functional morphology, feeding strategies.

MOTS CLÉS

Cetacea

mysticète à dents,

Éocène supérieur,

Pérou,

phylogénie,

anatomie.

morphologie

fonctionnelle,

stratégies alimentaires. degree of suction, as indicated by the large size of the palate. The anterior teeth of the holotype display a subhorizontal apical wear facet and the cheek teeth a moderately sloping wear surface, differing from the subvertical attrition facets of basilosaurids. This pattern suggests an efficient dental abrasion resulting from feeding upon abrasive food items or/and from the ingestion of sediment during prey capture, which could indicate some degree of bottom feeding. On the forelimb, the size and orientation of the acromion, the great length of the deltopectoral crest, the massiveness of the olecranon of the ulna, and the strong radial anterior process indicate powerful shoulder movements, which suggest an active use of the forelimb when foraging for food on the sea floor. The robustness of digits and the pachyosteosclerosis of ribs with pestle-like distal end corroborate such a scenario. Mystacodon selenensis represents a first step in the evolutionary history of feeding adaptations of early mysticetes; the latter are likely to have experimented an abundant set of feeding strategies and were probably very eclectic in prey choice and capture before hyperspecialized filter feeding became widespread in the suborder.

\section{RÉSUMÉ}

Mystacodon selenensis, Le plus ancien mysticète à dents connu (Cetacea, Mammalia) de l'Éocène supérieur du Pérou: anatomie, phylogénie et adaptations alimentaires.

Mystacodon selenensis Lambert, Martínez-Cáceres, Bianucci, Di Celma, Salas-Gismondi, Steurbaut, Urbina \& Muizon, 2017 est un mysticète à dents qui constitue le plus ancien représentant du sousordre dans l'état actuel des connaissances. L'holotype est un squelette relativement complet provenant de l'Éocène supérieur (Priabonien inférieur) du Membre Yumaque de la Formation Paracas, de la côte sud du Pérou. La description détaillée de ce spécimen est présentée dans ce travail et révèle de nombreuses similitudes avec les basilosauridés contemporains, incluant la rétention d'un coxal initialement articulé au membre postérieur non préservé. Toutefois, plusieurs caractères de $M$. selenensis rattachent ce taxon aux mysticètes, tels que le vaste palais avec un rostre aplati dorsoventralement, l'extension postérieure du palais en une plaque infraorbitaire du maxillaire, le raccourcissement de la partie prémaxillaire du rostre, le processus zygomatique du squamosal, étroitement apposé au processus postorbitaire du frontal, et la tête humérale, orientée plus proximalement que postérieurement. Une analyse de parcimonie place Mystacodon à la base des mysticètes, sans lien phylogénétique étroit avec Llanocetus le deuxième plus ancien mysticète connu (c. 34.2 Ma). La formule dentaire de M. selenensis est celle des basilosauridés (I 3/3, C 1/1, P 4/4, M 2/3). Les dents antérieures (incisives et canine) sont relativement plus petites que celles des basilosauridés, tandis que les dents jugales sont très proches en longueur relative; ces dernières sont, en revanche, nettement plus grandes que celles de tous les autres mysticètes à dents (à l'exception de Coronodon). Les dents jugales, relativement grandes, de Mystacodon suggèrent une stratégie d'alimentation de type prédateur, probablement aidée par des capacités de succion comme le laisse supposer la grande taille du palais. Les dents antérieures de l'holotype présentent des facettes d'usure apicales subhorizontales et les dents jugales des surfaces d'usure modérément inclinées qui diffèrent des facettes d'attrition subverticales des basilosauridés. Ce modèle suggère une abrasion efficace des dents résultant de l'absorption d'une nourriture abrasive, ou/ et de l'ingestion de sédiment lors de la capture des proies, ce qui impliquerait une alimentation, au moins en partie, sur le fond. Sur le membre antérieur, la taille et l'orientation de l'acromion, la grande longueur de la crête deltopectorale, le caractère massif de l'olécrâne de l'ulna, et le fort processus radial antérieur indiquent de puissants mouvements de l'épaule, qui suggèrent un usage actif du membre antérieur lors de la recherche de nourriture sur les fonds marins. La robustesse des doigts ainsi que la pachyostéosclérose et la dilatation distale des côtes semblent corroborer ce scénario. Mystacodon représente le premier pas dans l'histoire évolutive de l'adaptation alimentaire des premiers mysticètes ; ces derniers ont vraisemblablement expérimenté tout un ensemble de stratégies alimentaires et étaient probablement très éclectiques dans le choix et la capture de leurs proies, avant que ne se généralise, au sein du sous-ordre, une alimentation hyperspécialisée par filtration.

\section{INTRODUCTION}

The most spectacular characteristic of extant mysticetes (Cetacea, Mysticeti) is the presence of baleen, which are keratinous plates produced by the palatal epithelium, hanging in the oral cavity. Mysticetes use their baleen to sieve the water including small vertebrates, invertebrates, or plankton they ingest, thus retaining the food in their mouth. This filter-feeding capacity of mysticetes allows them to capture a large quantity of small prey indispensable to sustain their very large size. In relation with this feeding technique, baleen-bearing mysticetes are devoid of teeth. However, mysticetes did not lose their teeth in the earliest steps of their evolutionary history, and toothed mysticetes were actually fairly abundant during the Oligocene (Marx \& Fordyce 2015). 


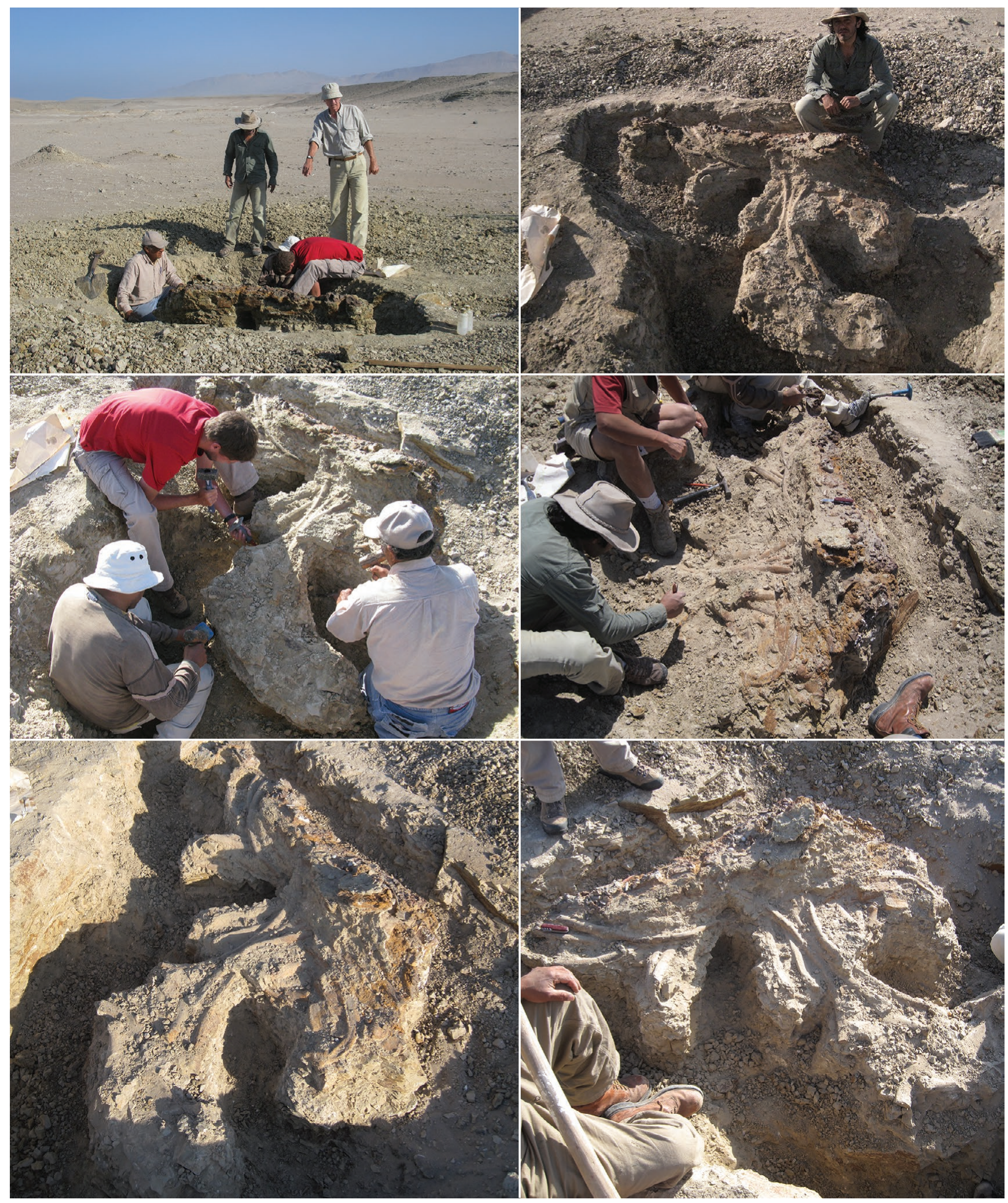

FIG. 1. - Views of the extraction of the postcranial skeleton of Mystacodon selenensis (MUSM 1917 holotype) at Playa Media Luna (Ica Department, Peru).

The first description of a toothed mysticete is that of Aetiocetus cotylalveus Emlong, 1966, from late Oligocene beds of Oregon (United States), which the author placed in the new family Aetiocetidae. Because of the observation of several plesiomorphic features, Emlong included Aetiocetus among archaeocetes, the paraphyletic group of ancient whales from which modern cetaceans did emerge (Uhen 2004; Uhen \& Gingerich 2001; Gingerich 2005, 2008). Nevertheless, Emlong 
(1966) pointed out some similarities of $A$. cotylalveus with baleen whales and Van Valen (1968) recognized this species as the first described toothed cetacean being phylogenetically closer to the extant mysticetes than to any odontocete or archaeocete. Subsequently, the mysticete affinities of other late Oligocene "archaeocetes" Mammalodon colliveri and Chonecetus sookensis were pointed out by Fordyce (1982) and Barnes et al. (1994, respectively.

Nowadays, numerous toothed mysticetes have been reported from North America (e.g. Emlong [1966]; Russell [1968]; Barnes et al. [1994]; Barnes \& Sanders [1996]; Deméré \& Berta [2008]; Marx et al. [2015]; Geisler et al. [2017]), South America (Lambert et al. 2017a); New Zealand (Fordyce 1989, 2003, 2004), Antarctica (Mitchell 1989; Fordyce \& Marx 2018), Japan (Barnes et al. 1994), and Australia (Pledge [2005]; Fitzgerald [2006; 2010]). Most of them come from Oligocene deposits, except Llanocetus denticrenatus from deposits of Seymour Island, Antarctic Peninsula, regarded as late Eocene (late Priabonian) in age (Mitchell 1989; Fordyce \& Marx 2018) and Mystacodon selenensis, from the southern coast of Peru, which has been assigned a middle Priabonian age (Lambert et al. 2017a).

Toothed mysticetes display a broad disparity of rostrum and dental morphologies, which determine different feeding strategies. Some taxa have been regarded as raptorial feeders (Janjucetus [Fitzgerald 2006; Hocking et al. 2017a, b]); others have been suggested as displaying some degree of specialization towards suction feeding (Mammalodon [Fitzgerald 2010]; unnamed aetiocetid NMV P252567 [Marx et al. 2016]), others as dental + baleen filter feeders (Aetiocetus [Deméré \& Berta 2008]; Deméré et al. [2008]), and others as dental filter feeders (Coronodon [Geisler et al. 2017]). The two latter have also been regarded as potential raptorial feeders by the same authors and, based on the orientation and the size of the orbit, Marx (2011) has inferred a specialized raptorial behavior in both Mammalodontidae and Aetiocetidae.

The discovery of toothed mysticetes with a wide variety of dental morphologies and implantations, as well as the related tentative interpretations of their feeding strategies, has raised the question of the transition from the toothed feeding apparatus of the single prey feeding raptorial basilosaurid archaeocetes to the baleen racks of the bulk filter feeding mysticetes. Several studies have considered the Aetiocetidae as a "transitional stage" between the early toothed mysticetes (e.g. Mammalodontidae) and the toothless mysticetes (Chaeomysticeti) (Barnes et al. 1994; Geisler \& Sanders 2003; Fitzgerald 2006, 2010; Deméré \& Berta 2008; Deméré et al. 2008). However, parsimony analyses by Marx (2011) and Marx \& Fordyce (2015) have retrieved the aetiocetids and the mammalodontids in a new clade, basal to the Chaeomysticeti, the baleen-bearing mysticetes. Moreover, Marx et al. $(2015,2016)$ and Hocking et al. $(2017 \mathrm{a}, \mathrm{b})$ have challenged the presence of baleen in aetiocetids [as hypothesized by Deméré \& Berta (2008) on the basis of osteological correlates], therefore rejecting their filter feeding strategy. These authors also question the transitional position of the
Aetiocetidae as advocated by Deméré et al. (2008). Furthermore, Hocking et al. (2017b) also challenged the capacity of dental filter feeding in Coronodon, proposed by Geisler et al. (2017), suggesting in contrast a mix of raptorial and suction feeding in the latter; they also concluded that suction feeding may have preceded the emergence of baleen. Therefore, both the evolutionary history and the feeding ecology of early mysticetes currently remain unclear and a matter of debate (Kienle et al. 2017; Hocking et al. 2017c).

Mystacodon selenensis is the oldest known mysticete so far (Lambert et al. 2017a). It comes from the late Eocene of the Ica Basin (Peru) and has been assigned an age of 36.4 $\mathrm{Ma}$, which is significantly older than the previously oldest known mysticete, Llanocetus denticrenatus, regarded as c. 34 Ma old (Mitchell 1989; Fordyce \& Marx 2018). Mystacodon selenensis corresponds also to the first occurrence of a toothed mysticete from the south-eastern Pacific Ocean. It is known by its holotype only, which includes a reasonably complete skull missing the basicranium, partial mandibles, several isolated teeth (besides those still in situ in the skull), cervical, thoracic, lumbar, and caudal vertebrae, almost complete forelimbs, and complete left innominate. This specimen is the first described toothed mysticete that preserves the scapular and pelvic girdles and most of the forelimb. It is noteworthy that forelimbs of other toothed mysticetes (e.g. Aetiocetus polydentatus and Fucaia goedertorum) are known but are still undescribed (Marx \& Boessenecker pers. comm.).

In the preliminary description of Mystacodon selenensis, this early mysticete was interpreted as morphologically intermediate between basilosaurids and later toothed mysticetes; the anatomy of the oral apparatus (including tooth wear) and forelimb lead the authors to suggest that $M$. selenensis was specialized to some degree for suction feeding and was possibly a benthic feeder (Lambert et al. 2017a).

The holotype of Mystacodon selenensis is here thoroughly described; especially its cranial and dental morphologies are compared to those of other toothed mysticetes and basilosaurids (see Appendix 2), with a focus on the evolution of feeding behaviours in early mysticetes. Incidence of forelimb anatomy on the feeding adaptation of $M$. selenensis is also considered.

\section{MATERIAL AND METHODS}

\section{ANATOMICAL TERMINOLOGY}

The anatomical nomenclature used in this description follows that of Kellogg (1936), Barnes et al. (1994), Fordyce (2002), Uhen (2004), Deméré \& Berta (2008), Mead \& Fordyce (2009), Fitzgerald (2010) and, when possible, the NAV (2012).

\section{PHYLOGENETIC ANALYSIS}

Lambert et al. 2017a) performed a parsimony analysis of the phylogenetic affinities of Mystacodon selenensis based on the data matrix provided by Marx \& Fordyce (2015). However, in their analysis Lambert et al. only retained 24 out of the 53 
taxa of Chaeomysticeti from the original matrix, representing most of the major clades of this large group. Although the New Zealand undescribed taxa of Marx \& Fordyce (2015)'s data matrix, to which we did not have access during this study, were excluded, we retained the undescribed toothed mysticete from the Oligocene of South Carolina (ChM PV $4745)$ and added a new specimen from the same area (ChM PV 5720), both examined by one of us (MM-C). Since the first description of $M$. selenensis, a major taxon of basal mysticete has been described, Coronodon havensteini Geisler et al. 2017. This early Oligocene toothed mysticete represented by exceptionally preserved skull with mandibles and some postcranial elements, adds considerably to our knowledge of early mysticete evolution. Furthermore, Fordyce \& Marx (2018) recently provided a description of the skull of Llanocetus denticrenatus, a late Eocene mysticete from Antarctica. These authors performed a thorough parsimony analysis of most mysticetes taxa, including the recently described $M$. selenensis and $C$. havensteini. It therefore appeared to us essential to revise the phylogenetic position of $M$. selenensis in the light of these newly described basal mysticetes. In the present study, we used the data matrix of Fordyce \& Marx (2018), of which we only retained 33 ingroup taxa and added two undescribed toothed mysticetes from North Carolina (ChM PV4745 and 5720). Concerning the outgroup, following Lambert et al. (2017a), we added Cynthiacetus peruvianus for which we had the holotype at hand, an almost complete skeleton with a perfectly preserved skull (Martínez-Cáceres et al. 2017). We also retained Zygorhiza kochii (USNM 11962), the outgroup basilosaurid included in Fordyce \& Marx (2018)'s matrix. We added Simocetus rayi and Squalodon spp. to the odontocete extinct taxa of the outgroup and the extant delphinid Tursiops, which is a much less derived odontocete than Physeter at the level of the skull morphology. With these changes, our analysis includes 43 taxa (eight outgroup and 35 ingroup). We also abundantly revised the character list of Fordyce \& Marx (2018): we added some new characters; we reintroduced some characters of Marx \& Fordyce (2015) excluded in Fordyce \& Marx (2018); we excluded eight characters of Fordyce \& Marx (2018); and we modified some formulations and codings for characters in the latter matrix. The list of excluded characters with a justification of this exclusion is provided at the end of the character list (Appendix 3) and changes in the formulations and codings are indicated for each concerned character. Our character list includes 282 characters (12 dental, 208 cranial, 25 mandibular, 30 postcranial, and 7 soft anatomy), among which 25 multistate characters are treated as additive.

The taxon/character states matrix was analysed using heuristic parsimony searches implemented by PAUP* version 4a (build 158) (Swofford 2002). Each heuristic parsimony search employed 1000 replicates of random taxon addition with TBR branch swapping, saving up to 10 trees. The revised and updated matrix is available in supplementary data (http://sciencepress.mnhn.fr/sites/default/files/documents/fr/g2019v41a11_1.nex) and in Morphobank (http:// www.morphobank.org).
The list of taxa, specimens, casts, and references, taken into account is this study (comparison and phylogenetic analysis) is presented in Appendix 2.

The list of genera and species cited in the text with authorship and date of publication is given in Appendix 1 .

\section{INSTITUTIONAL ABBREVIATIONS}

AMNH American Museum of Natural History, New York;

BMNH British Museum of Natural History, London;

CCNHM Mace Brown Museum of Natural History, Charleston;

CGM Cairo Geological Museum, Cairo;

ChM The Charleston Museum, Charleston;

FMNH Field Museum of Natural History, Chicago;

GNHM Gamagori Natural History Museum, Gamagori;

GSP-UM Geological Survey of Pakistan-University of Michigan collection, housed in Quetta, Balochistan, Pakistan;

GSM Georgia Southern University Museum, Stateboro;

KMNH Kitakyushu Museum of Natural History and Human History, Kitakyushu, Fukukoa;

IRSNB Institut royal des Sciences naturelles de Belgique, Brussels;

LACM Natural History Museum of Los Angeles County, Los Angeles;

MFM Mizunami Fossil Museum, Gifu;

MNHN Muséum national d'Histoire naturelle, Paris;

MSNTP Museo di Storia Naturale dell'Università di Pisa, Calci;

MUSM Museo de Historia Natural, Universidad Nacional Mayor de San Marcos, Lima;

NMB Natuurmuseum Brabant, Tilburg;

NMV Museum Victoria, Palaeontology Collection, Melbourne;

PIN Paleontological Institute, Russian Academy of Sciences, Moscow;

SCSM South Carolina State Museum, Columbia;

SMNK Staaliches Museum für Naturkunde, Karslruhe;

SMNS Staaliches Museum für Naturkunde, Stuttgart;

UCMP University of California, Museum of Paleontology, Berkeley;

UISPM Universitäts-Institut und Staatssammlung für Paläontologie und Historische Geologie, Munich;

UM Museum of Paleontology, University of Michigan, Ann Arbor;

USNM United States National Museum of Natural History, Smithsonian Institution, Washington DC;

UO University of Otago, Dunedin;

UWBM Burke Museum of Natural History and Culture, University of Washington, Seattle.

\section{SYSTEMATIC PALAEONTOLOGY}

Order CETACEA Brisson, 1762

Clade PELAGICETI Uhen, 2008

Clade NEOCETI Fordyce \& Muizon, 2001

Suborder MYSTICETI Flower, 1864

Family MYSTACODONTIDAE

Lambert, Martínez-Cáceres, Bianucci, Di Celma, Salas-

Gismondi, Steurbaut, Urbina \& Muizon, 2017

Genus Mystacodon

Lambert, Martínez-Cáceres, Bianucci, Di Celma, SalasGismondi, Steurbaut, Urbina \& Muizon, 2017

TyPe AND ONLY SPECIES INCLUDED. - Mystacodon selenensis. 


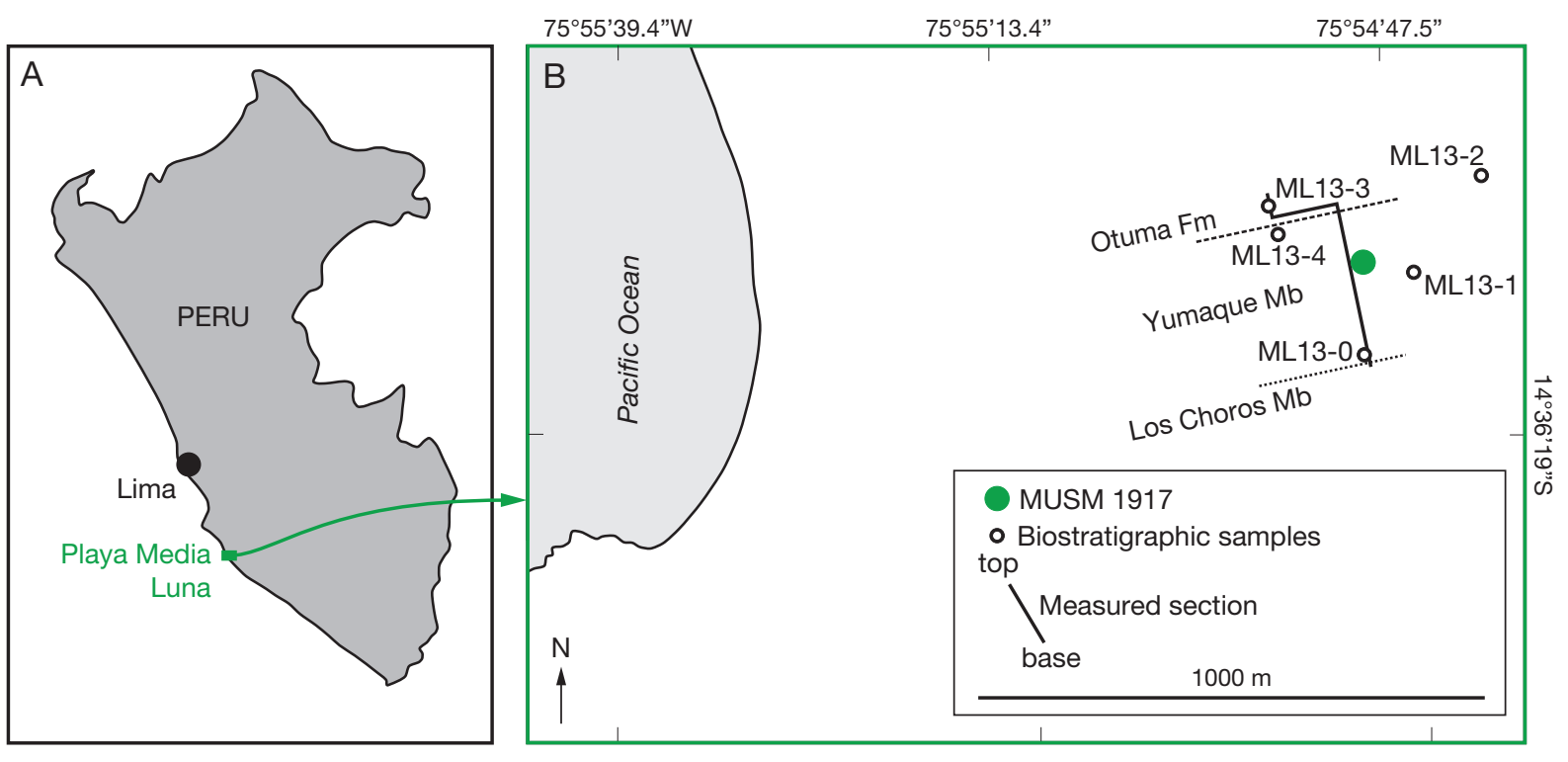

FIG. 2. - A, Schematic map of Peru with the position of the Playa Media Luna locality along the southern coast; B, detail of the Playa Media Luna locality showing the position of the holotype of Mystacodon selenensis MUSM 1917, the stratigraphic section, and part of the sediment samples taken for the biostratigraphic analysis. Modified from Lambert et al. (2017a).

ETYMOLOGY. — From ancient Greek mystacos ("moustache”) in reference to the suborder Mysticeti and odontos ("tooth"), "mysticete with teeth". DiagnOSIS. - The same as for the type species, Mystacodon selenensis.

\section{Mystacodon selenensis}

Lambert, Martínez-Cáceres, Bianucci, Di Celma, SalasGismondi, Steurbaut, Urbina \& Muizon, 2017

HoLOTYPE. - MUSM 1917, a partial skeleton. Associated elements include the skull, missing most of the basicranium and the right squamosal and jugal; a fragmentary left tympanic; both dentaries; thyrohyal; cervical and thoracic vertebrae; ribs; sternum (four elements, including manubrium and xiphisternum); partial right and left forelimbs; and left innominate.

Eтymology. - From Selene, the Greek goddess of the moon, in reference to the Playa Media Luna, the type locality.

TyPE LOCALITY. - The type specimen comes from the Playa Media Luna $\left(14^{\circ} 36^{\prime} 7.2^{\prime \prime}\right.$ S, $\left.75^{\circ} 54^{\prime} 48 \mathrm{~W}\right)$, close to the Pacific coast in the southern part of the Pisco Basin, at about the level of the $\mathrm{km} 400$ of the South Panamerican Highway (Fig. 1).

TyPe HORIZON AND AGE. - The holotype of Mystacodon selenensis MUSM 1917 was discovered in the middle part of the Yumaque Member of the Paracas Formation, $77 \mathrm{~m}$ above the contact with the Los Choros Member (Figs 2; 3) (see DeVries 2017 for a revised interpretation of the Eocene depositional sequence in the area). Layers of the Yumaque Member comprise finely laminated to massive, diatomacetous siltstones, containing pelagic microfossils, thin-shelled pectinid bivalves, and numerous fish scales; they represent deposition in distal (outer shelf), low-energy marine settings (Lambert et al. 2017a; DeVries 2017). The calcareous nannofossil investigation of 37 sediment samples from the Yumaque Member and the overlying lower part of the Otuma Formation, taken along the stratigraphic section in the type locality of Playa Media Luna, allowed positioning the type horizon in the lower part of calcareous nannofossil zone NP19/20 of Martini (1971); based on age estimations by Agnini et al. (2014), an age of 36.4 Ma (early Priabonian, early late Eocene) has been proposed (see Lambert et al. 2017a for more details).
EMENDED DIAGNOSIS. - Mystacodon selenensis is identified as a Neoceti based on the following derived characters, absent in basilosaurid archaeocetes: partly open mesorostral groove; anteroposteriorly elongated rostral portion of maxilla; presence of an antorbital process of the maxilla; supraoccipital shield anterodorsally inclined; and distal epiphysis of the humerus divided in two angled radial and ulnar facets.

Mystacodon selenensis is referred to the Mysticeti due to the following combination of derived characters: dorsoventrally thin posterolateral region of maxilla on rostrum; antorbital process of maxilla separated from lacrimal; presence of a maxillary infraorbital plate; apex of zygomatic process of squamosal closely apposed to postorbital process of frontal or situated ventral to the latter; external occipital crest restricted to anterodorsal half of supraoccipital shield; and triangular supraoccipital shield.

Mystacodon selenensis differs from all other toothed mysticetes in bearing the following combination of features: 1) elongated nasal, the nasal being longer than the length of the frontal + parietal, at midline; 2) anteriorly located antorbital foramina, at about the level of the diastema between P2 and P3; 3) absence of real antorbital notch; 4) long jugo-squamosal suture, with an anterior prolongation of the zygomatic process of the squamosal, extending as far as the level of the postorbital process of the frontal anteriorly; 5) short anterior process of the frontal separating the posterior apices of the nasals; 6) sutured mandibular symphysis, the posterior edge of which is at the level of the i3-p1 diastema; and 7) ventral border of the mandibular ramus being slightly concave ventrally.

Mystacodon selenensis also bears four additional derived characters: upturned (i.e., dorsally concave) anterior region of the rostrum; posteriormost upper tooth anterior to level of antorbital process of maxilla; broad-based rostrum (ratio between width of skull at rostrum base and width at postorbital process $>0.8$ ); and strong tuberosity on anterior edge of radius (the latter condition is unknown in the other toothed mysticetes).

Furthermore, Mystacodon selenensis bears a series of plesiomophic features: supraoccipital shield not extending anterior to anterior level of squamosal fossa; only two dorsal infraorbital foramina; a basilosaurid-like dental formula 3.1.4.2/3.1.4.3; no wide diastemata between posterior cheek teeth; sutured mandibular symphysis; and well-defined acetabulum on innominate. 
Mystacodon selenensis differs from Llanocetus denticrenatus in the following characters: 1) much smaller size (less than half the estimated body size); 2) rostrum narrower with concave edges while the preserved posterior part of the rostrum of Llanocetus is much wider and laterally expanded; 3 ) alveolar border of the maxilla on posterior region of the rostrum rounded dorsolaterally in cross-section with a subvertical lateral wall, while it is flat and crest-like in Llanocetus; 4) preserved parts of the palate lack deep lateral sulci, while they are distinctly present and abundant in Llanocetus; 5) premaxillae abruptly depressed just anterior to the nasals, while in Llanocetus the transition to the post narial part of the premaxillae is smooth; 6) upper molars closely approximated, while they are separated by large diastemata in Llanocetus; 7) upper molars much larger; 8) short diastema between P3 and P4 (less than one tooth mesiodistal length), while in Llanocetus the diastema is two to three times a tooth length; 9) much longer orbit; 10) nearly straight lateral edge of the supraorbital process, while it is deeply concave in Llanocetus; 11) posterior edge of the supraorbital process roughly straight, while it is concave in Llanocetus; 12) orbitotemporal crests extend posteriorly until anteroposterior mid-point of the parietals, while in Llanocetus they end anteriorly, at the posteromedial angle of the supraorbital process of the frontal; 13) dorsal edge of the parietals is subhorizontal in lateral view, while it ascends steeply toward the vertex in Llanocetus; 14) intertemporal bridge much narrower than long transversely, while it is as wide as long in Llanocetus; 15) anterior angle of nuchal crest posterior to anterior margin of squamosal fossa, while it approximately reaches the level of the middle of the fossae in Llanocetus; 16) lateral edges of the supraoccipital in dorsal view straight, while they are sigmoid in Llanocetus; 17) vertex and dorsal aspect of the braincase almost in the same plane as the posterior region of the rostrum, while in Llanocetus they slope anteriorly and distinctly overhang the rostrum; 18) distal extremity of anterior ribs expanded and pestle-like, while this condition is absent in Llanocetus.

Mystacodon selenensis differs from Coronodon havensteini in having a longer rostrum and longer diastemata between the premolars; much longer nasals associated to more anterior bony nares, located in the anterior half of the rostrum (in the posterior third in Coronodon); temporal fossae more elongated anteroposteriorly; a long and thin (dorsoventrally) zygomatic process of the squamosal (short and stout in Coronodon); a sharp external occipital crest; a tightly articulated mandibular symphysis; and an sub-horizontal or gently sloping tooth wear on all preserved teeth with strong edges at the apical surface.

In addition to its autapomorphies, Mystacodon selenensis differs from mammalodontids in having: a rostrum at least proportionally twice longer; much more anteriorly placed bony nares; a sharply triangular occipital shield; a well-developed external occipital crest (low, when present, in mammalodontids); a strong palatine sulcus on the medial edge of the premaxilla and maxilla anteriorly; much longer diastemata between the premolars; and absence of the markedly V-shaped fronto-parietal suture (as observed in mammalodontids).

As compared with aetiocetids, Mystacodon selenensis has a basilosaurid-like dental formula; an almost horizontal apical tooth wear; much larger postcanine teeth; and a long and slender zygomatic process of the squamosal, which is lowest at its anteriormost portion. M. selenensis lacks all the aetiocetid characteristic features, such as the extreme dorsoventral compression of the rostrum; the deeply concave lateral edge of the supraorbital process of the frontal in dorsal view; the anteroposteriorly short zygomatic process of the squamosal (as compared to that of basilosaurids); and the very thin jugal.

Finally, Mystacodon selenensis lacks cranial synapomorphies of Odontoceti: facial concavity; presence of premaxillary foramen and premaxillary sac fossa; and wide posterior expansion of maxilla overlapping the supraorbital region.

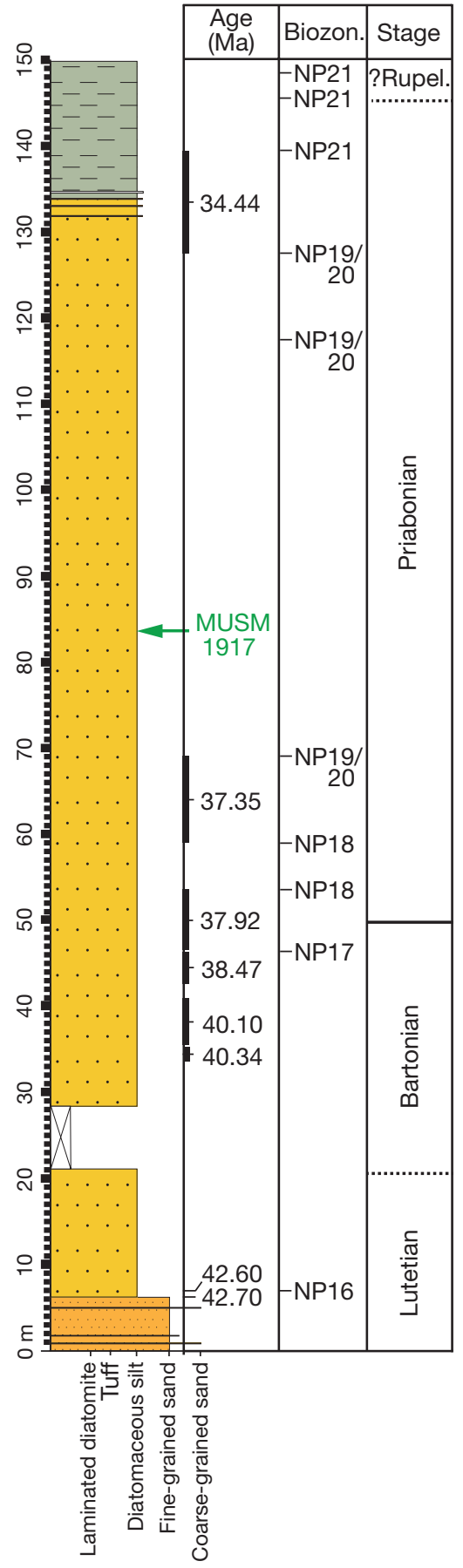

\section{Otuma Formation}

Yumaque Member of the Paracas Formation

Los Choros Member of the Paracas Formation

FIG. 3. - Simplified stratigraphic section through the middle Eocene to earliest Oligocene layers of the type locality of Playa Media Luna, indicating the position of the holotype of Mystacodon selenensis MUSM 1917 in the middle part of the Yumaque Formation (dated to $36.4 \mathrm{Ma}$, early Priabonian, early late Eocene), together with absolute ages for a series of sediment samples collected along the section. Ages are based on the calcareous nannofossil biostratigraphic analysis and corresponding biozonations (NP 16-21; Martini 1971; Agnini et al. 2014; Lambert et al. (2017a). Thickened bars indicate the range of uncertainty due to the distance between consecutive nannofossil-bearing samples. Modified from Lambert et al. (2017a). 
TABLE 1. - Comparison of the anteroposterior position of the external bony nares of Mystacodon selenensis with several archaeocetes and basal mysticetes. Abbreviations: LRPN, length of the rostrum posterior to the anterior end of the nasals; LR, total length of the rostrum. In taxa with no obvious antorbital notch or antorbital process of the maxilla, the posterior end of the rostrum is taken at the anterior edge of the lacrimal. Measurements for Maiacetus inuus have been taken from illustration of Gingerich et al. (2009: fig. 6); because the specimen GSP-UM 3475 is slightly distorted and because the length of the rostrum and postnarial rostrum have been calculated based on the scale bar, these values should be regarded as estimates (e). However, given the fact that the position of the nares is quantified with a ratio, this estimation should not have a significant impact on the value of the LRPN/LR ratio. A similar estimation has been made for the value of Saghacetus osiris (SMNS 11626), which has been measured and calculated from Kellogg (1936: pl. 20). Color code: pink, protocetid; grey, basilosaurids; green, toothed mysticetes.

\begin{tabular}{|c|c|c|c|}
\hline Taxon & LRPN & LR & LRPN/LR \\
\hline $\begin{array}{l}\text { Artiocetus clavis (GSP-UM 3458) } \\
\text { Maiacetus inuus (GSP-UM 3475) (see caption) } \\
\text { Rodhocetus kasrani (GSP-UM 3012) }\end{array}$ & $\begin{array}{l}199 \\
188^{e} \\
171\end{array}$ & $\begin{array}{l}306 \\
112^{e} \\
326\end{array}$ & $\begin{array}{l}0.65 \\
0.59 \\
0.52\end{array}$ \\
\hline $\begin{array}{l}\text { Cynthiacetus peruvianus (MNHN.F.PRU10) } \\
\text { Basilosaurus isis (CGM 42195) } \\
\text { Dorudon atrox (UM 101222) } \\
\text { Saghacetus osiris (SMNS 11626) (see caption) }\end{array}$ & $\begin{array}{l}235 e \\
219 \\
187 \\
130 e\end{array}$ & $\begin{array}{l}630 \\
591 \\
517 \\
418 \\
\end{array}$ & $\begin{array}{l}0.37 \\
0.37 \\
0.36 \\
0.31\end{array}$ \\
\hline $\begin{array}{l}\text { Mystacodon selenensis (MUSM 1917) } \\
\text { Aetiocetus weltoni (UCMP 12290) } \\
\text { Coronodon havensteini (CCNHM 108) }\end{array}$ & $\begin{array}{r}253 \\
53 \\
97\end{array}$ & $\begin{array}{l}544 \\
330 \\
724\end{array}$ & $\begin{array}{l}0.46 \\
0.16 \\
0.13\end{array}$ \\
\hline
\end{tabular}

TABLE 2. - Comparison of the rostrum proportions of Mystacodon selenensis with Basilosauridae and other Mysticeti. Width of the rostrum at base is measured at the level of the antorbital notch or at the corresponding place if notch is absent (i.e., at the lacrimal-maxilla suture). Length of the rostrum is measured from the centre of the line joining the antorbital notches to the apex of the premaxillae anteriorly. Abbreviation: e, estimated measurements. Color code: grey, basilosaurids; green, toothed mysticetes, blue, chaeomysticetes.

\begin{tabular}{|c|c|c|c|}
\hline Taxon & $\begin{array}{l}\text { Width of rostrum } \\
\text { at base }\end{array}$ & $\begin{array}{l}\text { Length of } \\
\text { rostrum }\end{array}$ & W/L \\
\hline $\begin{array}{l}\text { Cynthiacetus peruvianus (MNHN.F.PRU10) } \\
\text { Zygorhiza kochii (USNM 11962) }\end{array}$ & $\begin{array}{l}264 \\
173.5\end{array}$ & $\begin{array}{l}670 \\
359\end{array}$ & $\begin{array}{l}0.39 \\
0.48\end{array}$ \\
\hline $\begin{array}{l}\text { Mystacodon selenensis (MUSM 1917) } \\
\text { Aetiocetus weltoni (UCMP 122900) } \\
\text { Janjucetus hunderi (NMV P216929) } \\
\text { Coronodon havensteini (CCNHM 108) } \\
\text { Undescribed toothed mysticete (ChM PV 5720) }\end{array}$ & $\begin{array}{c}180.4 \times 2=360.8 \mathrm{e} \\
209 \\
165.5 \\
301 \\
187 \times 2=374 \mathrm{e}\end{array}$ & $\begin{array}{l}544 \\
330 \\
195 e \\
526 \\
822\end{array}$ & $\begin{array}{l}0.66 \\
0.63 \\
0.84 \\
0.57 \\
0.45\end{array}$ \\
\hline $\begin{array}{l}\text { Yamatocetus canaliculatus (KMNH VP000,017) } \\
\text { Piscobalaena nana (MNHN.F.SAS1618) } \\
\text { Pelocetus calvertensis (USNM 11976) }\end{array}$ & $\begin{array}{c}313 \\
248.3 \\
340 \times 2=680 e\end{array}$ & $\begin{array}{r}767 \\
723 \\
1350\end{array}$ & $\begin{array}{l}0.41 \\
0.34 \\
0.50\end{array}$ \\
\hline
\end{tabular}

\section{DESCRIPTION AND COMPARISON}

SKULL

\section{Bony skull}

General features. The cranium of the holotype of Mystacodon selenensis (Figs 4-14) includes the rostrum, left facial region, left supraorbital process, left zygomatic arch, dorsal portions of both the intertemporal region, the supraoccipital shield, and a fragmentary tympanic bulla.

In dorsal view, the posterior telescoping of the bony nares is poorly pronounced: as in basilosaurids the posterior end of the bony nares (corresponding to the anterior edge of the nasals) is located at mid-length of the rostrum. In contrast, the forward telescoping of the supraoccipital is similar to the condition observed in early mysticetes, such as mammalodontids or aetiocetids, with a nuchal crest that projects farther anteriorly than in basilosaurids, but which do not reach anteriorly the level of the anterior margin of the squamosal fossa. In this respect Mystacodon differs from Llanocetus, in which the telescoping is more pronounced, since the anteriormost median angle of the nuchal crest is well anterior to the squamosal fossa, reaching the level of the posterior half of the temporal fossae. Llanocetus is more derived than Mystacodon for this feature.

In lateral view (Fig. 6), the portion of the rostrum anterior to the nasals (composed of the premaxillae and maxillae) is slightly concave dorsally, which gives to the rostrum a characteristic upturned morphology. This condition is unusual as compared to other early mysticetes or to basilosaurids, and could be the result of some postmortem distortion of the skull. However, although the specimen bears numerous cracks, no significant displacement of the broken fragments seems to have occurred during fossilization, which would favor the hypothesis that no post mortem distortion occurred. Furthermore, the general morphology of the apex of the rostrum is quite symmetrical in ventral and dorsal view, and, although it is peculiar, the dorsal curvature is very regular and anatomically plausible. An interesting comparison can be made with the dentaries. On the left dentary (the most complete), in lateral view the anterior third of the bone displays a highly doubtful sigmoid morphology, which clearly departs from the regular curvature of the rostrum. More problematic is the total absence of diastema and embrasure pit between i3 and c, while large embrasure 


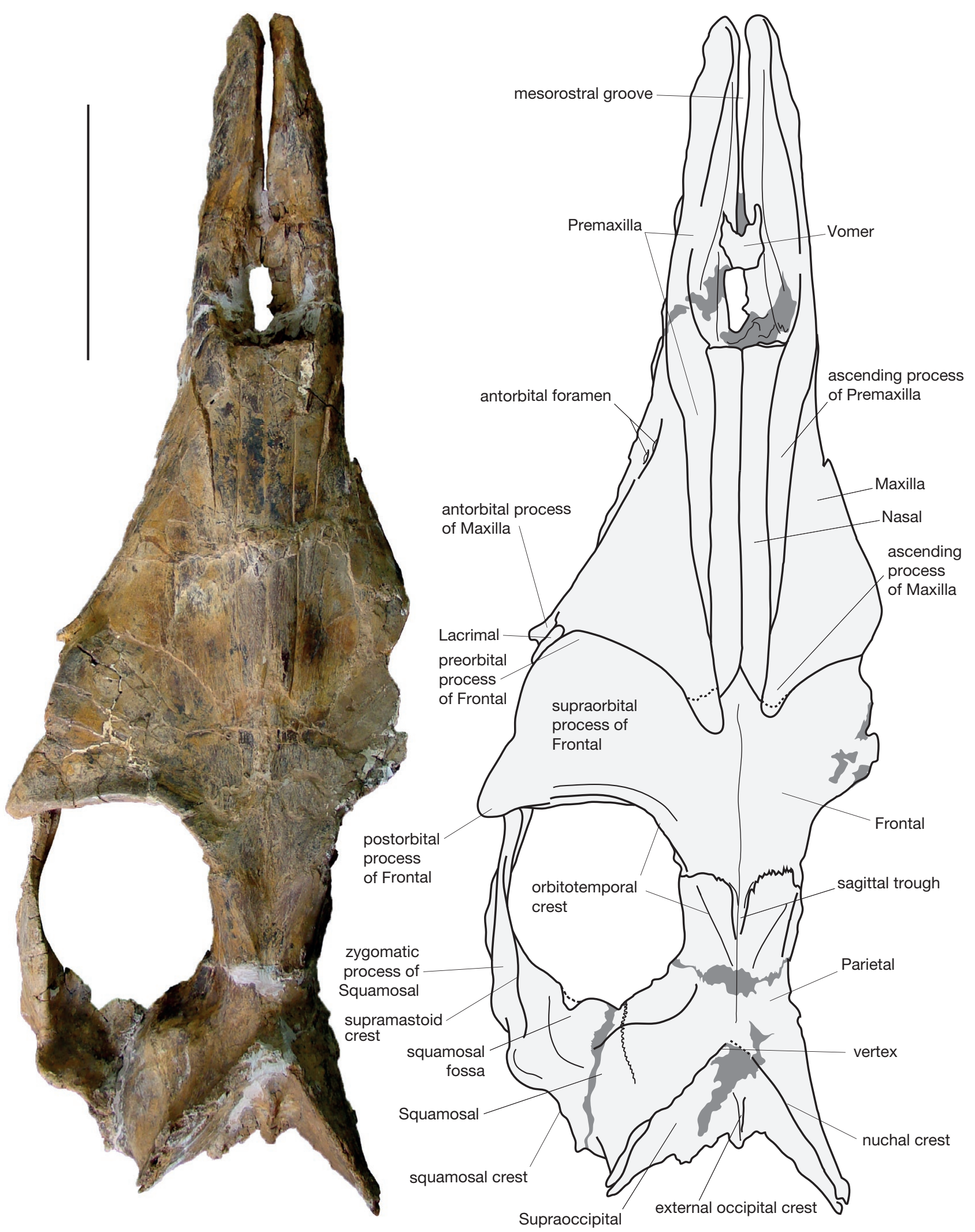

FIG. 4. - Dorsal view of the skull of Mystacodon selenensis (MUSM 1917, holotype). Grey-shaded regions indicate reconstructed parts. Scale bar: $20 \mathrm{~cm}$.

pits and diastemata are observed between the other lower incisors and premolars and, especially, between $\mathrm{I} 3$ and $\mathrm{C}$ on the rostrum. On the right dentary, the portion of the bone anterior to $\mathrm{i} 3$ is missing, but distinct diastema and embrasure pit are observed between $\mathrm{p} 1$ and c, matching well the condition of the maxilla. It is therefore highly probable that 


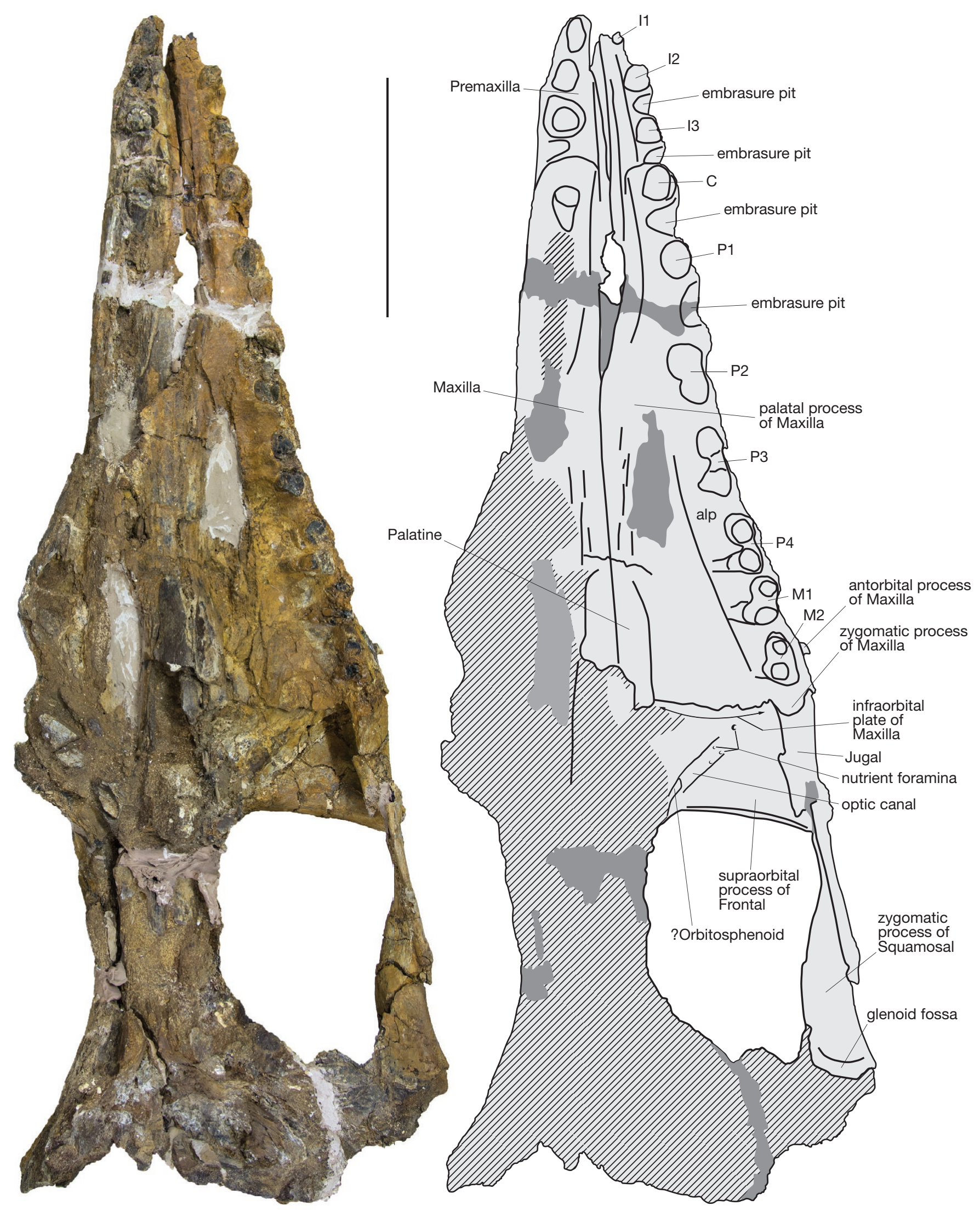

FIG. 5. - Ventral view of the skull of Mystacodon selenensis (MUSM 1917, holotype). Grey oblique lines and grey-shaded regions indicate respectively broken and reconstructed parts. Scale bar: $20 \mathrm{~cm}$. 

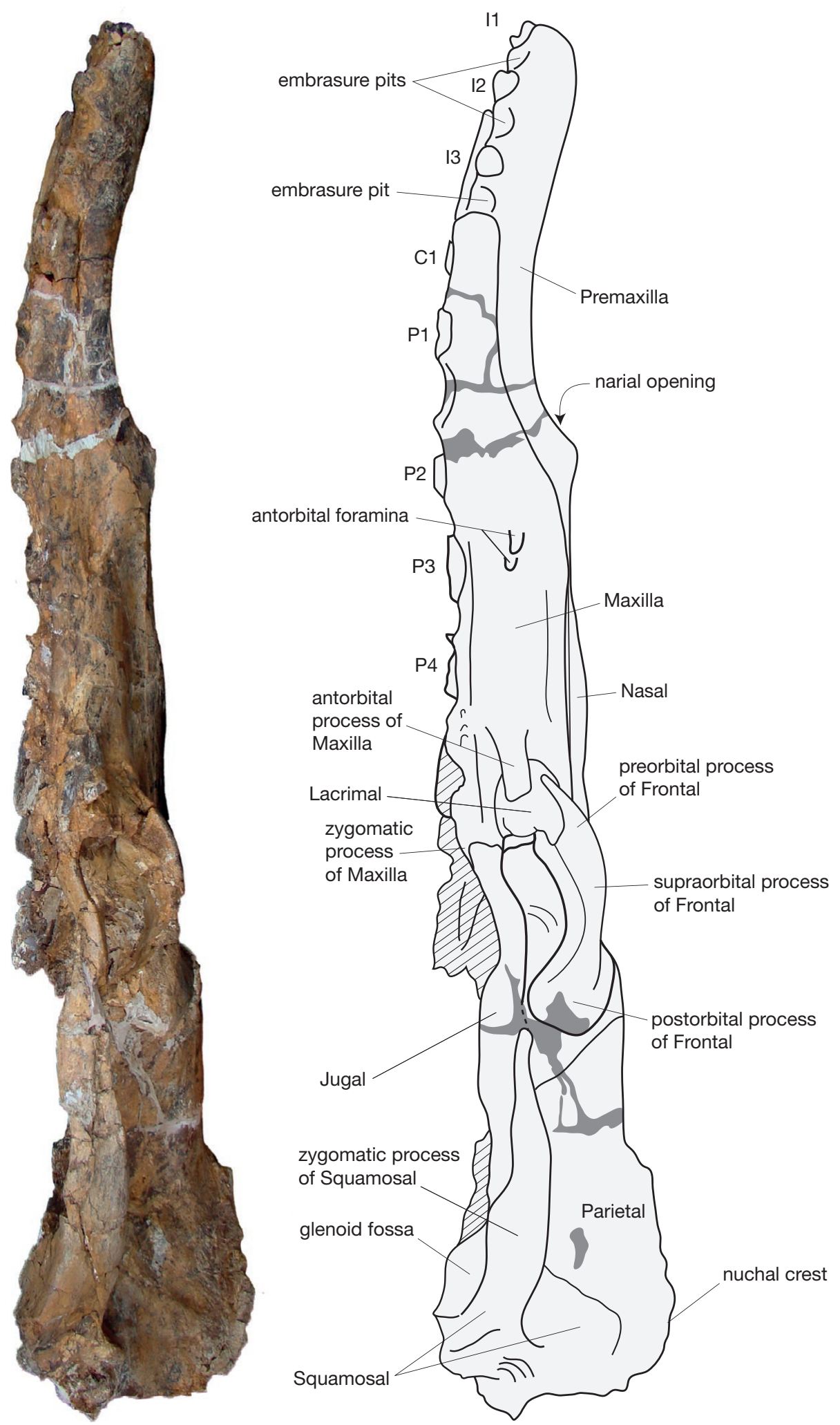

FIG. 6. - Lateral view of the skull of Mystacodon selenensis (MUSM 1917, holotype). Oblique lines and grey-shaded regions indicate respectively broken and reconstructed parts. Scale bar: $20 \mathrm{~cm}$.

the morphology of the left dentary is an artefact, and that distortion has affected the dentary rather than the anterior part of the rostrum.
Given this interpretation, the upturned morphology of the apex of the rostrum of Mystacodon is apparently unique among early pelagic cetaceans; it differs from the other toothed 
mysticetes, in which this part of the rostrum is straight, and from the Basilosauridae, in which it is either straight or slightly bent ventrally.

The anterior part of the rostrum (anterior to the nasals) of Mystacodon is narrow and the maxillae are not visible dorsally, their lateral aspect being subvertical. This condition resembles that of basilosaurids such as Dorudon, Cynthiacetus or Zygorhiza. Mystacodon differs in this respect from Llanocetus. Although the anterior part of the rostrum of the holotype of this latter taxon is missing, a small portion of the rostrum, anterior to the anterior edge of the nasal, is still preserved (approximately one third of the length of the nasal). In this part of the rostrum, the maxilla is still widely visible in dorsal view and expanded laterally. However, we cannot exclude that this character may, at least in part, be related to some dorsoventral flattening of the rostrum in the holotype of Llanocetus.

Dorsally, the external bony nares form the posterior half of the portion of the rostrum anterior to the nasals. The external bony nares are located approximately between the levels of $\mathrm{C}$ and P2, as is observed in most basilosaurids. They face anterodorsally and are proportionally larger than in all basilosaurids. The anteroposterior position of the bony nares is nevertheless clearly more reminiscent of that of basilosaurids than that of most other toothed mysticetes, in which it is clearly more posterior. In Mystacodon the posterior limit of the bony nares (i.e., the anterior edge of the nasals) is slightly posterior to the mid-length of the rostrum. As exemplified in Table 1, the ratio "length of the rostrum from base to anterior end of nasals/total rostrum length" (LRPN/LR) is slightly under 0.5. In toothed mysticetes geologically younger than Mystacodon (e.g. Aetiocetus and Coronodon), the posterior limit of the bony nares is much more posterior, the length of the postnarial part of the rostrum is very short, and the ratio is small ( $\mathrm{LRPN} / \mathrm{LR}=0.13,0.16$ ). In protocetids (e.g. Artiocetus and Maiacetus), the nares are placed well anterior on the rostrum (LRPN/LR $=0.69,0.65)$. In basilosaurids (e.g. Basilosaurus, Cynthiacetus, and Dorudon), the nares are significantly more posterior than in protocetids (LRPN/LR $=0.40,0.38,0.37$ ), but distinctly more anterior than in Oligocene toothed mysticetes. Surprisingly, the position of the bony nares of Mystacodon is intermediate between protocetids and basilosaurids, a condition that is therefore less derived than in the latter. However, this difference may be due to the fact the anterior (premaxillary) region of the rostrum (from C to I1) is proportionally much shorter in Mystacodon than in Cynthiacetus and other basilosaurids. As a matter of fact, the posterior edge of the external nares in Mystacodon is at the level of the anterior edge of P2 as in Cynthiacetus, whereas it is at the level of the anterior edge of the canine in protocetids. Comparison with toothed mysticetes, in which the rostrum is incompletely known (e.g. Llanocetus and Mammalodon), is not possible. However, it is clear that the bony nares of Llanocetus were much more anterior than in all the other mysticetes except Mystacodon. The posterior edge of the nares of Llanocetus is likely to have been close to mid-length of the rostrum as in the Peruvian taxon. As a matter of fact, the posterior margin of the bony nares of Llanocetus is located roughly at the level of P2 as in Mystacodon.
The posterior half of the rostrum and the interorbital region of the skull are dominated by the nasals medially, which overhang the maxillae and the frontals laterally. Although no antorbital notch is observed, this region is conventionally marked by the antorbital process of the maxilla. At its base, the rostrum of Mystacodon is distinctly wider than in basilosaurids (e.g. Cynthiacetus peruvianus). The table below provides a ratio of the rostrum width at base/rostrum length (Table 2). The rostrum proportions of Mystacodon distinctly depart from those of basilosaurids, but resemble those of Aetiocetus and Coronodon, which also have a rostrum that is wide at base and shorter than that of basilosaurids. Mystacodon differs from the extreme condition (very short rostrum) of Janjucetus and Mammalodon, and from the long rostrum of chaeomysticetes.

The lateral edge of the maxilla of Mystacodon is distinctly concave in the region between the antorbital process and the anterior edge of the nasals. This condition is similar to that of basilosaurids, but drastically differs from that of Llanocetus, in which the lateral edge of the maxilla is expanded laterally and markedly convex. In order to allow a comparison of the relative size and proportions of the skulls of Mystacodon, Cynthiacetus, and Llanocetus schematic reconstructions of dorsal and ventral views are presented on Figure 7, in which the three skulls have been reduced to the same bizygomatic width. On Figure 7A-C, the rostrum base of Mystacodon is clearly basilosaurid-like (although more massive and transversely wider) and strongly departs from that of Llanocetus.

The vertex, the most elevated point of the skull, is formed by the anterodorsal half of the nuchal crest, therefore by the supraoccipital. Because of the absence of a sagittal crest, the parietals do not participate to the vertex of Mystacodon. The vertex of the latter strongly differs from that of extant and most Neogene Neoceti, in which it is generally variously formed by part of the frontals, interparietal, nasals, premaxillae, and/or maxillae (Mead \& Fordyce 2009: 32). In lateral view the parietals are subhorizontal and are in a plane only slightly more ventral than the dorsal part of the nuchal crest, the latter being also subhorizontal. Mystacodon differs in this respect from Llanocetus, in which the parietals are markedly sloping anteroventrally. Therefore, in the latter the vertex and the dorsal aspect of the braincase are strongly elevated relative to the rostrum, whereas in Mystacodon the vertex and braincase are almost in the same plane as the post narial part of the rostrum.

In lateral view the orbit is teardrop-shaped in outline, with the apex of the teardrop posteriorly directed, and it faces anterolaterally (best seen in dorsal view). Its longitudinal diameter is proportionally greater than in both basilosaurids and chaeomysticetes, but smaller than in aetiocetids and mammalodontids, especially Janjucetus (see Lambert et al. 2017a: fig. S3).

The temporal fossa is large and slightly longer than wide transversely. As a consequence, the zygomatic process of the squamosal is long and extends far anteriorly, almost reaching the postorbital process of the frontal (cf. below). 
TABLE 3. - Comparative measurement of the surface of the palate in Cynthiacetus, Mystacodon, and Llanocetus. Measurements were calculated with ImageJ 1.48v $(\mathrm{NIH})$ and are given in pixels (metric measurements are irrelevant because the skulls have been rescaled to the same bizygomatic width). Size difference between "genus y" and "genus z" means that the palate of $z$ is xx\% larger than that of y. Hypothetical reconstruction of the posterior edge of the palates in Mystacodon and Llanocetus is inspired from the morphology observed in Janjucetus. Although this reconstruction is highly conjectural, it probably has little incidence on the size differences between the palates of the three taxa. Color code: grey, basilosaurids; green, toothed mysticetes.

\begin{tabular}{lccc}
\hline Taxon & $\begin{array}{c}\text { Total surface } \\
\text { of palate }\end{array}$ & $\begin{array}{c}\text { Palate surface } \\
\text { posterior to P1 }\end{array}$ & $\begin{array}{c}\text { Palate surface between P1 and } \\
\text { anterior edge of temporal fossa }\end{array}$ \\
\hline Cynthiacetus peruvianus (MNHN.F.PRU10) & 49469 & 39623 & 36753 \\
\hline Size difference between Cynthiacetus and Mystacodon & $+72 \%$ & $+96 \%$ & $+99 \%$ \\
\hline Mystacodon selenensis (MUSM 1917) & 85211 & 77875 & 73329 \\
\hline Size difference between Mystacodon and Llanocetus & $+56 \%$ & $+55 \%$ & $+55 \%$ \\
\hline Llanocetus denticrenatus (USNM 183022) & 133169 & 120966 & 113595 \\
\hline
\end{tabular}

Each upper quadrant presents ten alveoli, three in the premaxilla and seven in the maxilla, as observed in basilosaurids, similarly lacking the M3. Relatively long diastemata are observed between the premolars, but they shorten between the last premolars and are lacking between P4 and M1 and between M1 and M2. The posteriormost teeth are located closer to the lateral margin of the maxilla than the anterior teeth.

The ventral side of the skull is poorly preserved. The basicranium and the occipital condyles of MUSM 1917 are missing and the ventral surface of the rostrum is more damaged than its dorsal surface. Therefore, the vomer, palatines, pterygoids, basioccipitals, exoccipitals, periotics, most of tympanic bullae, alisphenoids, and orbitosphenoids are missing or strongly damaged.

Although the palate of the holotype of Mystacodon selenensis is damaged, the missing right maxilla can be reconstructed with mirror image of the left side, which allows a reasonable, although estimated, reconstruction (Fig. 7D-F). On this figure, a reconstruction of the palate of Mystacodon (orange) is compared to that of Cynthiacetus (pink) and to a reconstruction of that of Llanocetus (green). The latter is more uncertain than that of Mystacodon because the anterior part of the premaxillae is missing and the reconstruction of its length and width is hypothetical (although plausible). We calculated the surfaces of the three palates with ImageJ (Table 3). The results are given in pixels; metric measurements would be irrelevant since the three skulls have been reduced at the same bizygomatic width. A first measurement was made with the total palate as reconstructed for Mystacodon and Llanocetus. A total palate measurement retrieved a palate of Mystacodon 72\% larger than that of Cynthiacetus, and a palate of Llanocetus 56\% larger than that of Mystacodon. Therefore, as far as the surface of the palate is concerned Mystacodon is closer to Llanocetus than to Cynthiacetus. However, because of the uncertainty of our reconstruction of the anterior part of the rostrum in Llanocetus, we also measured the surface of the palate posterior to $\mathrm{P} 1$, the position of which is mentioned in Llanocetus by Fordyce \& Marx (2018). In this case, we obtained a palate of Mystacodon 96\% larger than that of Cynthiacetus and that of Llanocetus 55\% larger than that of Mystacodon. Furthermore, because on the holotypes of Mystacodon and Llanocetus the reconstruction of the posterior edge of the palate is also uncertain we measured the surface of the palate between the level of P1s and the level of the anterior edge of the temporal fossa. With this measurement, the palate of Mystacodon was 99\% larger than that of Cynthiacetus and that of Llanocetus was 55\% larger than that of Mystacodon. Therefore, the three measurements resulted in little difference except concerning the relative size of the total palate of Cynthiacetus and Mystacodon. In this case, the difference between $72 \%$ (total palate) and 96\%-99\% (the two other measurements) is at least partly related to the greater length and narrowness of the anterior palate (I1-C) of Cynthiacetus as compared to that of Mystacodon.

To conclude, the palate of Mystacodon is significantly larger than that of the basilosaurid Cynthiacetus and closer, in this respect, to that of Llanocetus, although distinctly smaller.

Cranial measurements are given in Table 4.

Premaxilla (PMx). The premaxilla is a long bone, which extends all along the rostrum, from the apex to the level of the antorbital process of the maxilla posterodorsally. It forms the anteriormost portion of the skull, and the anterior maxilla-free part of the rostrum corresponds to $c .28 \%$ of the total length of the rostrum (in lateral view). This part of the premaxilla is similar in length to that observed in Coronodon (c. 29\%) and in the undescribed toothed mysticete ChM PV 5720 (c. 32\%), but distinctly shorter than in Cynthiacetus (c. 41\%).

Posteriorly, the premaxilla has a narrow ascending process wedged between the maxilla laterally and the nasal medially. Anteriorly in the nares and in the mesorostral groove, the premaxilla is partially overlapped by the vomer; in this region, the vomer is partially broken off, but a fragment of the flattened bone is preserved and covers the premaxilla at the level of C1 (Fig 4). Furthermore, the imprint of the anterior missing portion of the vomer is observed along the anteromedial edge of the premaxilla in the mesorostral groove. In the anterior region of the rostrum, the premaxillae do not articulate at midline, being widely separated until the level of I3. However, their medial edges are more approximated ventrally than dorsally. Anteriorly, the medial faces of the premaxillae are slightly concave medially and form the lateral walls and the floor of the short mesorostral groove. The latter is fully exposed in dorsal view (Fig. 4) and extends anteriorly as far as the level of I2. Dorsally, the prenarial portion of the premaxilla bears a narrow and smooth sub-horizontal 
surface, which gradually widens posteriorly from the level of I 2 to the anterior border of the external bony nares, located at about the level of the canine. The premaxilla reaches its maximum transversal width at the level of the posterior edge of I3. Posterior to I3 the premaxillae become narrower and form the lateral walls of the bony nares, before becoming crest-like in the posterodorsal angle of the nares. From this region, the nasal process of the premaxilla (the posterodorsal extension of the premaxilla) extends far posteriorly; it is long and narrow, and articulates with the lateral edge of the nasal along $c .85 \%$ of its length. The ascending process of the premaxilla is approximately as long as the pre-nasal anterior portion of the bone (Figs 4; 9; 10). The naso-premaxillary (Na-PMx) suture is straight and sub-parallel to the sagittal plane. Posteriorly, the ascending process of the premaxilla narrows gradually to a point just anterior to the level of the preorbital process of the frontal.

In dorsal view, the maxillo-premaxillary (Mx-PMx) suture forms a conspicuous sulcus, although not as marked as in aetiocetids and chaeomysticetes. The anterior edge of the Mx-PMx suture is posterior to the embrasure pit for the lower canine. From its ventralmost point, the lateral portion of the suture runs dorsally for about $8 \mathrm{~mm}$, then it turns posterodorsally and runs parallel to the dorsal edge of the prenasal portion of the premaxilla. At the level of the ascending process, the MxPMx suture runs posteromedially and reaches the lateral edge of the nasal at a level slightly anterior to that of the preorbital process of the frontal. The posterior end of the premaxilla is posteriorly pointed (Figs 9; 10). No foramen is observed on the facial or prenarial surface of the premaxilla.

Ventrally, the palatal surface of the premaxilla is restricted to the anterior portion of the rostrum, anterior to the canine (Figs $5 ; 8$ ). On its lateral border, the alveolar process of the premaxilla bears alveoli for three incisors. The alveolus for I1 is smaller than those for I2 and I3, which are sub-equal in size. In this respect Mystacodon differs from the basilosaurid Cynthiacetus, in which I2 is larger than I3. The incisors are aligned anteroposteriorly and separated by small diastemata, which are proportionally shorter than those observed in basilosaurids and in the undescribed South Carolina toothed mysticete ChM PV5720. Such a condition is also observed in mammalodontids and aetiocetids. Two deep and laterally opened embrasure pits are observed on the diastemata between $\mathrm{I} 2$ and $\mathrm{I} 3$ and between $\mathrm{I} 3$ and $\mathrm{C} 1$; they received the crowns of $\mathrm{i} 3$ and $\mathrm{c1}$, respectively, when the jaws were closed.

The medial edges of the palatal surfaces of the premaxillae do not articulate at midline. Their posterior portions are missing from the level of the first premolar. The palatal portion of the Mx-PMx suture runs posteromedially from the anterior edge of the canine alveolus toward the midline, but its posteriormost portion is missing on both sides. It is difficult to evaluate if the vomer was exposed through a palatal window between the premaxillae, as observed in Aetiocetus weltoni. However, if the vomer was exposed ventrally, it should have been anterior to the level of the embrasure pit of $\mathrm{p} 1$, since the maxillae are in contact at this level on the sagittal plane (cf. below, Maxilla).
Close to the medial edge of the palatal surface of the premaxilla is a longitudinally oriented sulcus, which extends far anteriorly, until the level of the alveolus for I2. This sulcus extends posteriorly on the anteriormost portion of the maxilla, where it is shallower (cf. below, Maxilla).

Maxilla (Mx). The maxilla forms the lateral portion of the rostrum (excluding the anteriormost portion of the rostrum formed by the premaxilla) and most of the palate. It articulates anteromedially and medially with the premaxilla, and posteriorly with the frontal, lacrimal, jugal, nasal, and palatine.

On the dorsal face of the skull the maxilla occupies the lateral and posterior portions of the rostrum. Anteriorly, the maxilla is narrow and faces laterally at the level of P1-P2. Posterior to the level of the external bony nares (at the level of the diastema between P2 and P3), it gradually widens and its lateral surface faces slightly dorsolaterally. Two antorbital foramina (Figs 9; 10) are situated posterior to the level of P2. The largest antorbital foramen is at the level of the P2-P3 diastema, whereas the smaller, more posteroventral foramen is at the level of the P3 alveolus. Such a relative position of the antorbital foramina is similar to that observed in basilosaurids, while in more derived mysticetes as Mammalodon or Aetiocetus the antorbital foramina are more numerous and posterior to the tooth row. No other foramina are observed on the external surface of the maxilla of Mystacodon. The condition of Mystacodon resembles that of Llanocetus in the position and number (2) of antorbital foramina, but it differs from the latter in their orientation, which is more dorsal in Llanocetus.

Posterior to the antorbital foramina, two distinct surfaces (dorsomedial and lateral) can be distinguished on the facial aspect of the maxilla. The dorsomedial surface is smooth, triangular, and dorsally facing. It contacts the nasal process of the premaxilla medially and forms the ascending process of the maxilla (cf. below). Its posterior half, which abuts the elevated nasal region medially, is slightly concave dorsally. Ventrolateral to this region of the maxilla, the posterolateral surface of the maxilla is a narrow and rough. It is much narrower that the ascending process and, because it faces dorsolaterally to laterally, it is barely visible in dorsal view. Its lateral margin is thinner (i.e., less elevated) than in basilosaurids and participates in the zygomatic process of the maxilla (cf. below and Figs 7,9 and 10), which articulates posteriorly with the jugal.

This condition markedly differs from Llanocetus, in which the part of the maxilla in the posterolateral region of the rostrum is flat and wide. This morphology in the latter is conspicuous even though it was probably accentuated by some degree of postmortem dorsoventral flattening of the holotype. In this taxon, the alveolar border of the maxilla is flat and crest-like, and does not exhibit the subvertical, laterally facing condition observed in Mystacodon. The morphology of the maxilla at rostrum base constitutes one of the major morphological difference between the two taxa, as illustrated in Figure 7.

The ascending process and the posterolateral margin of the maxilla are separated by a crest, which extends posteriorly from the level of $\mathrm{P} 4$ and forms the prominent and laterally protruding antorbital process (Figs 9; 10). The latter is situated at the level 


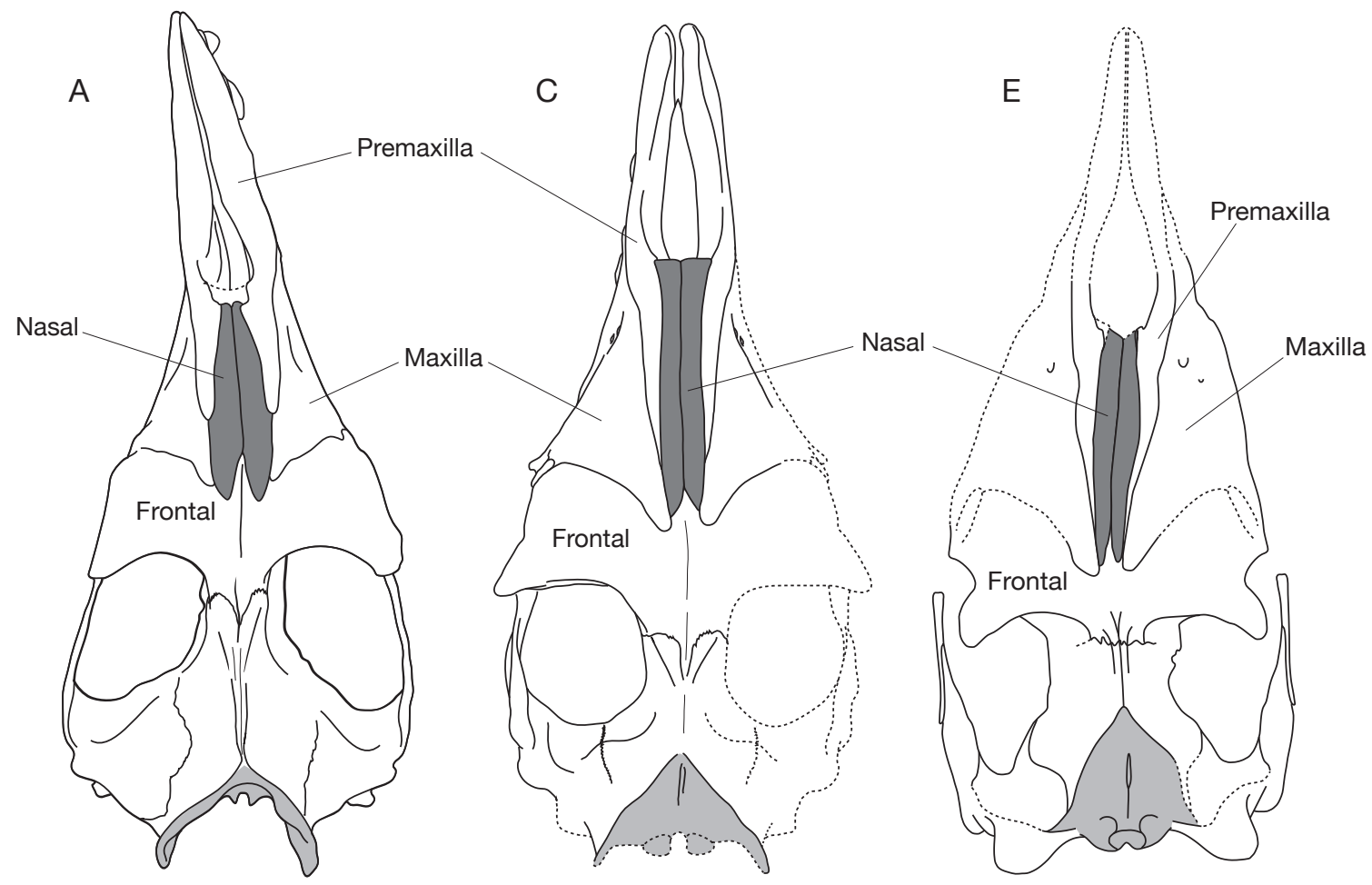

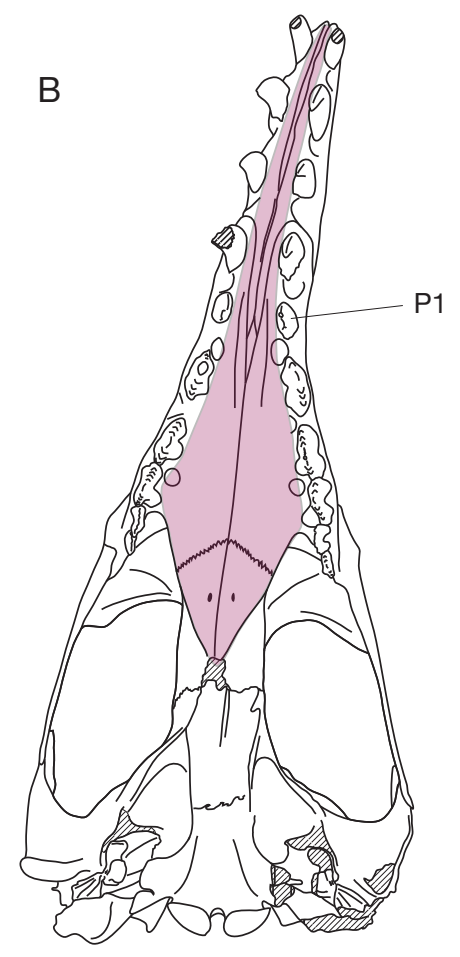

Cynthiacetus

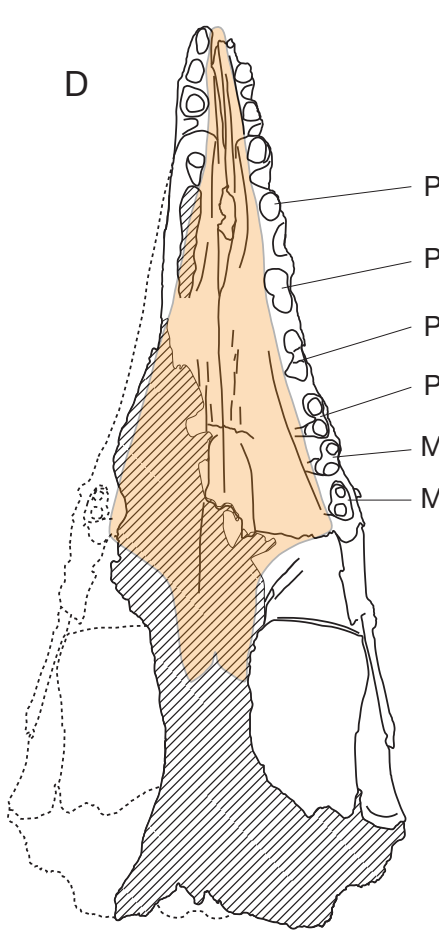

Mystacodon

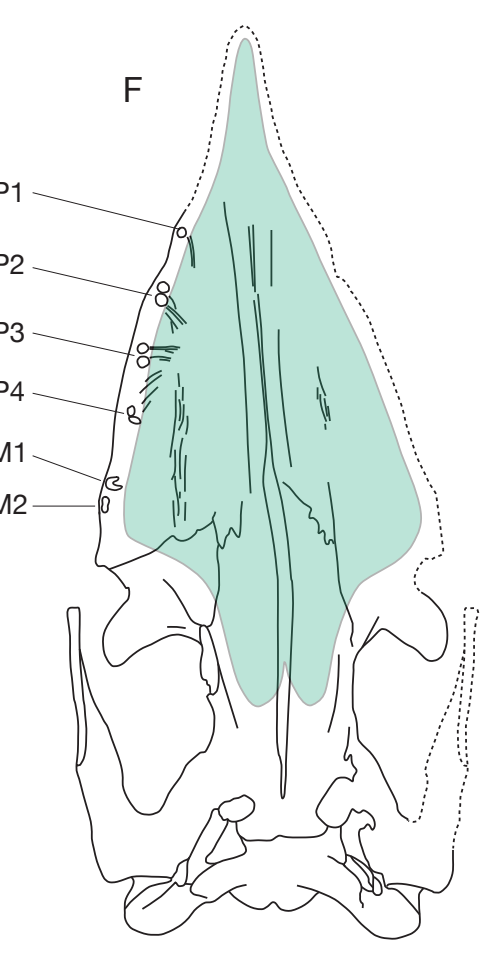

Llanocetus

FIG. 7. - Comparative reconstruction of the dorsal (A, C, E) and ventral (B, D, F) views of the skull of: A, B, Cynthiacetus peruvianus; C, D, Mystacodon selenensis; E, F, Llanocetus denticrenatus. Not to scale; drawings scaled to same bizygomatic width. Coloured shaded area on the ventral views are reconstructions of the palatal surface. The reconstruction of the palatal surface of Llanocetus is more hypothetical than that of Mystacodon since the anterior region of the rostrum is missing.

of the anterior edge of M2. It extends posterolaterally and does not contact the lacrimal. Dorsal to the antorbital process and ventrolateral to the fronto-maxillary $(\mathrm{Fr}-\mathrm{Mx})$ suture, the maxilla articulates with the lacrimal (Figs 9; 10). The maxillo-lacrimal (Mx-La) suture is anteriorly convex and best seen in lateral view.
The posteromedialmost portion of the maxilla forms the dorsal ascending process of the maxilla, which is markedly triangular in dorsal view (Figs 9; 10). It contributes to the anteromedian portion of the supraorbital shield (formed by the ascending process of the maxilla and the supraorbital 


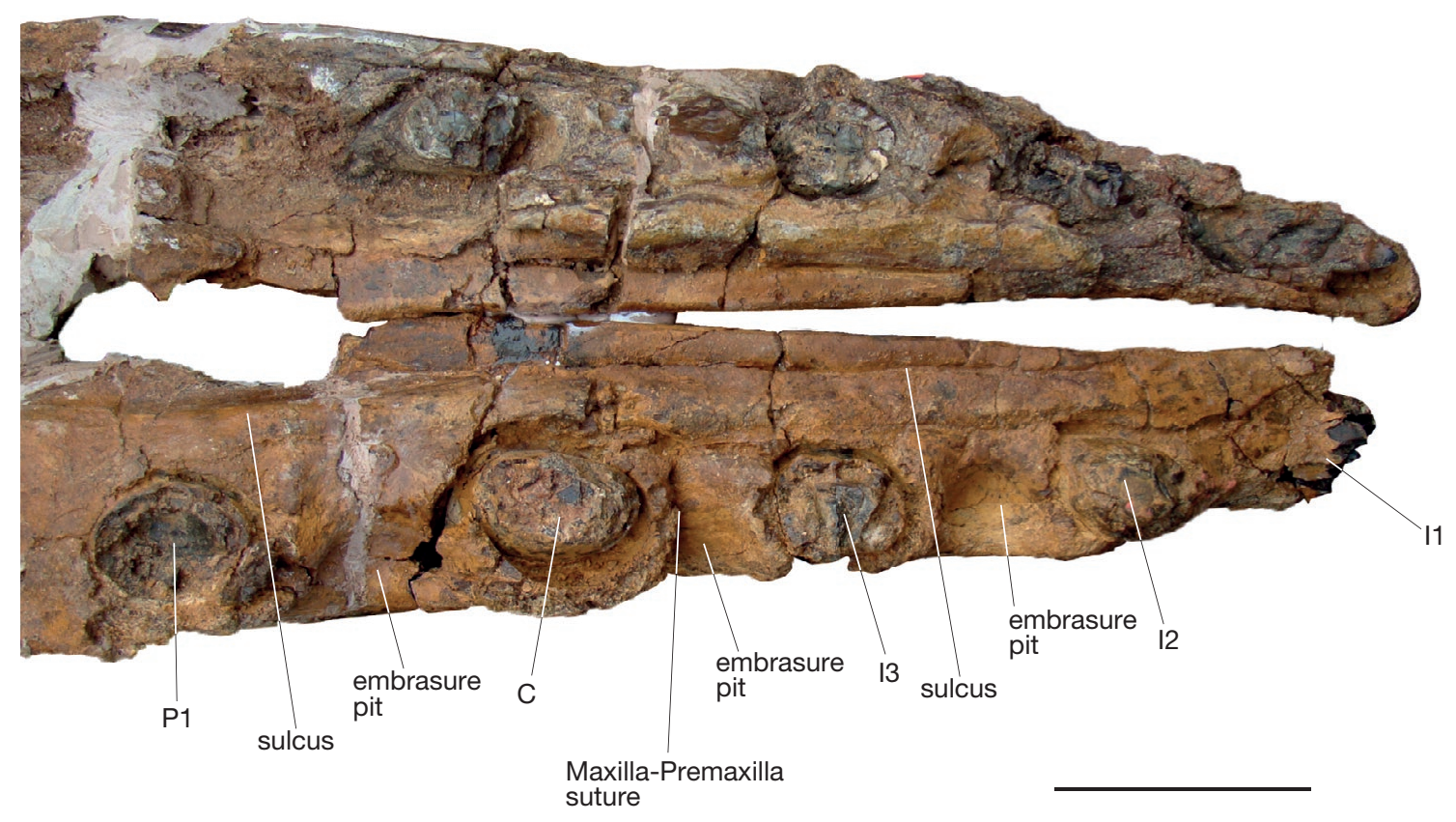

FIG. 8. - Ventral view of the anterior portion of the palate of Mystacodon selenensis (MUSM 1917, holotype). Scale bar: $5 \mathrm{~cm}$.

process of the frontal) and contacts the nasal medially and the frontal laterally. It narrows posteriorly and its posteriormost point is posterior to that of the nasal, being bounded medially and laterally by the frontal. A similar condition is observed in Llanocetus but not in basilosaurids, in which the nasals extend further posteriorly than the maxillae. The ascending processes of the maxillae in the holotype of Mystacodon selenensis are distinctly asymmetrical, the left process being larger and extending more posteriorly than the right. Since the ascending process of the premaxilla is wedged extensively between the nasal and the ascending process of the maxilla, the naso-maxillary ( $\mathrm{Na}-\mathrm{Mx})$ suture is much shorter than the Na-PMx suture and only makes $c .15 \%$ of the nasal length. The maxilla and the nasal are in contact until their posterior end and no anterior process of the frontal wedges between these two bones. This condition resembles that of basilosaurids and Llanocetus, and differs from that of mammalodontids (Janjucetus and Mammalodon), in which a conspicuous parasagittal anterior process of the frontal wedges between the maxilla and the nasal anteriorly. The ascending process of the maxilla is much larger in Mystacodon than in Cynthiacetus, and it extends more posteriorly. In contrast, it is much smaller in Mystacodon than in Llanocetus, a condition related to the extensive development of the maxilla in the latter. The ascending process of the maxilla of Mystacodon occupies approximately the same surface in dorsal view as the supraorbital process of the frontal, while it is smaller in Cynthiacetus. The dorsal exposure of the ascending process of the maxilla is also smaller than the supraorbital process of the frontal in other basal mysticetes (e.g. Coronodon, Janjucetus, and Mammalodon), and it is much smaller in Aetiocetus and Fucaia. In contrast, it is at least as large as the dorsal exposure of the supraorbital process of the frontal in Llanocetus. This large expansion of the ascending process of the maxilla observed in Mystacodon is related to the greater width of the rostrum at its base (Table 2), a condition even more extreme in Llanocetus (Fig. 7).

In dorsal view, the Fr-Mx suture is anterolaterally-posteromedially oriented and distinctly convex anteriorly (Figs 4; 9; 10). This condition resembles that of basilosaurids and most of the early diverging mysticetes. In this region, the maxilla does not overlap the frontal as it does in odontocetes. The anterolateral edge of the suture reaches the anterior edge of the preorbital process of the frontal and turns posterolaterally before it meets the Mx-La suture. In lateral view (Fig. 6), the ascending process of the maxilla is ventral to the nasal, the latter being the most elevated element of the facial region. The triangular region formed by the ascending process is roughly flat and subhorizontal. In the approximate center of this region the maxilla is flattened dorsoventrally and clearly wider than high, a condition observed in all basal mysticetes, but conspicuously emphasized in Llanocetus (in which, however, part of the flattening may be due to some postmortem deformation). Such a flattening of the ascending process is absent in basilosaurids and is part of a general trend of dorsoventral flattening of the rostrum, which is a key character of mysticete evolutionary history.

In ventral view, the maxilla is not as well preserved as in dorsal view (Figs 5; 8). On the lateral margin of the maxilla, the alveolar process is ventrally expanded, with a subvertical lateral edge, and is bordered medially by the palatal process of the maxilla, which is poorly preserved and crushed on both sides of the palate of the holotype of Mystacodon selenensis. However, interestingly, this aspect of the maxilla on the palate is distinctly rippled and features several shallow grooves on the medial half of the palatal processes, at the level of P2-P4. Some of these grooves connect to a vascular foramen at their posterior end. They are anteroposteriorly oriented, except for 

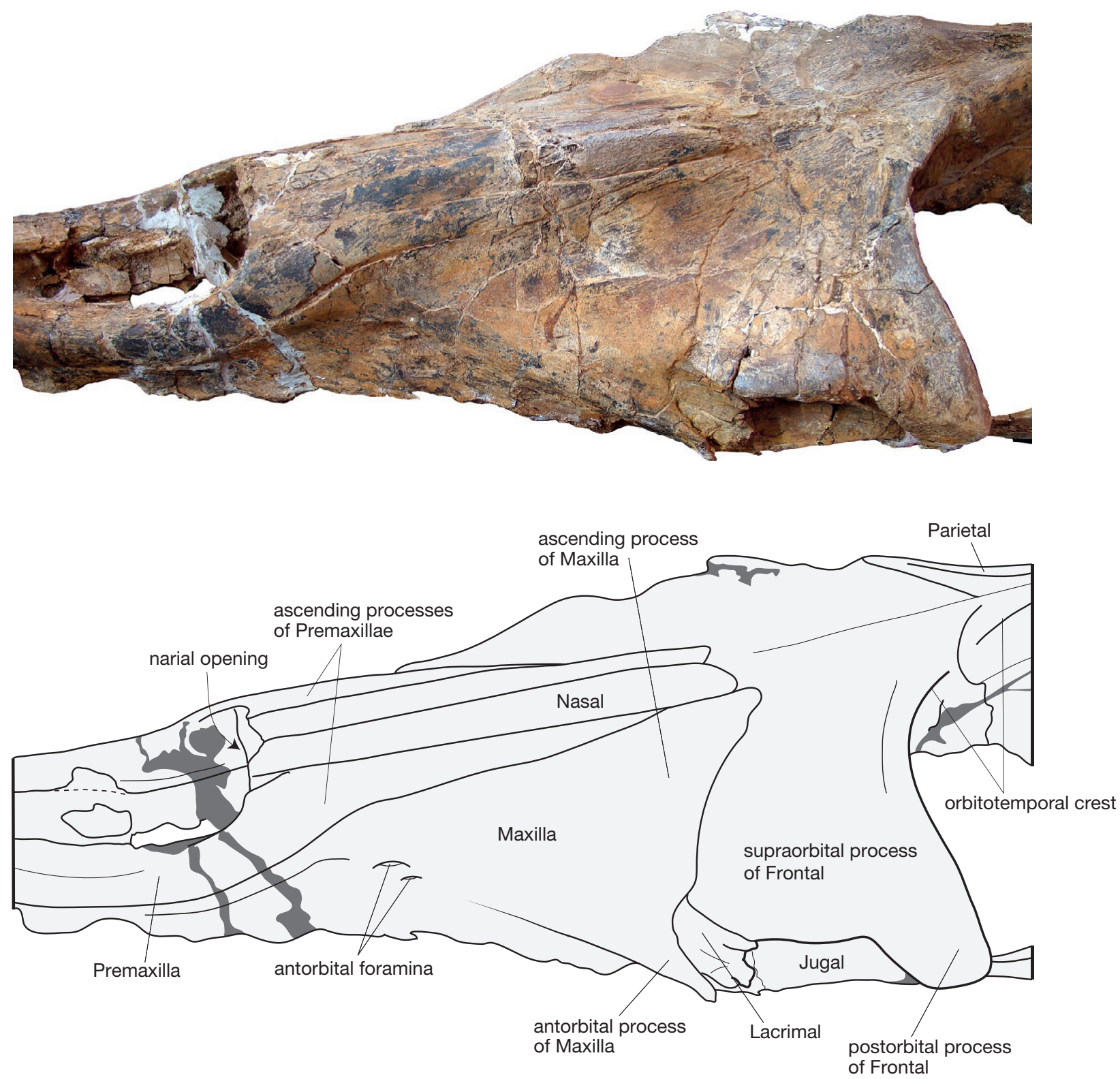

FIG. 9. - Dorsolateral view of facial region of Mystacodon selenensis (MUSM 1917, holotype). Grey-shaded regions indicate missing parts. Scale bar: $10 \mathrm{~cm}$.

an oblique groove at the level of the anterior root of $\mathrm{P} 2$ on the right maxilla (shallow groove on Fig. 11). Because of the poor preservation of the palate it is difficult to ascertain if these sulci are homologous to the deep grooves observed in chaeomysticetes, conducting the vessels for the vascularisation of the palate epithelium in the area where baleen are growing. Whatever their interpretation may be, it is noteworthy that most of the grooves of Mystacodon are distinctly shallower than in chaeomysticetes. Vascular grooves have also been observed on the palate of Aetiocetus and Llanocetus, but clearly deeper than in Mystacodon. (Fig. 11). Furthermore, the groove observed in Mystacodon are located in the medial portion of the maxilla, while the palatal grooves which supply blood to baleen epithelium are distinctly lateral in extant mysticetes since they are related to the superior alveolar artery (Ekdale et al. 2015). Some of these grooves in Mystacodon may rather be related to the greater palatine artery, which is more medially placed on the palate (Deméré et al. 2008; Ekdale et al. 2015).

The alveolar process of the maxilla bears alveoli for two singlerooted teeth (C1 and P1) and five double-rooted teeth (P2-M2). The alveoli for $\mathrm{C} 1$ to $\mathrm{P} 4$ are separated by four medium-sized diastemata. The diastema between $\mathrm{C}$ and $\mathrm{P} 1$ is longer that $\mathrm{P} 1$, the diastema between $\mathrm{P} 1$ and $\mathrm{P} 2$ is approximately the length of $\mathrm{P} 2$, and the diastema between $\mathrm{P} 3$ and $\mathrm{P} 4$ is half the length of $\mathrm{P} 4$. The anteriormost diastema (between $\mathrm{C} 1$ and $\mathrm{P} 1$ ) presents a well-defined embrasure pit; it is large, deep, laterally open, and received the crown of $\mathrm{p} 1$ when the jaws were closed. The second diastema (between P1 and P2) is the longest. It presents a very shallow depression, probably too shallow to be called a true embrasure pit, open laterally, and receiving the crown of $\mathrm{p} 2$ 
TABLE 4. - Cranial measurements (in mm) of the holotype of Mystacodon selenensis (MUSM 1917). Abbreviation: e, estimated measurements.

\begin{tabular}{|c|c|}
\hline Measurements & $\mathrm{mm}$ \\
\hline Condylobasal length (estimated) & $980 \mathrm{e}$ \\
\hline Half of the bizygomatic width (left side) & 199.8 \\
\hline Length of the rostrum, from its anterior edge to the level of the antorbital process of the maxilla & 544.00 \\
\hline $\begin{array}{l}\text { Length of the prenarial portion of the rostrum, from its anterior edge to the dorsal edge of the external bony nares, } \\
\text { at midline }\end{array}$ & 291.47 \\
\hline Width of the external bony nares, at the level of the anterior edge of the nasal process of the premaxilla & 92.84 \\
\hline Width of the rostrum at the level of $\mathrm{C} 1$ & 107.06 \\
\hline Width of the left half of the rostrum at the level of P2 & 87.80 \\
\hline Width of the left half of the rostrum at the level of P3 & 108.9 \\
\hline Length of the alveolar portion of the skull (estimated) & $603 e$ \\
\hline Length of the diastema between I1 and I2 & 24.4 \\
\hline Length of the alveolus for 12 & 29.07 \\
\hline Length of the diastema between 12 and 13 & 28.00 \\
\hline Length of the alveolus for 13 & 32.01 \\
\hline Length of the diastema between $\mathrm{I} 3$ and $\mathrm{C} 1$ & 21.9 \\
\hline Length of the alveolus for $\mathrm{C} 1$ & 35.7 \\
\hline Length of the diastema between $\mathrm{C} 1$ and $\mathrm{P} 1$ & 37.44 \\
\hline Length of the alveolus for P1 & 34.74 \\
\hline Length of the diastema between P1 and P2 & 39.42 \\
\hline Length of the alveolus for P2 & 57.44 \\
\hline Length of the diastema between P2 and P3 & 16.59 \\
\hline Length of the alveolus for P3 & 56.43 \\
\hline Length of the diastema between $\mathrm{P} 3$ and P4 & 15.31 \\
\hline Length of the alveolus for $\mathrm{P} 4$ & 50.59 \\
\hline Length of the diastema between $\mathrm{P} 4$ and $\mathrm{M} 1$ & 7.17 \\
\hline Length of the alveolus for M1 & 34.07 \\
\hline Length of the diastema between M1 and M2 (estimated) & $8.74 \mathrm{e}$ \\
\hline Length of the alveolus for M2 (estimated) & $33 e^{-170}$ \\
\hline Maximum length of the nasal, not at midline & 293.4 \\
\hline Maximum length of the premaxilla & 549.00 \\
\hline Length of the frontal at midline & 145.40 \\
\hline Length of the parietal at midline & 86.07 \\
\hline Length, from the posterior edge of the nasal at midline to the vertex & 231.51 \\
\hline $\begin{array}{l}\text { Length of the prenarial portion of the premaxilla, from its anterior edge to the level of P1, when the premaxilla forms } \\
\text { the lateral edge of the external bony nares }\end{array}$ & 149.60 \\
\hline $\begin{array}{l}\text { Length of the narial process of the premaxilla, from the level of the dorsal edge of the external bony nares } \\
\text { to the posterior edge of the premaxilla }\end{array}$ & 239.54 \\
\hline Width of left half of the skull, at the level of the preorbital process of the frontal & 164.09 \\
\hline Width of left half of the skull, at the level of the postorbital process of the frontal & 214.73 \\
\hline Width of the left supraorbital process of the frontal at its mid-length & 178.69 \\
\hline Minimal width of the intertemporal constriction & 62.72 \\
\hline Length of the orbit & 100.72 \\
\hline Maximum height of the orbit & 50.61 \\
\hline Maximum width of the supraoccipital in dorsal view & 184.2 \\
\hline Maximum length of the jugal (estimated) & $245.50 \mathrm{e}$ \\
\hline Length of the zygomatic process of the squamosal & 269.18 \\
\hline $\begin{array}{l}\text { Maximum length of the temporal fossa in dorsal view, from the posterior edge of the supraorbital process } \\
\text { of the frontal to the posterior wall of the squamosal fossa }\end{array}$ & 246.01 \\
\hline $\begin{array}{l}\text { Maximum width of the temporal fossa in dorsal view, from the orbitotemporal crest to the zygomatic process } \\
\text { of the squamosal }\end{array}$ & 166.82 \\
\hline Length of the glenoid fossa & 93.05 \\
\hline Width of the glenoid fossa & 61.43 \\
\hline
\end{tabular}

during jaw adduction. The two posterior diastemata (between P2-P3 and P3-P4) are the shortest. An extremely shallow depression on the P2-P3 diastema, medial to the dental row, provides space for the crown of $\mathrm{p} 3$. No well-defined diastemata and embrasure pits are present on the posterior portion of the palate between P4-M1-M2). In basilosaurids, diastemata are similarly absent on the posterior palate, but embrasure pits are clearly present between teeth anterior to P3. Basilosaurids and protocetids differ from Mystacodon in lacking a diastema between P3 and P4. Except for this difference the arrangement of the upper maxillary teeth of Mystacodon approaches the condition observed in basilosaurids, and strongly differs from that of other toothed mysticetes. In Llanocetus check teeth are separated by exceptionally long diastemata; for example, the diastema between $\mathrm{P} 4$ and $\mathrm{M} 1$ is more than three times the mesiodistal length of $\mathrm{P} 4$. An approaching condition is also observed in aetiocetids, in which the length of the diastema between maxillary teeth is, at least, twice the mesiodistal length of a tooth. A diastema shorter than one tooth length is present in mammalodontids, and no diastema between the four posterior maxillary teeth and a reduced diastema between the anterior maxillary teeth are observed in Coronodon. In relation 


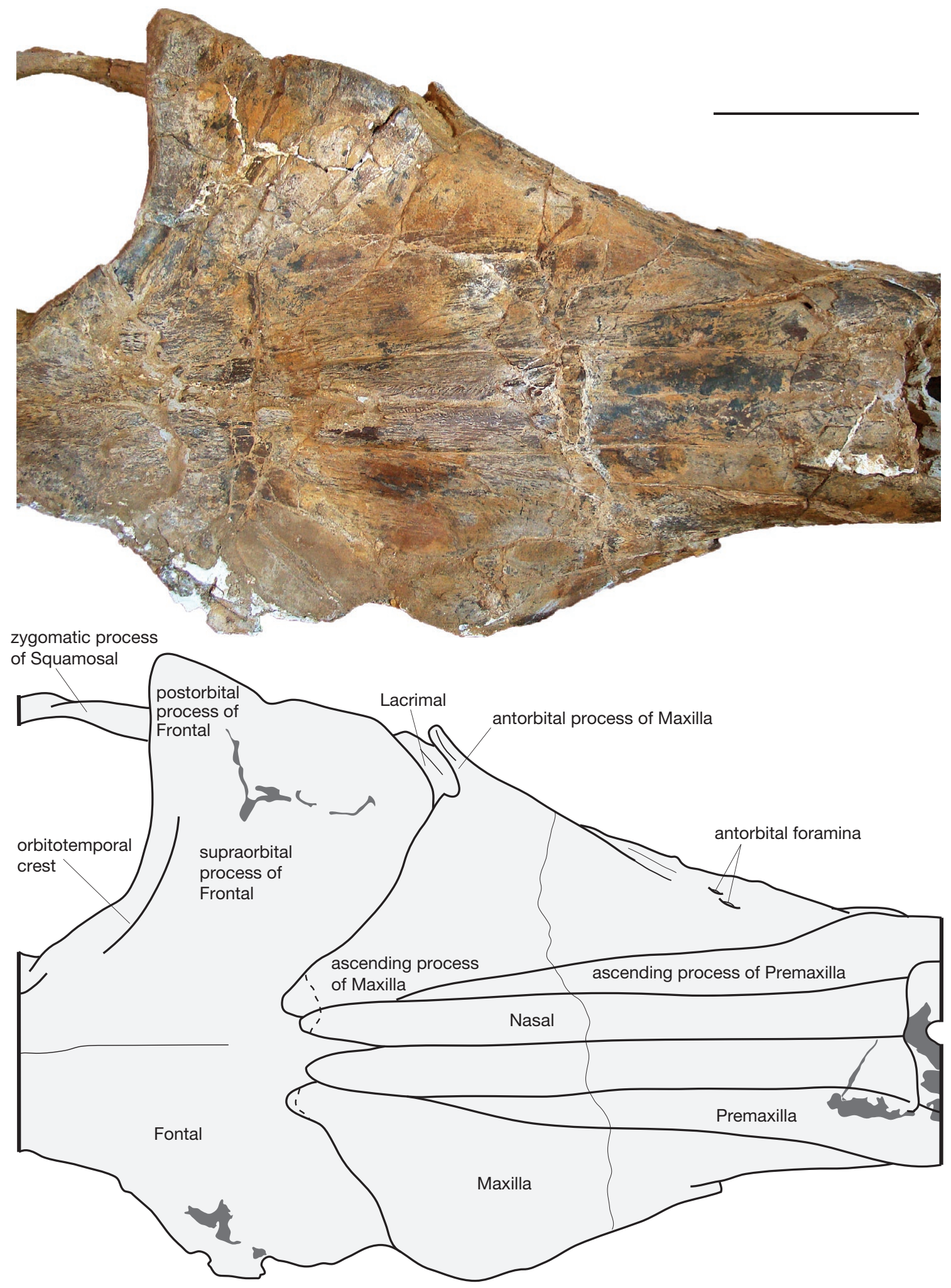

FIG. 10. - Dorsal view of facial region of Mystacodon selenensis (MUSM 1917, holotype). Grey-shaded regions indicate missing parts. Scale bar: $10 \mathrm{~cm}$.

to the small size of the teeth, embrasure pits are not present in Llanocetus, mammalodontids, and aetiocetids. On the other hand, pits are well developed between the anterior maxillary teeth and medial postcanine teeth (P2-M2) of Coronodon.
The zygomatic process of the maxilla extends posteriorly to the alveolar process and underlaps the anterior end of the jugal ventrally (Figs $6 ; 12 ; 13$ ). The process is short and rounded, but its apex is posterior to the preorbital process of 
TABLE 5. - Comparison of the intertemporal width to bizygomatic width in protocetids (pink), basilosaurids (grey), toothed mysticetes (green), and eomysticetid (blue). Abbreviation: e, estimated measurements.

\begin{tabular}{|c|c|c|c|}
\hline Taxon & $\begin{array}{l}\text { Intertemporal } \\
\text { Width (IW) }\end{array}$ & $\begin{array}{l}\text { Bizygomatic } \\
\text { Width (BW) }\end{array}$ & IW/BW \\
\hline $\begin{array}{l}\text { Artiocetus clavis (GSP-UM 3458) } \\
\text { Aegyptocetus tarfa (MSNUP I-15459) }\end{array}$ & $\begin{array}{l}39.72 \\
40.5\end{array}$ & $\begin{array}{l}308 \\
298\end{array}$ & $\begin{array}{l}0.13 \\
0.13\end{array}$ \\
\hline $\begin{array}{l}\text { Cynthiacetus peruvianus (MNHN.F.PRU10) } \\
\text { Basilosaurus isis (CGM 42195) } \\
\text { Zygorhiza kochii (USNM 11962) } \\
\text { Saghacetus osiris (BMNH 10228) } \\
\text { Dorudon atrox (from University of Michigan website) } \\
\text { Dorudon atrox (from reconstruction by Uhen 2004: fig. 6, based on } \\
\quad \text { UM100139, 93220, 101222) }\end{array}$ & $\begin{array}{l}73.6 \\
94.8 \\
53.4 \\
46.4 \\
83.3 \\
87.8\end{array}$ & $\begin{array}{l}478 \\
600 \\
336 e \\
380 \\
390 \\
492\end{array}$ & $\begin{array}{l}0.15 \\
0.16 \\
0.16 \\
0.12 \\
0.21 \\
0.17\end{array}$ \\
\hline $\begin{array}{l}\text { Mystacodon selenensis (MUSM 1917) } \\
\text { Llanocetus denticrenatus (USNM 183022) } \\
\text { Coronodon havensteini (CCNHM 108) } \\
\text { Janjucetus hunderi (NMV P216929) } \\
\text { Mammalodon colliveri (NMV P199986) } \\
\text { Fucaia goedertorum (LACM 131146) } \\
\text { Aetiocetus cotylalveus (USNM 25210) } \\
\text { Aetiocetus weltoni (UCMP 122900) } \\
\text { ChM PV 5270 }\end{array}$ & $\begin{array}{l}95.6 \\
355.6 \mathrm{e} \\
116.4 \\
49.65 \\
45.3 \\
67.5 \\
119 \mathrm{e} \\
88 \\
48.3\end{array}$ & $\begin{array}{l}399.6 e \\
886 e \\
463 \\
332 e \\
300 e \\
236 e \\
318 e \\
287 \\
501.5\end{array}$ & $\begin{array}{l}0.24 \\
0.40 \\
0.25 \\
0.15 \\
0.15 \\
0.28 \\
0.37 \\
0.31 \\
0.09\end{array}$ \\
\hline Yamatocetus canaliculatus (KMNH VP 000,017) & 75.3 & 427 & 0.18 \\
\hline
\end{tabular}

the frontal and participates in the floor of the orbit. Medial to the zygomatic process of the maxilla, the palatal process of the maxilla extends posteriorly all along the palate width and forms a distinct, transversely wide, and thin infraorbital plate (Figs 5; 14). This plate forms the floor of the posterior opening of the maxillary canal (maxillary foramen or ventral infraorbital foramen), which is the passageway of the antorbital nerve, part of the maxillary branch of the trigeminal nerve (CN V). The posterior edge of the infraorbital plate is convex posteriorly. An infraorbital plate is present in all mysticetes and represents a key synapomorphy of the suborder. The palatomaxillary (Pal-Mx) suture is not discernible in this region and it is difficult to evaluate if the palatine also participated in the infraorbital plate, although it seems that most of the infraorbital plate is formed by the maxilla in Mystacodon. As a result of the dorsoventral compression of the maxilla (cf. above), the maxillary foramen is distinctly wider than high. A similar feature was observed in the chaeomysticetes used for comparison (e.g. Pelocetus calvertensis and Piscobalaena nana).

The alveolus for the last upper molar (M2 in Mystacodon) is slightly anterior to the level of the posterior edge of the infraorbital plate of the maxilla, while in the other toothed mysticetes in which it is preserved, it is well anterior to the infraorbital plate. It is noteworthy that in some toothed mysticetes (such as Aetiocetus, Fucaia, and Mammalodon) the last upper molar is probably an M3.

Furthermore, the last molar of Mystacodon is also anterior to the anterior edge of the orbit, as in other toothed mysticetes, but also as in all odontocetes, including early taxa (e.g. Echovenator, Simocetus, and Waipatia). In basilosaurids (e.g. Basilosaurus, Cynthiacetus, and Dorudon) and in protocetids (e.g. Aegyptocetus, Artiocetus, and Rodhocetus), the last molar (M2 or M3, respectively), is located posterior to the anterior edge of the jugal and ventral to the anterior region of the orbit. Observed in toothed mysticetes and in odontocetes, the condition of Mystacodon could therefore be a diagnostic feature of the Neoceti.

The palatal surface of the maxilla is slightly concave ventrally transversely and this concavity increases posteriorly. On the anterior portion of the palatal process of the maxilla is a shallow sulcus, which runs anteroposteriorly and continues on the premaxilla (sulcus on Fig. 8). The palate gradually widens posteriorly and reaches its maximum width at the level of M2. As described above, the Mx-PMx suture runs posteromedially from the anterior edge of the alveolus for $\mathrm{C} 1$ to the midline. The portion where both maxillae contact each other at midline is not preserved, but it was most likely located posterior to the level of P1. Because of the poor preservation of the palatal surface, it is difficult to evaluate if the vomer was ventrally exposed at midline through a maxillary window.

Posterior to the level of the diastema between P2 and P3, the medial edges of the maxillae extend ventrally and form a ventrally rounded anteroposterior elevation on the median region of the palate. This dome extends as far as the posterior edge of the palate; being more elevated posteriorly, it accentuates the concavity of the palatal process of the maxilla, medial to the tooth row. This condition resembles that of most other mysticetes. However, because of the poor preservation of the palate, the original morphology of Mystacodon may have been emphasized by some postmortem distortion. Posteriorly, because of the poor preservation of this region, the Pal-Mx suture can only be inferred medially (cf. below, Palatine).

Nasal (Na). The nasal is extremely long as compared to other toothed mysticetes, distinctly longer than the prenarial portion of the rostrum; the maximum length of the nasal approximates that of frontal + parietal along midline (Fig. 4).

A comparison of the nasal length can be made on the basis of the bizygomatic width, which is probably the least variable measurement in the sample into consideration. As compared 


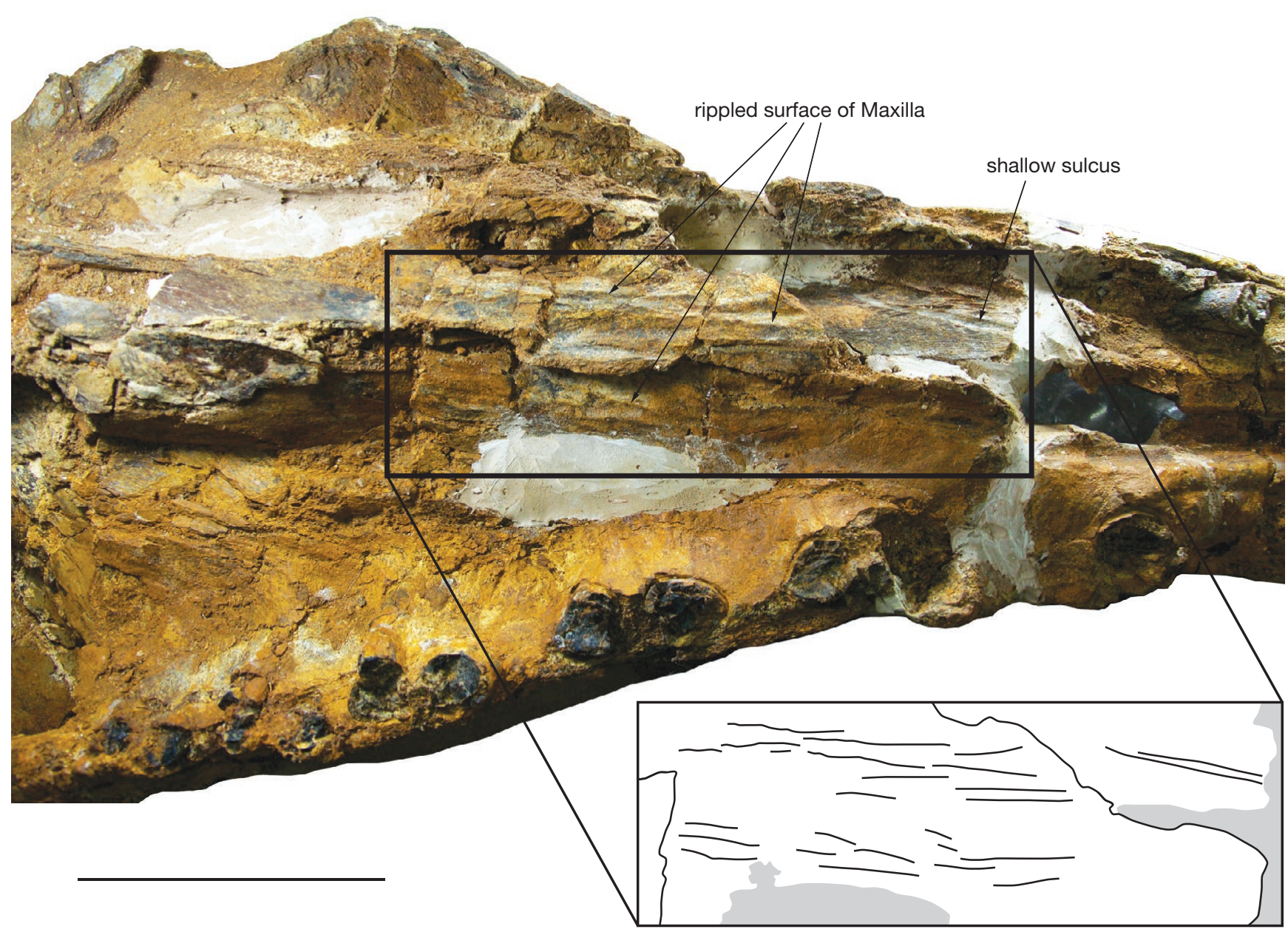

FIG. 11. - Ventral view of the skull of Mystacodon selenensis (MUSM 1917, holotype) showing rippled surface and shallow sulcus of the maxilla on the palate. Grey-shaded regions indicate missing parts. Scale bar: $10 \mathrm{~cm}$.

to most basal toothed mysticetes (e.g. Aetiocetus, Coronodon, Fucaia, and Janjucetus), the nasals of Mystacodon are between 1.5 and 2.8 times longer. They are also clearly longer (1.2 and 1.7 times) than in basilosaurids. In contrast, they clearly approach the size observed in protocetids, being still slightly longer than in the taxa considered here, and in several eomysticetids (see Boessenecker \& Fordyce 2017). Interestingly, the only toothed mysticete whose nasals are approximately as long as in Mystacodon is Llanocetus. It is noteworthy that the latter is from the late Eocene of Antarctica (approximately $34 \mathrm{Ma}$, Mitchell [1989]; Fordyce \& Marx [2018]), while the other toothed mysticetes measured in Table 5 are from latest early Oligocene or late to latest Oligocene beds, i.e., approximately 8 to $13 \mathrm{Ma}$ years younger. It is noteworthy that long nasals are also present in the eomysticetid Yamatocetus, in which the nasal approaches in length the bizygomatic width (Table 5), being in this respect proportionally longer than in Mystacodon. However, the nasals of Yamatocetus are shorter than the portion of the rostrum anterior to them, whereas they are clearly proportionally longer in Mystacodon. The condition in Yamatocetus is likely a consequence of the elongation of the rostrum in chaeomysticetes, as compared to the condition in toothed mysticetes.
Laterally, the nasal of Mystacodon selenensis articulates anteriorly with the premaxilla (85\% of the lateral edge) and posteriorly with the maxilla ( $15 \%$ of the lateral edge). Both nasals are in contact along midline for most of their length. However, their posterior apices diverge and articulate medially on approximately $5 \%$ of their length with a triangular anterior narial process of the frontals wedged between them. This process is much shorter than in the basilosaurids Basilosaurus, Cynthiacetus, and Dorudon. A narial process of the frontal is generally absent in other mysticetes, although a small process, similar in size to that of Mystacodon, is occasionally present in some taxa (e.g. Fucaia buelli, Incakujira anillodefuego, and Llanocetus denticrenatus).

The anterior region of the nasal distinctly widens in contrast to the condition observed in most basilosaurids (e.g. Basilosaurus, Cynthiacetus, Dorudon, and Zygorhiza) where the nasal tapers anteriorly. The condition of Mystacodon resembles that of some other toothed mysticetes (e.g. Aetiocetus, Fucaia, and probably Janjucetus); however, it differs from the condition in Coronodon, in which the very short nasal has roughly parallel edges in dorsal view. In Llanocetus the nasal regularly widens from the posterior to the anterior extremity, thus differing from the condition in Mystacodon, in which the nasal only 

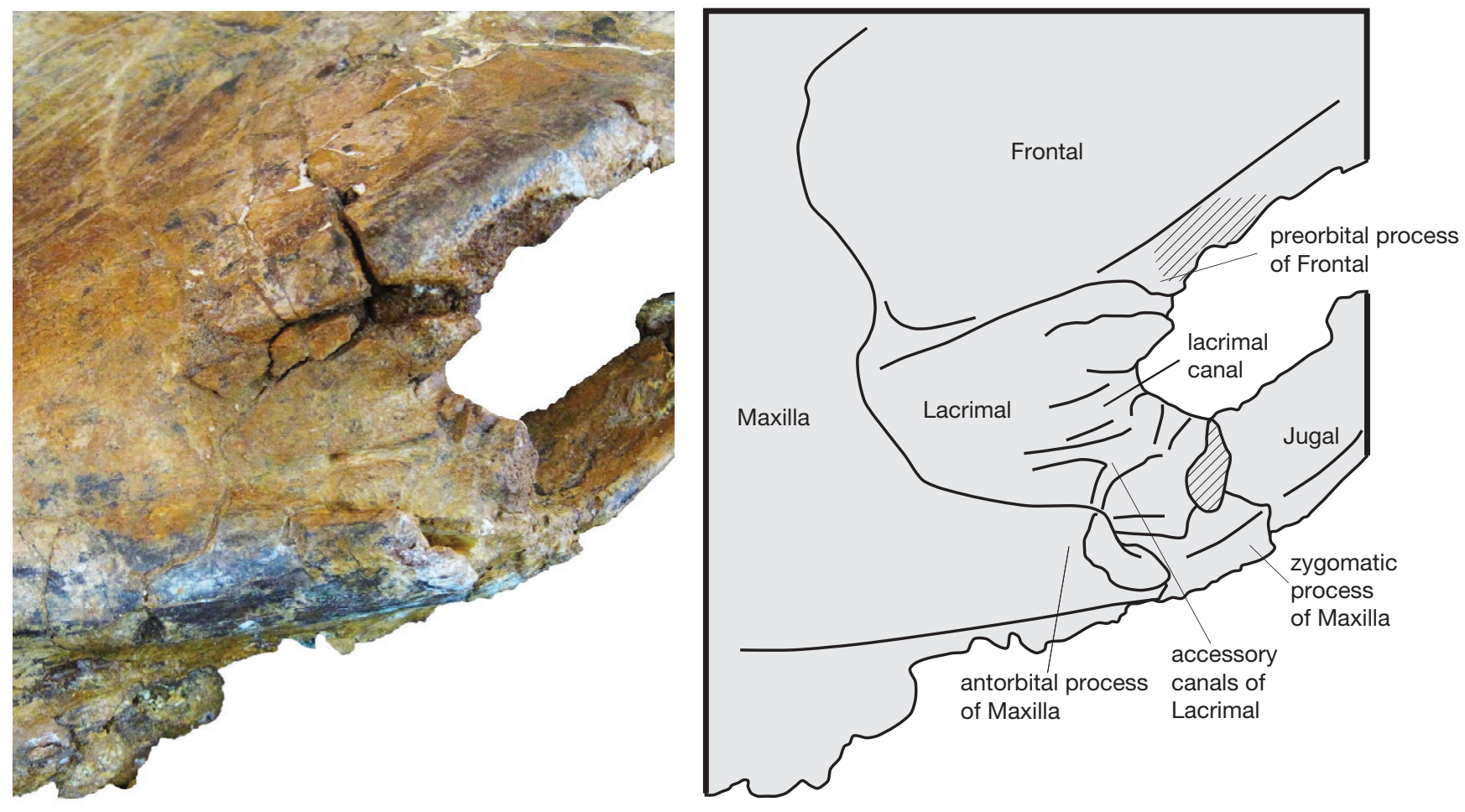

FIG. 12. - Lateral view of the lacrimal of Mystacodon selenensis (MUSM 1917, holotype). Oblique lines indicate broken parts. Scale bar: $5 \mathrm{~cm}$.

widens at its anterior extremity. The anteriormost end of the nasals of the holotype of $L$. denticrenatus being damaged, it is difficult to ascertain their morphology in this region. As a consequence of this widening, the dorsal edge of the external bony nares of these early mysticetes is formed by the nasals only, whereas in basilosaurids (e.g. Basilosaurus, Cynthiacetus, Dorudon, Saghacetus, and Zygorhiza) the nasals taper anteriorly and the premaxillae also participate in the composition of the dorsolateral wall of the bony nares. In protocetids (e.g. Artiocetus, Maiacetus, Protocetus, and Rodhocetus) the nasals widen anteriorly and participate alone to the dorsal edge of the nares (as in Mystacodon), a condition which could therefore be plesiomorphic.

Apart from the anterior extremities described above, in dorsal view, the medial and lateral edges of the nasal of Mystacodon are roughly parallel to each other and to the midline, except for the posterior extremities, which taper posteriorly. In lateral view, as mentioned above, the nasal is the most elevated element of the rostrum.

The anterior edge of the nasal is at the level of the diastema between P1 and P2, while its posterior edge is at the level of the mid-length of the supraorbital process of the frontal (Figs 9; 10). The relative position of the anterior and posterior edges of the nasal is approximately the same as in basilosaurids. In protocetids the anterior edge of the nasal is roughly at the level of the canine (slightly anterior in Artiocetus and slightly posterior in Maiacetus). In other toothed mysticetes the anterior edge of the nasal is slightly more posterior in Llanocetus (at the level of P2) and clearly more posterior in Mammalodon (at the level of P4), Janjucetus (at the level of
M1), and Aetiocetus and Coronodon (at the level of M2), in relation to the more posterior position of the external bony nares in these taxa.

Jugal $(\mathrm{J})$. The jugal is a narrow and long bone (length $=245.5$ $\mathrm{mm}$ ), which mainly contributes to the zygomatic arch.

The orbital portion of the jugal (anterior portion) is dorsoventrally flattened and forms the ventrolateral margin of the large and teardrop-shaped orbit. Contrary to Aetiocetus cotylalveus and basilosaurids, where the whole jugal is straight in lateral view, the anterior portion of the jugal of Mystacodon, which forms the ventral edge of the orbit, is strongly convex dorsally (Figs 6,13), except in the anterior third of the orbit, where it is concave dorsally. The condition of Mystacodon also differs from that observed in Janjucetus (Fitzgerald, 2006), in which the jugal is concave dorsally all along its length. The jugal of Mystacodon is more massive than in Aetiocetus, Janjucetus, and Cynthiacetus. While the orbital portion of the jugal is dorsoventrally compressed, the temporal portion of the jugal (= posterior portion, from the level of the postorbital process of the frontal) is transversely compressed and bladelike. The temporal portion of the jugal gradually becomes thinner posteriorly and articulates with the ventral surface of the zygomatic process of the squamosal. The anterior edge of the jugo-squamosal $(\mathrm{J}-\mathrm{Sq})$ suture is not preserved but it very probably reached the level of the postorbital process of the frontal. At this level, the zygomatic arch and the postorbital process of the frontal could have been in contact (cf. Frontal, Figs 13, 15). The J-Sq suture is considerably longer than in Aetiocetus, Coronodon, and Janjucetus, and more resembles the 

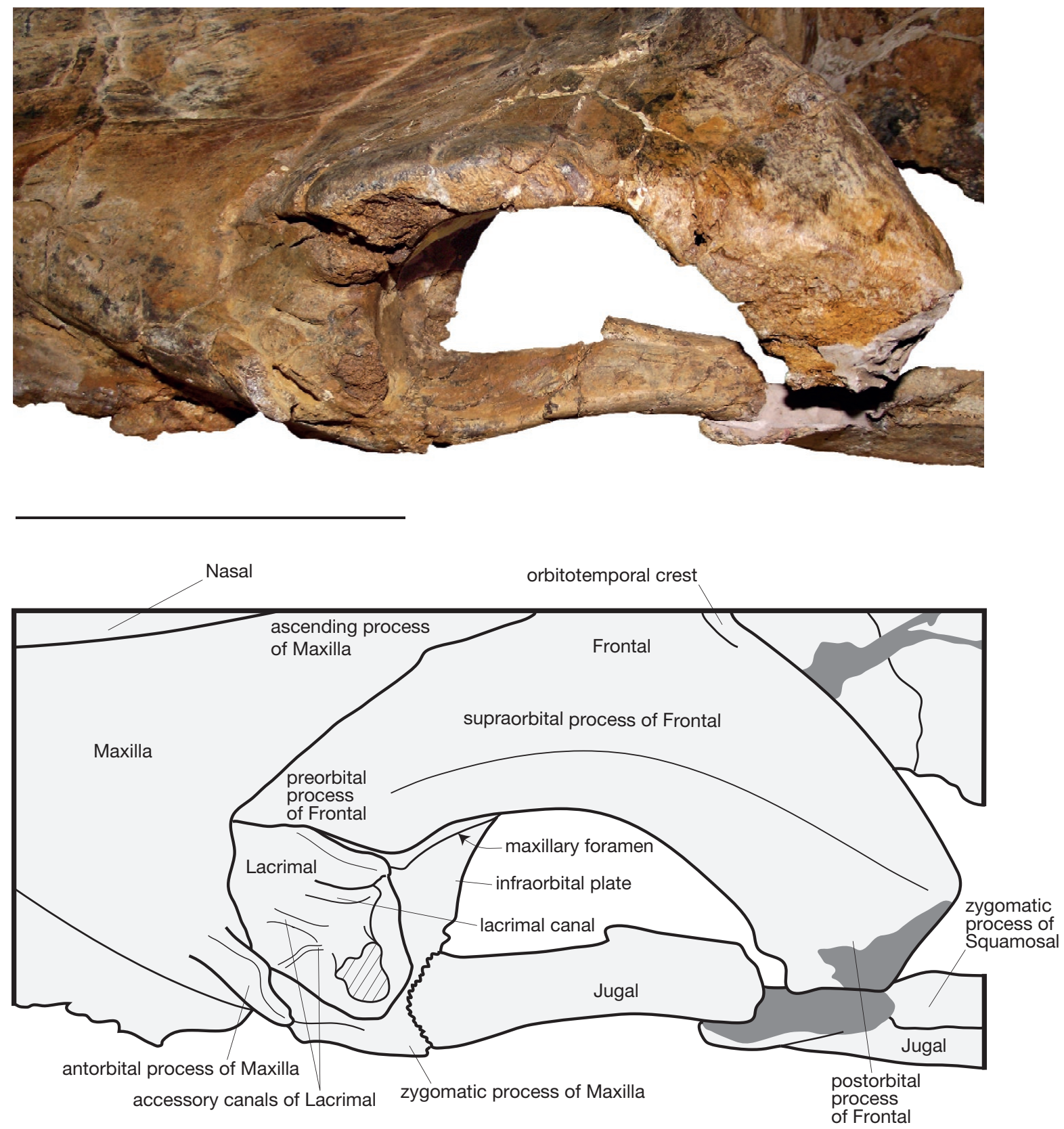

FIG. 13. - Dorsolateral view of the orbit of Mystacodon selenensis (MUSM 1917, holotype). Oblique lines and grey-shaded regions indicate respectively broken and reconstructed parts. Scale bar: $10 \mathrm{~cm}$.

condition observed in Llanocetus and basilosaurids (Kellogg 1936; Uhen 2004; Martínez-Cáceres et al. 2017; Fordyce \& Marx 2018).

In ventral view, the jugal is anteroposteriorly straight and posterolaterally oblique. Its posterior end reaches the anterior edge of the glenoid fossa of the squamosal, a condition also observed in basilosaurids.

Lacrimal (La). The lacrimal is a small bone of the facial region, bounded by the frontal dorsally and the maxilla anteroventrally, and contributing to the anterior wall of the orbit. Its general outline in Mystacodon resembles that observed in basilosaurids. Although its external surface faces laterally, it is clearly visible in dorsal view. It is somewhat squared in shape, and its anterior and posterior edges are anteriorly convex. The external surface of the lacrimal is separated from the antorbital process of the maxilla by a short but conspicuous gap (Figs $9 ; 10 ; 12 ; 13$ ).

The lateral surface of the lacrimal is slightly concave. A wide notch indicating the path for the main lacrimal canal is located on the dorsal half of the posterior edge of the lacrimal. Ventral to the latter, two accessory sulci cross the lateral surface of the lacrimal and converge posteriorly. The dorsalmost sulcus is horizontal; it is deeper than the ventral sulcus, which is curved and anteroventrally oriented. The relative position of the lacrimal canal and accessory sulci are illustrated in Figure 12. 
The orbital (posterior) surface of the lacrimal is smooth and concave. Its medial edge forms part of the lateral border of the maxillary foramen. The lacrimal does not contact the jugal ventrally or laterally. Moreover, the posterolateral corner of the lacrimal is broken and the remaining part is salient laterally. This condition indicates that it probably developed a lateral prominence, as in the basilosaurid Cynthiacetus.

Frontal (Fr). The frontal forms most of the supraorbital shield. On the holotype of Mystacodon selenensis, the left frontal is better preserved than the right, and only the left supraorbital process is preserved. In dorsal view (Figs 4; 9), the frontal articulates anteriorly with the nasal, maxilla, and lacrimal, and posteriorly with the parietal. In ventral view (Figs 5; 12), the frontal contacts the maxilla anteriorly and the palatine medially. Because part of the ventral surface of the skull is damaged, the fronto-sphenoid (Fr-Ali) and fronto-palatine (Fr-Pal) sutures, as well as the shape and position of the orbitosphenoid, cannot be observed in this specimen.

The frontal extends laterally in a large, triangular supraorbital process, which forms the roof of the orbit. The ventral surface of the supraorbital process is concave and the dorsal surface slightly convex (Figs 4; 9; 10).

In lateral view, the orbital rim between the pre- and postorbital processes is thick. The partly preserved postorbital process is especially massive, whereas the preorbital process is barely thicker than the edge of the supraorbital process at mid-length. The condition of Mystacodon resembles that of Coronodon, although in the latter the postorbital process is more slender and longer. The supraorbital process of Mystacodon is slightly thicker than in basilosaurids at mid-length, but the postorbital process is as massive. The supraorbital process is slightly thicker than in aetiocetids, but the latter differ in having a very long and posteroventrally expanded postorbital process. Mystacodon clearly departs from the condition of mammalodontids, in which the supraorbital process is thin and the postorbital process, although long, is relatively slender. The supraorbital process of Llanocetus is incompletely preserved but it has been securely reconstructed on the right side (Fordyce \& Marx 2018). It is apparently as large as in Mystacodon. The postorbital process of Llanocetus is massive, as in Mystacodon and basilosaurids, but it is less triangular than in Mystacodon, its anterior edge being directed more medially in dorsal view. Finally, the supraorbital process of Mystacodon is somewhat thicker than in basal chaeomysticetes (e.g. Eomysticetus and Yamatocetus). No foramen is observed on the dorsal surface of the supraorbital process of the frontal.

The dorsal aspect of the supraorbital process slopes anteroventrally. It is relatively flat and slightly convex dorsally in its anterior region. However, in lateral view, the lateral border of the process is distinctly convex dorsally. Moreover, the lateral edge of the process is more elevated than the medial region of the frontal and, consequently, the median portion of the facial region is lower than the orbit edge, being hidden in lateral view (Fig. 6). This feature is also observed in mammalodontids and aetiocetids, but absent in basilosaurids, odontocetes, chaeomysticetes, and the South Carolina toothed mysticete ChM PV5720. A similar condition is present in Llanocetus, but this morphology may, at least partly, be the result of postmortem distortion.

In dorsal view, the inter-frontal suture is partially fused at midline and is hardly distinguishable (Figs 4; 10). As mentioned above a small anterior process wedges between the posterior apices of the nasals at midline, being significantly smaller than in Basilosaurus and Dorudon.

In dorsal view, the orbital rim is almost straight, only displaying a weak and widely $\mathrm{V}$-shaped notch in its mid-point. It is anteromedially - posterolaterally oriented, to a greater extent than the condition observed in basilosaurids. A straight lateral edge of the supraorbital process in dorsal view is present in basilosaurids and Coronodon. In the other toothed mysticetes it is generally markedly concave, as in Mammalodontidae and Fucaia goedertorum, or deeply notched, as in Aetiocetus and Llanocetus. However, a condition similar to that of Mystacodon is observed on the toothed mysticete ChM PV 5720. In chaeomysticetes the dorsal edge of the orbit is generally moderately concave to straight, except in Pelocetus and Eschrichtius, in which it is deeply excavated.

Although not fully preserved on the holotype of Mystacodon selenensis, the postorbital process of the frontal was extremely thick and posterolaterally expanded. (Figs 6; 13; 15). It is closely approximated to the anterior edge of the zygomatic process of the squamosal. Because the apex of latter is not preserved, it is not possible to ascertain if the two processes were originally in contact. However, given their proximity as preserved, it is clear that they were at the least very close to each other. This condition differs from that in basilosaurids, in which these processes are widely separated, but resembles that of Aetiocetus and Janjucetus, whose processes are either very close or in contact. Such a condition is also observed in several early odontocetes (e.g. Simocetus rayi and the Agorophius spp. housed at the Charleston Museum) and could represent a diagnostic feature for the Neoceti.

On the ventral surface of the supraorbital process, the optic canal is anterolaterally oriented (Fig. 14). It is bounded by welldeveloped anterior and posterior orbital crests, the former being slightly ventral to the latter. At about the anterolateral end of the optic canal are small foramina that we interpret as possible nutrient foramina for the muscles controlling the movements of the eye. Posteromedially, the optic canal is separated into two canals by a small septum. Following Fordyce (2002), the largest and more posterior of these canals is interpreted as the path for the optic nerve, while the accessory and more anterior canal should be regarded as the path for the ophthalmic artery. In ventral view, a fragment of bone covers the posteromedial portion of the path for the ophthalmic artery. This fragment of bone could be a portion of the frontal or orbitosphenoid, and presents a smooth and dorsally concave surface, which could correspond to the path for the maxillary branch of the trigeminal nerve (or maxillary nerve, V2 in Figure 14).

The anteriormost portion of the ventral surface of the supraorbital process forms the roof of the maxillary foramen (passage for the antorbital nerve, branch of the maxillary nerve V2). Medial to the maxillary foramen is the sphenopalatine 

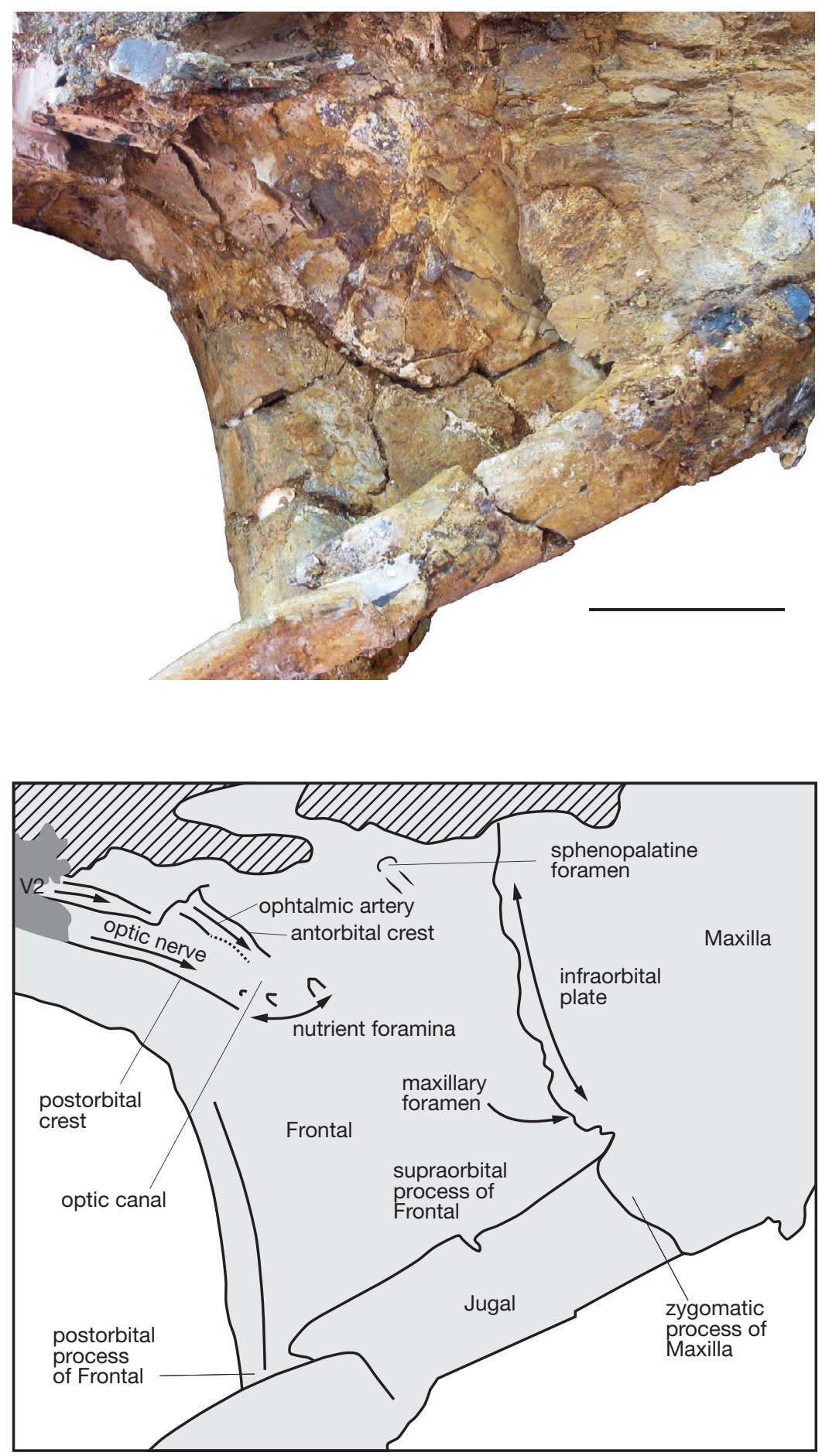

FIG. 14. - Ventral view of the left orbital region of Mystacodon selenensis (MUSM 1917, holotype). Oblique lines and grey-shaded regions indicate respectively broken and reconstructed parts. Scale bar: $5 \mathrm{~cm}$.

foramen (cf. below, Palatine). Because of the poor preservation of the external surface of the palate, the fronto-palatine suture cannot be observed in this region.

In dorsal view, the posterior edge of the supraorbital process of the frontal is almost straight and transversely oriented. It is located at mid-length of the anteroposterior extent of the frontal on the sagittal plane. The posterior edge of the supraorbital process is dorsoventrally thicker medially than laterally (thickness at the median end $=68 \mathrm{~mm}$, thickness at mid-length $=c .40 \mathrm{~mm}$ ). The posterior edge of the supraorbital process is proportionally thicker than in mammalodontids, Coronodon, the South Carolina toothed mysticete ChM VP5720, and the chaeomysticetes used for comparison in this work (Pelocetus and Piscobalaena), but resembles Aetiocetus in this respect. Its thickness also approaches the condition observed in basilosaurids. 
In dorsal view, the temporal fossa is limited anteriorly by the posterior edge of the supraorbital process of the frontal, and anteromedially by the well-developed orbitotemporal crest (Fig. 4). The orbitotemporal crest starts on the medial portion of the posterior edge of the supraorbital process and runs posteromedially on the dorsal surface of the cranium, towards the vertex. On the posterior portion of the frontals, both orbitotemporal crests bound a shallow sagittal depression at the level of the fronto-parietal suture. This depression is anteroposteriorly elongated and extends on the parietals posteriorly in a narrow trough. A similar depression (in the posteromedian region of the frontals, which extends on the parietals) is present in Llanocetus (sagittal trough in Fordyce \& Marx 2018), but also in basilosaurids (Basilosaurus, Chrysocetus, Cynthiacetus, Saghacetus, and some specimens of Zygorhiza). The saggital trough is narrower in basilosaurids than in Mystacodon and Llanocetus. Such a difference is probably related to the narrower intertemporal bridge of basilosaurids as compared to that in Mystacodon and Llanocetus. In Janjucetus, although a distinct trough is not as marked as in Mystacodon and Llanocetus, the posterior region of the frontals bears a distinct median depression, which is probably a homologous structure. A sagittal trough in the frontal and/or parietals is absent in taxa in which the sagittal crest extends as far as the frontal-parietal suture (e.g. Coronodon ChM 5720, Dorudon, some specimens of Zygorhiza, and all protocetids). Because it is present in many basilosaurids and several basal toothed mysticetes, such a trough may represent a symplesiomorphy within Mysticeti rather than a synapomorphy of the Llanocetidae as advocated by Fordyce \& Marx (2018)

Posterior to the supraorbital process of the frontal is the fronto-parietal $(\mathrm{Fr}-\mathrm{Pa})$ suture, in the intertemporal region. In dorsal view, the Fr-Pa suture is somewhat curved, posteromedially oriented, and anteriorly convex. Both Fr-Pa sutures meet at midline forming a posteriorly pointed suture, a plesiomorphic feature shared with basilosaurids. The Fr-Pa suture continues on the lateral wall of the cranium. It runs anteroventrally from the dorsal border of the intertemporal region, then it turns posteroventrally towards the anterior border of the squamosal fossa (Fig. 15). Ventrally, the Fr-Pa suture should meet the fronto-sphenoid ( $\mathrm{Fr}-\mathrm{Al}$ ) suture. A portion of the alisphenoid may be preserved on the anteroventral portion of the cranium, but a large breakage in this region does not allow identifying the Fr-Al suture. On the lateral wall of the skull and anterior to the Fr-Pa suture is a small and dorsoventrally elongated tubercle. Such a tubercle is present on both sides of the cranium. A similar tubercle is present in Llanocetus, but absent in Janjucetus and Mammalodon. It is also present in Cynthiacetus, but in this taxon, it faces dorsally rather than laterally as in Mystacodon and Llanocetus. This tubercle likely received anterior fibers of the temporalis muscle (temporalis superficialis?).

Palatine (Pal). The palatine participates in the posterior portion of the palatal surface. The palatine articulates anterodorsally with the maxilla and posterodorsally with the frontal. The palato-maxillary (Pal-Mx) suture is only hardly distinguishable on the median portion of the palate, at about the level of $\mathrm{P} 4$. The medial portion of the palatine is ventrally oriented and both palatines meet at midline forming a salient and rounded ventral transverse convexity. Because of the poor preservation of the specimen, no foramen or palatal crest can be inferred with certitude in this region. Portions of the narial passage can barely be observed on both sides, posterior to the level of M2.

Anteriorly, the lateral portion of the palatine fuses with the medial portion of the maxilla, and the Pal-Mx suture is not observable in this region. As mentioned above (cf. Maxilla), the lateralmost portion of the palatine could contribute to the infraorbital plate. Moreover, a small sphenopalatine path and foramen can be observed in the anteromedial portion of the orbital roof, medial to the infraorbital plate and the maxillary foramen (Fig. 14). The sphenopalatine foramen transmits the sphenopalatine artery and the caudal nasal nerve (continuation of the pterygopalatine nerve and branch of the maxillary nerve V2) to the nasopharyngeal duct.

Parietal $(\mathrm{Pa})$. The parietal is mainly involved in the dorsal portion of the braincase and in the intertemporal region of the skull. It is paired and articulates anteriorly with the frontal, anteroventrally with the alisphenoid, posteriorly with the occipital shield, and ventrally and posteroventrally with the squamosal. The left parietal is better preserved than the right in MUSM 1917. However, the anteroventral portion of the former is missing.

In dorsal view, the cranium of Mystacodon selenensis presents an important intertemporal constriction, which is absent in extant cetaceans but present in basilosaurids as well as in early neocetes. The anterior portion of the parietal is linguiform and extends anteriorly on the dorsolateral margin of the intertemporal constriction (Fig. 4). As mentioned above, a break on the cranium prevents to evaluate if the bone in contact with the anteroventral portion of the parietal is the frontal or the alisphenoid. Because in basilosaurids and Aetiocetus weltoni, such a position is occupied by the alisphenoid, a similar condition is hypothesized in Mystacodon (Fig. 15). Thus, the parietosphenoid ( $\mathrm{Pa}-\mathrm{Al})$ suture is posteroventrally oriented towards the squamosal fossa.

The intertemporal constriction of Mystacodon (made of the parietal along midline) is proportionally shorter and slightly wider than in basilosaurids. The intertemporal constriction is well developed in all toothed mysticetes. It is slightly narrower in mammalodontids and Coronodon, and much narrower in ChM 5720. In contrast, it is distinctly wider in aetiocetids and Llanocetus (Table 6).

The medial edges of the parietals do not form a sagittal crest, and the interparietal suture is almost fused on midline. The orbitotemporal crests are more developed than in basilosaurids and delimit dorsally the temporal fossa in lateral view. They run posteromedially from the posterior edge of the supraorbital process of the frontal to the vertex. The condition of Mystacodon differs from that of Llanocetus, in which the orbitotemporal crests do not extend posteriorly on the parietals and end at the posteromedial angle of the supraorbital process of the frontal. 


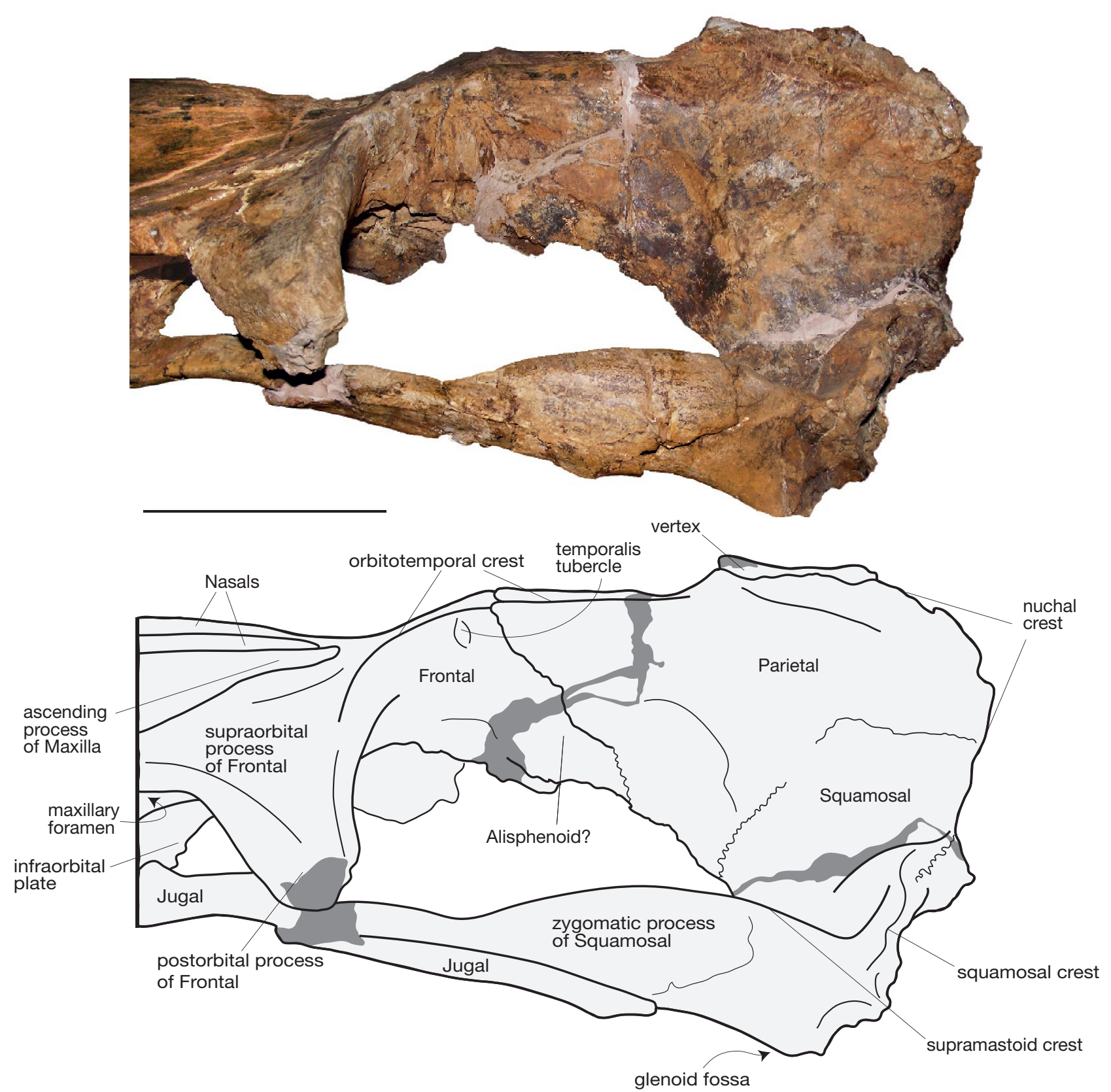

FIG. 15. - Dorsolateral view of the left temporal fossa of Mystacodon selenensis (MUSM 1917, holotype). Grey-shaded regions indicate missing parts. Scale bar: $10 \mathrm{~cm}$.

On the vertex (at the anteriormost region of the nuchal crest), the medial edges of the parietals are separated by the supraoccipital. In dorsal view, the parieto-occipital (Pa-SO) suture is straight and follows the nuchal crest posterolaterally from the vertex to the posterolateral angle of the cranium (Figs 4; 15; 16). The Pa-SO suture turns ventrally at the posteriormost point of the nuchal crest and meets the parieto-squamosal (Pa-Sq) suture. The Pa-Sq suture is partially fused, but remains discernible. It is sinuous and runs anteriorly from the nuchal crest for about $48 \mathrm{~mm}$; then it turns anteroventrally towards the anteromedial edge of the squamosal fossa (Figs 15; 16). There is no conspicuous parietal foramen on the lateral wall of the cranium, contrary to the condition observed in basilosaurids.
The braincase of Mystacodon is slightly expanded laterally. Therefore, the posterior portion of the parietal faces anterolaterally. In dorsal view, the lateral expansion of the braincase is more pronounced at the anteroposterior level of the vertex. In lateral view, the expansion is at the mid-height of the cranium, at the $\mathrm{Pa}-\mathrm{Sq}$ suture.

Squamosal (Sq). The squamosal contributes to the ventrolateral wall of the cranium, to the zygoma, and to the anterolateral portion of the basicranium. It articulates anterodorsally and dorsally with the parietal, anteroventrally with the alisphenoid, and posteriorly with the exoccipital. 
TABLE 6. - Comparison of the relative length of the nasals of Mystacodon selenensis to several archaeocetes and toothed mysticetes. Measurements of Protocetus atavus, Dorudon atrox (UISPM Mn9), Zygorhiza kochii, and Saghacetus osiris have been made based on Kellogg (1936)'s photographs; Measurements of Maiacetus inuus have been made from Gingerich et al. (2009: fig 6). The length of the nasal of Llanocetus denticrenatus is an estimate because the anterior edge of the nasal of the holotype and single known specimen is probably incomplete; however, the missing part must be reduced because the laterally diverging (and medially concave) premaxillae anterior to the most anterior preserved portion of the nasal indicate that they are close to the posterior end of the external bony nares. Therefore, the ratio obtained for Llanocetus may be only slightly underestimated. In any case this ratio should be regarded more as an indication than a precise value. Color code: pink, protocetids; grey, basilosaurids; green, toothed mysticetes; blue, eomysticetids. Abbreviation: e, estimated measurements.

\begin{tabular}{|c|c|c|c|}
\hline Taxon & Nasal Length & Bizygomatic Width & NL/BW \\
\hline $\begin{array}{l}\text { Artiocetus clavis (GSP-UM 3458) } \\
\text { Maiacetus inuus (GSP-UM 3475) (see caption) } \\
\text { Protocetus atavus (SMNS 11084) }\end{array}$ & $\begin{array}{l}215 \\
193 e \\
165 e\end{array}$ & $\begin{array}{c}306 \\
282 e \\
120.5 \times 2=241 e\end{array}$ & $\begin{array}{l}0.70 \\
0.68 \\
0.68\end{array}$ \\
\hline $\begin{array}{l}\text { Cynthiacetus peruvianus (MNHN.F.PRU10) } \\
\text { Dorudon atrox (from University of Michigan website) } \\
\text { Dorudon atrox (from reconstruction by Uhen [2004: fig. 6], based on } \\
\text { UM100139, 93220, 101222) } \\
\text { Dorudon atrox (UISPM Mn9, specimen now destroyed) } \\
\text { Dorudon atrox (UM101222) } \\
\text { Zygorhiza kochii (USNM 11962) } \\
\text { Basilosaurus isis (CGM 42195) } \\
\text { Saghacetus osiris (BMNH 10228) } \\
\text { Saghacetus osiris (SMNS 11626) }\end{array}$ & $\begin{array}{l}285 e \\
238 \\
249 \\
207 \\
240 \\
173 \\
252 \\
186 \\
153\end{array}$ & $\begin{array}{l}481 \\
389 \\
498 \\
406 \\
490 \text { e } \\
355 \\
557 \\
394 \\
357\end{array}$ & $\begin{array}{l}0.51 \\
0.49 \\
0.48 \\
0.45 \\
0.47 \\
0.43\end{array}$ \\
\hline $\begin{array}{l}\text { Mystacodon selenensis (MUSM 1917) } \\
\text { Fucaia goedertorum (LACM 131146) } \\
\text { Aetiocetus weltoni (UCMP 122900) } \\
\text { Aetiocetus cotylalveus (USNM 25210) } \\
\text { Coronodon havensteini (CCNHM 108) } \\
\text { Janjucetus hunderi (NMV P216929) } \\
\text { Llanocetus denticrenatus (USNM 183022) }\end{array}$ & $\begin{array}{l}293.4 \\
105 \\
138 \\
118 \\
193 \\
85 e \\
628 e\end{array}$ & $\begin{array}{c}199.8 \times 2=399.6 \mathrm{e} \\
220 \mathrm{e} \\
287 \\
316 \\
577 \\
164 \times 2=328 \mathrm{e} \\
432 \times 2=864 \mathrm{e}\end{array}$ & $\begin{array}{l}0.73 \\
0.47 \\
0.48 \\
0.37 \\
0.33 \\
0.26 \\
0.72\end{array}$ \\
\hline Yamatocetus canaliculatus (KMNH VP000,017) & 420 & 460 & 0.91 \\
\hline
\end{tabular}

The Pa-Sq suture has already been described above and is figured in the Figure 15. Posteriorly, this suture joins the nuchal crest at the dorsoventral level of the postorbital process of the frontal. From this point, the squamosal contacts the occipital shield and participates in most of the ventral (vertical) portion of the nuchal crest. However, because the supraoccipital and the exoccipitals are fused, it is unclear if the squamosal contacts only the exoccipital or if it also contacts the supraoccipital. In lateral view, the ventral portion of the nuchal crest is almost vertical, being slightly anteroventrally inclined. In posterior view and at about the level of the maximum lateral inflation of the braincase, the nuchal crest (and thus, the squamo-occipital suture) turns ventrolaterally (Figs 15; 16).

Anterior to the ventral edge of the nuchal crest, the squamosal forms the temporal crest (we follow Mead \& Fordyce [2009] in using this term rather than lambdoid crest). The latter is sinuous and anterolaterally oriented. It draws an anterolaterally directed curve before reaching the supramastoid crest on the dorsal margin of the zygomatic process.

Posteroventrolaterally the temporal crest delimits the posterior wall of the squamosal fossa. The latter is $50 \mathrm{~mm}$ high (from its floor to the dorsal margin of the temporal crest). Although the anterior part of the squamosal fossa is incomplete, since it can be easily restored, it is possible to evaluate that its anterior edge was slightly anterior to the level of the vertex (Fig. 4). Fitzgerald (2010) suggested that the relative anterior position of the vertex as compared to the anterior edge of the floor of the squamosal fossa is an apomorphic and diagnostic feature for the Mysticeti and represents an early stage on the cranial telescoping. However, as in Mystacodon, the vertex of several early mysticetes, is posterior to the anterior edge of the squamosal fossa (e.g. Coronodon, Fucaia, Janjucetus, and Mammalodon). In contrast, the vertex is markedly anterior in Llanocetus, the toothed mysticete ChM PV 5270, Aetiocetus, and chaeomysticetes. Therefore, this condition is probably only a synapomorphy of one clade among mysticetes (which evolved convergently in ChM PV 5270), and not of the suborder, as illustrated by the complex distribution of this character among ancient mysticetes.

The zygomatic process of the squamosal is long, extending along the whole length of the temporal fossa. As mentioned above, it either contacted the postorbital process of the frontal or was very close to it. Its proximal half is dorsoventrally elevated (maximum height of $45 \mathrm{~mm}$ at about the anteroposterior level of the vertex), with a convex dorsal edge. The dorsoventral height of the zygomatic process gradually decreases anteriorly towards the low distal portion. This portion, which borders the anterior quarter of the temporal fossa, is dorsoventrally much lower, appearing as a narrow and low anterior extension of the zygomatic process; at its apex, it is $c .75 \%$ lower than the highest region of the proximal part $(c .10 \mathrm{~mm})$ (Figs $6 ; 15)$. Such an extension is present in Llanocetus but is absent in all other toothed mysticetes; in Coronodon the zygomatic process is very short and very massive; in Janjucetus the process is longer than in Coronodon, but it remains high for its whole length; in Aetiocetus the process is moderately elevated, but it is higher than the apex of the process of Mystacodon and it is lower proximally than distally (it is noteworthy that a similar condition is observed in Yamatocetus, a basal Chaeomysticeti). Distinctly departing 


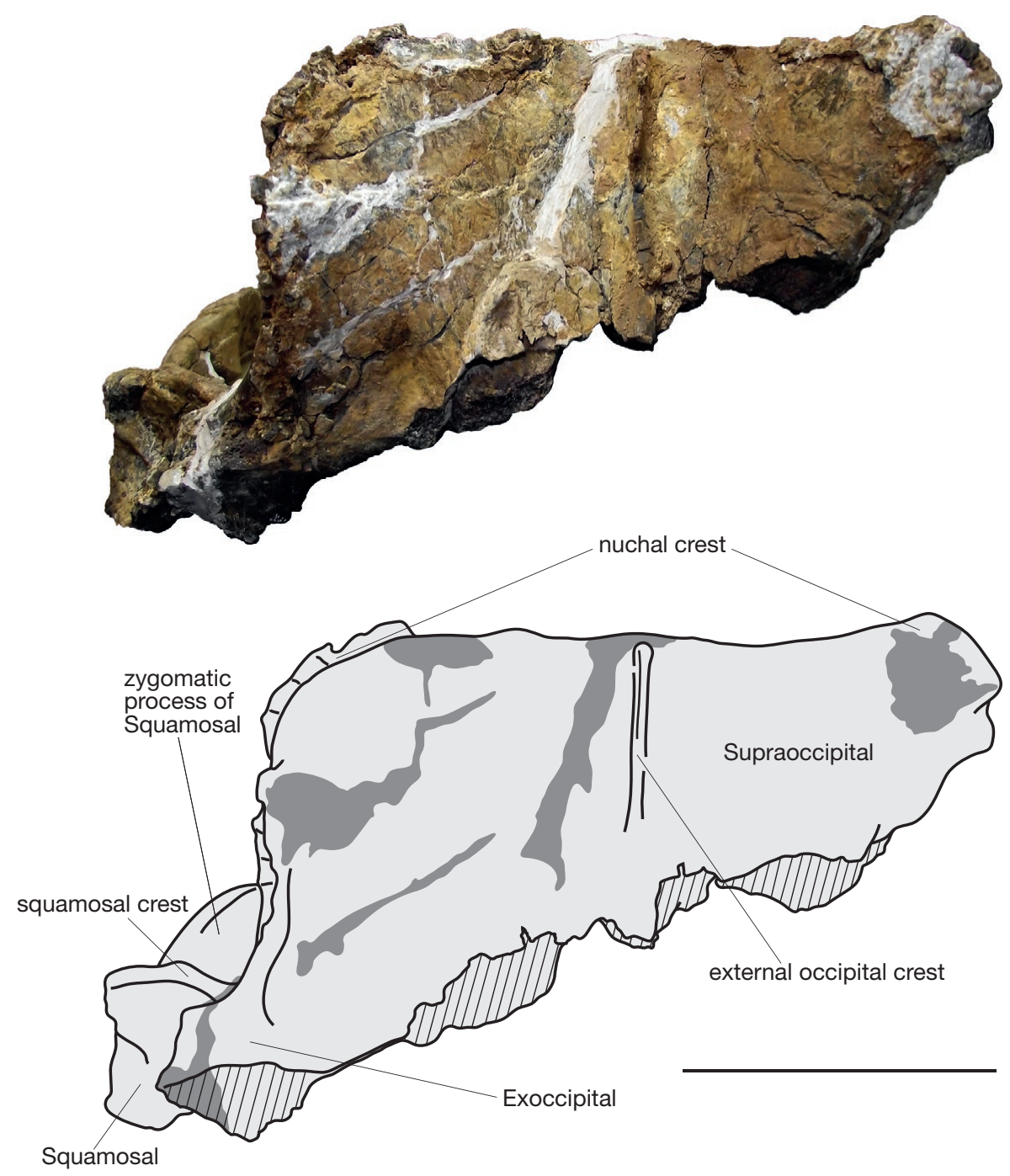

FIG. 16. - Posterior view of the skull of Mystacodon selenensis (MUSM 1917, holotype). Grey-shaded regions and oblique lines respectively indicate reconstructed and broken parts. Scale bar: $10 \mathrm{~cm}$.

from that of these other toothed mysticetes, the condition of Mystacodon is strongly reminiscent of that of basilosaurids (e.g. Cynthiacetus, Dorudon, and Saghacetus), which also have a very thin distal part of the zygomatic process as compared to its proximal part (Kellogg 1936; Uhen 2004; MartínezCáceres et al. 2017, personal observations on MMNS 445 [Cynthiacetus maxwelli] and uncatalogued specimens of C. peruvianus at the MUSM). A similar condition is also observed in protocetids (e.g. Aegyptocetus and Artiocetus) and could therefore represent a plesiomorphic condition. In dorsal view, the proximal portion of the zygomatic process of the squamosal is anteroposteriorly directed, while its distal portion is slightly tilted anteromedially.

The zygomatic process of the squamosal articulates ventrally with the temporal portion of the jugal, forming a nearly straight suture, with the posterior part slightly dipping ventrally. As mentioned above (cf. Jugal), this contact is much longer in MUSM 1917 than in the other described toothed mysticetes, except Llanocetus in which it is proportionally as long as in Mystacodon. In contrast, the condition in Llanocetus and
Mystacodon clearly resembles the condition observed in some basilosaurids (e.g. Cynthiacetus, Dorudon, and Saghacetus).

From the posterior quarter of the jugal and posteriorly, the ventral surface of the zygomatic process widens transversely and forms the glenoid or mandibular fossa (Mead \& Fordyce 2009). Only the dorsally concave anterior portion of the glenoid fossa is preserved in MUSM 1917.

The squamosal contributes to define the posterior region of the temporal fossa: laterally through the zygomatic portion of the squamosal, ventromedially through the squamosal portion of the lateral wall of the cranium, posteriorly through both the ventrolateral part of the nuchal crest and the temporal crest, and posteroventrally through the squamosal fossa (Fig. 4).

Tympanic bulla. A fragment of the left tympanic bulla has been recovered. It consists in the posterior portion of the involucrum including part of the medial posterior prominence. Not much can be described from this very incomplete bone, except that the posterior half of the involucrum is approximately twice as wide as the anterior part (Fig. 17). 


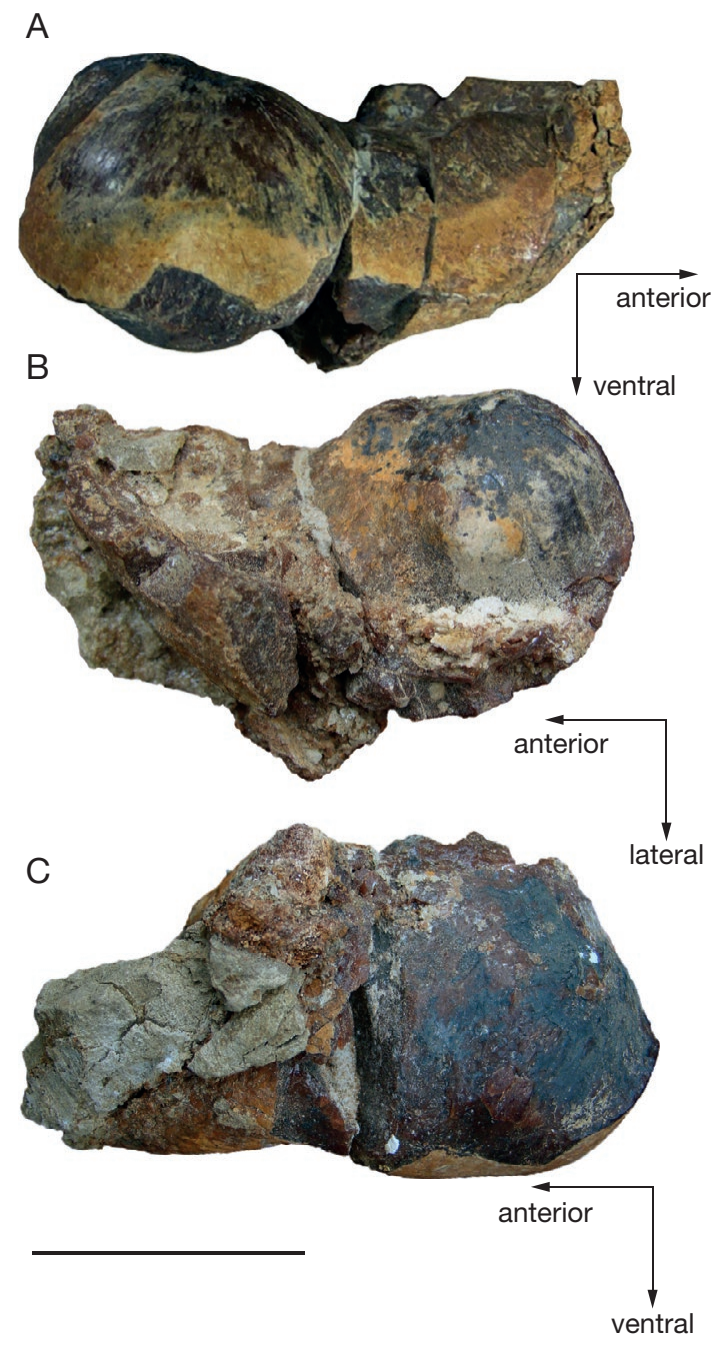

FIG. 17. - Tympanic fragment (involucrum) of Mystacodon selenensis (MUSM 1917, holotype). A, medial view; B, dorsal view; C, lateral view. Scale bar: $3 \mathrm{~cm}$.

Supraoccipital (SO). The holotype of Mystacodon selenensis only preserves the dorsal portion of the occipital shield, which is entirely formed by the supraoccipital. A small fragment of the exoccipital is preserved on the left ventrolateral side of the occipital shield (Fig. 16).

In dorsal view, the supraoccipital is triangular in outline, posterodorsally facing and transversely concave (Fig. 4). It articulates anteriorly with the parietals, forming the dorsal portion of the nuchal crest. The anteromedial portion of the nuchal crest forms the vertex of the skull (Fig. 4). Its anterior tip is located posterior to the level of the anterior edge of the squamosal fossa.

Just posterior to the vertex the well-developed external occipital crest is $75 \mathrm{~mm}$ long, extending towards the foramen magnum (not preserved on the specimen).

Made of the parietal anteriorly and the supraoccipital posteriorly, the dorsal portion of the nuchal crest runs horizontally and posterolaterally as a straight line (in dorsal view) for $155 \mathrm{~mm}$. At its posterior edge, the nuchal crest turns at $90^{\circ}$ downwards and continues as a subvertical portion for
$81 \mathrm{~mm}$. Whereas the dorsal portion of the nuchal crest is prominent and thin, its ventral portion is low, massive, and inflated. Most of the ventral portion of the nuchal crest is formed by the squamosal and the exoccipital. The nuchal crest of Mystacodon differs from that of Llanocetus, in which the branches are sigmoid in dorsal view, and from that of mammalodontids and aetiocetids, in which it is clearly rounded. On the other hand, it resembles the straight crest observed in Coronodon and ChM PV 5720.

As mentioned above the apex of the nuchal crest of Mystacodon is slightly posterior to the anterior edge of the squamosal fossa, as is observed in mammalodontids, whereas it is well anterior in Coronodon, ChM PV 5720, and Llanocetus. In contrast, the anterior point of the vertex is more anterior in Mystacodon than in basilosaurids and protocetids.

In posterior view (Fig. 16), the occipital shield of Mystacodon selenensis is transversely wider than in basilosaurids. Similar proportions are observed in some early neocetes (e.g. Aetiocetus, Llanocetus, Mammalodon, and Simocetus), but a narrow occipital shield is observed in Coronodon and Janjucetus.

\section{Mandible}

The mandibles of MUSM 1917 are incomplete. The betterpreserved left dentary (Figs 18-20) includes most of the alveolar portion (horizontal ramus or corpus mandibularis) and the anterodorsal portion of the coronoid process (the anterodorsal part of the vertical ramus or ramus mandibularis). Only the anterior portion of the corpus is preserved from the right dentary (Fig. 21). Therefore, the actual height of the coronoid process, as well as the shape and relative position of both the mandibular condyle and mandibular foramen, cannot be characterized. The length of the dentary can be evaluated to $c .80 \mathrm{~cm}$, on the basis of the distance from the glenoid fossa to the anterior apex of the rostrum.

In lateral view, the anterior end of the dentary is rounded and its ventral margin is longitudinally concave. The section of the anterior portion of the dentary is semi-circular and transversely compressed, with a flat medial surface. Posterior to the level of the alveolus for $\mathrm{p} 4$, the height of the corpus strongly increases, and posterior to $\mathrm{m} 3$ the ramus bears a prominent and wide (in lateral view) coronoid process.

In dorsal view, the dentary is not straight as in other toothed mysticetes (aetiocetids, Coronodon, and mammalodontids), but concave laterally, similar to the condition observed in basilosaurids. This concavity has its major inflexion point just posterior to the level of the alveolus for $\mathrm{p} 2$.

On the anterior portion of the medial aspect of the dentary, a conspicuous, unfused mandibular symphysis extends posteriorly to the level of the posterior edge of the canine. Several deep longitudinal sulci and thick ridges on the symphyseal surface indicate the presence of strong mandibular ligaments (Fig. 21C), which originally maintained the two dentaries tightly articulated. The symphysis is proportionally shorter than in basilosaurids, which had a long symphysis extending posteriorly until the posterior edge of $\mathrm{p} 1$. The condition of aetiocetids (Aetiocetus and Fucaia) and Coronodon strongly differs from that of Mystacodon: in these taxa, 


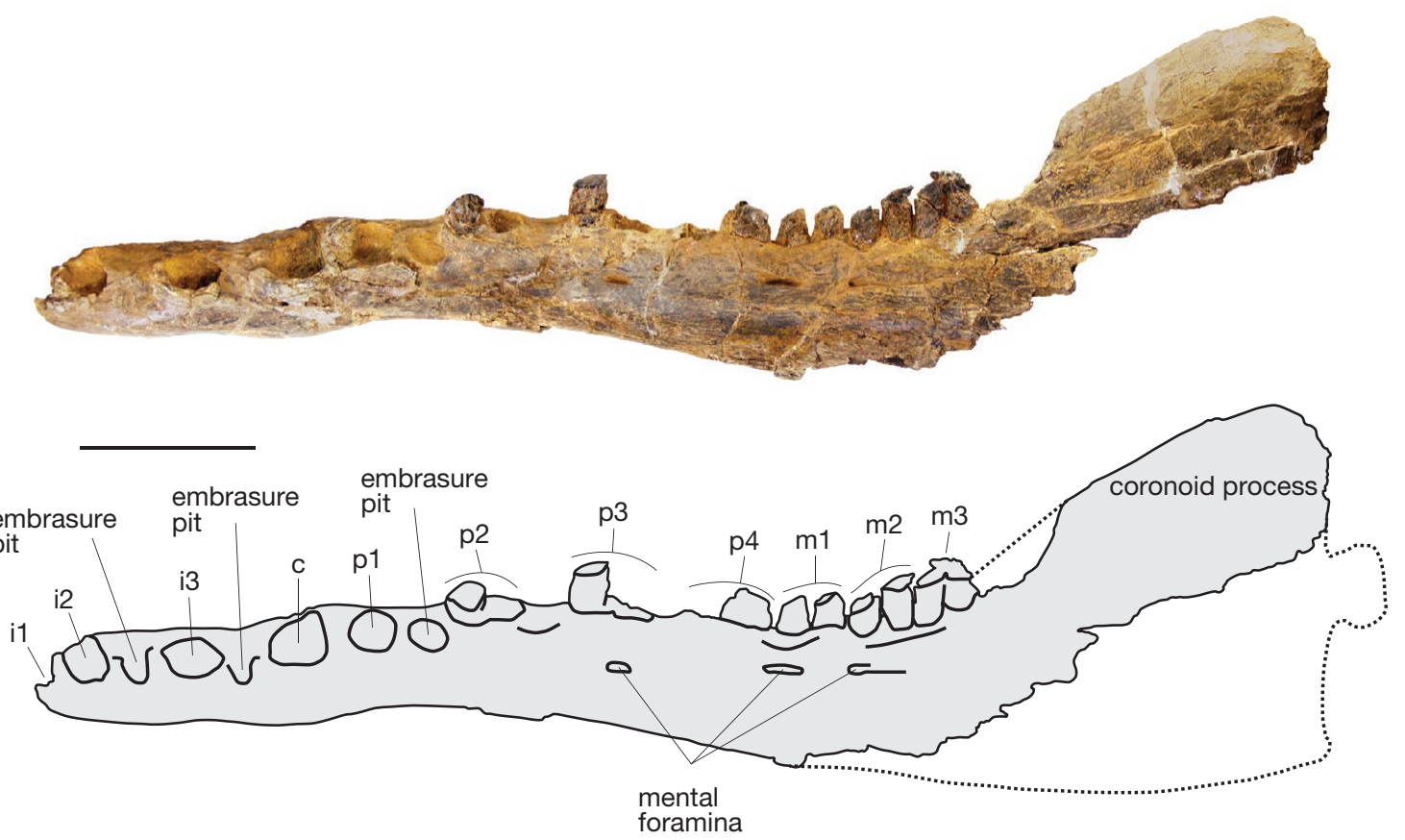

FIG. 18. - Lateral view of the left dentary of Mystacodon selenensis (MUSM 1917, holotype). Scale bar: $10 \mathrm{~cm}$.
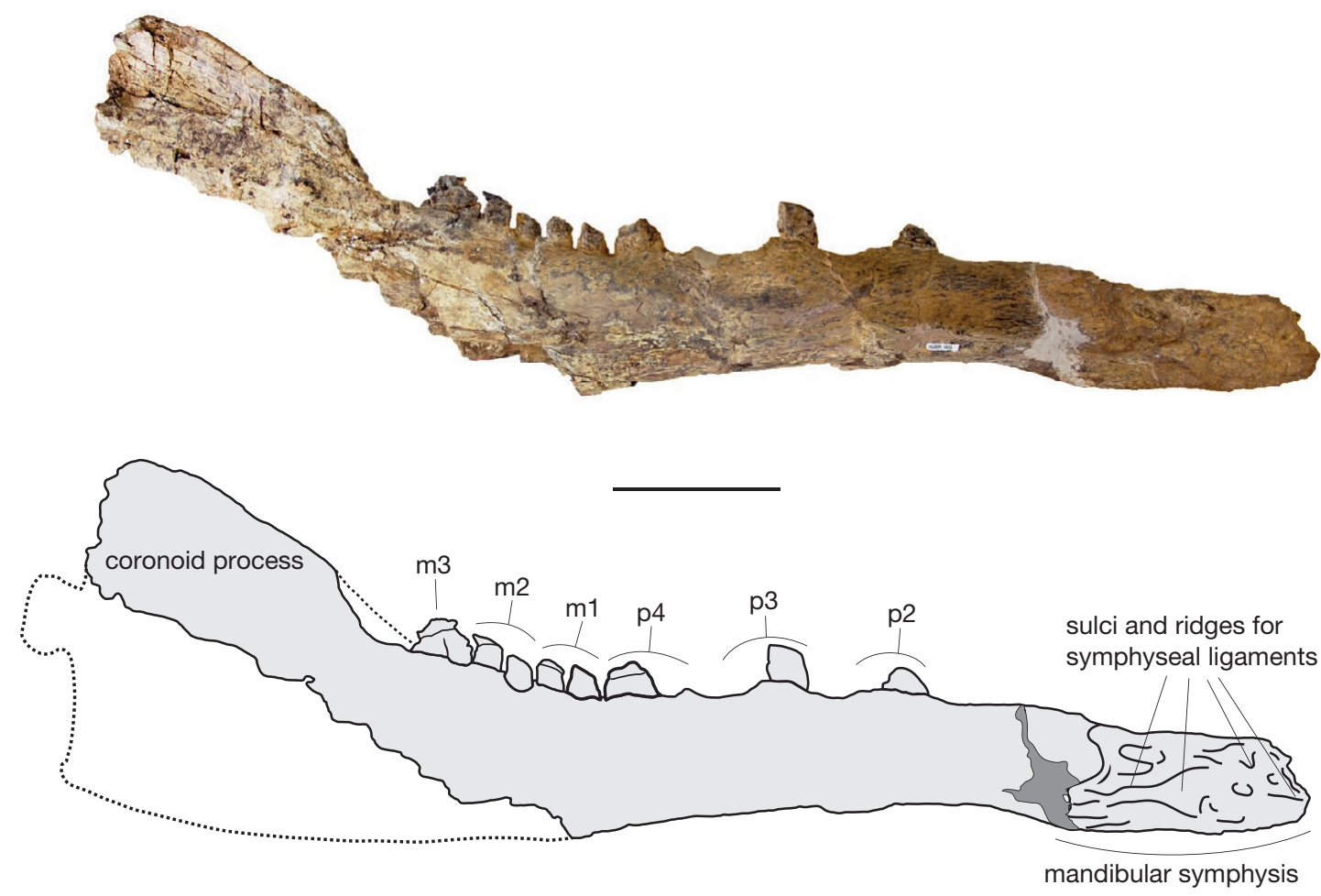

FIG. 19. - Medial view of the left dentary of Mystacodon selenensis (MUSM 1917, holotype). Grey-shaded regions indicate reconstructed parts. Scale bar: $10 \mathrm{~cm}$.

there is no real solid symphysis, but a simple longitudinal groove, or even an undulating surface (in Coronodon), indicating the presence of a loose fibrocartilaginous symphysis as in chaeomysticetes. Such a derived condition certainly permitted movements of the dentaries (which was not the case in Mystacodon). Furthermore, the loose symphysis of these taxa is clearly shorter than that of Mystacodon. Whereas it is also considerably shortened, the mandibular symphysis of Janjucetus lacks a symphyseal groove and displays a sutural surface as seen in Mystacodon (Fitzgerald 2012). The symphysis of Mystacodon occupies the whole anterior portion of the medial surface of the dentary from the apex to the 


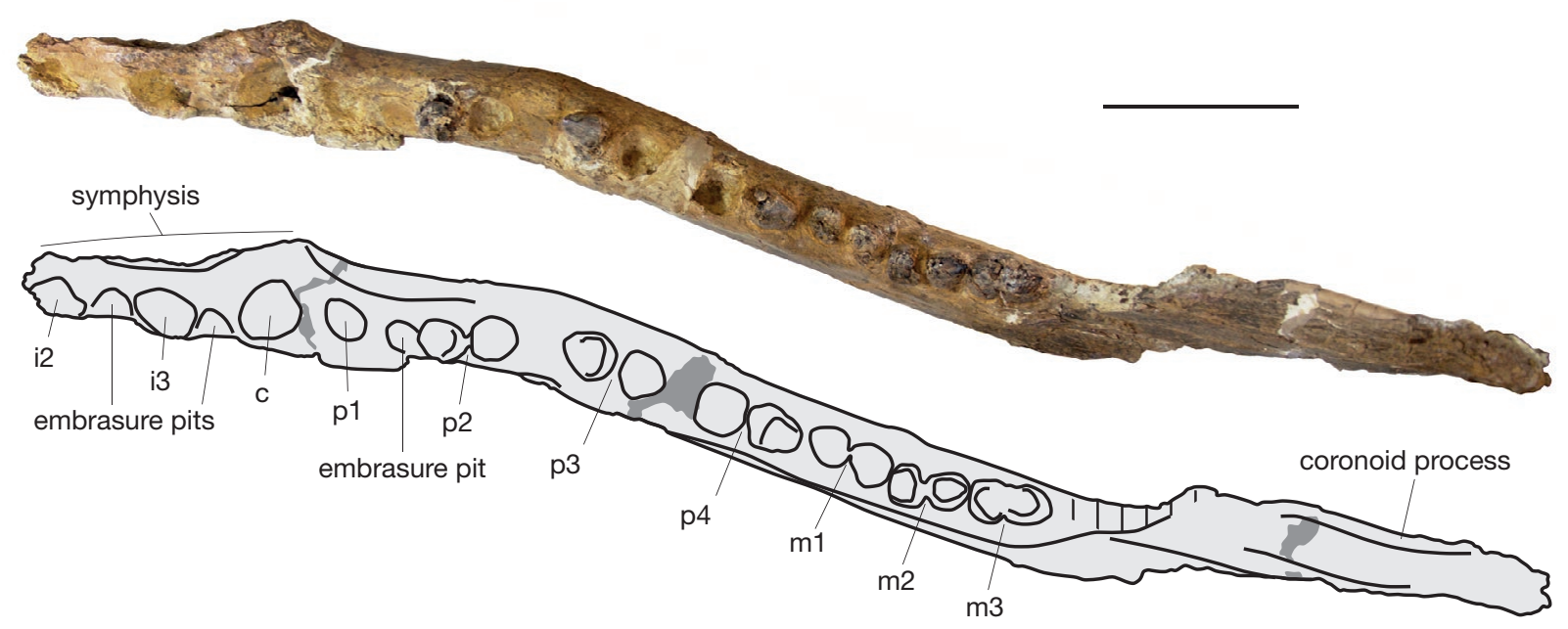

FIG. 20. - Dorsal view of the left dentary of Mystacodon selenensis (MUSM 1917, holotype). Oblique lines and grey-shaded regions indicate respectively broken and reconstructed parts. Scale bar: $10 \mathrm{~cm}$.
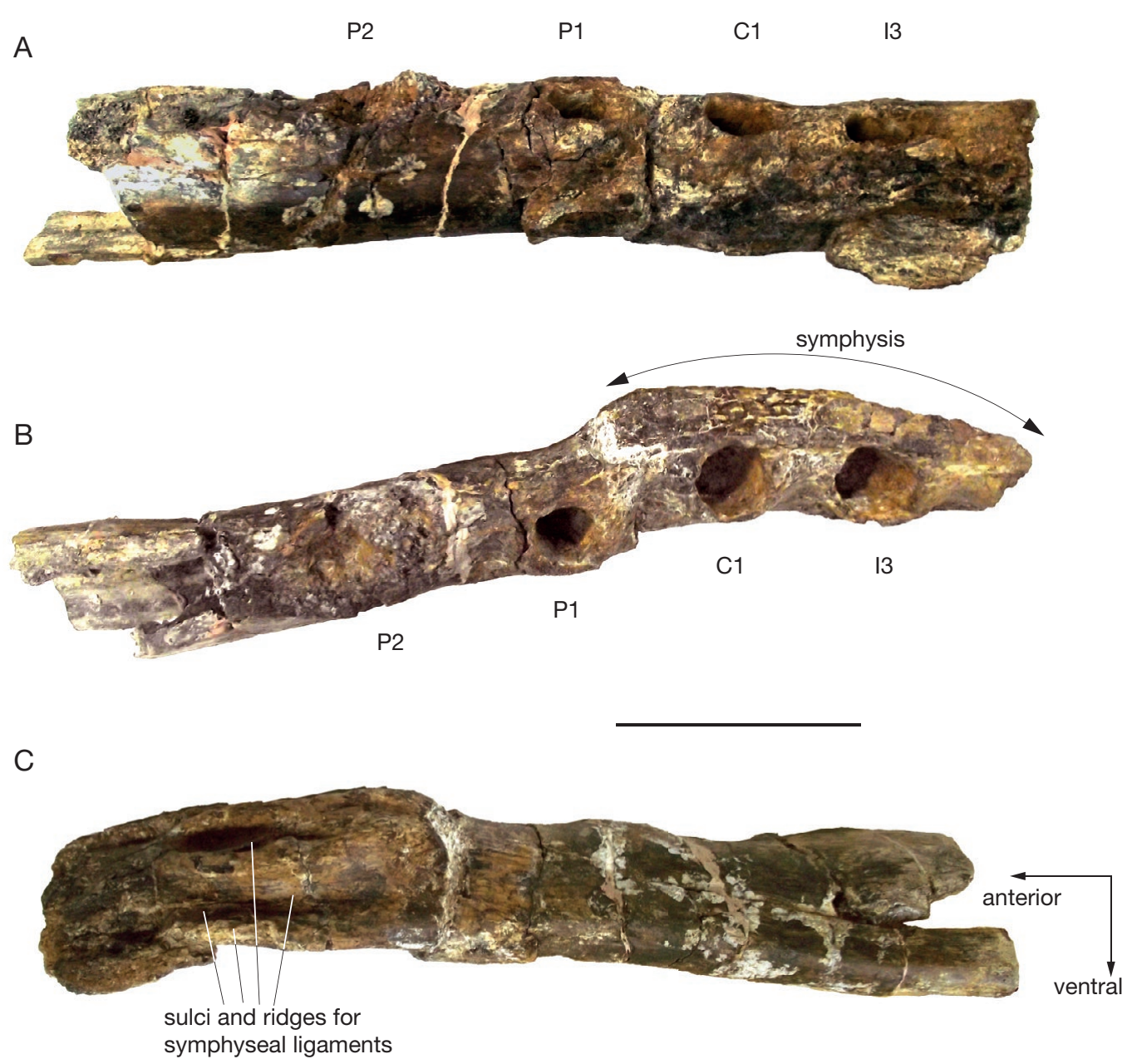

FIG. 21. - Right dentary of Mystacodon selenensis (MUSM 1917, holotype) showing the alveoli of i1-3. A, lateral view; B, dorsal view; C, medial view. Scale bar: $10 \mathrm{~cm}$.

level of the diastema between $\mathrm{C} 1$ and $\mathrm{P} 1$. At the posterior end of the symphysis is a prominent crest that separates the symphyseal surface from the rest of the medial surface of the dentary (Figs 20;21). Such a structure is absent in all the other mysticetes.
The dentary bears alveoli for 11 teeth as is observed in basilosaurids and Janjucetus (see Fitzgerald 2012). This dental count differs from that observed in Aetiocetus, Fucaia, and Mammalodon, which bear 12 teeth per lower quadrant. Whereas the number of lower incisors is uncertain in Coronodon, it is 


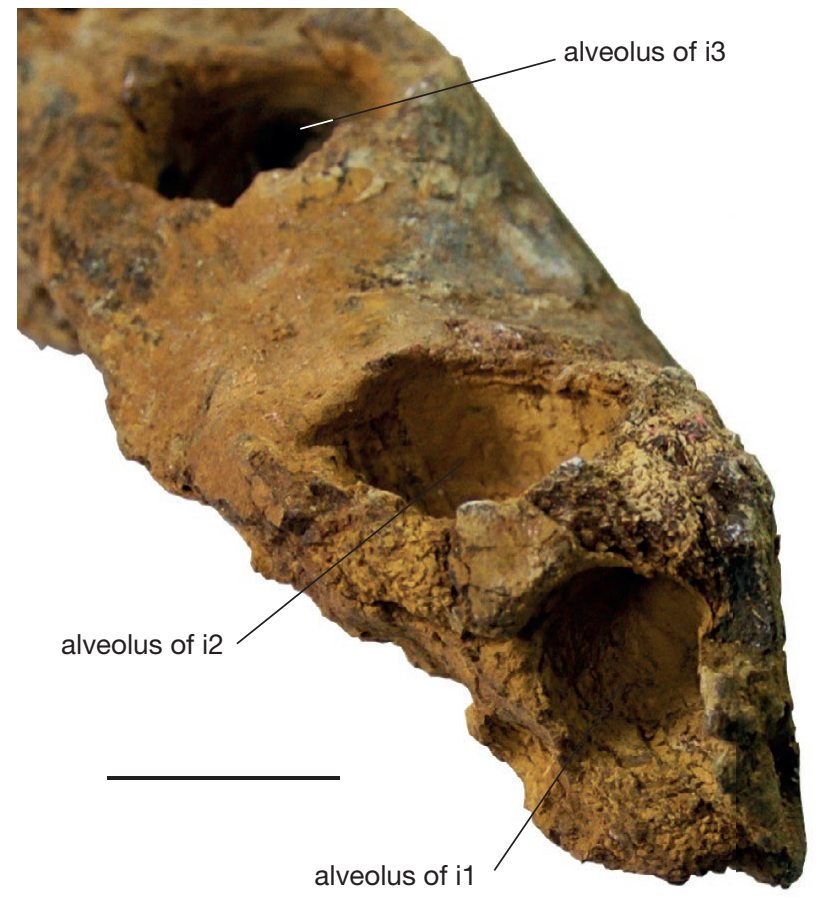

FIG. 22. - Anterior view of the left dentary of Mystacodon selenensis (MUSM 1917, holotype). Scale bar: $2 \mathrm{~cm}$.

clear that this taxon had three lower molars as in Mystacodon, and therefore probably had the primitive lower tooth count of Janjucetus, Mystacodon, and basilosaurids. No incisors, canines or first premolars are preserved in the mandibles, and only the left dentary presents the alveolar portion corresponding to p3-m3 (Figs 18-20). The alveoli for i1-p1 and those for roots of $\mathrm{m} 1-\mathrm{m} 3$ are circular in outline, while those for roots of p2-p4 are mesiodistally elongated.

In dorsal view (Fig. 20), the anterior alveoli are somewhat laterally oriented and the alveolar row gradually rotates medially from $\mathrm{i} 1$ to $\mathrm{p} 1$. Therefore, $\mathrm{p} 2$ is the first tooth whose alveoli are fully dorsally oriented.

The alveolus for $\mathrm{i} 1$ is very small and close to the alveolus for i2. Both teeth are closely approximated and not separated by a diastema (Fig. 22). A similar condition is observed in the basilosaurids Cynthiacetus, and Dorudon. The alveoli for i2-p4 are separated by diastemata. The diastemata separating the alveoli for i2-p2 are short and bear conspicuous embrasure pits for the corresponding anterior upper teeth (I2-P1). The embrasure pits are deep and open laterally. The embrasure pit for $\mathrm{C} 1$ (third embrasure pit, between $\mathrm{c}$ and $\mathrm{p} 1$ ) is one of the largest and is clearly visible on the right dentary. As mentioned above, no diastema and embrasure pit are observed between c and $\mathrm{p} 1$ on the left dentary, a condition most likely resulting of some post-mortem distortion of the bone (Figs 18-20). The posteriormost, fourth embrasure pit is between p1 and $\mathrm{p} 2$, and received $\mathrm{P} 1$; it is the shallowest of the four, being a simple dorsolabially facing cupula. As long as the anterior diastemata, the posterior diastemata located between p2-p4 do not display any pit or depression. More posteriorly, the alveoli for $\mathrm{p} 4-\mathrm{m} 4$ are not separated by diastemata. This condition
A

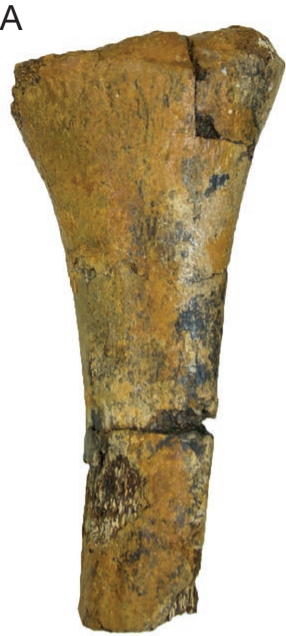

B
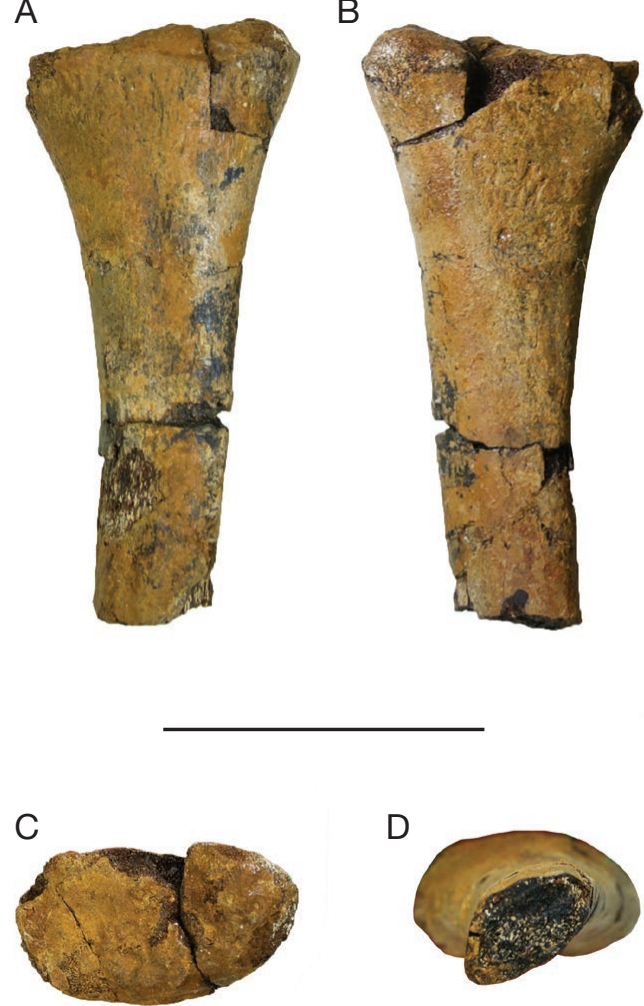

FIG. 23. - Left thyrohyal of Mystacodon selenensis (MUSM 1917, holotype). A, ventral view; B, dorsal view; C, proximal view; D, distal extremity of the bone as preserved. Scale bar: $5 \mathrm{~cm}$.

differs from that of basilosaurids and Coronodon, in which p3 is adjacent to $\mathrm{p} 4$, and lacking diastema between these teeth.

Three large mental foramina are visible on the lateral surface of the mandible posteriorly, at about the level of the alveoli for $\mathrm{p} 3, \mathrm{~m} 1$, and $\mathrm{m} 2$. These three mental foramina are followed posteriorly by a deep sulcus.

\section{Hyoid}

A small incomplete long bone is referred to the proximal half of a thyrohyal (Fig. 23). The complete extremity is triangular, being twice as wide as the narrowest width of the bone (at the incomplete extremity). Because it closely resembles the triangular morphology observed in Cynthiacetus, we interpret the complete extremity as the proximal end of the left thyrohyal, which articulates with the basihyal. In proximal view, the bone is conspicuously flattened, its cross section being $45 \mathrm{~mm}$ long and $25 \mathrm{~mm}$ wide. It is more flattened than in Cynthiacetus and differs from the condition of Basilosaurus, in which the proximal extremity of the thyrohyal is roughly circular (Martínez-Cáceres et al. (2017: fig. 36). One of its edges (along the long axis) is conspicuously convex, whereas the other edge is roughly rectilinear. Correlatively, one aspect of the bone (ventral) is markedly convex, whereas the other (dorsal) is roughly flat. The proximal extremity bears an irregular surface indicating that the contact with the basihyal was not a functional articulation but a synchondrosis. The distal extremity of the bone as preserved is also markedly 
TABLE 7. - Comparison of the additive mesiodistal lengths of the anterio teeth (incisors and canine) (ATL) in toothed mysticetes and in the basilosaurid Cynthiacetus to the bizygomatic width (BZW) of their skull. When a tooth was not preserved, as in Coronodon, measurement was estimated (e) from the alveolus, and when one zygomatic process was missing, the bizygomatic width was estimated (e) from the better-preserved side of the skull. Color code: grey, basilosaurids; green, toothed mysticetes.

\begin{tabular}{llcc}
\hline Taxon & BZW & ATL & ATL/BZW \\
\hline $\begin{array}{l}\text { Cynthiacetus peruvianus } \\
\text { (MNHN.F.PRU10) }\end{array}$ & 477 & 181 & 0.38 \\
\hline $\begin{array}{l}\text { Mystacodon selenensis } \\
\text { (MUSM 1917) }\end{array}$ & $400 \mathrm{e}$ & 110 & 0.27 \\
$\begin{array}{l}\text { Coronodon havensteini } \\
\quad(C C N H M \text { 108) }\end{array}$ & 463 & 110 & 0.23 \\
\begin{tabular}{l} 
Aetiocetus weltoni (UCMP 122900) \\
\hline
\end{tabular} & 287 & 31 & 0.10 \\
\hline
\end{tabular}

compressed (length: $23.5 \mathrm{~mm}$; width: $15 \mathrm{~mm}$ ) and its long axis forms an angle of approximately $40^{\circ}$ with the long axis of the proximal synchondrosis.

\section{Dentition}

The alveolar portion of the skull and mandible of the holotype of Mystacodon selenensis is completely preserved on the left side only. Premaxilla, maxilla and dentary have respectively three, seven and 11 alveoli. Mystacodon is heterodont and has the following dental formula: I 3/3, C 1/1, P 4/4, M 2/3. The dental formula is the same as in basilosaurids, Coronodon, and Janjucetus (with some incertitude due to the lack of the anterior incisors on the holotype of Coronodon havensteini; see Geisler et al. 2017). It differs from that of Mammalodon and ChM VP 5720, which bear three upper and four lower molars. Mystacodon also differs from Aetiocetus, which has 11 upper and 12 lower teeth (seven upper and eight lower postcanines) in A. weltoni (Deméré \& Berta 2008) and 13-14 upper and 14-15 lower teeth in A. polydentatus (Barnes et. al. 1994). Because the postcanine teeth of Aetiocetus are extremely similar, it is not possible to differentiate the premolars from the molars. In fact, some degree of homodonty seems to be already present in Aetiocetus, and polyodonty is probably incipient (Barnes et al. 1994).

The dentition of the holotype of Mystacodon selenensis is the permanent one. Although most of the roots are present in natural position within the alveoli, the crowns are poorly preserved, except for the left lower molars, although very worn. Additionally, six isolated teeth were found associated with the specimen.

The anterior teeth (I1-C) are proportionally conspicuously smaller than in Cynthiacetus. On Table 7 the additive mesiodistal length of the upper incisors and canine (sum of the incisors and canine lengths) is compared to the bizygomatic width. The anterior teeth length of Mystacodon is 29\% shorter than in Cynthiacetus, but approaches the length observed in Coronodon, although slightly greater. In contrast, it is almost three times larger than in Aetiocetus weltoni, in which the teeth are extremely reduced.

The cheek teeth of the holotype of Mystacodon selenensis are poorly preserved, either broken of strongly worn. How- ever, because the base of their crown and/or their roots are still preserved in their alveoli it is possible to measure their mesiodistal length. Comparative measurements indicate that they are approaching the mesiodistal relative length observed in Cynthiacetus, and are distinctly larger than in Aetiocetus, Janjucetus, and Llanocetus. In the following table (Table 8), we compared the additive mesiodistal lengths of the cheek teeth (LCT), sum of lengths of P1 to last molar, to the bizygomatic width of the skull (BZW) and to the length of the cheek teeth series, measured as the distance from the anterior edge of P1 to the posterior edge of the last molar (LCTS), a measurement which therefore includes the diastemata in contrast to LCT. LCT/BZW ratio in Mystacodon is close to that in Cynthiacetus and Coronodon, but distinctly departs for the three other taxa. This comparison indicates that the cheek teeth of Mystacodon and Coronodon are relatively close in size to those of basilosaurids (slightly larger, according to our results). In contrast, they are proportionally two to three times as large as those of Aetiocetus, Janjucetus, and Llanocetus. LCT/LCTS reveals the relative length of the diastemata in the cheek teeth series. This ratio in Mystacodon is also closer to that in Cynthiacetus and Coronodon than to that in Aetiocetus and Llanocetus, which indicates the shorter diastemata in the former than in the latter. On the other hand, it is similar to that of Janjucetus, in which the diastemata are very short.

Upper dentition. The upper incisors (housed in the premaxilla) are single-rooted and circular in cross section (Fig. 8). The first upper incisor (I1) is the smallest and is somewhat procumbent. The second (I2) and the third (I3) upper incisors are sub-equal in size. The crowns of all the upper incisors are broken and it is not possible to characterize the enamel.

Most of the crown of the upper canine (C) is missing in both sides. At its base, the crown is oval in cross section and somewhat elongated mesiodistally. It is also slightly longer mesiodistally than the upper incisors. A part of the single and posteriorly directed root can be observed on the right side (Fig. 8).

The P1-M2 are only preserved on the left side, but their crown is almost totally broken off and only the roots are still implanted in their alveoli, which are located very close to the lateral border of the maxilla. Although the lateral margin of the maxilla is thinner than in basilosaurids, the roots are not exposed in the dorsal view of the skull. Thus, they should be short or slightly posteromedially oriented, as observed in Mammalodon. The first upper premolar (P1) is somewhat oval in cross section. It was probably single-rooted, since no longitudinal median groove (indicating the fusion of two coalescent roots) is observable.

As in basilosaurids, the five posterior upper teeth (P2-M2) are mesiodistally elongated and double-rooted (Fig. 24). The roots are well separated and easily differentiable, contrary to what is observed in aetiocetids, Coronodon, and mammalodontids, where the roots are fused, at least, in their proximal half. The distal root is lingually expanded in the three posterior upper teeth (P4-M2), a condition most likely resulting from the fusion of a third lingual root (a reminiscence of the protocone of protocetids) with the distal root. This condition 

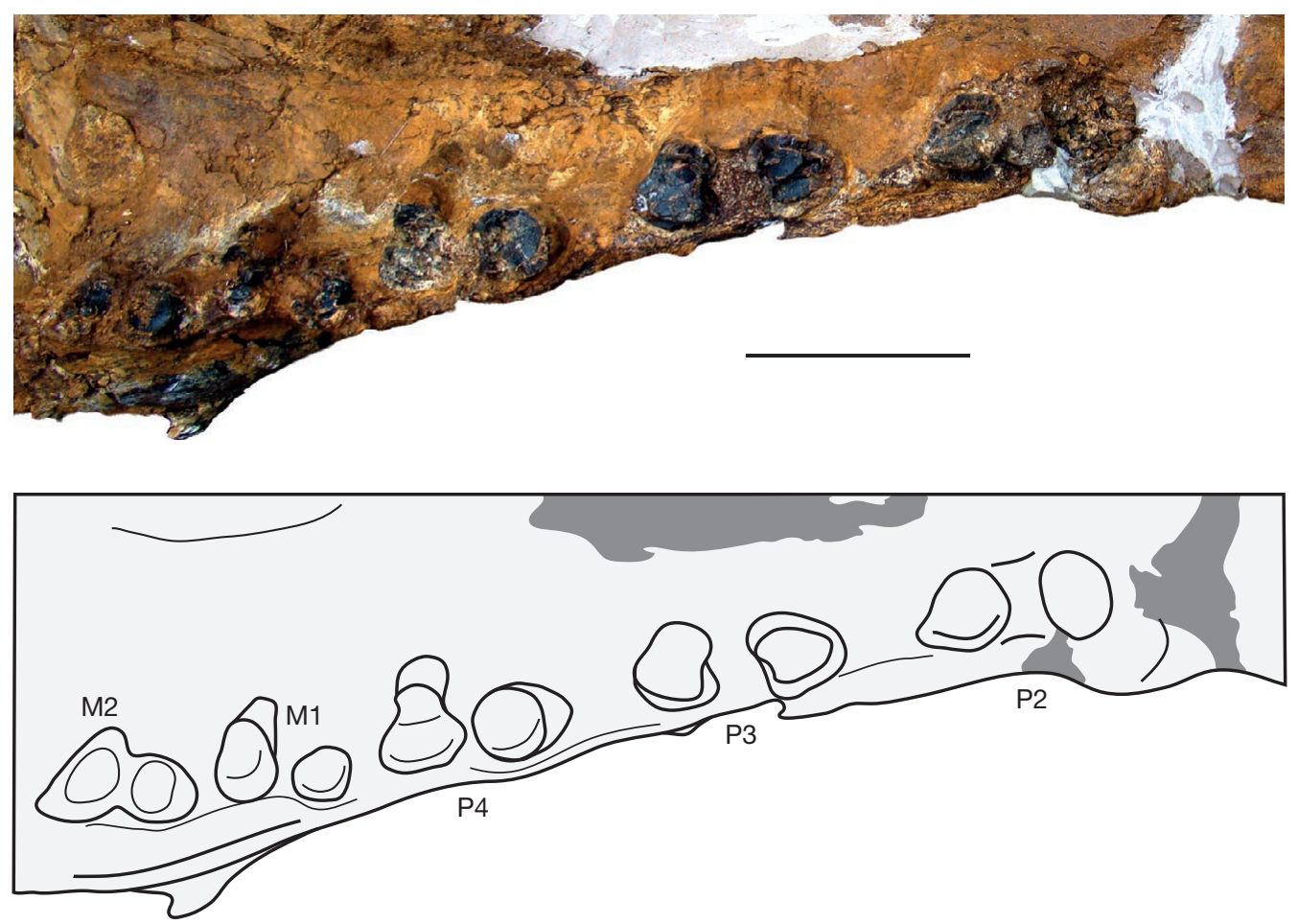

FIG. 24. - Mystacodon selenensis (MUSM 1917, holotype): ventral view of the posterior portion of the alveolar process showing P2-M2. Grey-shaded regions indicate reconstructed parts. Scale bar: $5 \mathrm{~cm}$.

TABLE 8. - Comparison of the additive mesiodistal lengths of cheek teeth (LCT) in toothed mysticetes and in the basilosaurid Cynthiacetus to the bizygomatic width (BZW) of their skull and to the length of the cheek tooth series (LCTS, distance from the anterior edge of P1 to the posterior edge of the last molar, therefore including diastemata). When a tooth was not preserved, measurement was estimated (e) from the alveolus (for instance, in Coronodon and Llanocetus) and when one zygomatic process was missing, the bizygomatic width was estimated from the better-preserved side of the skull. Color code: grey, basilosaurids; green, toothed mysticetes.

\begin{tabular}{|c|c|c|c|c|c|}
\hline Taxon & BZW & LCT & LCTS & LCT/BZW & LCT/LCTS \\
\hline Cynthiacetus peruvianus (MNHN.F.PRU10) & 477 & 305 & 347 & 0.64 & 0.84 \\
\hline Mystacodon selenensis (MUSM 1917) & $400 \mathrm{e}$ & 262 & 377 & 0.65 & 0.69 \\
\hline Janjucetus hunderi (NMV P216929) & $326 e$ & 86 & 134 & 0.26 & 0.64 \\
\hline Llanocetus denticrenatus (USNM 183022) & $886 e$ & $180 \mathrm{e}$ & 578 e & 0.20 & 0.31 \\
\hline Aetiocetus weltoni (UCMP 122900) & 287 & 52 & 213 & 0.18 & 0.24 \\
\hline Coronodon havensteini (CCNHM 108) & 463 & $318 \mathrm{e}$ & 349 & 0.68 & 0.91 \\
\hline
\end{tabular}

is also observed in basilosaurids and in Janjucetus, although the lingual inflation is less pronounced in the latter. Because the crowns of all the upper molars and premolars are either missing or very damaged, no information is available on the upper postcanine dental morphology.

Lower dentition. No teeth are preserved in the alveoli for i1-p1. These alveoli are sub-equal in size and circular in outline. The fact that the alveolus for $\mathrm{cl}$ is not larger than those of the other anterior teeth (incisors and p1) suggests an incipient homodonty, at least in most anterior teeth. Indeed, this condition differs from that observed in basilosaurids, where canines are distinctly larger than incisors. The alveolus for the first lower incisor (i1) is anteriorly oriented and is the smallest alveolus in MUSM 1917. The lower incisors and the lower canine were single-rooted; p1 was either singled-rooted or had two coalescent roots.
The p2-p4 are mesiodistally elongated and double-rooted, as observed in the upper dentition (Fig. 20). Only the mesial half of the tooth is preserved on left $\mathrm{p} 2$ and $\mathrm{p} 3$, and only the distal half is preserved on $\mathrm{p} 4$. The enamel is damaged on both lingual and labial surfaces and cannot be characterized in any premolar. Because most of the enamel is worn off on the premolars preserved in situ, no trace of a cingulum can be observed, but see below the description of isolated partial teeth referred to premolars.

The preserved portion of the crowns of $\mathrm{p} 3$ and $\mathrm{p} 4$ shows a flat and oblique abrasion wear surface with sharp edges, the teeth appearing truncated in lateral view (Figs 18; 25). The wear surface is posterodorsally oriented on the preserved mesial half of $\mathrm{p} 3$. On the preserved distal half of $\mathrm{p} 4$ it appears to be oriented anterodorsally. However, this tooth has been slightly displaced in its alveolus and it is difficult to evaluate the original inclination of its wear surface. 


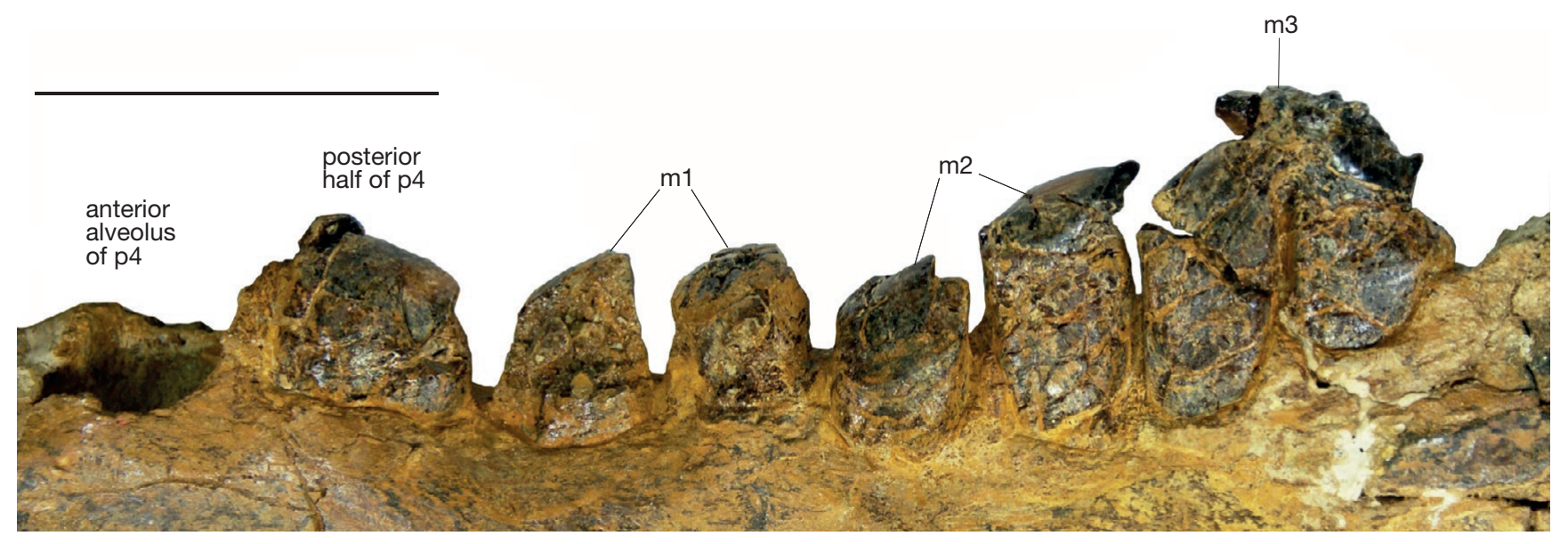

FIG. 25. - Mystacodon selenensis (MUSM 1917, holotype). Lateral view of the left mandible showing the posterior part of p4 and m1-3. Scale bar: $5 \mathrm{~cm}$

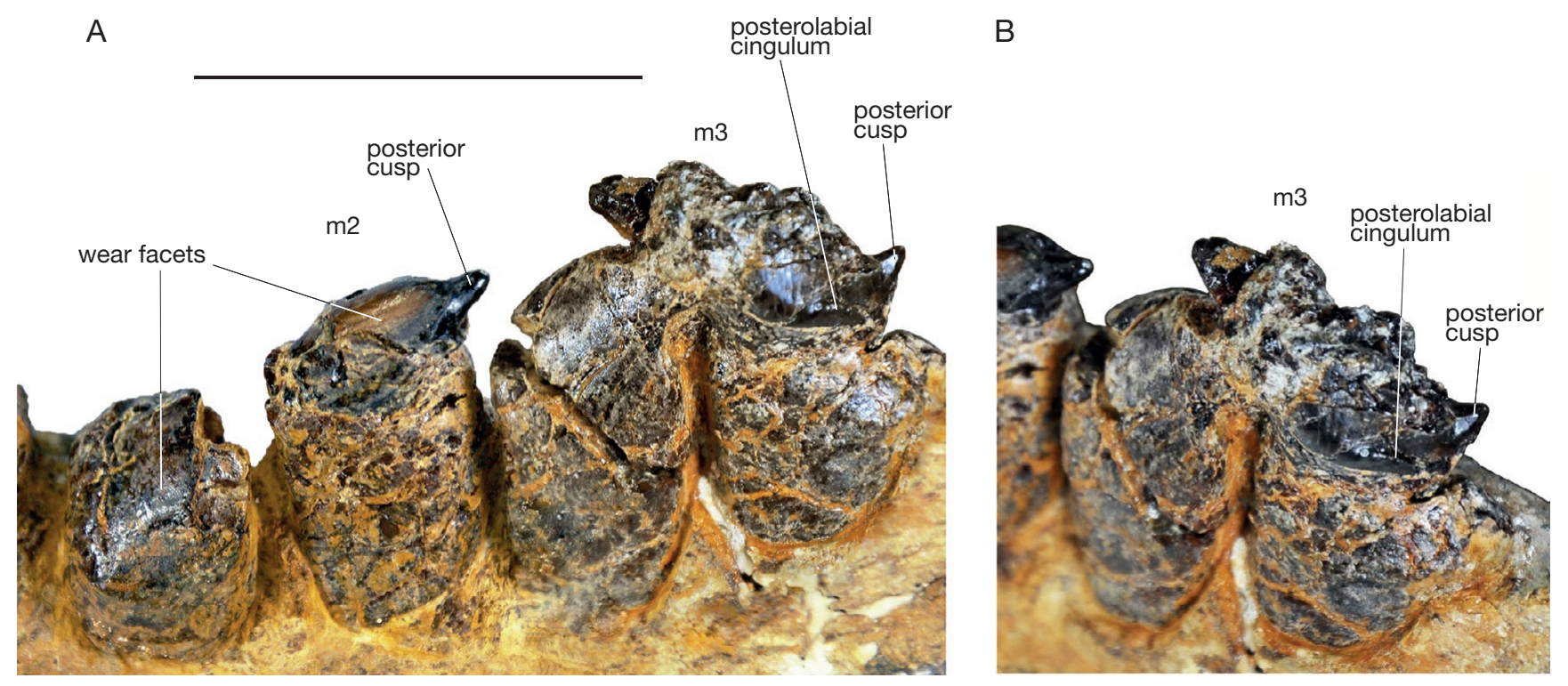

FIG. 26. - Mystacodon selenensis (MUSM 1917, holotype). A, posterolateral view of the left mandible showing the extensive wear facets on m2 and the remaining posterior accessory cusp on $\mathrm{m} 2$ and $\mathrm{m} 3$ and the posterolingual cingulum of $\mathrm{m} 3$; B, posterodorsolateral view of left $\mathrm{m} 3$. Scale bar: $4 \mathrm{~cm}$.

The lower molars are in their original position in the corresponding alveoli, except for the posterior root of $\mathrm{m} 2$, which is probably slightly displaced dorsally. As in basilosaurids, the lower molars are double-rooted, but smaller and shorter than the lower premolars. The crown of the three molars is heavily worn apically, to such a point that abrasion wear, on $\mathrm{m} 1$ and $\mathrm{m} 2$, reached the level where the two roots are separated from each other. All the molars present a flat wear surface, similar in shape and orientation to that of $\mathrm{p} 3$, and inclined anteriorly. Although very damaged, it is possible to observe some ornamentation, consisting of fine longitudinal ridges, on the remaining parts of the enamel of $\mathrm{m} 2$ and $\mathrm{m} 3$. Interestingly, a small accessory denticle is preserved just above the crown-root boundary on the distal carina of $\mathrm{m} 2$ and $\mathrm{m} 3$. This denticle points markedly posteriorly (Figs $18 ; 25 ; 26$ ). It is approximately twice larger on $\mathrm{m} 2$ and oriented distinctly more posteriorly than on $\mathrm{m} 3$. These denticles suggest that at least part of the cheek teeth of Mystacodon did have radially oriented accessory denticles, possibly similar to the condition of Coronodon and several heterodont odontocetes (Geisler et al. 2017; Hocking et al. 2017a, b; Lambert et al. 2017b). On $\mathrm{m} 3$, the distal half of the base of the crown is preserved. In this region, the $\mathrm{m} 3$ of Mystacodon bears a conspicuous cingulum formed by three adjoined cuspules.

Three well-preserved isolated teeth were found in association to the skull and mandible (designated here as teeth I, II, and III respectively; Fig. 27). They present a sub-horizontal abrasion wear surface with sharp edges, similar to that observed on the lower molars and premolars. This particular morphology provides to the crowns the shape of a truncated pyramid in lateral view.

Tooth I (Fig. 27A-C) is smaller than the other two isolated teeth. It is single-rooted and lacks a cingulum. In occlusal view, the crown is somewhat oval in cross section, but asym- 


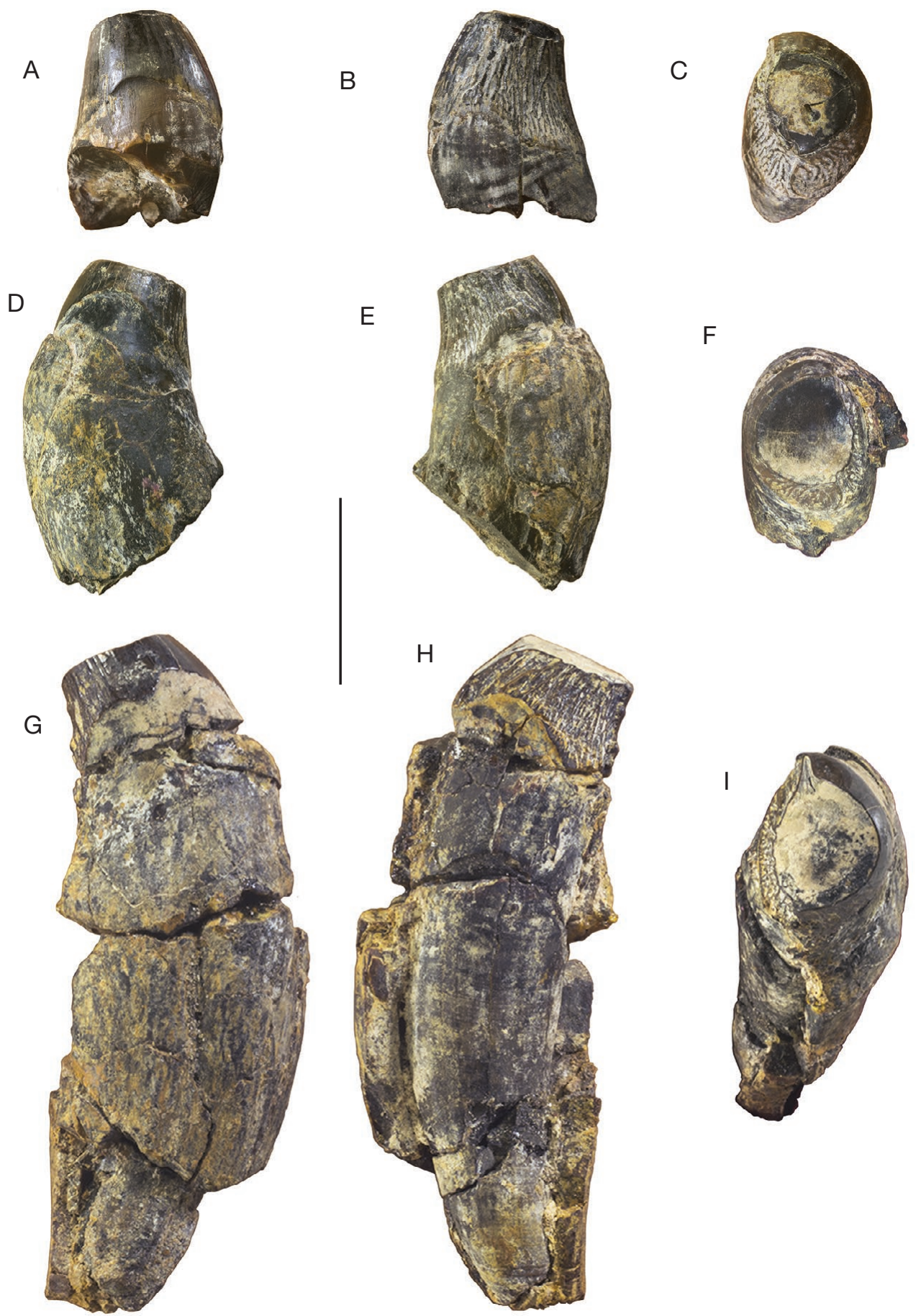

FIG. 27. - Mystacodon selenensis (MUSM 1917, holotype). A-C, right i2 or i3 (tooth I); D-F, left i3 or c (tooth II); G-I, right ?p1 (tooth III); A, labial view; B, lingual view; C, occlusal view; D, labial view; E, lingual view; F, occlusal view; G, labial view, H, lingual view; I, occlusal view. Scale bar: $3 \mathrm{~cm}$.

metrical. The lingual and labial sides have been identified by comparison with other toothed mysticetes, especially Aetiocetus weltoni and Mammalodon colliveri, in which the labial surface has smooth enamel and is strongly convex in occlusal view. In contrast, the lingual surface is almost flat and presents distinctly wrinkled enamel. The mesiolingual angle of the tooth bears a salient crest which extends from the base of the crown as far as the occlusal preserved part of the tooth. This crest is mesiolingually oriented; a similar but weaker crest is observed distolingually. As a consequence, the lingual edge of the tooth is almost flat (slightly convex) and the labial aspect is strongly convex. In lateral view, the crown is slightly curved posteriorly and the proximal portion of the root is posteriorly oriented. The wear surface is flat, horizontal, and sub-circular. This tooth is interpreted here as a lower incisor, probably the right $\mathrm{i} 2$ or i3 (it is too large to be an i1), since the roots and part of the crowns of the six upper incisors are preserved on the premaxillae. 
A
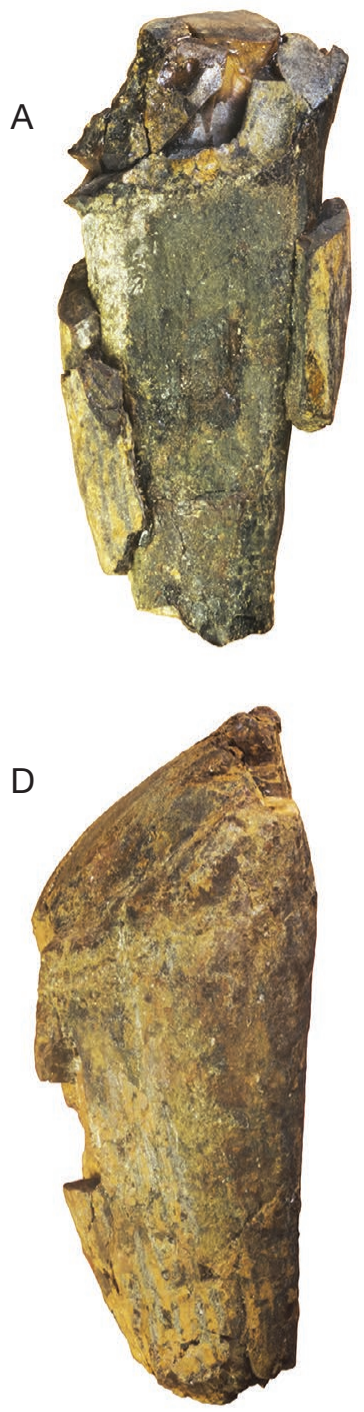

G

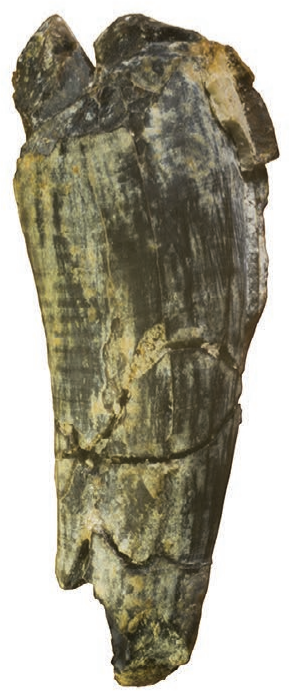

B

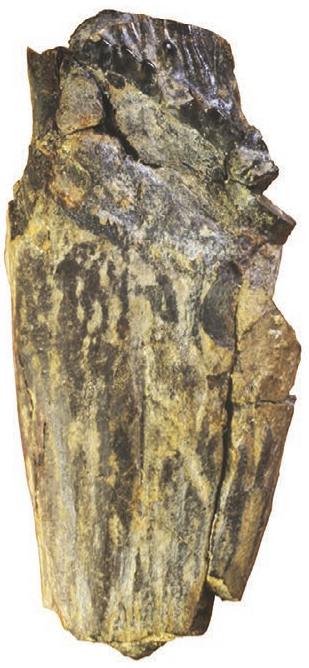

E

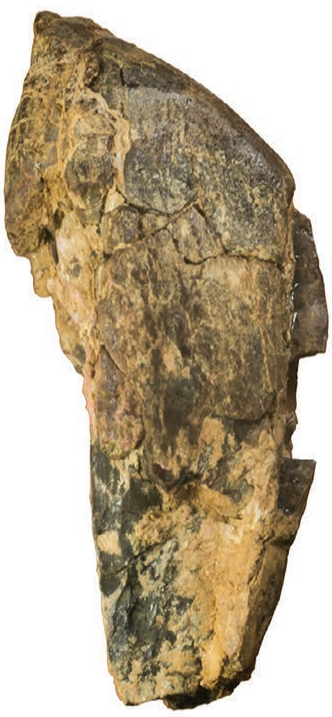

$\mathrm{H}$

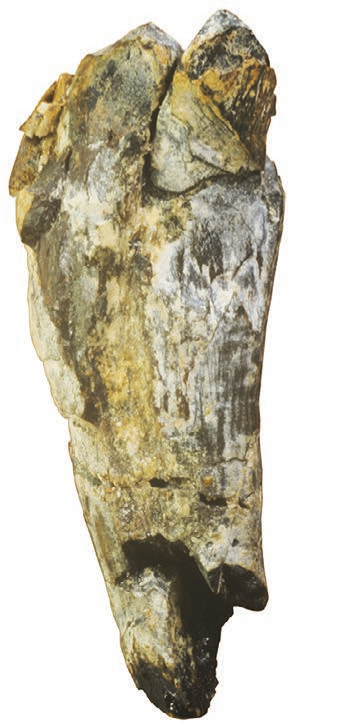

C

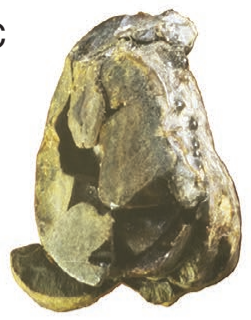

F

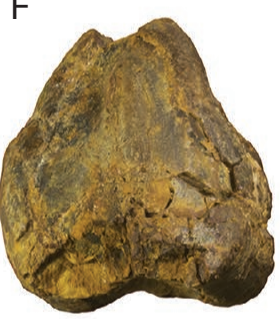

I

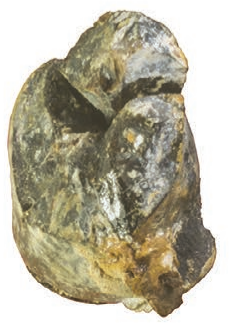

FIG. 28. - Mystacodon selenensis (MUSM 1917, holotype). A-C, posterior of right ?p2 (tooth IV); D-F posterior half of right ?p3 (tooth V), G-I, right ?i2 (tooth VI). A, labial view; B, lingual view; C, occlusal view; D, labial view; E, lingual view; F, occlusal view; G, labial view, H, lingual view; I, occlusal view. Scale bar: 3 cm. 
The second isolated tooth (tooth II, Fig. 27D-F) is slightly larger and more massive than tooth I. Its crown is roughly circular in cross section and both the lingual and labial surfaces are convex. As observed on tooth $\mathrm{A}$, the labial surface is smooth, while the lingual surface has wrinkled enamel. At the lingual base of the crown is a very weak cingulum, which does not reach the mesial and distal angles of the tooth. As on tooth A the mesiolingual and distolingual angles of the tooth bear distinct vertical crests. The lingual aspect of the tooth is slightly convex and the labial one is strongly convex. The wear surface is asymmetrical in outline with the lingual edge less convex; it is perpendicular to the axis of the crown, and its borders are sharp. Besides, the unique root seems to be less posteriorly oriented than on the first isolated tooth (tooth I), which indicates a more posterior position along the jaw. Based on its orientation and shape, this tooth is referred to a left i3 or $\mathrm{c} 1$.

The third isolated tooth (tooth III; Fig. 27G-I) is slightly larger than tooth II. Although its cross section is somewhat oval and mesiodistally longer than labiolingually wide, the crown of this tooth is not as mesiodistally elongated as the posterior premolars. Tooth III has a unique and massive root, and bears a weak lingual cingulum. The labial surface is very convex in apical view and its enamel is mostly smooth, with some longitudinal ridges located in its distal portion. On the other hand, the lingual surface is rather flat (weakly convex) in apical view and bears strongly wrinkled enamel. Most of the crown has been worn off and the abrasion wear surface is located near the base of the crown. The latter is a flat and oval surface, almost perpendicular to the axis of the crown and slightly dipping mesially. The wear surface continues into an extremely narrow surface at the mesial margin of the crown, as a result of the abrasion of the mesiolingual crest. This secondary wear surface is almost parallel to the axis of the tooth and forms an angle of $130^{\circ}$ with the main wear surface in lingual view. According to its size, morphology, and orientation, this isolated tooth is probably a right $\mathrm{p} 1$.

Three other isolated partial teeth, designated here as teeth IV, V, and IV, likely represent the anterior or posterior half of upper or lower premolars (IV and V) and an anterior single-rooted tooth (VI) (Fig. 28). The teeth are heavily apically worn, and bear a sloping (but not subvertical) wear surface thus differing from teeth I, II, and III. Given their preservation, a precise identification of theses teeth is difficult. However, two teeth (IV and V) bear a deep sulcus on one edge of the root (Fig. 28A-F). This sulcus is present on the posterior edge of the anterior root and on the anterior edge of the posterior root of upper and lower premolars 2-3, which corroborates the fact that the partial teeth IV and V correspond to the anterior or posterior half of premolars. As compared to the preserved roots of the premolars in situ on the cranium and mandible, teeth IV and V better combine respectively with the posterior halves of the right $\mathrm{p} 2$ and $\mathrm{p} 3$. All the enamel of tooth $\mathrm{V}$ has been worn off, but tooth IV retains strongly wrinkled enamel on most of its lingual edge (Fig. 28A). Furthermore, the base of the crown exhibits a robust basal cingulum formed by a series of basal cuspules. Tooth
VI is a single-rooted tooth. Its root is almost complete and is slightly bent in lateral view, which allows for the identification of its mesial and distal edges. (Fig. 28G-I) Most of the crown is broken but a small portion with wrinkled enamel is preserved on the posterolingual edge of the tooth and no basal cingulum is observed on this part of the crown. Because of the angle observed between the preserved part of the crown and the root, the latter appears to have been implanted obliquely in the jaw and therefore could correspond to a single-rooted anterior tooth. Given its relatively small size and (lingual) curvature, it more likely corresponds to a right i2 than to an i3 or canine; it is too large to be an i1.

\section{POSTCRANIAL SKELETON}

Part of the postcranial skeleton of the holotype of Mystacodon selenensis is preserved, including vertebrae, forelimbs, and one innominate. Vertebrae include the axis, centra of two posterior cervical vertebrae (C3? and C7?), and six thoracic vertebrae (T2?, T3?, T9?, T10?, T12?, and T14?). Some ribs and rib fragments are preserved: one anterior rib (possible R1 or R2), two median ribs (possibly R5, 6, or 7?), and two posterior ribs. The pectoral girdle and forelimbs of MUSM 1917 are relatively complete and include the two scapulae, humeri, radii, ulnae, seven different carpal bones, three metacarpals, and five phalanges. The only element of the pelvic girdle recovered is the left innominate. If most of the vertebrae and ribs are poorly preserved, the forelimb and innominate are well preserved and represent the first described limb and girdle elements of an early toothed mysticete. Although the forelimb of Aetiocetus polydentatus and Fucaia goedertorum is well preserved, it still remains undescribed (Marx \& Boessenecker pers. comm.).

\section{Vertebrae}

The preserved vertebrae are poorly preserved since they have suffered intense weathering by desert winds at the surface of the ground at Playa Media Luna.

Axis (Fig. 29). The axis bears an anteroposteriorly long neural process, which extends anteriorly dorsal to the odontoid process, as is observed in Cynthiacetus and Yamatocetus. Although the process is missing its posterodorsal angle, it is possible to observe that it was elevated well above the neural canal, as in Cynthiacetus and Yamatocetus, but differing from the condition in Piscobalaena (Bouetel \& Muizon 2006). The transverse process is partly broken; it was located at the base of the centrum and right and left processes were diverging posterolaterally, as in Cynthiacetus and Yamatocetus. In this respect, the axis of Mystacodon clearly differs from that of a "classical" chaeomysticete such as Piscobalaena, in which the process is attached along the whole height of the centrum and is directed laterally rather than posterolaterally. As in Cynthiacetus and Yamatocetus the centrum of the axis of Mystacodon is long anteroposteriorly, much longer than in extant chaeomysticetes. The odontoid process is relatively well developed and salient anteriorly as compared to extant chaeomysticetes, more resembling the condition of Cynthiacetus and Yamatocetus. 

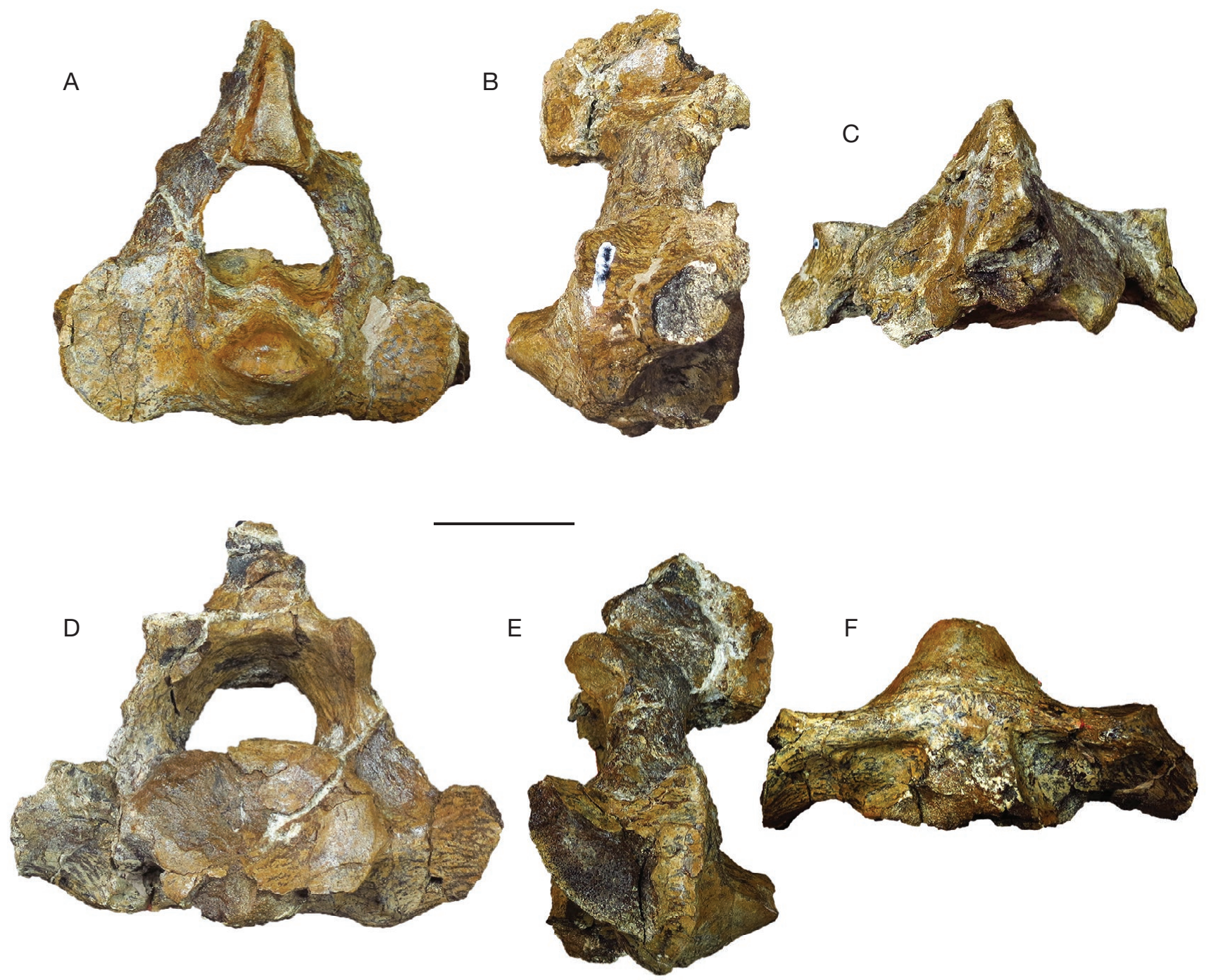

FIG. 29. - Mystacodon selenensis (MUSM 1917, holotype). Cervical vertebra: axis; A, anterior view; B, left lateral view; C, dorsal view; D, posterior view; E, right lateral view; $\mathbf{F}$, ventral view. Scale bar: $5 \mathrm{~cm}$.

Other cervical vertebrae (Figs 30,31). The other remains of cervical vertebrae are centra tentatively referred to C3 (Fig. 30) and C7 (Fig. 31). Possible referral of the second centrum to a $\mathrm{C} 7$ is based on the relatively long centrum, a condition that is often observed in C7 of mammals. Because of their incompleteness and the uncertainty of their position these vertebrae provide little information (apart from their size and unfused condition) and do not allow significant comparison with other early mysticetes of basilosaurids.

Thoracic vertebrae (Figs 32-37). Six partial thoracic vertebrae have been tentatively identified on the basis of the position and morphology of the transverse process as compared to that of Cynthiacetus peruvianus (Martínez-Cáceres et al. 2017). However, we admit that this interpretation might be biased, because there is no indication that the vertebral formula of Mystacodon is similar to that of Cynthiacetus.

On the first preserved vertebra, tentatively identified as a $\mathrm{T} 2$, the transverse process has a massive nodular morphol- ogy and is laterally oriented (Fig. 32). It is probably referred to a T2 because the transverse process (in anterior view) is at the level of the dorsal half of the neural canal (on T1 of C. peruvianus the process is at the level of the ventral half of the canal). The articular facet for the tuberculum of the rib is not really individualized from the remaining dorsal portion of the transverse process (no metapophysis or mammillary process is observed at this level of the vertebral column, two structures which are present in the more posterior thoracic vertebrae). On the second preserved vertebra (T3?), the transverse process is oriented slightly more dorsally than on T2? and is located at the level of the dorsal edge of the neural canal and slightly above (Fig. 33). The condition of these two vertebrae corresponds to the morphology of the anterior thoracic vertebrae of Cynthiacetus peruvianus.

The more posterior thoracic vertebrae have been tentatively referred to T9 and T10, because on T9? the transverse process is divided into a metapophysis (mammillary process) and the transverse process itself, which bears the articular facet for 

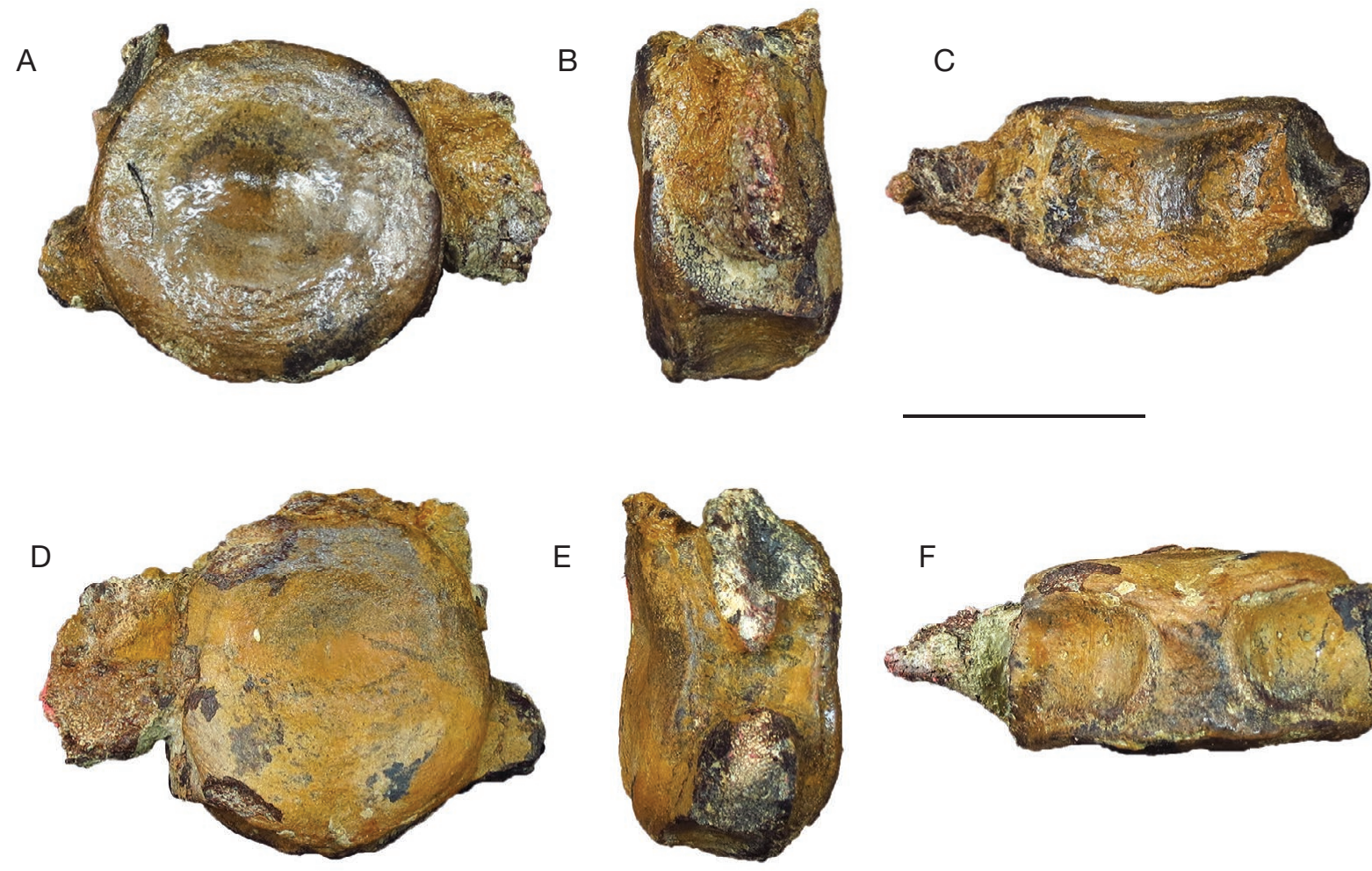

E
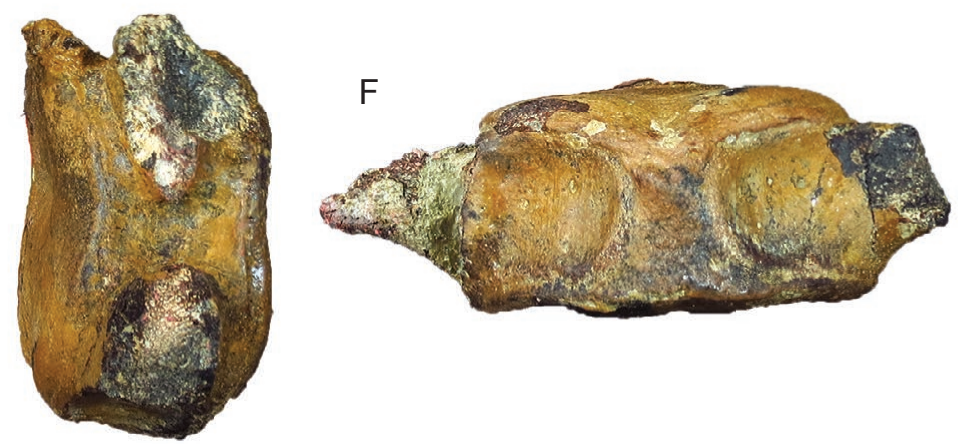

FIG. 30. - Mystacodon selenensis (MUSM 1917, holotype). Cervical vertebra: ?C3; A, anterior view; B, left lateral view; C, dorsal view; D, posterior view; E, right lateral view; F, ventral view. Scale bar: $5 \mathrm{~cm}$.

A

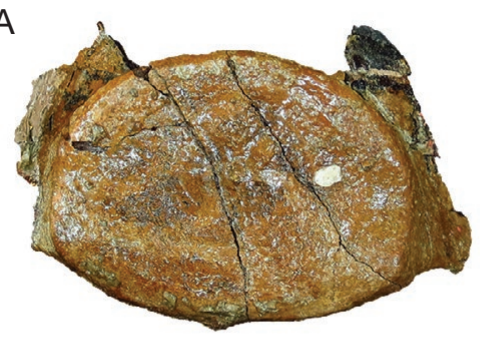

B

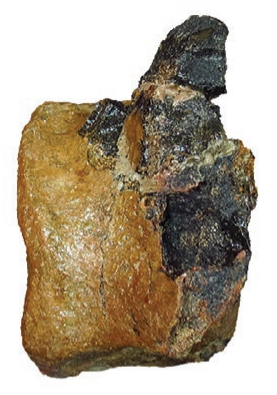

E

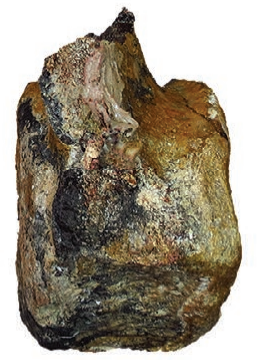

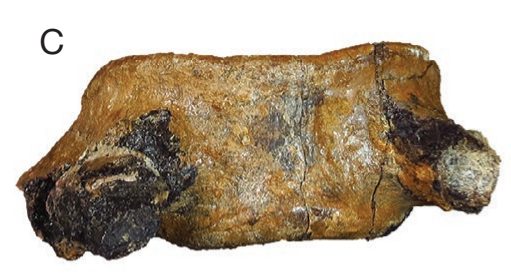

$\mathrm{F}$

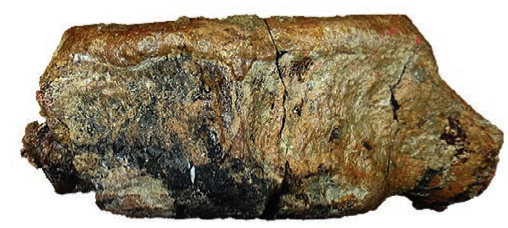

FIG. 31. - Mystacodon selenensis (MUSM 1917, holotype). Cervical vertebra: ?C7; A, anterior view; B, left lateral view; C, dorsal view; D, posterior view; E, right lateral view; F, ventral view. Scale bar: $5 \mathrm{~cm}$.

the tuberculum of the rib (Figs 34; 35). The metapophysis is subvertical in anterior view and posteriorly inclined in lateral view. The transverse process is high, located at the level of the dorsal edge of the neural canal as in observed on T8 and T9 of Cynthiacetus peruvianus (Fig. 34). On the following vertebra, which is tentatively referred to a T10, the 

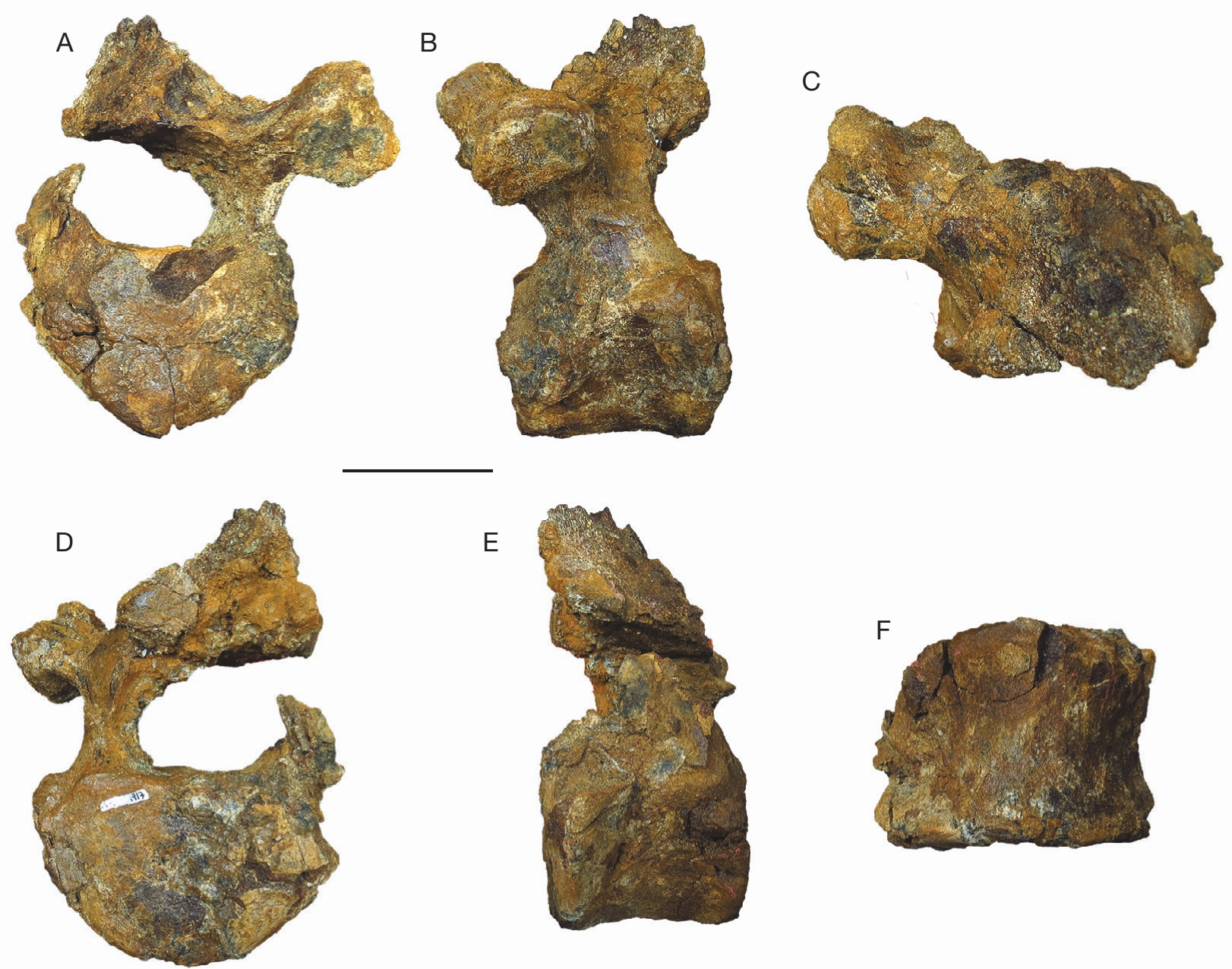

FIG. 32. - Mystacodon selenensis (MUSM 1917, holotype). Thoracic vertebra: ?T2; A, anterior view; B, left lateral view; C, dorsal view; D, posterior view; E, right lateral view; $\mathbf{F}$, ventral view. Scale bar: $5 \mathrm{~cm}$.

transverse process is slightly more ventral and more widely separated from the metapophysis (Fig. 35). The posterior vertebra is probably a T12, because the transverse process is markedly more ventral, located at the level of the lower edge of the neural canal (Fig. 36). It is therefore unlikely that it was the vertebra directly following T10?, but more probably was separated from the latter by one vertebra. The last preserved thoracic vertebra bears a transverse process that is located on the lateral side of the centrum, distinctly below the ventral edge of the neural canal (Fig. 37). This position corresponds to T14 of $C$. peruvianus. Because T13 and T15 of this basilosaurid have a transverse process located respectively more dorsal and more ventral on the centrum than that of the thoracic vertebra of Mystacodon in question, we tentatively refer the latter to a T14 (Fig. 37).

Ribs (Figs 38, 39). The ribs of MUSM 1917 are poorly preserved; most of them are incomplete, often missing their proximal end. However, seven relatively complete ribs can be determined with some confidence as far as their approximate position in the thoracic cage is concerned, based on a comparison with the well-preserved rib cage of Cynthiacetus.
In general, the ribs of Mystacodon are more massive than in Cynthiacetus. They are distinctly pachyosteosclerotic, resembling in this respect the basilosaurid condition (Buffrénil et al. 1990; Houssaye et al. 2015).

One rib, of which only the proximal end is preserved, is wide (Fig. 38A), with a conspicuous sulcus on both sides and a massive proximal end. Because of this morphology, we refer it to a R1 or R2. The capitulum in incomplete but the tuberculum is well preserved and less salient than in Cynthiacetus.

The most complete rib features a strong proximal curvature (stronger than on the first rib described above) with a relatively short and stout capitulum (Fig. 38B, C). Its proximal region (with the maximum curvature) is wide and flat with distinct sulci on both sides. It could correspond to R3 to R5. As in Cynthiacetus the distal extremity is conspicuously widened transversely. This widening is not pestle-like (i.e., with a circular cross-section) as in Basilosaurus, but more resembles the wide and flat condition (i.e., with an oval cross-section) observed in Cynthiacetus.

Three other ribs lacking their proximal extremity also bear a similar distal expansion, although less developed (Fig. 38D-I). As compared to the distal expansion of the ribs of Cynthiacetus 

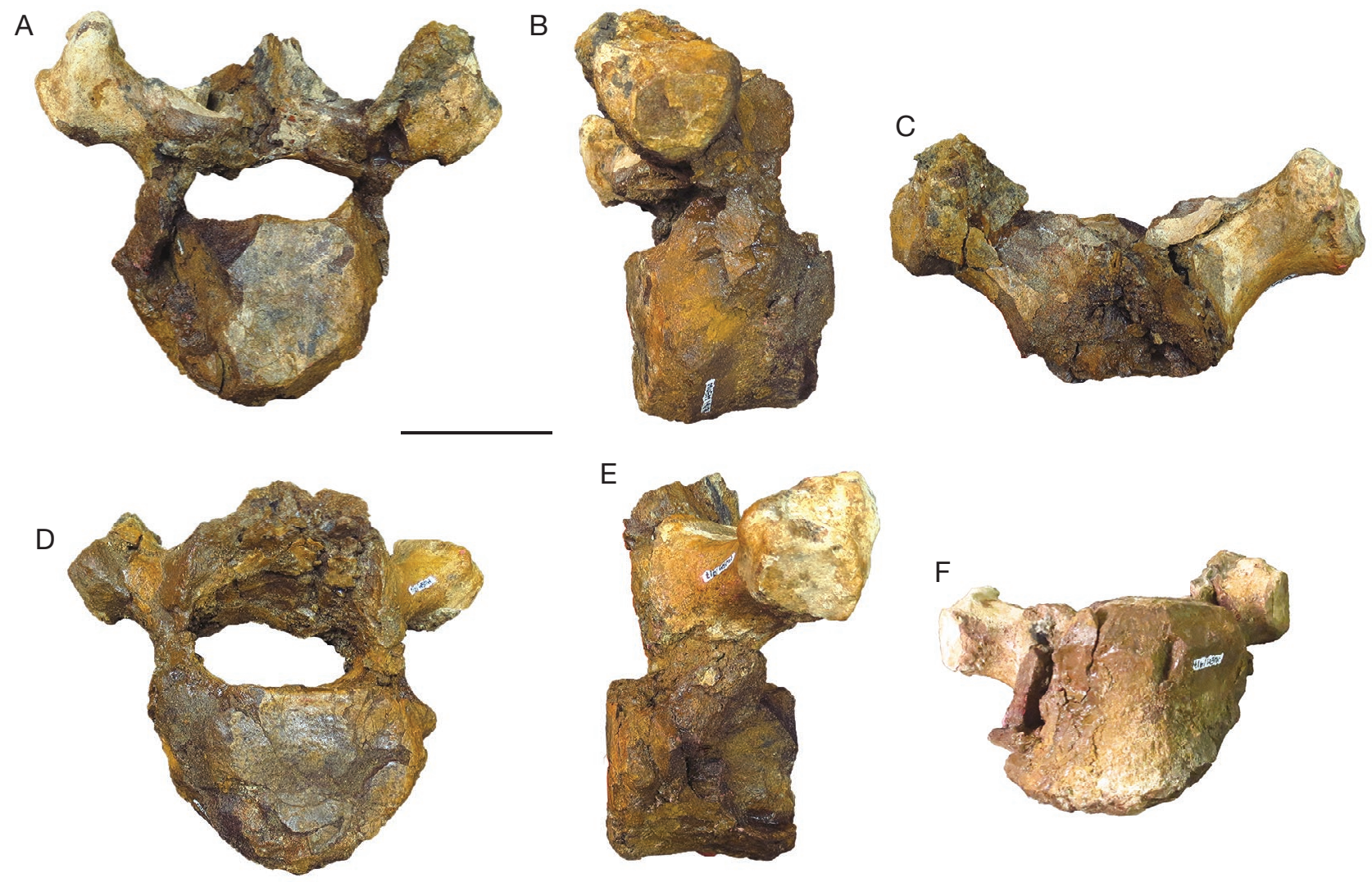

FIG. 33. - Mystacodon selenensis (MUSM 1917, holotype). Thoracic vertebra: ?T3; A, anterior view; B, left lateral view; C, dorsal view; D, posterior view; E, right lateral view. $\mathbf{F}$, ventral view. Scale bar: $5 \mathrm{~cm}$.

we estimate that they could represent R5, R6, or R7. However, their curvature is less developed than on the corresponding ribs of Cynthiacetus, which is an indication that they might be more posterior ribs. If this interpretation is correct, then the distal expansion of the ribs, which is limited to R2-8 in the holotype of Cynthiacetus peruvianus, could extend more posteriorly in the rib cage of Mystacodon.

An almost complete rib is referred to a posterior rib because it has a rounded proximal epiphysis lacking separate capitulum and tuberculum (Fig. 38J). Such ribs in Cynthiacetus correspond to the last five thoracic vertebrae. It is slender and its diaphysis is more than twice narrower than the first completely preserved rib (R3 to 5) (Fig. 38B, C). Furthermore, the proximal curvature is reduced as is observed on the last five ribs of Cynthiacetus. The distal extremity is very slightly expanded, much less than in anterior ribs, but clearly differing from Cynthiacetus, in which the posterior ribs distinctly taper distally.

A pair of very short ribs is identified as the last ribs of the thoracic cage (Fig. 38K-O). They are approximately 75\% shorter than the posterior rib described above. As in other posterior ribs, the tuberculum and capitulum are fused in a single tuberosity, which attached on the apex of the transverse process of the last thoracic vertebra They present a characteristic triangular expansion of their proximal extremity. The apical articular head is hemispherical and is flanked antero- and posterodistally by two tuberosities for muscular attachment.
The anterior tuberosity is possibly for the levator costae; it is oval-shaped and does not extend distally. The posterior tuberosity is possibly for the serratus dorsalis caudalis; it is less salient than the anterior tuberosity and the muscular attachment apparently extends more distally along the posterior edge of the rib. The rib is distinctly curved medially and flattened transversely. Its lateral surface is markedly flat whereas its medial aspect is convex. The distal extremity of the bone strongly tapers anteroposteriorly and mediolaterally. The mediolateral compression of the rib is so pronounced that the bone is distinctly linguiform at its distal apex (Fig. 38L).

The last rib of Mystacodon strongly differs from that of Cynthiacetus and Dorudon, which is circular in cross section and much less reduced as compared to the more anterior posterior ribs. Among extant mysticetes, a conspicuous reduction of the last rib is observed in balaenids, whereas the last ribs of balaenopterids are only slightly shorter than the more anterior posterior ribs. Complete fossil chaeomysticete rib sets are not common, but such a reduction in length of the last rib is not observed in Pelocetus calvertensis (Kellogg 1965), Thinocetus arthritus (Kellogg 1969), and Balaenoptera siberi (Pilleri 1989), which may contradict our tentative identification of this pair of bones as posteriormost ribs.

In order to evaluate the compactness, and thus the degree of osteosclerosis, of the thoracic skeleton of Mystacodon, a thin section has been made in a rib fragment from the anteriormedian region of the thoracic cage of the holotype. A more 

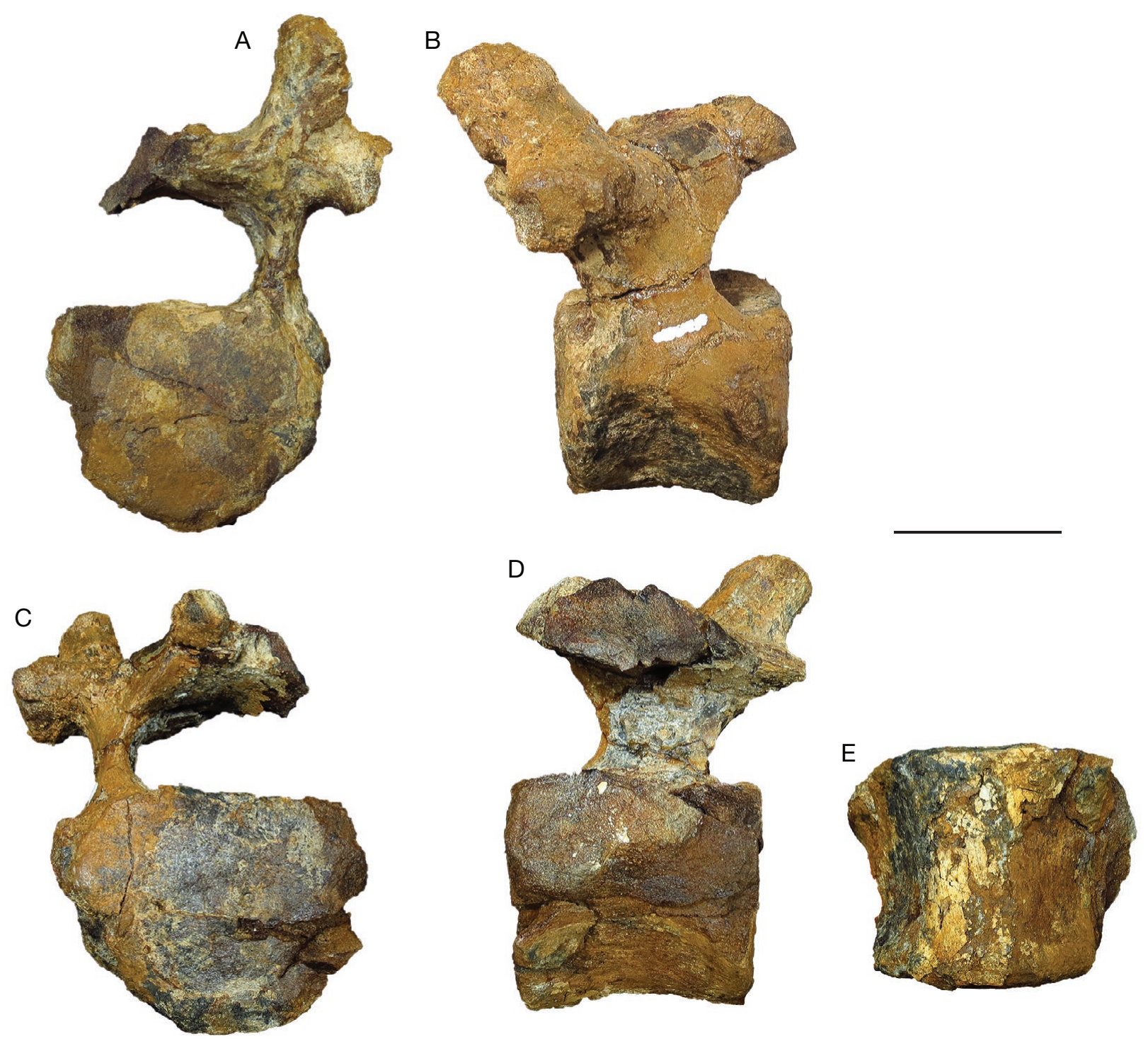

FIG. 34. - Mystacodon selenensis (MUSM 1917, holotype). Thoracic vertebra: ?T9; A, anterior view; B, left lateral view; C, posterior view; D, right lateral view; E, ventral view. Scale bar: $5 \mathrm{~cm}$.

thorough paleohistological study is currently in progress, to allow for a more detailed comparison with other mysticetes (e.g. Beatty \& Dooley 2009; Boessenecker \& Fordyce 2015a, b). Considering its diameter and cross-section morphology, the rib fragment is from the median part of the diaphysis (Fig. 39A). The section is distinctly oval-shaped. It lacks a well-defined medullary cavity, but the central region of the section is filled with trabecular bone. A thick cortical layer of dense bone surrounds the cancellous region. The dense cortical bone is much thicker medially than laterally as is observed in Dorudon atrox (Uhen 2004: 158) and Basilosaurus isis (Houssaye et al. 2015: fig. 13B) (Fig. 39B, C). A compactness index (CI) of 0.807 was calculated with the image processing software "Bone Profiler" (Girondot \& Laurin 2003). This value is slightly greater than that obtained by Houssaye et al. (2015) in Dorudon on a mid-diaphysis section (0.792). In contrast, it is lower than that obtained in Basilosaurus in the same region of the rib (0.879). Therefore, the compactness index of Mystacodon is compatible with that observed in basilosaurids. Because the $\mathrm{CI}$ in terrestrial mammals ranges from 0.374 to 0.817 for a 95\% interval confidence, Buffrénil et al. (2010) suggested a threshold of 0.817 as an inferior CI limit for bone osteosclerosis. However, they also indicated that some terrestrial mammals are above this threshold. Considering this osteosclerosis threshold, basilosaurids are osteosclerotic (Basilosaurus) or at the limit of osteosclerosis (Dorudon). Because one measurement only has been obtained for Mystacodon, it is clear that further study is necessary to securely define its condition. However, because this measurement is intermediate between similar mesasurements in Basilosaurus and Dorudon, as the latter, Mystacodon was probably very close to osteosclerosis, if not osteosclerotic. A compactness index was also calculated in other mysticetes (Fig. 39D, E). A section in the proximal third of a left R4 or R5 of Piscobalaena nana (MNHN.F.SAS1618) resulted in a $\mathrm{CI}$ of 0.657 and a section in the median region of a right R8 or R9 of Balaenoptera acutorostrata (IRSNB - 

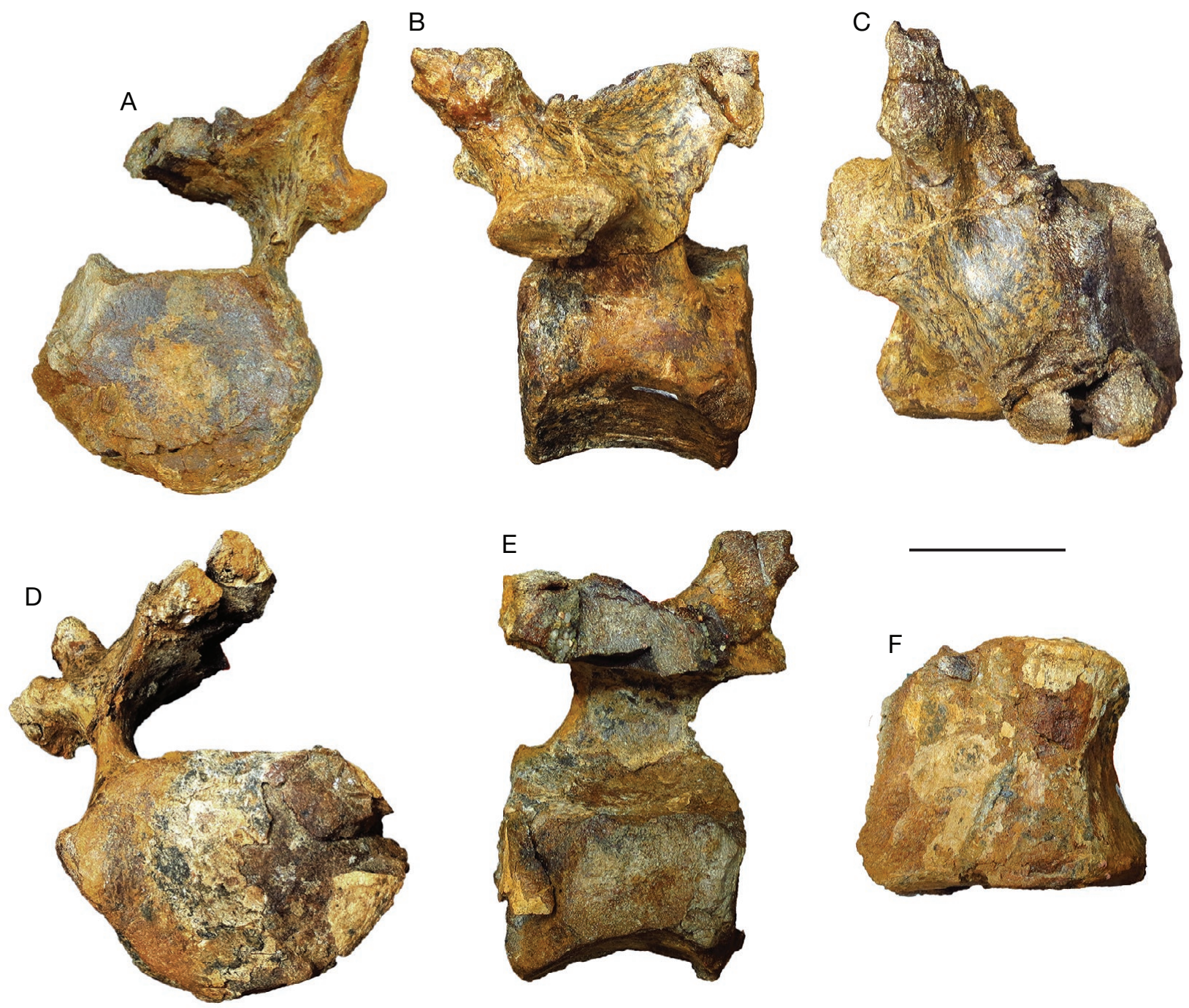

FIG. 35. - Mystacodon selenensis (MUSM 1917, holotype). Thoracic vertebra: ?T10; A, anterior view; B, left lateral view; C, dorsal view; D, posterior view; E, right lateral view; $\mathbf{F}$, ventral view. Scale bar: $5 \mathrm{~cm}$.

uncatalogued specimen) resulted in a CI of 0.569 . According to the threshold of Buffrénil et al. (2010) these ribs are clearly not osteosclerotic.

The rib cage of Mystacodon therefore displays a more massive constitution than in Cynthiacetus, with a distal expansion of the ribs (pachyostosis) probably extending to the posterior region of the rib cage (only from R2 to R8 in the holotype of Cynthiacetus peruvianus). This latter condition, combined with a rib bone inner structure close to osteosclerosis, resulted in a significant increase of the weight of the anterior part of the postcranial skeleton in Mystacodon.

Sternum (Fig. 40). Most of the sternum is preserved and it includes four elements: a large manubrium (St1) two intermediate sternebrae (St2 and St3), and a xiphisternum (St4), which, although incomplete, is evaluated to be at least $30 \%$ longer than S2 and S3.

The manubrium (L: $154 \mathrm{~mm}$; anterior W: $127 \mathrm{~mm}$ ) is very similar to that of Cynthiacetus peruvianus, but slightly proportionally larger (see Table 9 below) and more compact in outline (massive). The anterior edge of the manubrium is a saddle-shaped surface (parabolic shield of Fordyce \& Marx 2018), which transversely widens anteriorly. The lateral edges of the surface form two blunt semicircular ridges, which are widely separated anteroventrally and which converge posterodorsally. The ridges do not extend on the ventral aspect of the bone. The anterolateral ridges of the manubrium surround laterally two shallow fossae, which face dorsolaterally in Mystacodon and almost extend on the dorsal aspect of the bone. This condition differs from that in Cynthiacetus, in which these fossae are more laterally oriented. The anterior shield of the manubrium, the ridges surrounding the fossae, and probably the fossae themselves likely received the origin of the sternohyoideus muscle, which inserts on the basihyal (Schulte \& de Forest Smith 1918; Howell 1927, 1930a). The action of this muscle is to pull the hyoid complex and the tongue posteriorly, an action that tends to create a depression in the mouth, thus generating intraoral suction (Werth 2007). Fordyce \& Marx (2018) have inferred the presence of a powerful sternohyoideus in Llanocetus from the large size 

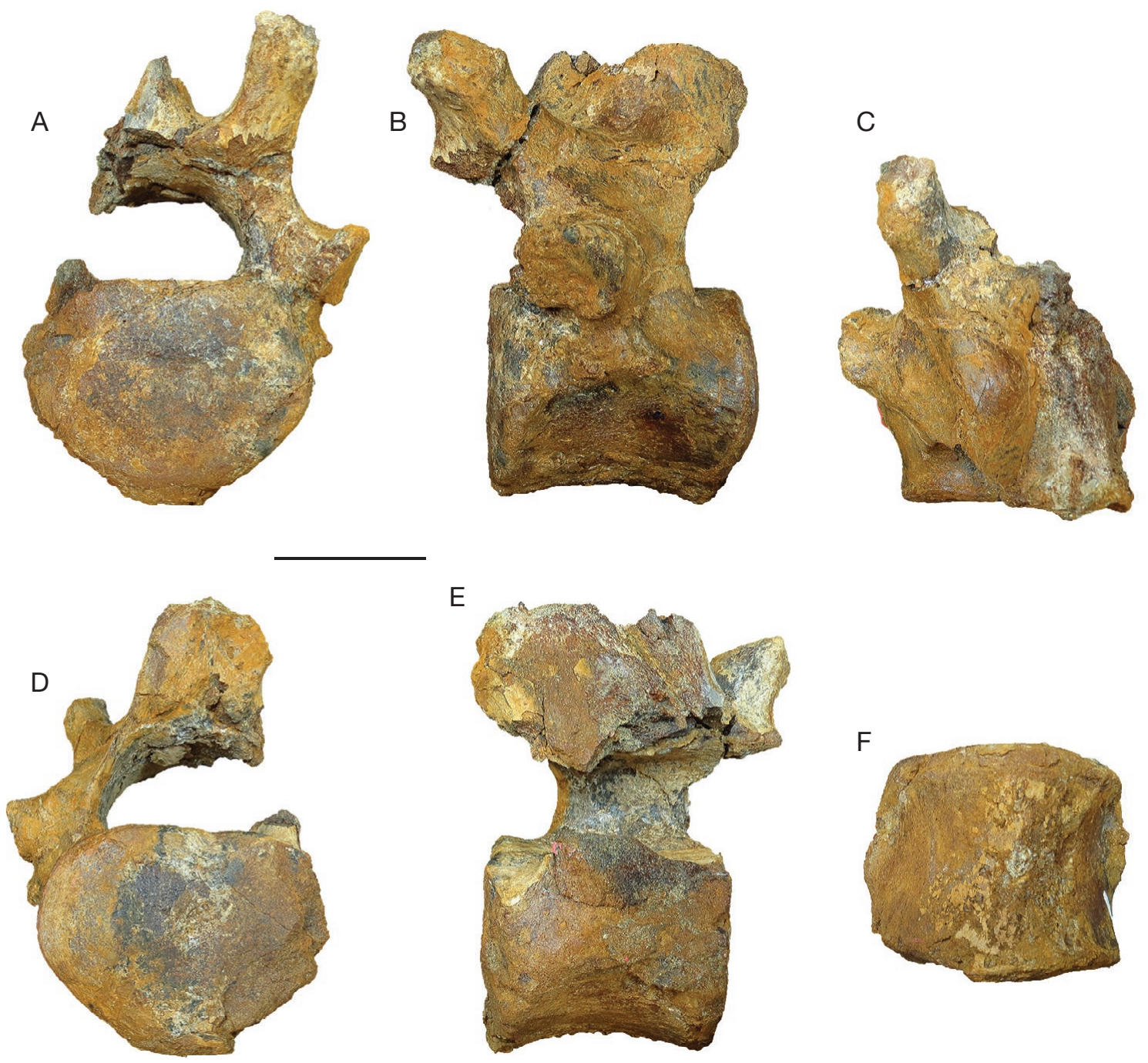

FIG. 36. - Mystacodon selenensis (MUSM 1917, holotype). Thoracic vertebra: ?T12; A, anterior view; B, left lateral view; C, dorsal view; D, posterior view; E, right lateral view; $\mathbf{F}$, ventral view. Scale bar: $5 \mathrm{~cm}$.

of the sternum and regarded this condition as facilitating suction feeding.

Posterior to the fossae, on the lateral edges of the manubrium, two salient anteroposteriorly elongated irregular tuberosities (Fig. 40A) likely received the costal cartilages, which attached at the distal end of the first ribs during life (Fitzgerald 2010). These tuberosities face dorsolaterally and are not visible ventrally. Because of these tuberosities, the median region is wide and short, and does not exhibit the distinct lateral concavity observed in Cynthiacetus, in which the costal cartilages probably attached in a more anterior position than in Mystacodon. The ventral aspect of the manubrium of Mystacodon is distinctly flat to concave, whereas its dorsal aspect is markedly convex. The posterior synchondrosis surface for the second sternebra is strongly $\mathrm{V}$-shaped and tapers posteriorly to a greater extent than the condition observed in Cynthiacetus. The manubrium of Mystacodon resembles that of Llanocetus in its general morphology. It differs however from this taxon in its narrower posterior end, which is V-shaped to rounded, whereas it is less convex and extends further posteriorly in Llanocetus.
As compared to the bizygomatic width, the manubrium of Mystacodon is larger than in Cynthiacetus in anterior width and length. It is proportionally slightly transversely wider than in Llanocetus, but it is slightly shorter (Table 9). Because the sternohyoideus originates on the anterior shield of the manubrium, a greater relative width of this region could be an indication of a more powerfull action of this muscle, and therefore a greater ability for suction feeding. In this respect, Table 9 indicates an increasing gradient toward suction feeding: Cynthiacetus < Llanocetus < Mystacodon.

The second sternebra (L: $124 \mathrm{~mm}$; W: $86 \mathrm{~mm}$ ) is much longer than in Cynthiacetus. It is approximately 30\% longer than wide and distinctly less massive than the manubrium. Its lateral edges are roughly parallel (very slightly convex laterally). As on the manubrium, the dorsal aspect is slightly concave but, in contrast to St 1 , the ventral side is flat to convex. The anterior synchondrosis surface forms a half-circle, which protrudes anteriorly, whereas the posterior surface is roughly flat and transversely oriented, being slightly narrower than the anterior surface. 

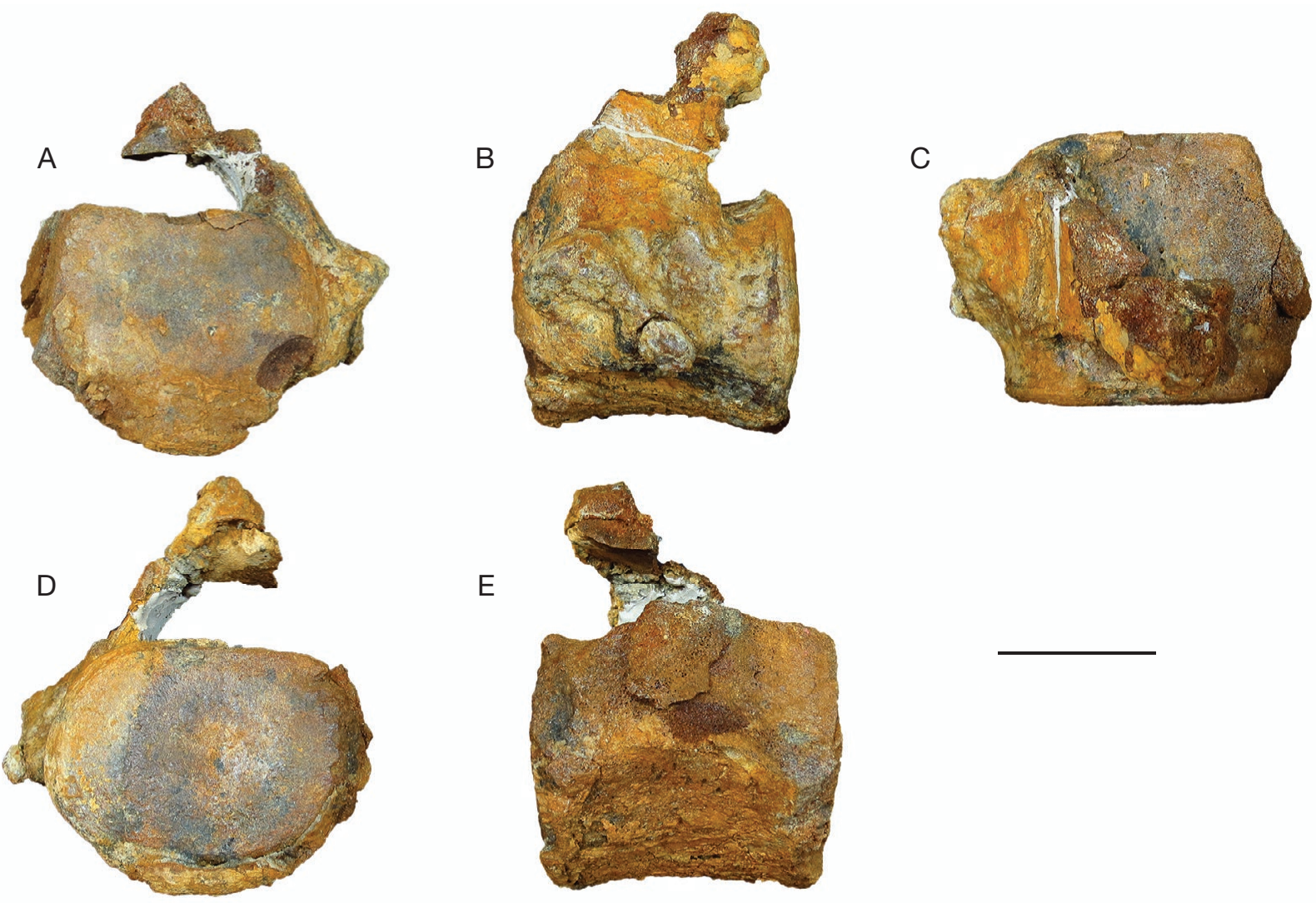

E

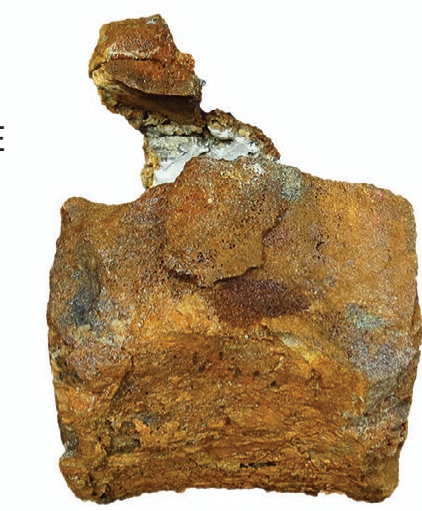

FIG. 37. - Mystacodon selen
lateral view. Scale bar: $5 \mathrm{~cm}$

TABLE 9. - Compared size of the manubrium as related to bizygomatic width in a basilosaurid (Cynthiacetus) and two toothed mysticetes (Mystacodon and Llanocetus). Abbreviations: AWMn, anterior width of the manubrium; BzW, bizygomatic width; LMn, length of the manubrium; Mn, manubrium; e, estimated measurements. Color code: grey, basilosaurids; green, toothed mysticetes.

\begin{tabular}{lccccc}
\hline Taxon & $\begin{array}{c}\text { Anterior Width } \\
\text { Mn }\end{array}$ & Length Mn & BzW & AWMn/BzW & LMn/BzW \\
\hline Cynthiacetus peruvianus (MNHN.F.PRU10) & 123 & 155 & 478 & 0.257 & 0.324 \\
\hline $\begin{array}{l}\text { Mystacodon selenensis } \\
\text { (MUSM 1917) }\end{array}$ & 119 & 154 & $399 \mathrm{e}$ & 0.298 & 0.386 \\
$\begin{array}{l}\text { Lanocetus denticrenatus } \\
\text { (USNM 183022) }\end{array}$ & 256 & 384.6 & $886 \mathrm{e}$ & 0.289 & 0.433 \\
\hline
\end{tabular}

The third sternebra (L 123 estimated; W: $82 \mathrm{~mm}$ ) is damaged in its anteroventral aspect. However, the dorsal side is well preserved and exhibits a semicircular synchondrosis surface for articulation with St2. The sternebra narrows posteriorly to fit the anterior synchondrosis surface of the xiphisternum.

Most of the xiphisternum is preserved. However, the anterior and posterior parts are not in contact and its length can only be estimated. Given the backward reduction of the width of the bone two or three centimeters are missing and its length is evaluated to $190 \mathrm{~mm}$, which is approximately $50 \%$ longer than $\mathrm{St} 2$ and $\mathrm{St} 3$. The anterior preserved part of the xiphisternum is much narrower than St2 and St3, since its greatest width is $50 \mathrm{~mm}$. its lateral edges are roughly parallel (very slightly convex laterally). The anterior synchondrosis surface is roughly quadrate and much smaller than in St2 and St3. The posterior preserved part is distinctly narrower than the anterior part and ends in a rounded posterior extremity, which is approximately twice as narrow as the anterior end of the bone.

As a whole the sternum of Mystacodon is wider and more massive than in Cynthiacetus for the anterior part (manubrium), whereas the posterior three sternebra are more elongated and slender. The sternum of Mystacodon is formed by four sternebrae, in contrast to the condition in Basilosauridae for which this region is preserved, which have five sternebrae (Uhen 2004; Martínez-Cáceres et al. 2017). The sternum of Mystacodon was approximately $460 \mathrm{~mm}$ long. 


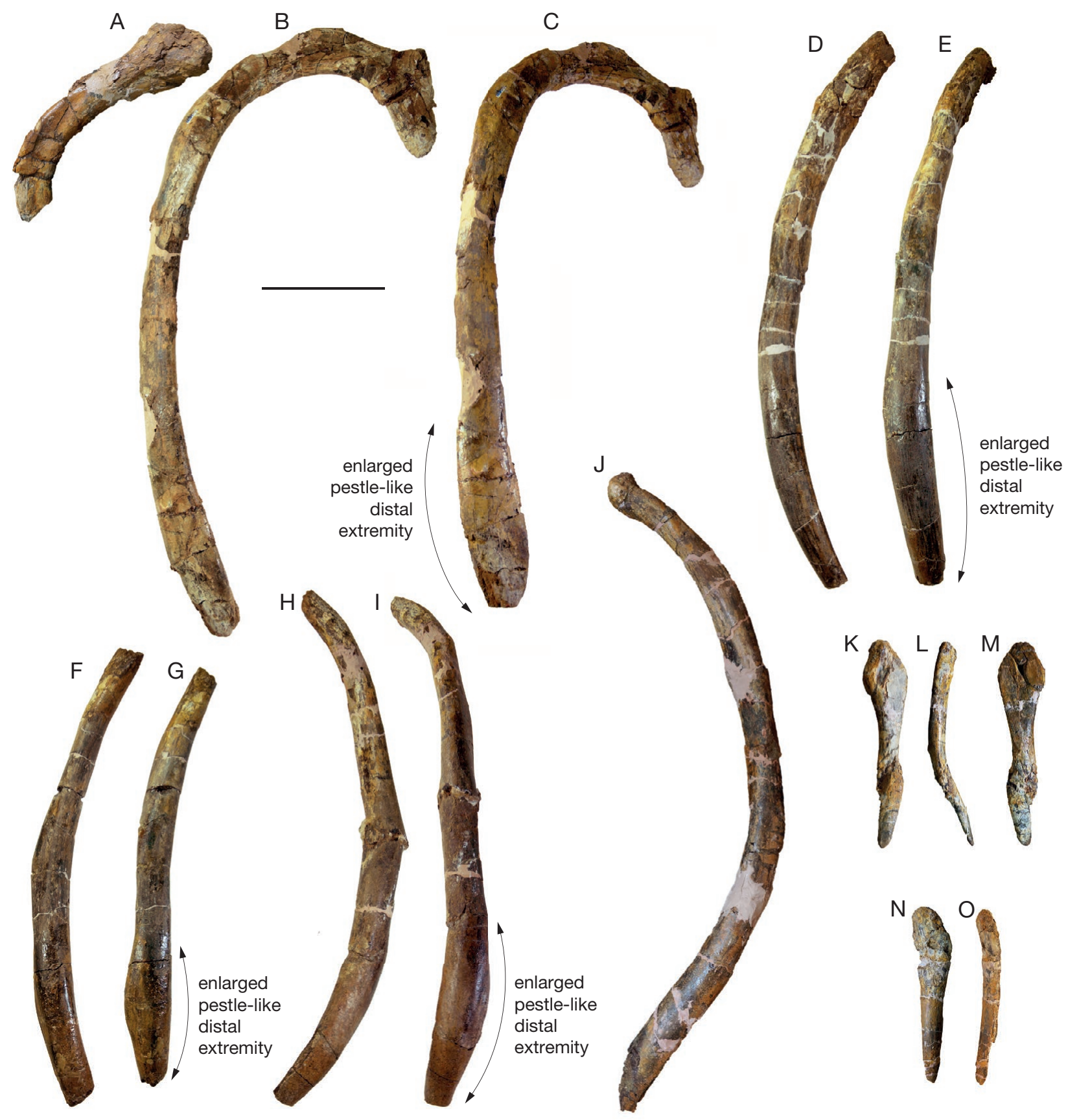

FIG. 38. - Mystacodon selenensis (MUSM 1917, holotype). Ribs; A, proximal extremity of ?R1 or R2 in anterior view; B, left anterior rib (possibly R3 to R5) in posterior view; C, the same in posterolateral view; D, left rib (possibly R5 to R7) in posterior view; E, the same in posterolateral view; $\mathbf{F}$, left rib (possibly R5 to R7) in posterior view; G, the same in posterolateral view; H, right rib (possibly R5 to R7) in posterior view; I, the same in posterolateral view; J, right posterior rib in posterior view; $\mathbf{K}$, right last rib in medial view; $\mathbf{L}$, the same in anterior view; $\mathbf{M}$, the same in lateral view; $\mathbf{N}$, left last rib in medial view; $\mathbf{O}$, the same in anterior view. Scale bar: $10 \mathrm{~cm}$.

\section{The pectoral girdle and forelimb}

Scapula. (Fig. 41) The two scapulae are known, but only the right is complete. It is a large triangular bone, which is slightly longer than high (proximodistally), as is observed in Basilosaurus and Dorudon. Comparisons, in this respect are not possible with the scapula of Cynthiacetus peruvianus, which is partly reconstructed (Martínez-Cáceres et al. 2017), and no scapula of other toothed mysticetes has been described so far. The oldest known chaeomysticete scapula, to which that of Mystacodon can be compared, is that of the eomysticetid Yamatocetus (Okazaki 2012). The scapula of the latter is clearly longer and lower than that of Mystacodon. The vertebral border of the scapula is regularly and strongly convex in the latter. This condition is more pronounced than in Basilosaurus and Dorudon; in Yamatocetus the vertebral border forms a conspicuous angle in its posterior third, the border being straight anterior and posterior to the angle. Therefore, in this respect, Mystacodon 


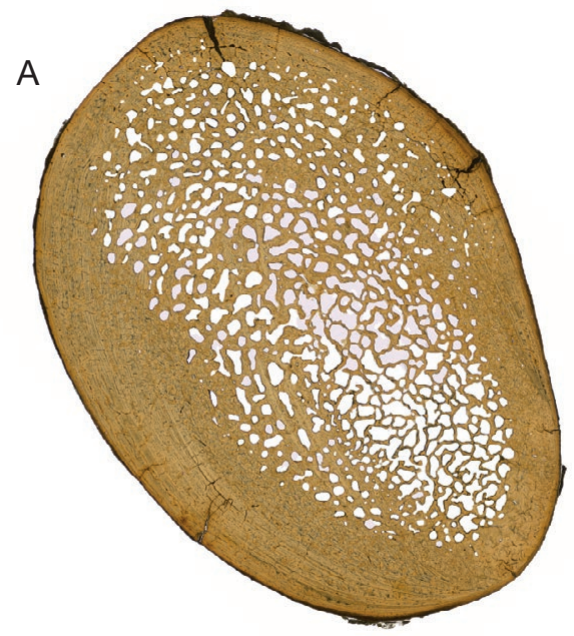

Mystacodon selenensis

$\mathrm{B}$
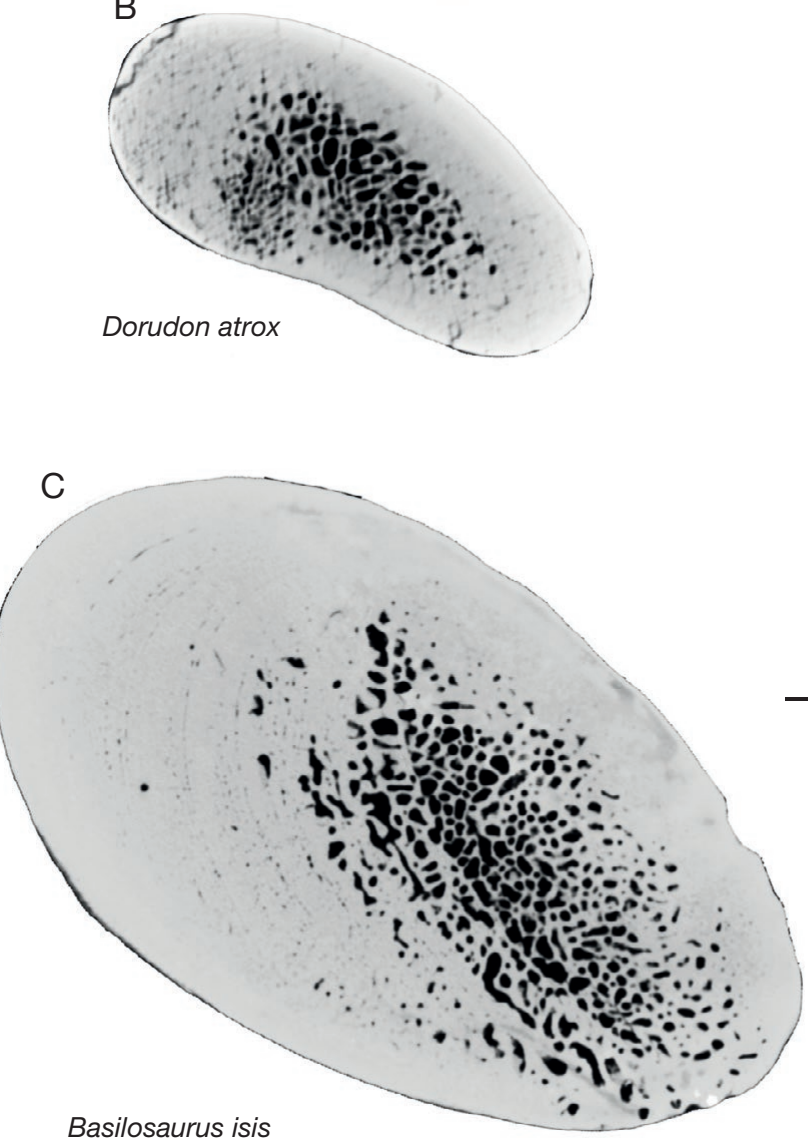

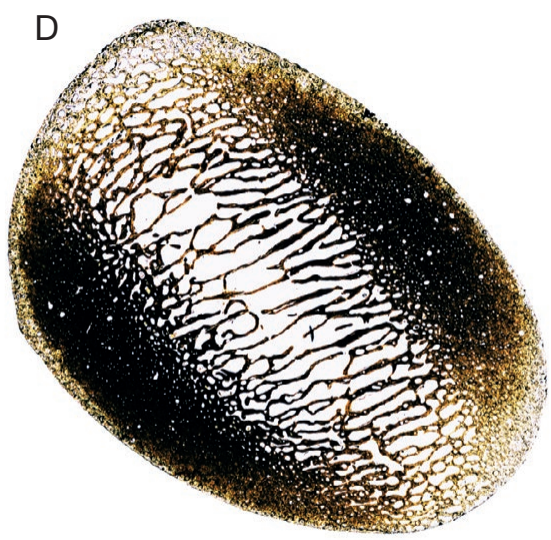

Piscobalaena nana

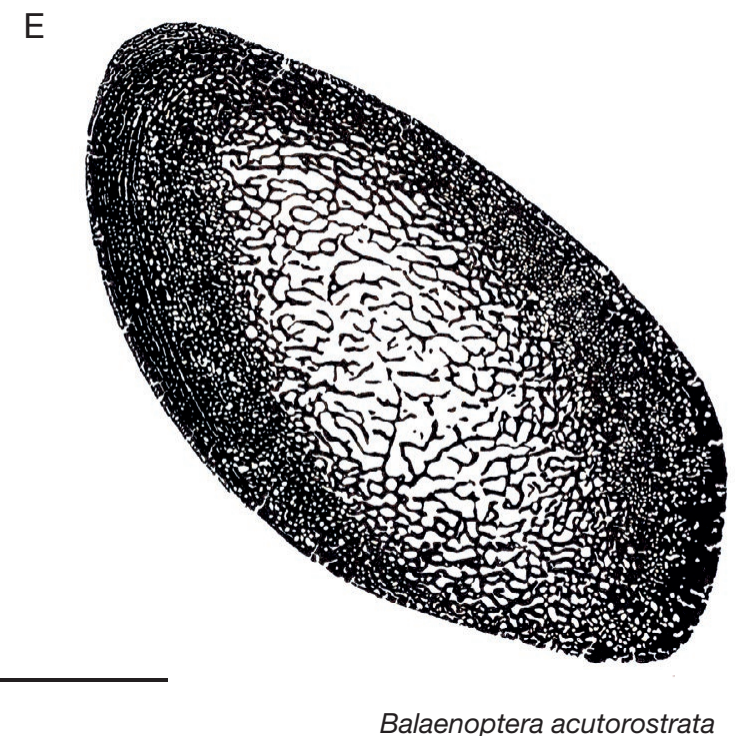

anterior

medial

FIG. 39. - Ribs transverse sections of Mystacodon, basilosaurids, and chaeomysticetes. A, Mystacodon selenensis (MUSM 1917, holotype): section of an anterior-median (right?) rib of the thoracic cage in the median region of the diaphysis; B, Dorudon atrox (UM 101222): section of a left R4 at mid-diaphysis (reversed); C, Basilosaurus isis (WH 074): section of a left R4 at mid-diaphysis. B and C are reproduced from Houssaye et al. (2015). D, Piscobalaena nana (MNHN.F. SAS1618). E, Balaenoptera acutorostrata (IRSNB uncatalogued). Abbreviations: ant, anterior; med, medial. Scale bar: $1 \mathrm{~cm}$.

more resembles basilosaurids than eomysticetids. On the lateral face of the scapula the supraspinatus fossa is large for a mysticete and resembles that of basilosaurids both for its shape and extent. The anterior edge of the fossa markedly projects anteriorly and is strongly convex, a condition that resembles much those of Cynthiacetus and Dorudon. As in Dorudon the spine is well developed (although slightly lower) and extend until the vertebral border of the bone. As in Dorudon the spine does not projects anteriorly and does not cover the distal region of the supraspinatus fossa, a condition observed in all chaeomysticetes (condition unknown in other toothed mysticetes). As a consequence, 


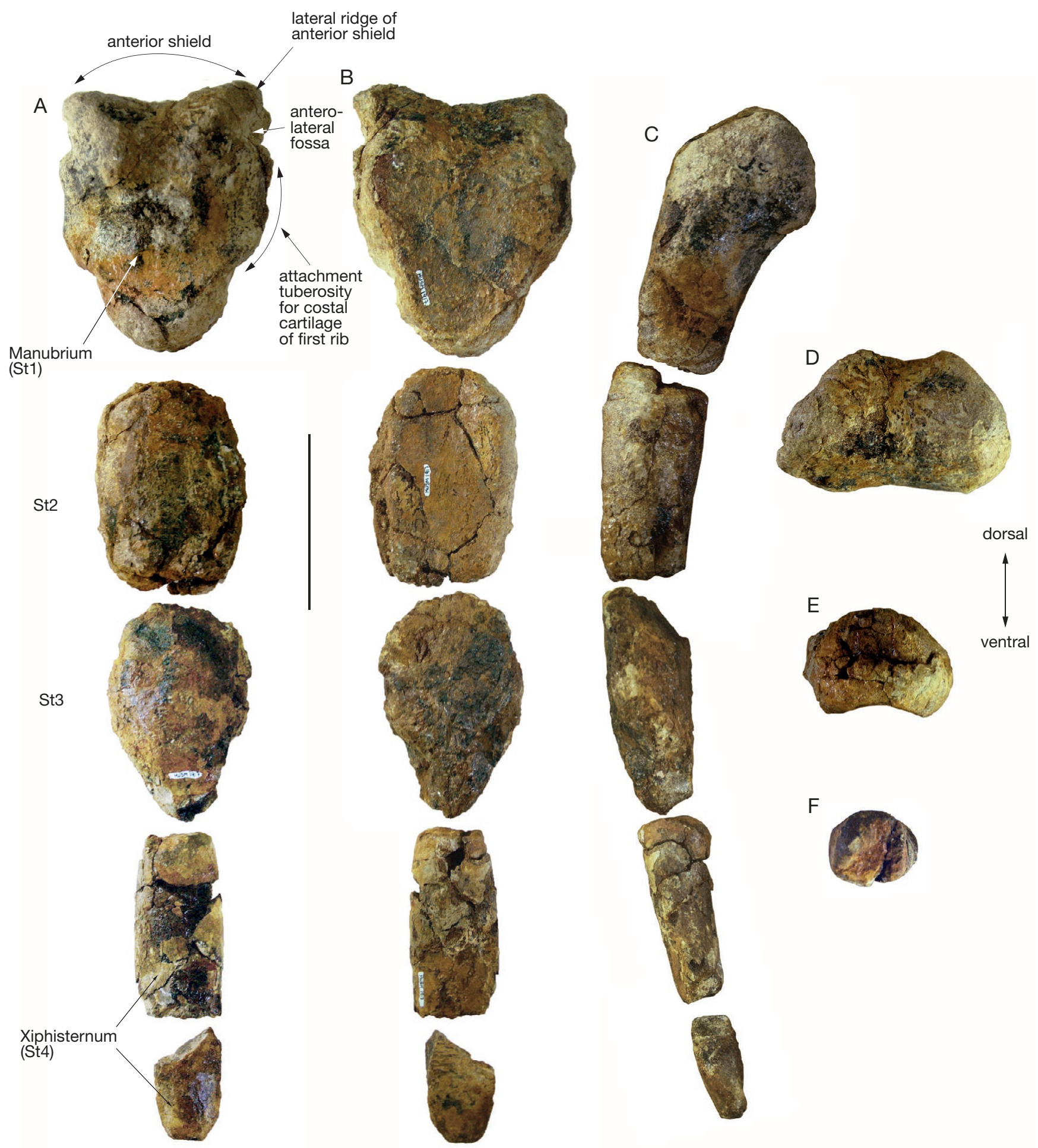

FIG. 40. - Mystacodon selenensis (MUSM 1917, holotype). Sternum: A, dorsal view; B, ventral view; C, left lateral view; D, anterior view of the manubrium; E, Anterior view of St2; $\mathbf{F}$, anterior view of the xiphisternum. Scale bar: $10 \mathrm{~cm}$.

the fossa is visible in lateral view, until the proximal base of the acromion. At the distal extremity of the spine the acromion is very large and massive. It is larger than in any basilosaurid and any other mysticete. At its base, on the spine, the width of the acromion is more than one third the total length of the spine. The acromion is slightly expanded at its apex, contrary to the condition observed in basilosaurids and other mysticetes, in which it generally slightly tapers or, at the least, remains as wide as at its base. As a consequence, the median region of the process is conspicuously constricted in Mystacodon. An apical expansion of the acrominon is convergently observed in some delphinoids 
A

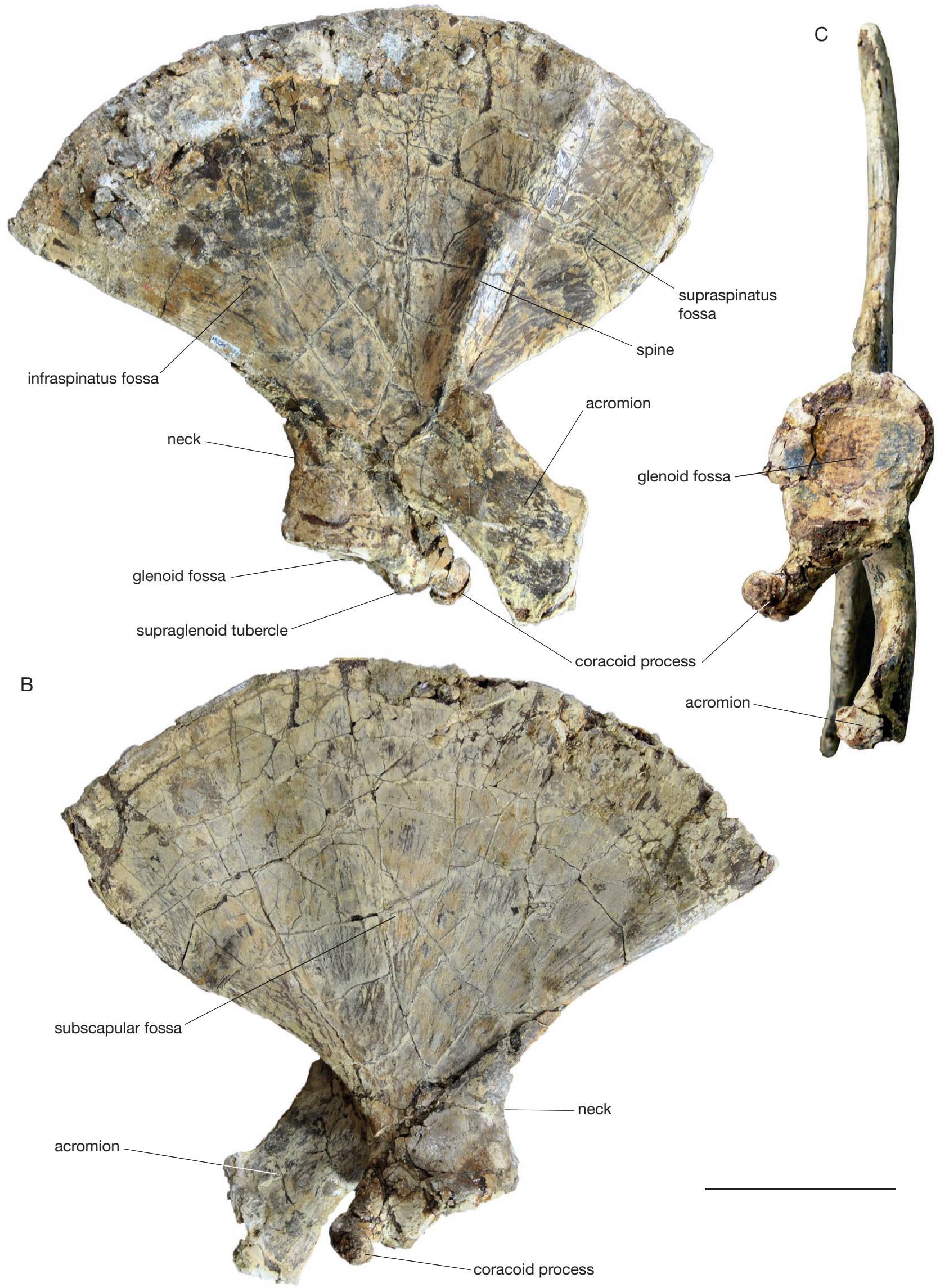

FIG. 41. - Mystacodon selenensis (MUSM 1917, holotype). Right scapula: A, lateral view; B, medial view; C, distal view. Scale bar: $10 \mathrm{~cm}$. 


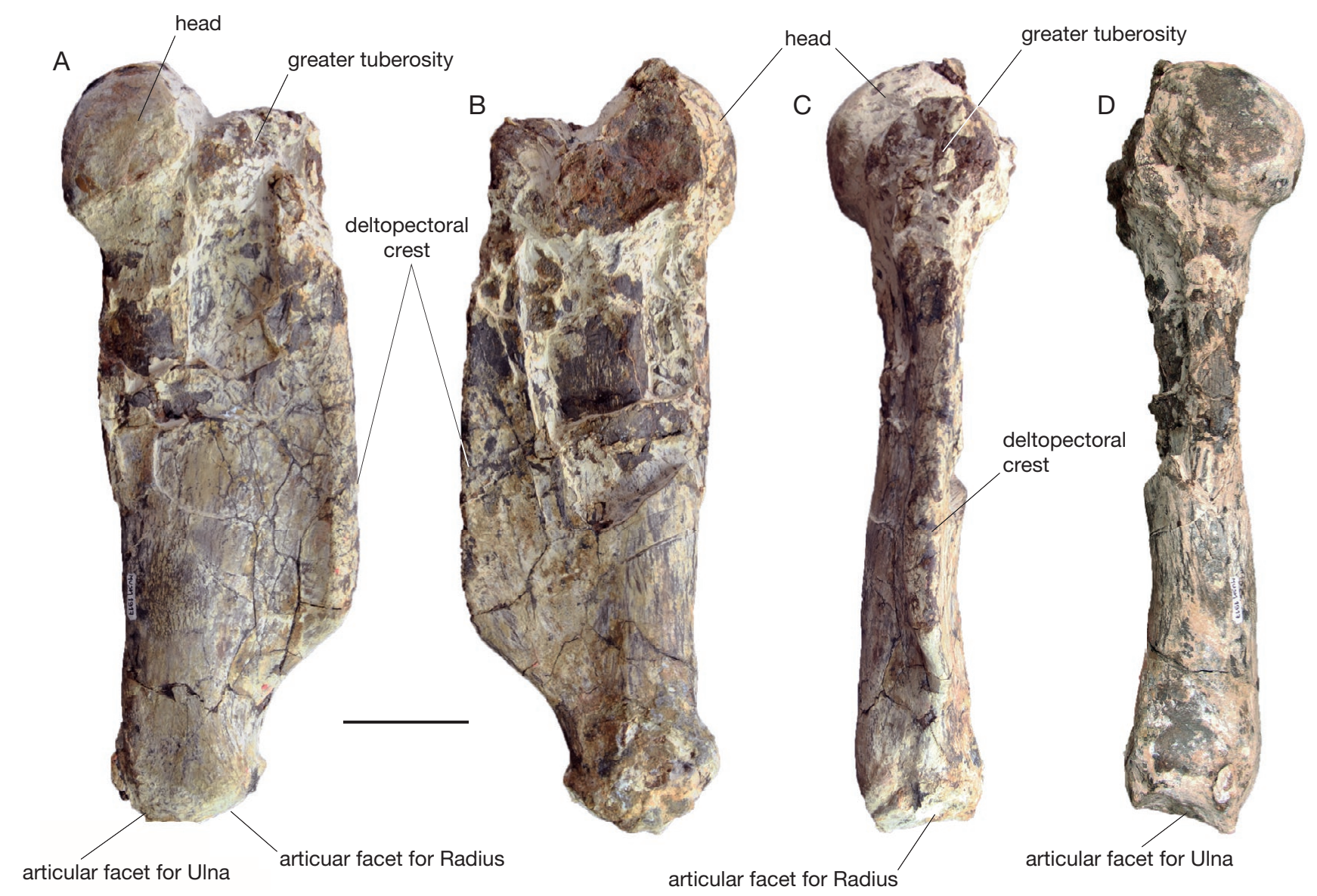

FIG. 42. - Mystacodon selenensis (MUSM 1917, holotype). Right humerus: A, lateral view; B, medial view; C, anterior view; D, posterior view. Scale bar: 5 cm.

(e.g. Phocoenoides dalli [Andrews 1911] and Albireo whistleri [Barnes 2008]), A striking feature of the acromion of Mystacodon is the strong distal projection of the process, which forms an angle of $c .115^{\circ}$ with the proximal portion of the spine. In other words, the acromion is almost aligned with the posterior edge of the scapula. This condition is very similar to that of Dorudon (in which the angle is even greater, at $c .130^{\circ}$; see Uhen 2004: fig. 98), but differs from that in other basilosaurids, in which the acromion is generally set at an angle close to $90^{\circ}$ with the spine and at an angle of $c .150^{\circ}-160^{\circ}$ with the posterior edge of the scapula (e.g. Basilosaurus, Chrysocetus, and Cynthiacetus; see Kellogg 1936; Uhen \& Gingerich 2001; Martínez-Cáceres et al. 2017). In other mysticetes, the acromion never projects distally as it does in Mystacodon and Dorudon. The size of the acromion of Mystacodon suggest a powerful deltoideus, an abductor and extensor of the shoulder

On the posterior edge of the large infraspinatus fossa, a low ridge extends from the distal base of the acromion to the vertebral border of the scapula at about $5 \mathrm{~cm}$ from the posterior angle of the bone. This ridge delimitates a shallow fossa, which is likely to have received the origin of the teres major muscle. This fossa closely resembles in size and morphology that observed in basilosaurids (e.g. Basilosaurus, Chrysocetus, and Dorudon).
The medial aspect of the scapula is a large and smooth subscapular fossa, which only presents large undulations corresponding to the attachment of the subscapularis muscle.

The distal region of the subscapular fossa meets the neck of the scapula, which is short and wide as compared to that of Dorudon. The distal end of the scapula bears the glenoid cavity for the scapulo-humeral articulation. The articular facet is moderately concave and faces conspicuously posteroventrally. In lateral view, the long axis of the facet (line joining the anterior and posterior edges) is at an angle of approximately $30^{\circ}$ with the anteroposterior axis of the scapular blade (line joining the anterior and posterior angles). A similar angle is observed in basilosaurids (e.g. Basilosaurus, Cynthiacetus, and Dorudon). Such an angle is present in basal chaeomysticetes (e.g. Yamatocetus), while a very small angle is observed in the Miocene chaeomysticetes Piscobalaena and Thinocetus (Kel$\operatorname{logg} 1965$; Bouetel \& Muizon 2006). Instead the two lines are approximately parallel in the Miocene balaenopteroid Pelocetus and in the extant mysticetes (e.g. Balaena, Balaenoptera, and Megaptera).

At the anterior edge of the glenoid fossa is a robust coracoid process, which is strongly recurved medially. It differs from the slightly recurved process of Cynthiacetus and from the straight and anteriorly projecting process of Basilosaurus, Dorudon, and Yamatocetus. Posterodistal to the coracoid 


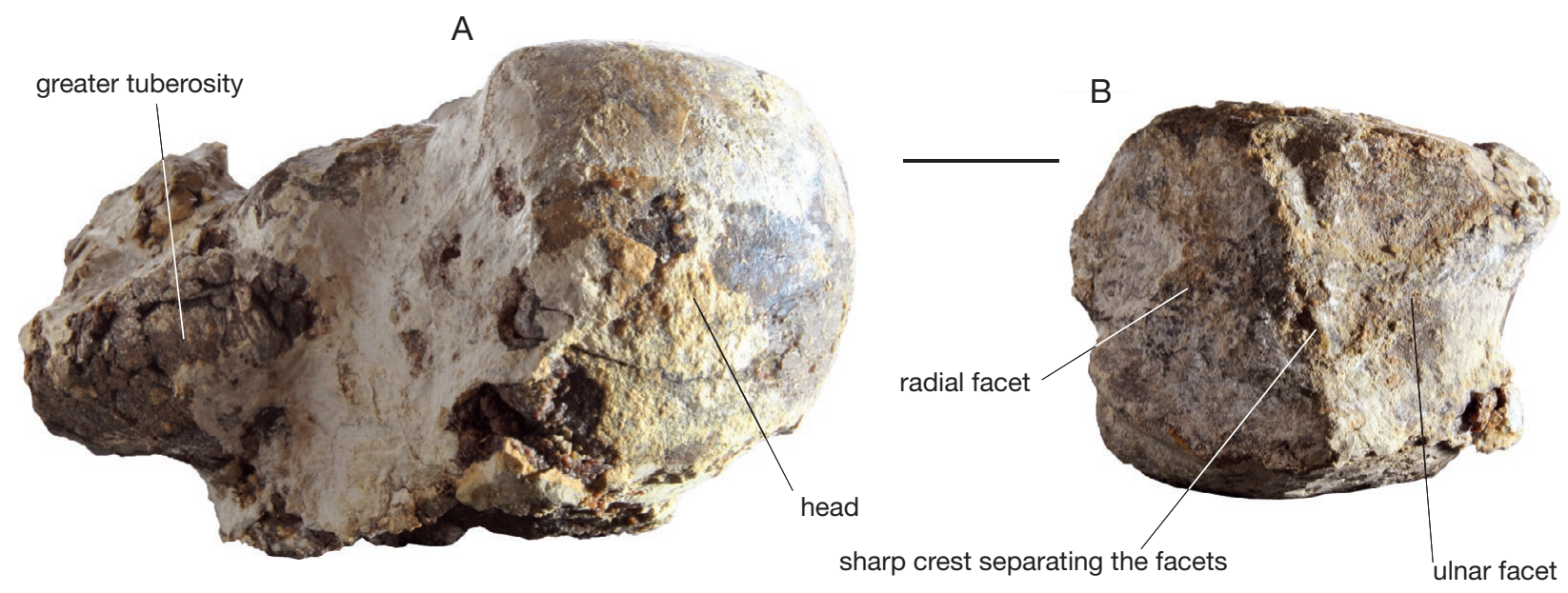

FIG. 43. - Mystacodon selenensis (MUSM 1917, holotype). Right humerus: A, proximal view; B, distal view. Scale bar: $2 \mathrm{~cm}$.

process, at the anterior edge of the scapulohumeral facet, is a moderately developed supraglenoid tubercle, for the origin of the biceps brachii muscle. This tubercle resembles the condition observed in basilosaurids, and is apparently more developed than in Yamatocetus.

On the posterior edge of the glenoid fossa, the attachment area for the triceps brachii caput longum is a well-developed isosceles triangle, whose base is an arc of approximately $45^{\circ}$ of the scapulohumeral facet.

Humerus (Figs 42; 43). Both humeri of the holotype of Mystacodon selenensis are known but none of them is perfectly preserved. The right humerus is missing the lesser tuberosity and the left is seriously crushed in its proximal region.

As in all Pelagiceti (Basilosauridae + Neoceti), the bone is short and massive. As evidenced on Table 10, the humerus of Mystacodon is more massive than those of basilosaurids, but it is slightly more slender than that of Yamatocetus.

The humerus of Mystacodon selenensis retains some plesiomorphic features of basilosaurids (well-developed deltopectoral crest and well-individualized tuberosities), but also presents key synapomorphies of the Neoceti such as the ankylosis of its distal articulation (elbow).

Because of its inadequate preservation, description and comparison of the proximal part of the bone is difficult. However, it is possible to observe that the bone is distinctly flattened mediolaterally, as in Yamatocetus and geologically younger chaeomysticetes. The humeral head is as convex as in Cynthiacetus, more so than in Yamatocetus, and it is oriented posteroproximally. The proximal component is subequal to slightly greater than the posterior component. It is is less pronounced than in Yamatocetus. As in the latter genus, the neck is more attenuated than in Cynthiacetus. The deltopectoral crest is long and extends farther distally than in basilosaurids and Yamatocetus. In Mystacodon the deltopectoral crest extends until the distal quarter of the humerus, whereas in basilosaurids it reaches the distal third, in Yamatocetus slightly more than the distal half, and in Piscobalaena and Incakujira, it remains on the proximal half of the humerus, as in most Neogene and extant
TABLE 10. - Proportions of the humerus in several basilosaurids and basal mysticetes. Abbreviations: L, maximum proximodistal length of the humerus; $\mathbf{W}$, width of the diaphysis at mid-length of the deltopectoral crest; e, estimated measurements. This measurement of the width has been selected in order to reduce the impact of the anteriorly very salient distal end of the deltopectoral crest in some basilosaurids, especially Dorudon. This feature is absent in the basal mysticetes taken into account, and the width of the diaphysis measured at the distal end of the deltopectoral crest would have increased the width in basilosaurids and would have provided an artificially increased robustness index in the latter. Color code: grey, basilosaurids; green, toothed mysticetes; blue, chaeomysticetes.

\begin{tabular}{lccc}
\hline & Length & $\begin{array}{c}\text { Width of } \\
\text { proximal } \\
\text { diaphysis }\end{array}$ & W/L \\
\hline Taxon & 265 & 66.5 & 0.25 \\
\hline $\begin{array}{l}\text { Dorudon atrox (UM 101222) } \\
\text { Cynthiacetus peruvianus } \\
\text { (MNHN.F.PRU10) }\end{array}$ & 322 & 77 & 0.24 \\
$\begin{array}{c}\text { Chrysocetus healyorum } \\
\text { (SCSM 87.195) }\end{array}$ & 175.3 & 50 & 0.28 \\
\hline $\begin{array}{l}\text { Mystacodon selenensis } \\
\text { (MUSM 1917) }\end{array}$ & $320 \mathrm{e}$ & 103 & 0.32 \\
$\begin{array}{l}\text { Yamatocetus canaliculatus } \\
\text { (KMNH VP 000,017) }\end{array}$ & 177 & 61 & 0.34 \\
\hline
\end{tabular}

mysticetes. However, the deltopectoral crest extends slightly on the distal half of the bone in some Miocene taxa (e.g. Pelocetus and Thinocetus). The length of the deltopectoral crest in Mystacodon is probably related to more powerful movements of the shoulder in this taxon relative to other mysticetes and Basilosaurids. It corroborates the robustness of the deltoideus muscle as hypothesized in the scapula section on the basis of the large size and orientation of the acromion. The length of the deltopectoral crest also indicate a larger insertion of the pectoralis muscle, a powerful adductor of the forelimb. In anterior view, the deltopectoral crest of Mystacodon is straight. In this respect, it differs from the condition in basilosaurids, in which the deltopectoral crest is strongly bent laterally in its median region, but it resembles the condition of Yamatocetus, which has a straight crest. The posterior edge of the diaphysis is straight, whereas it is markedly salient and convex posteriorly in Cynthiacetus, Dorudon, and Yamatocetus. 


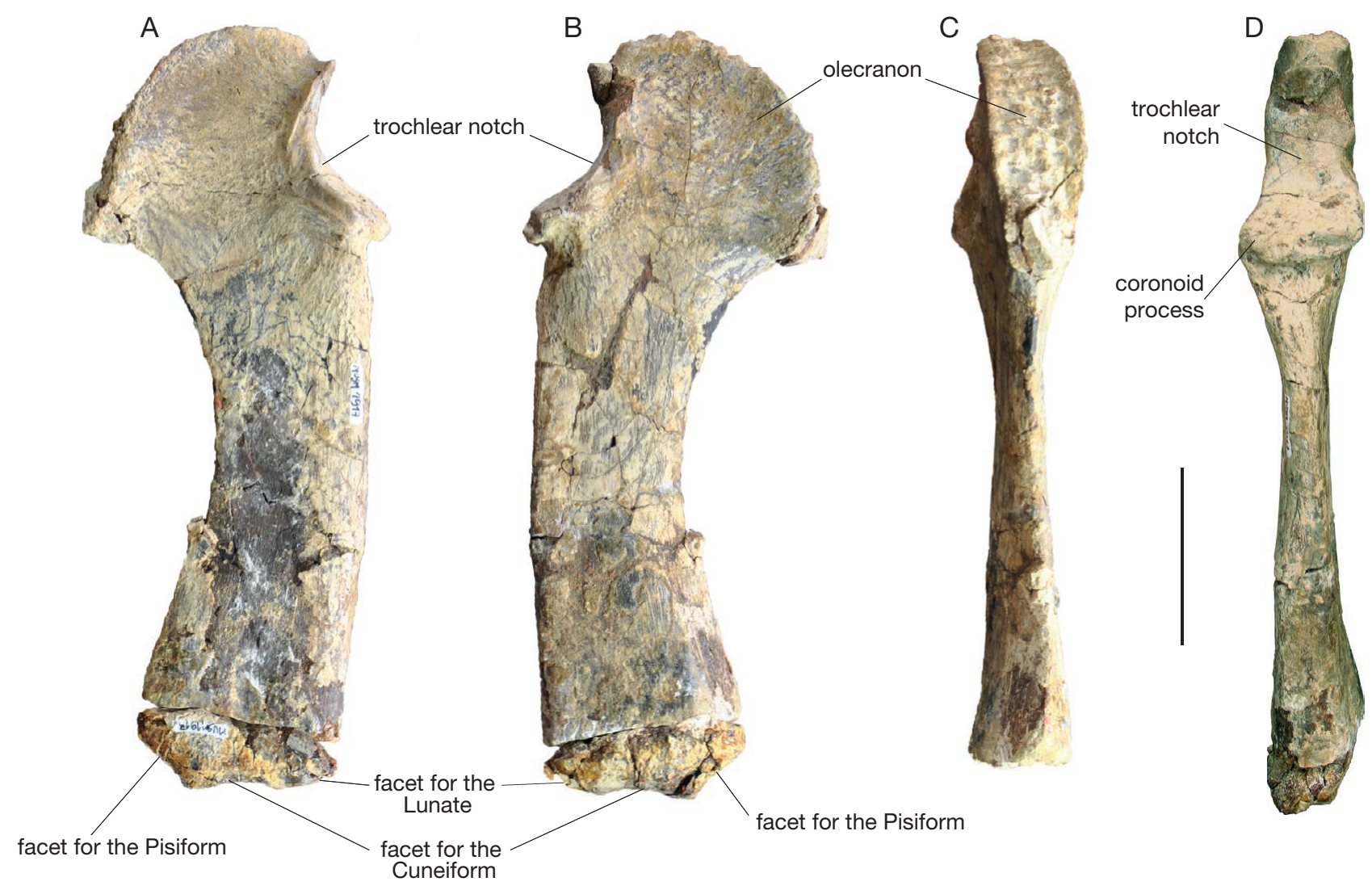

FIG. 44. - Mystacodon selenensis (MUSM 1917, holotype). Left ulna: A, medial view; B, lateral view; C, posterior view; D, anterior view. Scale bar: 5 cm.

The distal epiphysis bears two distinct articular facets for the ulna and the radius. The facets draw an angle of approximately $105^{\circ}$, which prevented mobility of the elbow; an angle between the two facets is similarly observed in Yamatocetus and all other neocetes for which this bone is preserved (with the possible exception of the stem odontocete Mirocetus; Sanders \& Geisler 2015). All basilosaurids have a single saddle-shaped functional trochlea on the distal articular facet of the humerus, which indicates some degree of mobility (at least flexion/extension) of the elbow joint (Uhen 2004; Martínez-Cáceres et al. 2017).

Ulna (Figs 44; 45). Noteworthy aspects of the ulna of Mystacodon concern its length and the morphology of the olecranon process. The ulna of Mystacodon is short as compared to other mysticetes and clearly resembles, in this respect, the ulna of basilosaurids. It is in fact proportionally even shorter than in some basilosaurids (Basilosaurus and Cynthiacetus) and departs significantly from the other mysticetes as shown in Table 11.

As in most Pelagiceti, the olecranon of Mystacodon is enlarged and its distal edge (at the proximal extremity of the bone) is long and forms an arc. The olecranon of Mystacodon is proximodistally shorter and its distal arc of circle is longer than in basilosaurids (e.g. Cynthiacetus and Dorudon). However, the enlargement of the olecranon arc is less marked than in the early chaeomysticete Yamatocetus, but also than in later taxa such as Pelocetus and Thinocetus. This enlargement is especially pronounced in Pelocetus and Yamatocetus, in which the pos- terodistal corner of the olecranon markedly extends distally, well beyond the level of the distal edge of the trochlear notch. In Mystacodon this corner is at the level of the distal edge of the trochlear notch. Because of this distal extension of the posterodistal corner of the olecranon, in chaeomysticetes with a well-developed olecranon (e.g. Balaenoptera siberi, Incakujira, Pelocetus, and Yamatocetus), the distal edge of the process forms a deep notch and a marked angle (generally an acute angle) with the posterior edge of the diaphysis. In Mystacodon the posterior edges of the diaphysis and of the olecranon do not bear a notch, but form a regular and smooth curve as is observed in basilosaurids.

Transversely, at its apex, the olecranon is approximately as wide as the proximal region of the trochlear notch. This condition departs from that of basilosaurids (e.g. Dorudon or Cynthiacetus), in which the olecranon is thin and distinctly narrower than the proximal trochlear notch. This morphology in Mystacodon indicates a robust attachment of the tendon of the triceps brachii, caput longum, which originates on the distal region of the posterior edge of the scapula (Schulte 1916; Evans \& de Lahunta 2013). Because of the ankylosis of the elbow (see below) in Mystacodon, the action of the triceps is restricted to a flexion of the shoulder. Therefore, robust capacity of flexion of the shoulder corroborates the powerful extension suggested by the length and orientation of the acromion on the scapula and by the long distal extension of the deltopectoral crest on the humerus. 
TABLE 11. - Proportions of the ulna of Mystacodon selenensis as compared to basilosaurids and some chaeomysticetes. Abbreviations: L, total length of the ulna not including the distal epiphysis, which is often missing in fossil specimens; W, width of the diaphysis at mid-length. Color code: grey, basilosaurids; green, toothed mysticetes; blue, chaeomysticetes.

\begin{tabular}{lccc}
\hline Taxon & W & L & W/L \\
\hline Cynthiacetus peruvianus (MNHN.F.PRU10) & 48 & 252 & 0.19 \\
Dorudon atrox (UM 101222) & 58 & 219 & 0.26 \\
Basilosaurus cetoides (USNM 4675) & 63 & 334 & 0.19 \\
\hline Mystacodon selenensis (MUSM 1917) & 48 & 206 & 0.23 \\
\hline Yamatocetus canaliculatus & 46 & 269 & 0.17 \\
$\quad$ (KMNH VP 000,017) & & & \\
Pelocetus calvertensis (USNM 23059) & 52 & 426 & 0.12 \\
Thinocetus arthritus (USNM 23794) & 55 & 397 & 0.138 \\
Incakujira anillodefuego (GNHM Fs-098-12) & 75 & 519 & 0.14 \\
Piscobalaena nana (MNHN.F.SAS892) & 41 & 263 & 0.15 \\
\hline
\end{tabular}

TABLE 12. - Proportions of the radius of Mystacodon selenensis as compared to basilosaurids and some chaeomysticetes. Abbreviations: Wd, maximum anteroposterior width at distal extremity of the radius; $\mathbf{L}$, maximum length of the radius (including distal epiphysis); e, estimated measurements. Note: when the epiphysis was missing, a correction has been applied on the basis of the proportion of the length of radius without distal epiphysis vs length of distal epiphysis in Incakujira and Yamatocetus. The average of the correction in the two taxa is 0.066 . Color code: grey, basilosaurids; green, toothed mysticetes; blue, chaeomysticetes.

\begin{tabular}{lrlc}
\hline Taxon & Wd & L & Wd/L \\
\hline Cynthiacetus peruvianus (MNHN.F.PRU10) & 43 & 221 & 0.19 \\
Dorudon atrox (UM 101222) & 48 & 193 & 0.25 \\
Basilosaurus cetoides (USNM 4675) & 54 & $266 e$ & 0.20 \\
\hline Mystacodon selenensis (MUSM 1917) & 62 & 187 & 0.33 \\
\hline Yamatocetus canaliculatus & 55 & 217 & 0.25 \\
$\quad$ (KMNH VP 000,017) & & & \\
Pelocetus calvertensis (USNM 23059) & 48 & $422 e$ & 0.21 \\
Thinocetus arthritus (USNM 23794) & 88 & $410 \mathrm{e}$ & 0.21 \\
Incakujira anillodefuego (GNHM Fs-098-12) & 141 & 543 & 0.26 \\
Piscobalaena nana (MNHN.F.SAS1617) & 65 & 247 & 0.26 \\
\hline
\end{tabular}

The olecranon of Mystacodon extends posteroproximally from the diaphysis of the ulna, with a greater proximal component, as in basilosaurids, and differs from the condition of chaeomysticetes, in which it is oriented more posteriorly than proximally.

The trochlear notch is deeply excavated and its anterodistal part is conspicuously wider than the posteroproximal part, as is observed in Cynthiacetus.

The distal epiphysis was not fused to the diaphysis. The former bears anteriorly a relatively short facet for the lunate, oriented anterodistally. Posteriorly, the facet for the cuneiform is roughly as large as that for the lunate, but it is oriented posterodistally. Posterior to the facet for the cuneiform is a smaller facet, likely for the pisiform.

Radius (Fig. 46). The radius of Mystacodon is a short bone, corresponding to the shortness of the ulna. It is markedly more massive than in Cynthiacetus and the chaeomysticetes taken into account in Table 8, with a wide and stout distal extremity. Noteworthy is the relative similarity between basilosaurids and chaeomysticetes considered in Table 12 for the robustness of the radii.

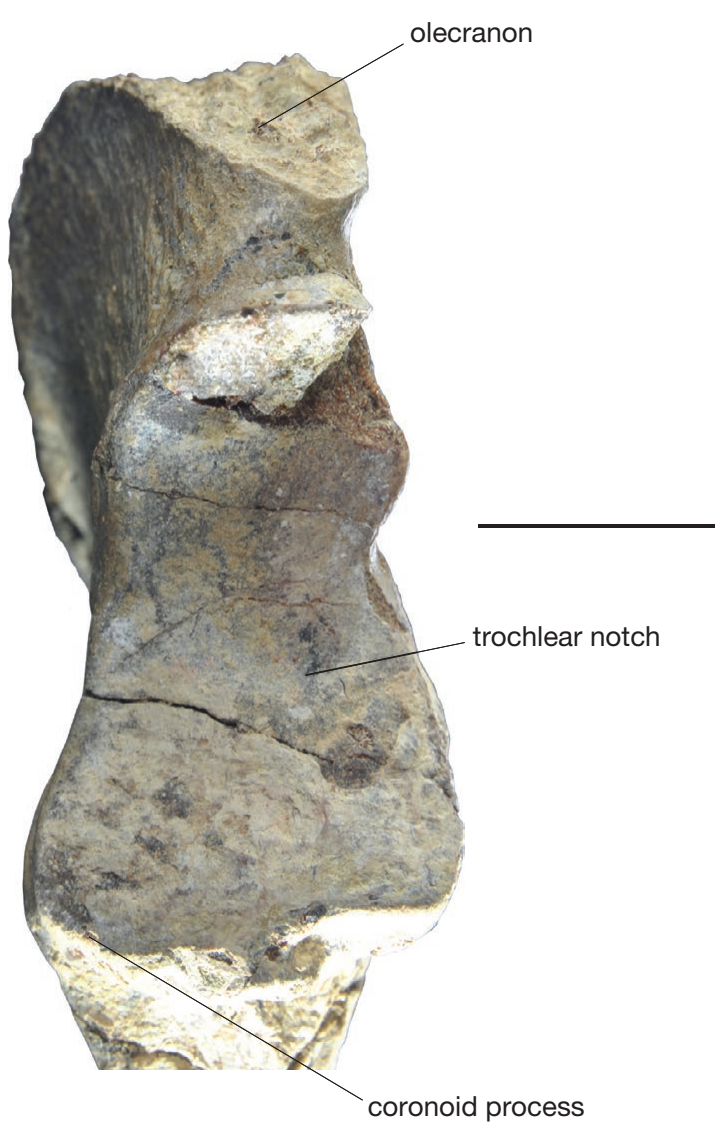

FIG. 45. - Mystacodon selenensis (MUSM 1917, holotype). Left ulna: anteroproximal view of the humeral articulation. Scale bar: $2 \mathrm{~cm}$.

The radius of Mystacodon is markedly bent posteriorly, more so than in chaeomysticetes and even than in basilosaurids. The most striking feature of the radius of Mystacodon is the great size and massiveness of an anteroproximally projecting process on the anterior radial crest. Proximally this process ends abruptly approximately at the proximal quarter of the bone. Distally, it gradually reduces in height and thickness, and extends as a low radial crest until a level slightly more distal than mid-length of the radius. Such a process is unknown in any other Pelagiceti. Basilosaurids show a conspicuous angulation on the anterior edge of the radial crest, but which does not approach in any way the condition of the process observed in Mystacodon. An even weaker angulation is observed in chaeomysticetes, being somewhat more developed, however, in the basal eomysticetid, Yamatocetus. In basilosaurids, the protruding angulation of the radial crest probably received the insertion or the brachialis muscle, a flexor of the forearm which originates on the lateral aspect of the proximal region of the humeral diaphysis, just distal to the head and greater tubercle (Uhen 2004). Therefore, this muscle is a strict flexor of the elbow. One could therefore infer similar origin and insertion of the brachialis in Mystacodon. However, such an inference would be conflicting with the unambiguous ankylosis of the elbow as indicated by the strong angulation between the ulnar and radial facets on the distal epiphysis of the humerus (see discussion below). 

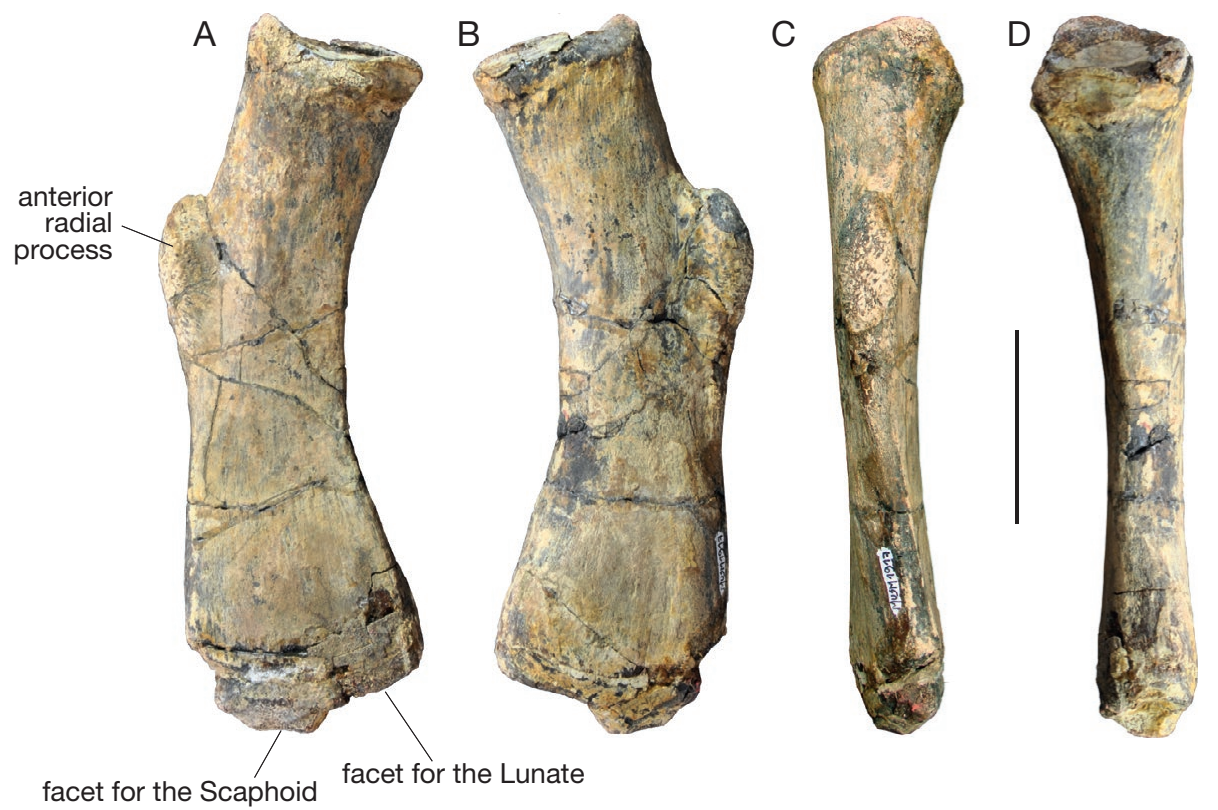

FIG. 46. - Mystacodon selenensis (MUSM 1917, holotype). Left radius: A, lateral view; B, medial view; C, anterior view; D, posterior view. Scale bar: 5 cm

The distal epiphysis of the radius bears two articular facets: a large posterior facet for the lunate and a smaller anterior facet for the scaphoid.

Carpus (Fig. 47). Six different carpal bones are preserved. All these bones bear functional articular facets, as in basilosaurids, and contrasting with the carpal bones of all extant chaeomysticetes, which have lost their articular facets, are embedded in cartilage, and are connected by synchondroses (e.g. Cooper et al. 2007a, b). Because the carpal bones of the holotype of Mystacodon selenensis have not been found articulated, their determination is not easy. As a matter of fact, there exists no published articulated carpus of any basal mysticete and the carpus has only been described for two basilosaurids: Dorudon atrox (Uhen 2004) and Cynthiacetus peruvianus (Martínez-Cáceres et al. 2017). Additionally, two carpal bones of Zygorbiza kochii have been referred by Kel$\operatorname{logg}(1936)$ to an unciform and a magnum. In the case of the holotype of M. selenensis, another difficulty is to determine the side, right or left, to which the preserved bones pertain.

Apparently, most of the carpals of Mystacodon are preserved except the trapezium. Fig. 47 presents a possible arrangement of the carpal and metacarpal bones of Mystacodon; however, given the great mediolateral symmetry of the cetacean carpal bones, this reconstruction may represent a mix of left and right carpals.

As a whole the carpus of Mystacodon is very similar to that of Dorudon and Cynthiacetus. However, the pisiform is more massive than that of Dorudon, being distinctly shorter and wider, and almost quadrate. The lunate has a short articular facet with the ulna and its facet with the radius is approximately three times as long as the former. This condition resembles that of Cynthiacetus, but differs from that of Dorudon, in which both facets are similar in size (in lateral view). The lunate of
Mystacodon also resembles that of Cynthiacetus in being much shorter proximodistally than that of Dorudon. The scaphoid has a subcircular lateral aspect as in Dorudon; it is more ovaleshaped in Cynthiacetus. On the distal carpal row the unciform has the same pentagonal morphology as observed in Cynthiacetus and Dorudon, and articulates with the cuneiform and lunate proximally and with the magnotrapezoid anteriorly. As in Dorudon and Cynthiacetus, the magnum and trapezoid are fused, a condition that differs from that of the protocetids Rodhocetus and Maiacetus, in which the two bones are separated (Gingerich et al. 2001, 2009). The magnotrapezoid articulates proximally with the lunate (posteriorly) and with the scaphoid (anteriorly). It articulates posteriorly with the unciform and distally with the McIII (posteriorly) and with the MCII (anteriorly). In protocetids the McII articulates with the trapezoid proximally.

Metacarpus and Phalanges (Fig. 47). Five metacarpals of Mystacodon are preserved. They are slightly more massive than those of Cynthiacetus and Dorudon, especially the Mc V, which is longer than in these basilosaurids. The first metacarpal is much smaller and more slender than the four others, as is observed in Dorudon. A major difference with Dorudon is in the Mc I. Although this bone is incomplete in the holotype of Mystacodon selenensis and lacks its proximal epiphysis, it preserves its distal epiphysis. In this respect, it differs from the condition of Dorudon, in which the Mc I tapers distally with no possible articulation with a phalanx (Uhen 2004). A small and slender phalanx has been recovered, which apparently articulates with the Mc I of Mystacodon and is far too small to fit any other metacarpal of the specimen. If our interpretation is correct, Mystacodon would thus be more generalized than Dorudon in this respect and would resemble the primitive condition of protocetids (Maiacetus and Rodhocetus), in which 
digit I is complete with one metapodial and two phalanges (Gingerich et al. 2001, 2009).

Only four phalanges are known. The slender phalange mentioned above has been referred to digit I. Two others (proximal and middle phalanges) have been referred to digit III and a proximal phalanx slightly smaller than that of digit III has been referred to digit IV (it is too large to be referred to digits II and V). The phalanges of Mystacodon are markedly shorter and more massive than those of Dorudon and Cynthiacetus. The proximal phalanges of digits III and IV are slightly shorter that their respective metapodials, whereas they are distinctly longer in Dorudon and Cynthiacetus. Interestingly the condition of Mystacodon closely resembles in this respect that of Maiacetus and Rodhocetus. This condition in Mystacodon indicates a more robust hand in general than in basilosaurids. The similarity observed with these protocetids is especially interesting because the latter are partly terrestrial and certainly needed more robust phalanges than the fully aquatic basilosaurids (see below, feeding strategies of Mystacodon).

Innominate (Fig. 48). The left innominate of MUSM 1917 has been recovered. Innominates of mysticetes are extremely rare in the fossil record (e.g. Bouetel \& Muizon 2006; Gol'din 2014), and this specimen represents the first known pelvis bone of a basal neocete. It strongly resembles the innominate of basilosaurids (Lucas 1900; Kellogg 1936; Gingerich et al. 1990; Uhen \& Gingerich 2001) and drastically differs from that of modern cetaceans (Beneden \& Gervais 1880; Howell 1930a; Bouetel \& Muizon 2006; Gol'din 2014), in which it is generally reduced to a small rod-like bone. It also markedly differs from the pelvis of amphibious non-Pelagiceti cetaceans (e.g. the protocetids Georgiacetus, Natchitochia, and Rodhocetus), which has a morphology close to that of terrestrial mammals, with unreduced (or little reduced) ilium, ischium, and pubis, and a large obturator foramen (Uhen 2014; Bebej et al. 2016).

The innominate of Mystacodon is complete and better preserved than in most basilosaurids for which this bone is known (Basilosaurus cetoides, Chrysocetus, and Cynthiacetus). Because no other basal mysticete innominate is known, comparisons will be done with the three partial basilosaurid innominates so far described. In the comparison below the pelvis of Basilosaurus and Chrysocetus will be oriented following the interpretation of Martínez-Cáceres et al. (2017). The pelvis interpreted by Gingerich et al. (1990) and Uhen \& Gingerich (2001) as the right is regarded here as being the left (and vice versa). In this respect, we follow Kellogg (1936) on the orientation and laterality of the pelves of Basilosaurus cetoides (USNM 12261). On the basis of their interpretation Gingerich et al. (1990) and Uhen \& Gingerich (2001) proposed a particular rotation of the basilosaurid pelvis, where the ilium is posterodorsally oriented and the pubic symphysis is anteroventrally located. Given our different interpretation of the left and right pelves this reconstruction is not followed here; no evidence for a rotation of the innominate is observed in the holotype of Mystacodon selenensis and we use the same orientation as in living cetaceans, where the ilium is anterior and the ischium and the pubis are posterior.

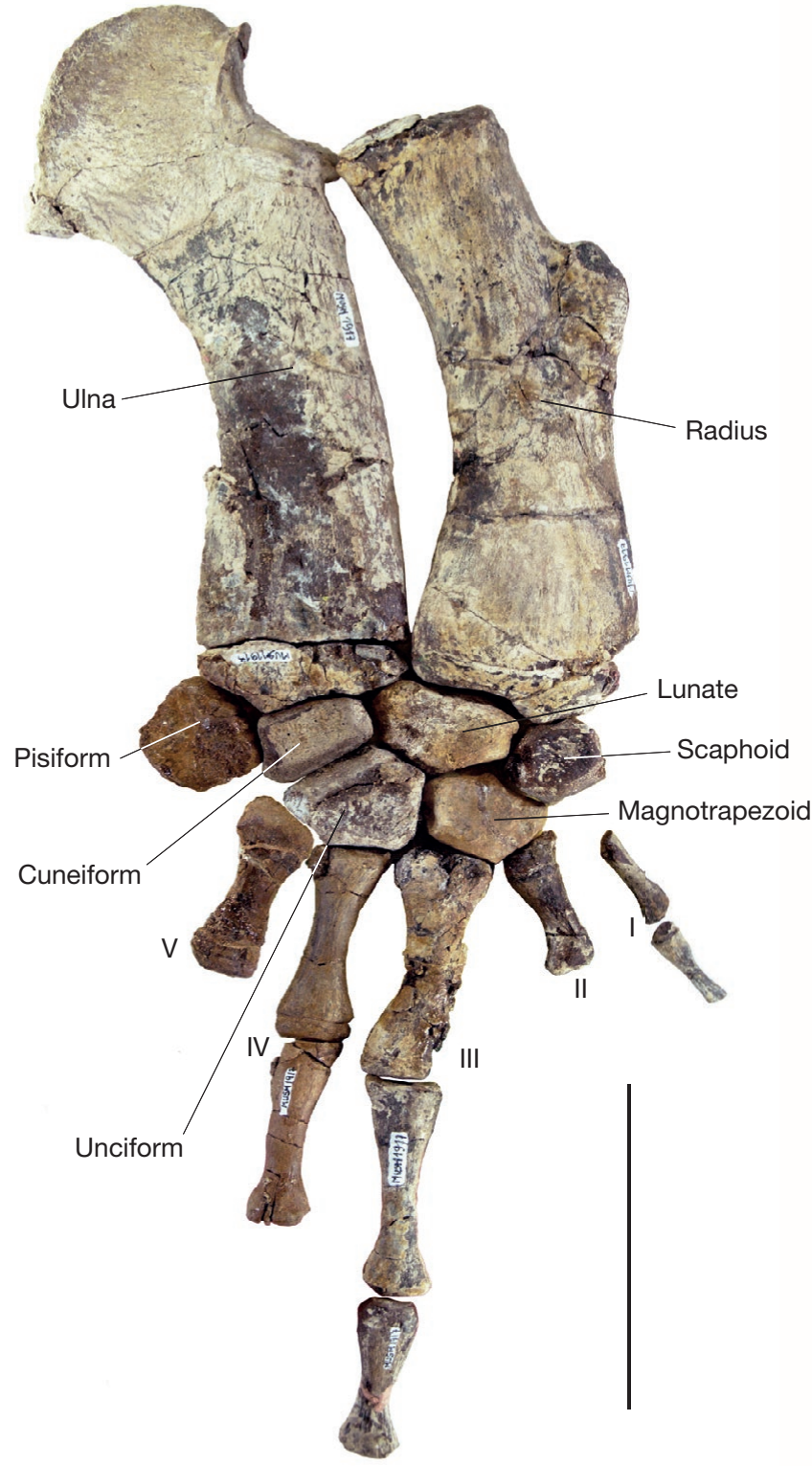

FIG. 47. - Mystacodon selenensis (MUSM 1917, holotype). Left forearm and hand in medial view. Metacarpal $\mathrm{V}$ is the mirror image of right $\mathrm{McV}$, because the left one is missing. Scale bar: $10 \mathrm{~cm}$.

In overall size, the pelvis of Mystacodon is proportionally smaller than in any non-Pelagiceti cetacean (Gingerich et al. 1994, 2009; Hulbert 1998; Uhen 1999; Madar et al. 2002; Uhen 2014; Bebej et al. 2016). The bone is distinctly concave laterally and bears well-defined acetabulum and obturator foramen. As in Basilosaurus and Chrysocetus, the three pelvic bones (ilium, ischium, and pubis) of the innominate are identifiable, but strongly modified in Mystacodon. In lateral view, the innominate has a strongly convex ventral border and a slightly concave dorsal border. The three pelvic bones are fused in Mystacodon and contribute to the formation of a relatively deep acetabulum, as compared to that of Basilosaurus isis, but resembling that of Basilosaurus cetoides and Chrysocetus. This acetabulum received the head of a reduced femur, as in B. isis and Cynthiacetus peruvianus. Given the size and depth 


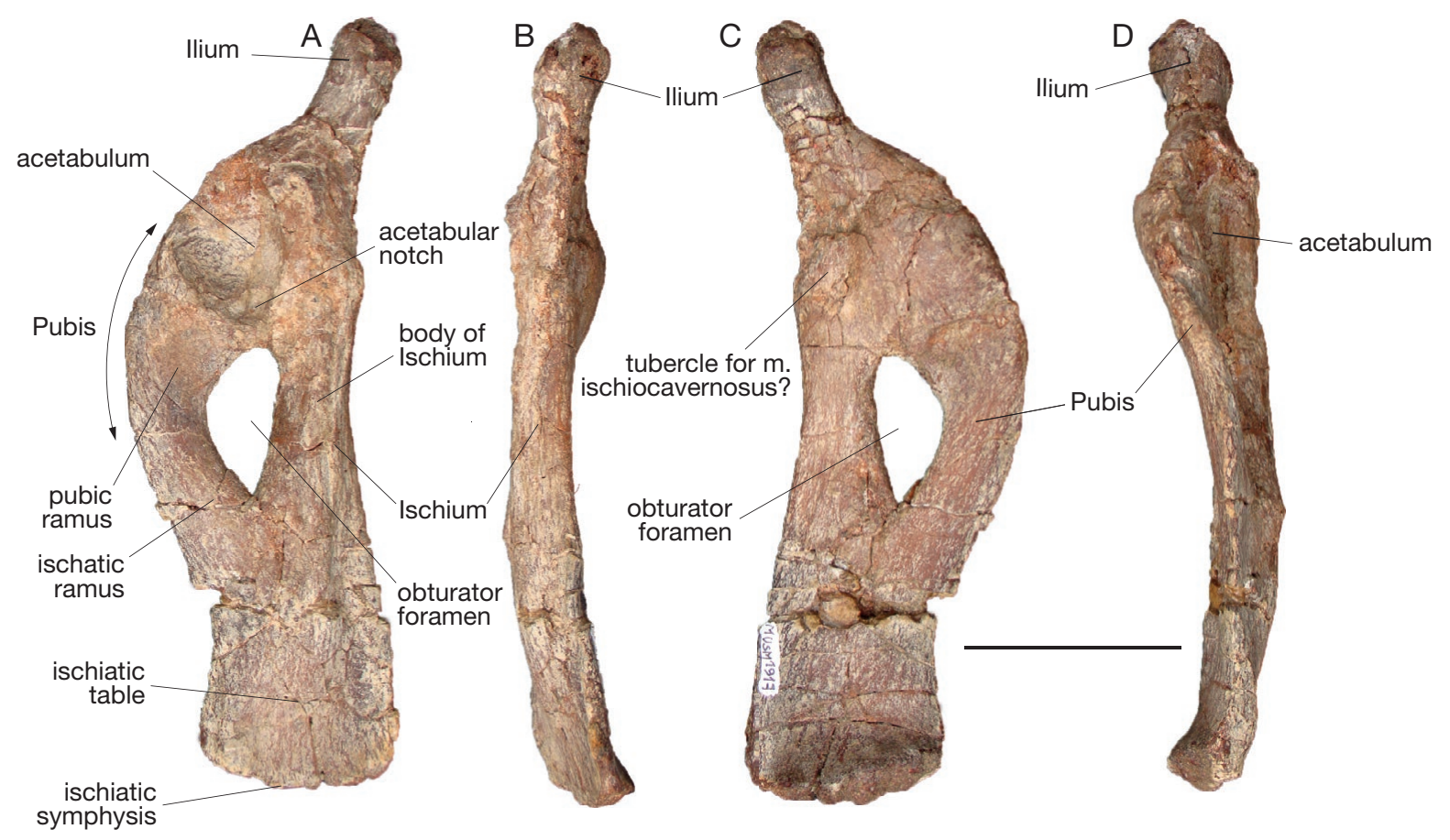

FIG. 48. - Mystacodon selenensis (MUSM 1917, holotype). Left innominate: A, lateral view; B, dorsal view; C, medial view; D, ventral view. Scale bar: 5 cm.

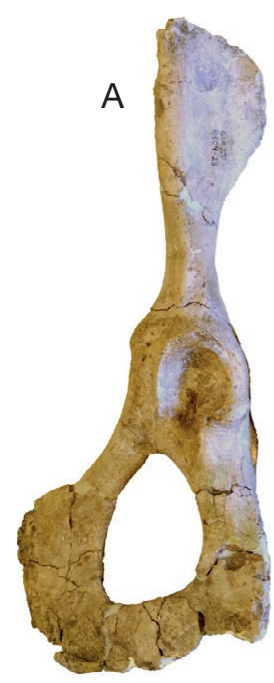

Georgiacetus

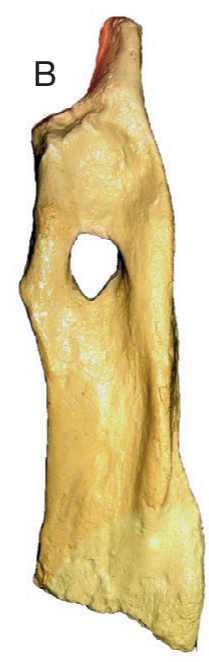

Basilosaurus isis

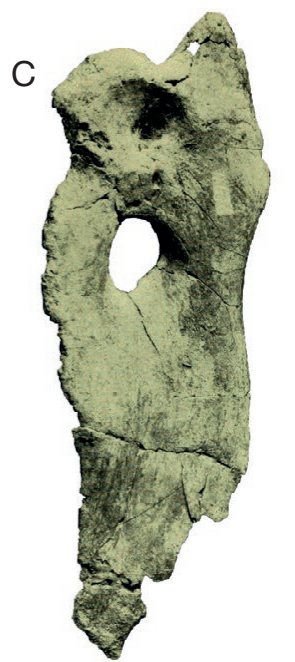

Basilosaurus cetoides

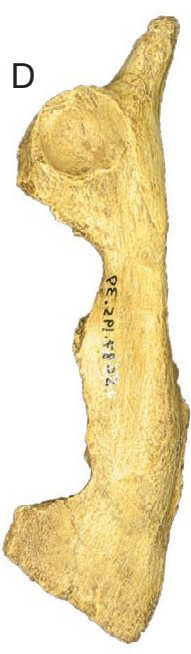

Chrysocetus

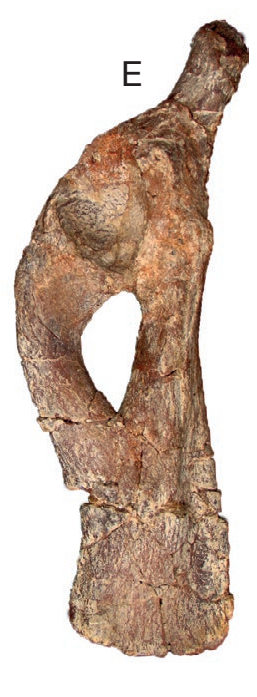

Mystacodon

FIG. 49. - Lateral view of innominate of some extinct cetaceans. A, Georgiacetus vogtlensis (GSM 350); B, Basilosaurus isis (CGM 42176, cast); C, Basilosaurus cetoides (USNM 12261); D, Chrysocetus healyorum (SCSM 87-195, cast, right innominate, reversed); E, Mystacodon selenensis (MUSM 1917). Not to scale.

of the acetabulum, it is likely that Mystacodon had a mobile articulation of the hip and an external hindlimb, as proposed for the aforementioned basilosaurids.

As in basilosaurids, the ilium is greatly reduced as compared to non-basilosaurid archaeocetes, and it is not splayed in a large triangular bone; it is a cylindrical and short process at the anterodorsal angle of the innominate. Therefore, in lateral view the ilium is dorsal to the dorsal margin of the acetabulum; a similar condition is observed in Chrysocetus and Basilosaurus cetoides (see
Kellogg 1936: fig. 25). The ilium of Basilosaurus isis described by Gingerich et al. (1990) is in a less dorsal position and is located in the anterodorsal region of the acetabulum. In lateral view, this iliac process of Mystacodon forms an angle of $155^{\circ}$ with the ischial ramus of the innominate (Fig. 48). In Chrysocetus and extant mysticetes, the iliac process similarly presents an anterodorsal orientation, while in Basilosaurus it is parallel to and in continuation with the ischial ramus of the innominate (Fig. 49). Since Chrysocetus has been suggested as the sister taxon of the neocetes 


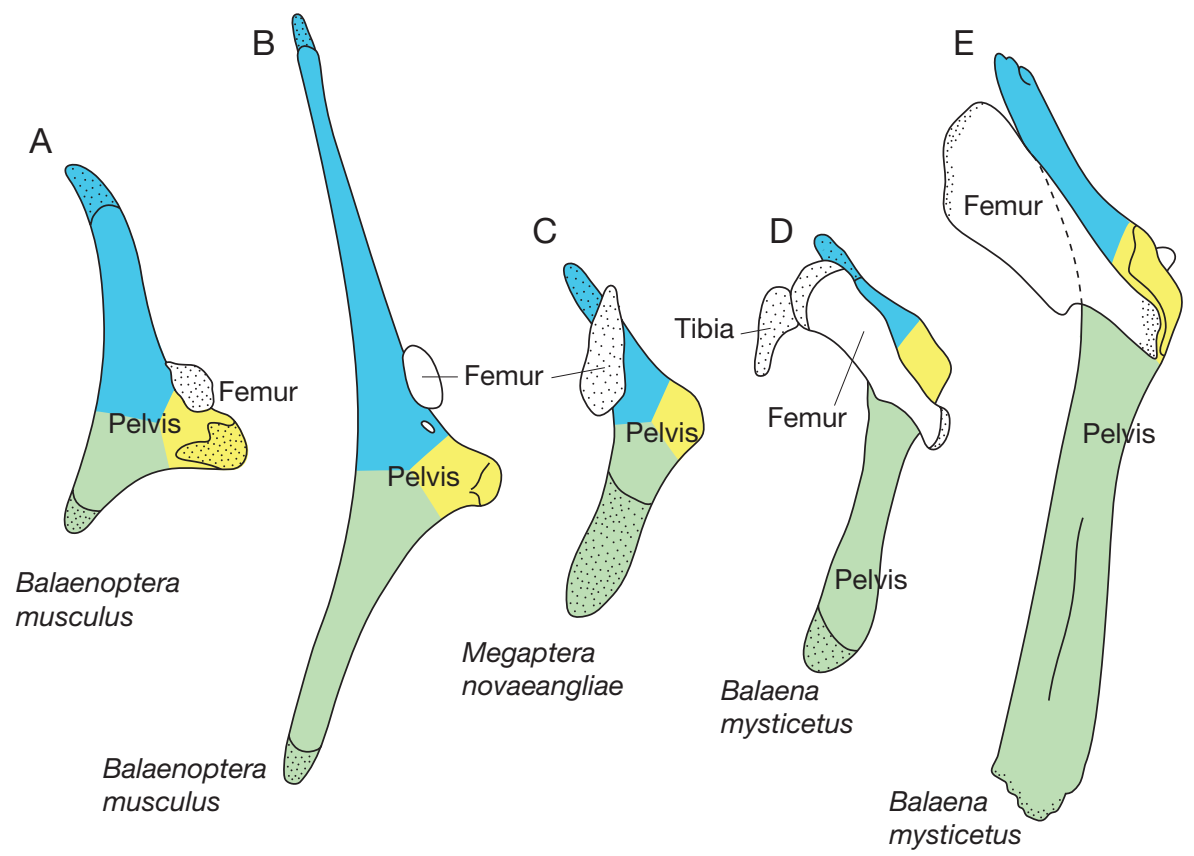

FIG. 50. - Lateral view of the right pelvic bones of some extant mysticetes. A, Balaenoptera musculus; B, Balaenoptera musculus; C, Megaptera novaeangliae; D, E, Balaena mysticetus. The iliac, pubic and ischial portions are, respectively, in blue, yellow and green. Modified from Struthers (1893).

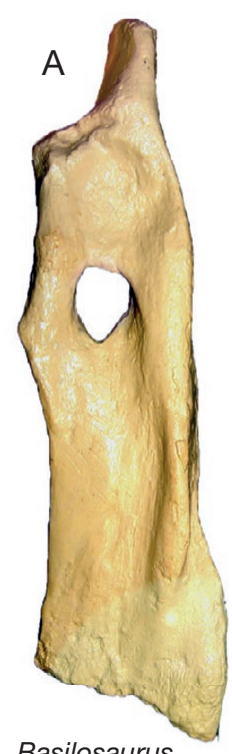

Basilosaurus

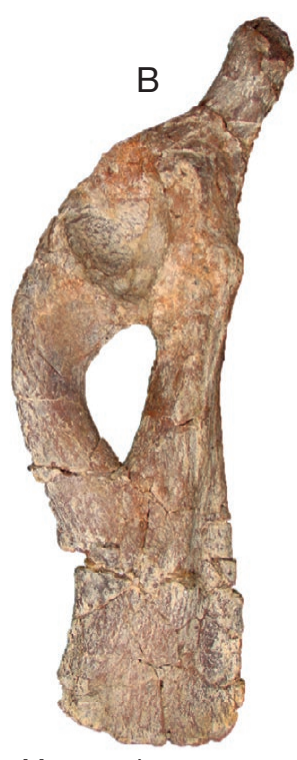

Mystacodon

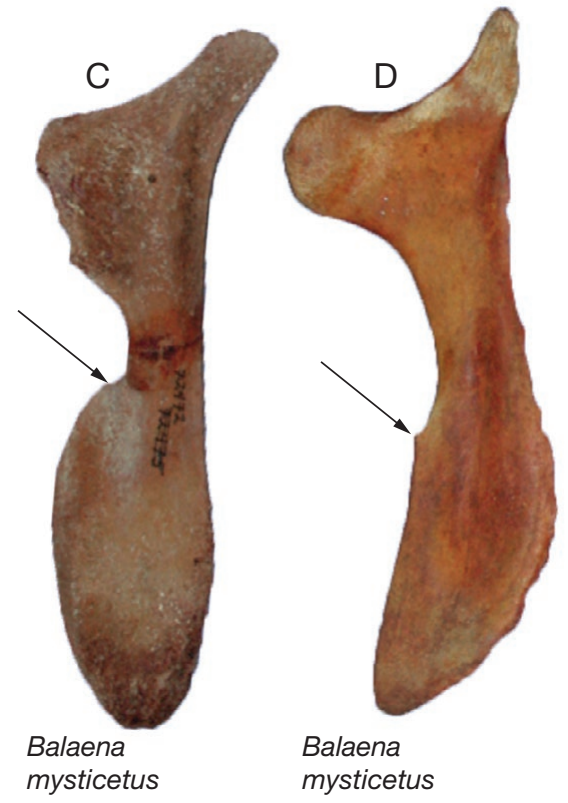

FIG. 51. - Lateral view of the left innominate of some extinct and extant cetaceans. A, Basilosaurus isis (CGM 42176, cast); B, Mystacodon selenensis (MUSM 1917); C, Balaena mysticetus (LACM 072472), young female; D, B. mysticetus (LACM 0722490), adult female. Arrows indicate the posterior end of the vestigial obturator foramen in B. mysticetus. Not to scale.

(Uhen \& Gingerich 2001, but see Martínez-Cáceres et al. 2017), the orientation of the iliac process shared by Chrysocetus, Mystacodon, and extant mysticetes may bear a phylogenetic signal.

In extant cetaceans, a portion of the internal abdominal muscular mass attaches on the ilium (Struthers 1881, 1888, 1893; Howell 1930b; Tajima et al. 2004). These muscles include part of the $M$. rectus abdominalis and part of the $M$. obliqus abdominalis (regarded as M. ilio-abdominis in Howell 1930a).
The ilium of MUSM 1917 probably should serve for similar muscular attachment.

As compared to other cetaceans, the iliac process of Mystacodon is markedly shorter than in protocetids (e.g. Georgiacetus vogtlensis; Fig. 49) and balaenopterids (e.g. Balaenoptera musculus; Fig. 50), and sub-equal in size to that in basilosaurids (e.g. Basilosaurus isis; Fig. 49) and balaenids (e.g. Balaena mysticetus; Fig. 51). 
Some general anatomical considerations of the ischiopubic relationships in terrestrial mammals are needed in order to interpret the morphology and condition of these bones in basilosaurids and Mystacodon. In terrestrial mammals (e.g. the dog, Evans \& de Lahunta 2013: 145 and figs 4-120), the pubis is made of three major parts, the body (1) from which extend the cranial ramus (2) anteriorly and the caudal ramus (3) posteriorly. The caudal ramus fuses with the opposite side to form the symphysis pubis, which is the anterior part of the symphysis pelvis. Posterior to the pubis, the ischium is formed of three elements. Posterolaterally a large plate, the ischiatic table (1) extends from the ischiatic tuberosity and the medial edge of the innominate. From the ischiatic table, the body (2) extends anterodorsally and borders dorsolaterally the obturator foramen to reach anteriorly the acetabulum. Anteroventromedially the ramus of the ischium (3) extends from the table, forms the posterior part of the ventromedial border of the obturator foramen, and joins the caudal ramus of the pubis. The ventromedial ischiopubic suture ossifies early in ontogeny and is located approximately mid-way anteroposteriorly on the ventral border of the obturator foramen. The left and right ischiatic rami join ventromedially to form the ischiatic symphysis, which form the posterior part of the pelvic symphysis. In non-Pelagiceti cetaceans (e.g. Ambulocetus, Georgiacetus, Maiacetus, Natchitochia, Pakicetus, and Rodhocetus; Uhen 2014; Bebej et al. 2016), the anterior edge of the pelvic symphysis is approximately at the level of the anterior edge of the obturator foramen, as is observed in terrestrial mammals. Therefore, the pelvic symphysis likely includes a conspicuous pubic component. In Pelagiceti (e.g. Basilosaurus, Chrysocetus, and Mystacodon), the anterior edge of the pelvic symphysis is so posterior to the obturator foramen that the former has to be an ischiatic symphysis, with no pubic component at all.

In Mystacodon, because of the absence of a pubic symphysis as explained above, the three parts of the pubis of terrestrial mammals are reduced to a single continuous pubic ramus, which extends from the posteroventral portion of the acetabulum anteriorly to the ramus of the ischium posteriorly. The pubic ramus is an arched and transversely compressed blade, which limits ventrally most of the obturator foramen. Its highest dorsoventral section is located at its anterior end, where it contacts the posteroventral margin of the acetabulum. Because the pubis and ischium are fused, there is no indication of a contact between the two bones. However, given the position of the ventral ischiopubic suture in immature terrestrial mammals (Barone 1976: pl. 313; Evans \& de Lahunta 2013: figs 4-122), approximately at the middle of the ventral edge of the obturator foramen, we estimate that it may have had a similar position in Mystacodon.

In lateral view, the obturator foramen of Mystacodon is teardrop-shaped, with the apex posteriorly oriented. It is limited ventrally by the ischiatic ramus posteriorly and by the pubic ramus anteriorly; it is limited dorsally by the body of the ischium. The obturator foramen is anteroposteriorly elongated, being more than twice longer than wide ( $\mathrm{L}=$
$35 \mathrm{~mm}$; W = $16 \mathrm{~mm}$ ). In Basilosaurus isis (CGM 42176, see Gingerich et al. 1990) the foramen is less elongated and approximately as wide as in Mystacodon (left: $\mathrm{L}=23.5$ $\mathrm{mm}$; W $=17.5 \mathrm{~mm}$; Right: $\mathrm{L}=27.5 \mathrm{~mm}$; $\mathrm{W}=16 \mathrm{~mm}$ ). Because the obturator foramen of Mystacodon is larger than in Basilosaurus, it is probable that, given what is mentioned above, the pubis was anteroposteriorly longer in the former. Furthermore, the pubis of Mystacodon is clearly wider and more massive than in Basilosaurus. In extant mysticetes, the pubis is vestigial or absent (Figs 50; 51), and, as a consequence, there is no obturator foramen. Therefore, Mystacodon interestingly appears to be less derived in this respect than Basilosaurus. At the anteroventral region of the acetabulum (formed by the pubis), the pelvis of Mystacodon lacks the well-developed prominence observed in both $B$. isis and $B$. cetoides, which probably served for the insertion of the perineal musculature or the $M$. quadratus lumborum. In extant cetaceans, part of the perineal musculature (M. puboventralis, $M$. levator ani) inserts on the ventral margin of the ischium (Howell 1930a, b), while in MUSM 1917, these muscles probably inserted on the ventral margin of the pubic ramus.

A well-defined acetabular notch is observed on the posterior edge of the acetabulum. It opens into the obturator foramen on its anterior margin, at the level of the suture of the acetabular portions of the ischium and pelvis. A smooth and shallow acetabular notch is present in Basilosaurus, but it is apparently absent in Chrysocetus.

The ischium forms more than the posterior half of the innominate. Anteriorly, it participates in the formation of the posterodorsal portion of the acetabulum and bears a prominent acetabular rim, which separates the acetabulum from the body of the ischium. At the anterior end of the ischiatic body, on its medial and dorsal surfaces, a strong protuberance possibly received the origin of the $M$. ischiocavernosum (M. erector penis). If correct, this would indicate that the holotype of Mystacodon selenensis is a male individual. The width (dorsoventral) of the ischiatic body progressively increases posteriorly until the posterior level of the posterior end of the obturator foramen, where it becomes continuous with the ischiatic table. The dorsal edge of the body is slightly concave dorsally and its ventral edge is straight and posteroventrally inclined.

The part of the ischium posterior to the obturator foramen forms a high and transversely compressed rectangular plate, which corresponds to the ischiatic table of terrestrial mammals. On the dorsal margin of the table, along the lateral side of the ischium, is an anteroposteriorly elongated, wide and shallow groove or fossa, which extends anteriorly on the body. This fossa is bordered ventrally by a wide ridge. Both the ridge and the fossa do not extend until the posterior end of the ischium. Similar structures are also present in Basilosaurus and Chrysocetus, but considerably more developed (especially in Basilosaurus isis) (Fig. 49). The dorsal margin of this plate probably received the insertion of the $M$. ischiocaudalis and the homologous of the posterior ligament of the femur (observed in extant mysticetes) (Struthers 1881; 1888). The posteroventral region of the obturator foramen 
is formed by the ramus of the ischium. It is robust and meet the pubis anteriorly possibly close to mid-point of the ventral edge of the obturator foramen.

The part of the innominate of Mystacodon posterior to the obturator foramen is roughly as long as the part anterior to it. This condition contrasts with that observed in Basilosaurus isis and Chrysocetus healyorum. In these basilosaurids, the ischium greatly extends posteriorly and forms the larger portion of the innominate (Fig. 49). In this respect, the condition of basilosaurids appears more derived than that of Mystacodon.

The ischiatic table is transversely compressed and its posterior end is somewhat bent medially. The posterior extremity of the bone is slightly convex posteriorly and roughly perpendicular to the main anteroposterior axis of the innominate. It differs from the condition in Basilosaurus and Chrysocetus, in which it is clearly oblique, the posterodorsal angle extending more posteriorly than the anteroventral angle. Besides, possibly due to a slight deterioration of the bone, a symphyseal surface is not clearly observed on the holotype of Mystacodon selenensis. It is therefore possible that, as in recent mysticetes (Struthers 1881, 1888, 1893; Howell $1930 \mathrm{~b})$, the posterior ends of both right and left ischia were also connected through the great interpelvic ligament. But maybe both conditions could have been present, in other words, a loose pelvic symphysis tightened by ligaments.

In conclusion, the pelvis of Mystacodon is definitely basilosaurid-like in outline, although it must be recalled that no pelvis of other basal mysticete has been described so far. In fact, the only extinct mysticete pelves presently described are the highly modified innominates of Piscobalaena nana and other undetermined cetotheriids (Bouetel \& Muizon 2006; Gol'din 2014). However, the pelvis of Mystacodon differs from that of basilosaurids in: having a larger obturator foramen; the pubis being more curved and dorsoventrally higher; lacking the posterior lengthening of the ischiatic table; and having a conspicuously less developed dorsal ridge and fossa. As compared with extant mysticetes, the innominate of Mystacodon selenensis resembles to some extent that of Balaena mysticetus in having a shorter and narrower ilium. Measurements of the forelimb are given in Table 13.

\section{DISCUSSION}

\section{PhylogeneTIC AFFinities of MYSTACODON SELENENSIS} (FIG. 52)

The parsimony analysis was performed as explained in the material and methods section above. The analysis resulted in four most parsimonious trees with the following scores (length, 970; CI, 0.377; RI, 0.724; RC, 0.273; HI 0.622). All the unresolved branchings are observed in the clade Cetotheriidae and thus do not concern the basal groups and taxa of mysticetes, which represent our major interest here.

Zygorhiza and Cynthiacetus are the most basal taxa followed by the clade Odontoceti, all being included in the outgroup (Fig. 52).
TABLE 13. - Measurements of girdles and forelimb of the holotype of Mystacodon selenensis (MUSM 1917) in mm. Abbreviation: e, estimated measurements.

\begin{tabular}{|c|c|}
\hline Scapula & \\
\hline Anteroposterior length & 375 \\
\hline Proximodistal length & 295 \\
\hline $\begin{array}{l}\text { Length of the acromion from the attachment line on } \\
\text { the spine to the apex }\end{array}$ & \\
\hline Proximal & 92 \\
\hline Middle & 104 \\
\hline Distal & 89 \\
\hline Proximodistal width of acromion & \\
\hline Proximal & 76 \\
\hline Medial & 53 \\
\hline Distal & 73 \\
\hline Anteroposterior length of glenoid cavity & 72 \\
\hline Transverse width of glenoid cavity & 65 \\
\hline $\begin{array}{l}\text { Length of coracoid process from anterior edge of glenoid } \\
\text { cavity to apex }\end{array}$ & 35 \\
\hline Humerus & \\
\hline Proximodistal length & 30.7 \\
\hline $\begin{array}{l}\text { Length of the bone proximal to distal extremity of } \\
\text { deltopectoral crest }\end{array}$ & 21.5 \\
\hline Length of the bone distal to distal extremity of deltopectoral crest & 88 \\
\hline Length of deltopectoral crest & $200 e$ \\
\hline $\begin{array}{l}\text { Anteroposterior length of diaphysis at level of distal end of } \\
\text { deltopectoral crest }\end{array}$ & 86 \\
\hline $\begin{array}{l}\text { Anteroposterior length of diaphysis at level of mid-length } \\
\text { of deltopectoral crest }\end{array}$ & 96 \\
\hline Width of diaphysis at level of distal end of deltopectoral crest & 39 \\
\hline Width of diaphysis at level of mid-length of deltopectoral crest & 32 \\
\hline Width of distal epiphysis & 50 \\
\hline Length of distal epiphysis & 62 \\
\hline Ulna & \\
\hline Proximodistal length of diaphysis & 20 \\
\hline Proximodistal length of humeral facet & 54 \\
\hline Maximum width of humeral facet & 36.5 \\
\hline Length of diaphysis at mid-length & 47 \\
\hline Width of diaphysis at mid-length & 8.5 \\
\hline Length of diaphysis at distal extremity & 58 \\
\hline Width of diaphysis at distal extremity & 22.5 \\
\hline Length of olecranon (cord of the arc of curvature) & 85 \\
\hline Maximum width of the olecranon & 26.5 \\
\hline Radius & \\
\hline Proximodistal length & 187 \\
\hline Anteroposterior length of proximal epiphysis & 45 \\
\hline Transverse width of proximal epiphysis & 42 \\
\hline Length of pronator tuberosity & 42 \\
\hline $\begin{array}{l}\text { Distance between proximal end of pronator tuberosity and } \\
\text { proximal epiphysis }\end{array}$ & 50 \\
\hline Length of diaphysis at mid-length & 45 \\
\hline Width of diaphysis at mid-length & 21.5 \\
\hline Anteroposterior length of diaphysis at distal extremity & 62 \\
\hline Transverse width of diaphysis at distal extremity & 25 \\
\hline Inominate & \\
\hline Anteroposterior length & 185 \\
\hline Maximum dorsoventral width & 54.5 \\
\hline Dorsoventral width of acetabulum & 28.5 \\
\hline Anteriposterior width of acetabulum & $35 \mathrm{e}$ \\
\hline Length of obturator foramen & 37 \\
\hline Maximum width of obturator foramen & 16.5 \\
\hline Maximum width of ischiatic plate & 46 \\
\hline Width of ilium at apex & 17 \\
\hline
\end{tabular}

The earliest diverging mysticete is Mystacodon, which is not retrieved here as the sister group of Llanocetus (contra Fordyce \& Marx 2018). The next diverging clade is the Mammalodontidae (Janjucetus + Mammalodon), followed by the clade composed of Coronodon and the undescribed 
Charleston Museum mysticetes (ChM PV 4745 and 5720). The next branching is Llanocetus, which is retrieved as the sister group of the clade composed of the Aetiocetidae (Aetiocetus spp. + Fucaia) + Chaeomysticeti (the latter being the toothless mysticetes).

However, given the relatively high homoplasy index (0.628) for this analysis, we performed an analysis with down-weighted homoplastic characters, using Goloboff criterion with a value of $\mathrm{K}=3$. It resulted in a single most parsimonious tree, which provides a better resolution within the clade Cetotheriidae, but with no change in the basal branchings compared to our strict consensus.

In this analysis (with ACCTRAN character state optimization), Mysticeti are defined by seven unambiguous synapomorphies:

- Character $5(0>1)$ : Height of the maxilla relative to width at transverse midpoint of a section anteroposteriorly located at the level of posterior third of the bone length but anterior to antorbital process: roughly as high as wide or lower; - Character $54(0>1)$ : Anteriormost portion of jugal broadly underlapped by maxilla (i.e., presence of a zygomatic process of the maxilla);

- Character $57(0>1)$ : Maxillary infraorbital plate present; - Character $102(0>1)$ : Position of apex of zygomatic process of squamosal closely apposed to the postorbital process or situated ventral to the latter;

- Character $117(0>1)$ : external occipital crest restricted to anterior half of supraoccipital shield;

- Character $226(0>1)$ Height of dentary at anterior extremity: not tapering dorsoventrally;

- Character $265(0>1)$ : Orientation of humeral head in medial or lateral view: posterior to posteroproximal (with the posterior component equal to or much greater than the proximal one.

Mysticetes are further defined by four ambiguous synapomorphies:

- Character $115(0>1)$ : Overall outline of supraoccipital in dorsal view: triangular;

- Character $137(0>1)$ : Basioccipital crest: wide and bulbous;

- Character $158(0>1)$ : Pyramidal process: present;

- Character $160(0>1)$ : Anterior bullar facet: flattened and not clearly distinguishable from fovea epitubaria.

We have also performed the analysis with DELTRAN optimization and, as expected, the same seven unambiguous synapomorphies were obtained, whereas only one different ambiguous synapomorphy was found:

- Character $87(0>1)$ : On fronto-parietal suture, frontals project posteriorly along the sagittal plane and separate the left and right parietal anteriorly.

This analysis further confirms the non-monophyly of the group Mammalodontidae + Aetiocetidae, a result that has also been retrieved in recent mysticete phylogenetic analyses (Fitzgerald 2006, 2010; Boessenecker \& Fordyce 2015b, 2017; Bisconti \& Bosselaers 2016; Bisconti et al. 2017; Fordyce \& Marx 2018) contra Marx \& Fordyce (2015) and Geisler et al. (2017).
FEEDING STRATEGIES OF TOOTHED MYSTICETES

Extant mysticetes are toothless filter feeders and have developed different, highly specialized feeding strategies. These strategies involve a strongly modified feeding apparatus and the utilization of baleen, which are filtering structures made of keratin hanging from the palate. Different groups of toothed mysticetes lack, to various degrees, part of the cranial and mandibular specializations of Chaeomysticeti, and therefore their feeding strategies should be different. Before the latest works (Deméré et al. 2008; Fitzgerald 2010; Marx 2011; Geisler et al. 2017), it was commonly accepted that toothed mysticetes had an active raptorial behavior, similar to that of basilosaurids (Fordyce 1982; Mitchell 1989).

Deméré et al. (2008) and Deméré \& Berta (2008) suggested that incipient baleen (proto-baleen) could have been present in the Aetiocetidae. They interpreted the lateral foramina on the palate of Aetiocetus weltoni and A. cotylalveus as nutrient foramina supplying the epithelium that produces baleen. In the context of such a hypothesis, aetiocetids are regarded by Deméré \& Berta (2008) as transitional forms, which use their primitive baleen in bulk filtering. This hypothesis is further supported by the fact that aetiocetids have a cylindrical mandible and a non-sutured mandibular symphysis, as observed in the Chaeomysticeti (Emlong 1966; Barnes et al. 1994; Deméré \& Berta 2008). However, Deméré et al. (2008) and Deméré \& Berta (2008) also suggested that aetiocetids probably also captured single prey with their functional adult dentition, with the raptorial technique proposed for basilosaurids (e.g. Cynthiacetus and Dorudon). However, as mentioned by these authors, the size of the prey items "was limited by the spacing between baleen elements and/or teeth". Therefore, aetiocetids would have combined some raptorial and filter feeding strategies. Because of the small size of their teeth, it is unlikely that they could have preyed upon large organisms and, therefore, the raptorial feeding of aetiocetids was thus probably suction-assisted.

Recently, Marx et al. (2015) described a new aetiocetid, Fucaia buelli, from the early Oligocene of Washington state, and concluded that suction assisted raptorial feeding was likely to have been present in aetiocetids and mammalodontids, with possible benthic suction in Mammalodon.

More recently, Marx et al. (2016) disputed Deméré \& Berta (2008)'s interpretation and argued that aetiocetids were devoid of baleen and were not filter feeders, but rather specialized towards suction feeding. These conclusions were mainly based on the presence of a distinctive wear pattern in the teeth of a new aetiocetid from the late Oligocene of Oregon (NMV P252567). The authors concluded that the transition from raptorial biting feeder (+ simple tooth sieving) basilosaurids to filter feeder chaeomysticetes was characterized by a suction feeding (+ simple tooth sieving) stage in aetiocetids and mammalodontids, and a suction feeding + baleen filtering stage in eomysticetids and eschrichtiids (Marx et al. 2016: fig. 5).

Geisler et al. (2017; July) described a new toothed mysticete, Coronodon havensteini, from the late early Oligocene of South Carolina. According to these authors, Coronodon had no baleen, but its closely apposed teeth (while they are widely 


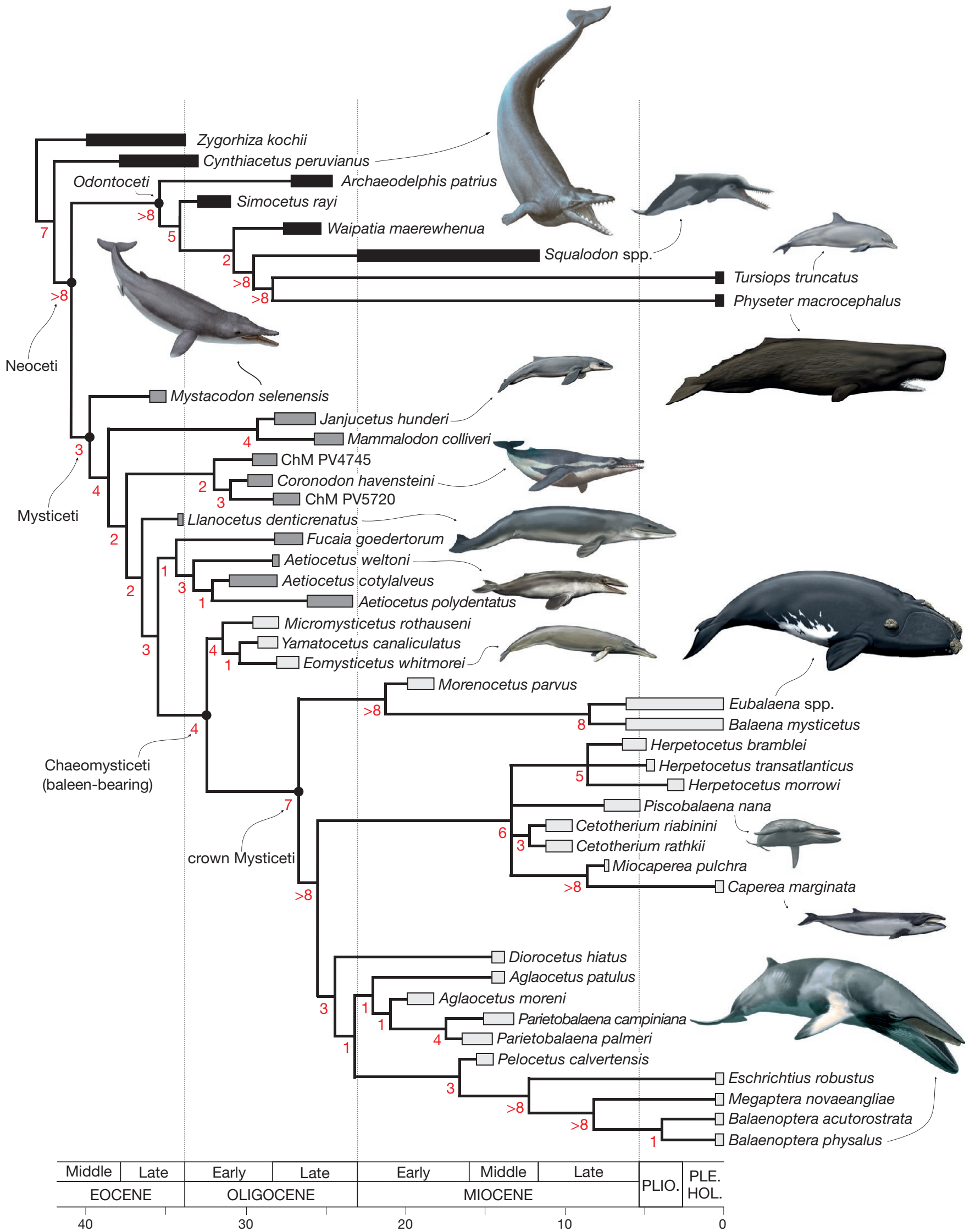

FIG. 52. - Phylogenetic relationships of Mystacodon selenensis: strict consensus tree or four equally parsimonious trees resulting from the analysis of the data matrix of 282 characters and 43 taxa with equally weighted homoplastic characters $(\mathrm{L}=970 ; \mathrm{Cl}=0.377 ; \mathrm{RI}=0.724 ; \mathrm{RC}=0.273 ; \mathrm{HI}=0.622)$. The Bremer index is given at nodes in red. Reconstructions of Aetiocetus, Caperea, Eomysticetus, Eubalaena, Janjucetus, Physeter, and Tursiops are by Carl Buell; reconstructions of Balaenoptera, Coronodon, Cynthiacetus, Mystacodon, Piscobalaena, and Squalodon, are by Alberto Gennari. 
spaced in aetiocetids and llanocetids) with radially disposed accessory cusps allowed for filter feeding in a pattern similar to that observed in the extant leopard seal. They however, concluded that Coronodon was rather eclectic and probably used a mix of feeding strategies, combining raptorial ram feeding with dental filter feeding. It is clear that the powerful teeth of Coronodon might have been very efficient in raptorial feeding as in basilosaurids. As a matter of fact, the best living ecological morphotype to be compared with Coronodon, the leopard seal, Hydrurga leptonyx, is a formidable raptorial feeder as well as an efficient filter feeder (Rogers 2017). Geisler et al. (2017; July)'s interpretation was contradicted by Hocking et al. (2017b; August), who analyzed tooth sharpness in a range of terrestrial and marine raptorial and filter feeding mammals, and also concluded that Coronodon employed a mix of raptorial and suction feeding, but with no filter feeding.

A few months before this debate Lambert et al. (2017a; May) described Mystacodon selenensis and, on the basis of its planar dental wear and other cranial features, hypothesized some degree of specialization towards suction feeding, and possibly bottom feeding, in this taxon, which is the oldest mysticete currently known. Such an interpretation would lend support to the hypothesis of Marx et al. $(2015,2016)$ and Hocking et al. (2017b; August) that suction feeding might have preceded filter feeding in mysticete evolution. Although we do not intend to participate in this debate (which is beyond the scope of this study) it is noteworthy that the fossil record of early mysticetes is, so far, very scarce in the late Eocene and Oligocene, a critical transitional epoch in mysticete evolution. It is likely that a great variety of feeding adaptations were acquired independently in several lineages, and that the feeding strategies of most of the early tooth-bearing mysticetes were, in part, eclectic.

An important point in the problem of feeding strategies of toothed mysticetes lies in the presence or absence of small "proto-baleen", which could have coexisted with teeth in some taxa (Deméré \& Berta 2008; Deméré et al. 2008). Baleen plates of extant mysticetes are ever-growing keratinized appendages of the palatal epithelium, which are formed with the joining of tubular bristles (or horn tubes) and are frayed along their lingual edge into a fringe of tapered bristles (Werth 2000); in some taxa, baleen plates can be heavily calcified (Szewciw et al. 2010). Baleen plates are produced by the gingival epithelium on the lateral region of the palate. In this region, the maxilla of baleen-bearing mysticetes features large anteroposteriorly or anterolaterally directed sulci and grooves. These grooves are the passageway for large branches of the superior alveolar artery, which provide to the gingival epithelium the major vascularization required to produce the ever-growing baleen plates. They differ from the sulci on the medial portion of the palate (palatine and maxillary), which convey the palatine artery and nerve and represent the generalized mammalian palatine foramina (Deméré et al. 2008: 16; Ekdale et al. 2015). The lateral palatine foramina and sulci are generally wide indicating abundant blood supply. In Piscobalaena, for instance, a small (c. 3 to $4 \mathrm{~m}$ long) baleen-bearing cetothere from the late Miocene of the Pisco Formation (Bouetel \&
Muizon 2006; Marx et al. 2017), the width of these grooves varies from 2 to $5 \mathrm{~mm}$ for a skull length of $c .100-110 \mathrm{~cm}$.

Some toothed mysticetes also present lateral palatal grooves and sulci, which have been interpreted differently by authors. Deméré et al. (2008) observed eight foramina and corresponding sulci on the lateral edge of the left maxilla of the holotype of Aetiocetus weltoni. Foramina vary from 1 to $2 \mathrm{~mm}$ in diameter, and sulci from 2.5 to $15.5 \mathrm{~mm}$ in length. The sulci are oriented obliquely relative to the sagittal plane except the anterior two ones. Diameter of the sulci of $A$. weltoni is only slightly proportionally smaller than in Piscobalaena since the condylobasal length of the holotype of $A$. weltoni is $62 \mathrm{~cm}$. In contrast, the length of the sulci is significantly shorter in A. weltoni. The anterolateral orientation of the sulci is similar in both taxa, the posterior ones being at an angle of more than $45^{\circ}$ with the sagittal plane and directed towards the alveoli (A. weltoni) or the alveolar groove (Piscobalaena). Deméré et al. (2008) also mention the presence of lateral palatal grooves in Aetiocetus cotylalveus, Fucaia goedertorum and in an undescribed species of Morawanocetus (see also Sawamura et al. 2006; Sawamura 2008).

As mentioned above, the interpretation of Deméré \& Berta (2008) and Deméré et al. (2008) has been challenged by Marx et al. (2016). These authors stated that the presence of palatal foramina does not necessarily indicate the presence of baleen but instead more probably would have supplied blood to well-developed gums. Their interpretation is, in part, supported by a detailed study of the dental wear of an aetiocetid (NMV P252567) from the late Oligocene of Oregon, in which they conclude that an active use of teeth (evidenced by conspicuous dental wear and facets) renders unlikely the coexistence of such teeth and baleen, also considering the risk of functional interference between interdigitating teeth and nearby baleen. Although this risk could have been real if true baleen plates (even small) were actually present in these taxa, it is noteworthy, however, that it was probably minimal in the case of non-plate-like keratinous appendages, which may have represented the first evolutionary stage of the baleen of extant mysticetes. It is likely that baleen (or baleen plates) did not appear at once on the palate of early mysticetes, but the palate was more probably progressively invaded by keratinous appendages, which merged later to form true baleen plates (but see Uhen et al. [2008a] for an alternative scenario explaining the origin of baleen plates from keratinized gums similar to those observed in the extant porpoise Phocoenoides dalli]. Furthermore, it is noteworthy that, if keratinous appendages (possibly isolated bristles) were actually present in aetiocetids, they were probably medially juxtaposed to the tooth row on the palate, and not in the diastemata between the teeth because such a location would have been hindered by the placement of the lower teeth in their upper diastemata and embrasure pits. If this was actually the case, such a condition would have greatly reduced or even avoided the functional interference mentioned by Marx et al. (2016).

Marx et al. (2016) interpreted the dental wear pattern of the aetiocetid NMV P252567 as related to suction feeding, what we accept here, but it is worth noting that this behavior 
is not incompatible with filter feeding as exemplified in the edentulous extant Gray whale.

Another toothed mysticete exhibiting numerous palatal foramina and sulci is Llanocetus denticrenatus from the late Eocene of Antarctica (Fordyce \& Marx, 2018). The sulci of Llanocetus are large and range from c. 2 to $10 \mathrm{~mm}$ in diameter. They are located on the lateral region of the maxilla and are variably oriented. The most lateral sulci are converging toward alveoli of P2-P4, whereas some other slightly more medial sulci are anteroposteriorly oriented. The latter are clearly much larger than the former and can be up to $10 \mathrm{~mm}$ wide. In a recent study of this taxon Fordyce \& Marx (2018) suggested that these sulci were supplying blood to well-developed gingiva. However, the large size of these sulci suggests a major vascularization of the palatal epithelium, which, in turn, would suggest some vascularization need greater than what would be expected for simple gums. These large sulci may rather suggest an abundant blood supply such as that requested for ever-growing keratinous production (keratinous appendages being growing much more rapidly than gums). Whether this production was actual proto-baleen plates is conjectural, but it may have been related to the production of some keratinous appendages (plate-like or not), which may have preceded the appearance of the true baleen plates of chaeomysticetes. Nevertheless, the production of keratinous appendages on the palate of some toothed mysticetes does not exclude the possibility that part of the major vascularization system could have also supplied blood to well-developed gums, which could have been keratinized following the model suggested by Uhen et al. (2008a). Fordyce \& Marx (2018) have argued against the presence of baleen in Llanocetus, considering the risk of interference between interdigitating teeth and baleen plates. The same arguments as those mentioned above for aetiocetids could be opposed to Fordyce \& Marx (2018) interpretation on Llanocetus. Furthermore, if gums were well developed in Llanocetus (partly occupying the long diastemata), as suggested by Fordyce \& Marx (2018), what we are ready to accept, it is unlikely that any kind of keratinous appendage was present between the teeth but, more likely, on the palate medial to them. We therefore think that there is no contradiction between the presence of well-developed gums and some kind of palatal keratinous appendage (with a currently unknown shape, extent, and function) in Llanocetus, as suggested by the large size of the palatal sulci observed in the holotype of this taxon. It is noteworthy that, if actually present, these keratinous appendages would have very probably been produced by the gingival epithelium (which forms the gums) as in extant mysticetes.

Interestingly, no trace of enlarged foramina or sulci are observed in toothed mysticetes with well-developed teeth and lacking very large diastemata [e.g. Coronodon, Charleston Museum toothed mysticetes (ChM PV 4745, 5720), Mammalodontidae, Mystacodon]. Aetiocetidae and Llanocetus, in which palatal foramina and sulci have been observed, have small postcanine teeth, which are widely separated by welldeveloped diastemata (up to three tooth mesiodistal lengths in Llanocetus). Therefore, these taxa seem to have already encompassed some reduction of their dental apparatus as compared to other toothed mysticetes and basilosaurids. As a consequence, given their size and spacing, the teeth of more derived aetiocetids (see below) and Llanocetus were probably not very efficient in raptorial feeding although their wear facets clearly indicate that they were functional. This condition had to be compensated for (at least partially) by replacement feeding strategies such as suction feeding (Marx et al. 2016; Peredo et al. 2017; Fordyce \& Marx 2018; Peredo \& Pyenson 2018) and/or incipient filter feeding (Deméré \& Berta 2008). It is noteworthy that the recently described most basal aetiocetid Salishicetus (Peredo \& Pyenson 2018) has shorter diastemata between posterior cheek teeth than the other taxa of the family, suggesting gradual increase of diastemata in aetiocetids and a progressive swap from raptorial feeding to other kind(s) of feeding strategies (suction and/or filter feeding). The teeth of Llanocetus are also anteroposteriorly longer than high and palmate denticulate as those of Coronodon, which has been regarded as a dental filter feeder (Geisler et al. 2017). However, the attrition and especially the apical abrasion facets observed by (Fordyce \& Marx 2018) in Llanocetus are likely related to suction feeding. Nevertheless, the morphology and the wide separation of the accessory cusps on the premolar (P2-P4) suggests that dental filter feeding could have also been possible, and not incompatible with suction feeding. Although the wide diastemata of Llanocetus would have reduced the efficiency of dental filter feeding (Fordyce \& Marx 2018), if some keratinous appendage were present medial to these teeth, they could have compensated for this weakness. Fordyce $\&$ Marx (2018) have argued that the pronounced dental wear (attrition facets) they observed in Llanocetus implies biting of preys and tooth-on-tooth shearing (therefore, possibly, some raptorial feeding), an interpretation that we accept here. However, this remark only concerns the molars of Llanocetus. The diastema between M2 and M1 is apparently less than one tooth mesiodistal length, which is consistent with an efficient occlusion of upper and lower molars. In contrast, the diastemata between M1 and P4 and between the premolars is at least two to three times longer than one tooth mesiodistal length and probably prevented any contact between upper and lower teeth and tooth-on-tooth shearing was highly improbable. If a contact actually occurred it may have been only occasional. In fact, the portion of the tooth-bearing palate on which efficient tooth-on-tooth shearing is not possible (i.e., anterior to M1) approximately corresponds to $90-80 \%$ of its surface. Therefore, the portion of the palate anterior to M1 could have been devoted to suction and/or dental filter feeding (if some keratinous apendages were actually present) with some biting action on the food retained in the oral cavity by the molars. A posterior biting of preys in the oral cavity is therefore not incompatible with suction and/or some kind of filter feeding (see above). Moreover, in the case of a raptorial capture by the anterior teeth of a moderately large prey (i.e., that could not be swallowed without tearing), which is also possible, the posterior molars would have processed them as indicated by their abundant subvertical attritional facets. To conclude, it is probable that several feeding strategies were jointly present in 
Llanocetus which would confirm the eclectic feeding behavior of mysticetes in their early evolutionary history.

Furthermore, the monophyly of the Mammalodontidae + Aetiocetidae clade is one of the major phylogenetic arguments of Marx (2011), Marx et al. (2015), Marx et al. 2016, and Hocking et al. (2017b) to refute the hypothesis of Deméré \& Berta (2008) proposing the presence of incipient baleen in Aetiocetidae. Because baleen is clearly absent in Mammalodontidae (Fitzgerald 2006, 2010), if the latter form a clade with the baleen-bearing Aetiocetidae, itself being sister-group to all the other baleen-bearing mysticetes, the former authors consider it unlikely that such a specialized adaptation as baleen could have appeared twice during mysticete evolution. Geisler et al. (2017) accepted the presence of baleen in Aetiocetidae but, since their analysis retrieved a monophyletic Aetiocetidae + Mammalodontidae clade, they interpreted the absence of baleen in Mammalodontidae as a reversal, possibly related to the development of suction feeding in this family. In this context, the topology of the strict consensus of our parsimony analysis sheds new light on this debate, since the Aetiocetidae and the undisputed baleen-bearing mysticetes form a clade that could be supported at least by the synapomorphic acquisition of palatal keratinous appendages. Because baleen is absent (or supposed to be) in the other neocetes, in this phylogenetic hypothesis, this acquisition would have occurred once. Furthermore, the position of Llanocetus as a sister group of the clade Aetiocetidae and Chaeomysticeti renders possible a single acquisition of palatal keratinous appendages in the clade "(Llanocetus, (Aetiocetidae, Chaeomysticeti)). Therefore, according to our result, there is no phylogenetical impediment to the possible presence of "proto-baleen" (or some kind of keratinous appendage) in Llanocetus and Aetiocetidae, although the basal aetiocetid Salishicetus, with larger teeth and shorter diastemata, shows a morphology of the oral apparatus less suited for the accommodation of teeth and baleen (Peredo \& Pyenson 2018). Nevertheless, it is noteworthy that the holotype (and only known specimen) of Salishicetus is very incomplete and, especially, the skull is very poorly known (only by a posterolateral fragment of the braincase). It is noteworthy that $60 \%$ of the characters in the data matrix of Peredo \& Pyenson (2018) are coded indeterminate, which casts doubts on the clustering of Salishicetus at the base of the Aetiocetidae. Therefore, we think that the discovery of a more complete specimen (with better preserved skull) is necessary to confirm the familial referral of this taxon.

\section{BIOLOGY AND FEEDING STRATEGY OF MYSTACODON Cranial and dental morphology}

Although Mystacodon strongly resembles basilosaurids in many aspects, it clearly differs from these "archaeocetes" in several features of the anterior part of the rostrum and dentary, as well as dental morphology. The external bony nares are more anteriorly placed and the prenarial part of the rostrum is shorter in Mystacodon than in basilosaurids. As a consequence, the postnarial portion of the rostrum is much longer. These two features result in a larger palatal surface (Table 3; Fig. 7) and a greater volume for the oral cavity. This volume is further increased by the development of an infraorbital plate of the maxilla (absent in basilosaurids), which extends the palate posteriorly and constitutes a solid separation between the posterior mouth and the orbit. These cranial features suggest some degree of suction feeding capacities in Mystacodon (Werth 2006; Johnston \& Berta 2011; Fitzgerald 2012; Lambert et al. 2017a), which contrast with the strictly raptorial feeding strategies of basilosaurids (e.g. Fahlke 2012; Snively et al. 2015).

Werth (2006) has stated that blund heads, wide jaws and reduced anterior teeth in extant odontocetes was related to suction feeding. These features were also regarded by Boessenecker et al. (2017) as related to suction feeding, together with the reduction of cheek teeth and increase in size of their diastemata. Although the condition of Mystacodon is not comparable to that of extant odontocetes, it can be interestingly compared to that of basilosaurids. As compared to Cynthiacetus, the rostrum (from antorbital notch to apex of premaxillae) of Mystacodon is definitely shorter and more massive (Table 2); the anterior rostrum (i.e., the maxilla-free portion of the premaxillae) is $31 \%$ shorter than in Cynthiacetus (see premaxilla section above); and the anterior teeth (incisors and canine) of Mystacodon are 29\% shorter mesiodistally (as related to bizygomatic width) than in Cynthiacetus (Table 7). As compared to additive length of the cheek teeth, the total length of the cheek teeth row (i.e., teeth + diastemata) of Mystacodon is c. 18\% greater than in Cynthiacetus (Table 8). Therefore, the features mentioned above indicate that Mystacodon was probably less raptorial than Cynthiacetus and more inclined to some suction feeding. This interpretation is corroborated by the powefull sternohyoideus muscle inferred from the large size of the anterior region of the manubrium (see above, sternum section).

Mystacodon lacks the skull features associated with bulk filter feeding in Chaeomysticeti [nutrient grooves on the palate to supply the epithelium producing the baleen (they are apparently absent in the poorly preserved palate of the holotype of M. selenensis), edentulous jaws, laterally bowed dentaries, ligamentous mandibular symphysis, and cranial kinesis]. The features cited above indicate that Mystacodon was certainly not a bulk filter feeder.

Basilosaurids have an elevated and strongly developed sagittal crest (absent in Mystacodon), a larger temporal fossa, and a dorsoventrally higher neurocranium, thus indicating a stronger origin and a greater development of the temporal muscles compared to the Peruvian mysticete. However, whereas the anterior teeth of Mystacodon are clearly less robust than the large conical canine and incisors of basilosaurids (Table 7), the cheek teeth of Mystacodon are proportionally similar in mesiodistal length (their height is unknown because of their poor preservation and degree of wear) to those of Cynthiacetus (Table 8). Therefore, the relatively large size of its cheek teeth seems to predispose Mystacodon to some kind of raptorial feeding, to a much greater extent than in Aetiocetus, Llanocetus, and Janjucetus (see Table 8). A condition similar to that of Mystacodon is also present in Coronodon, which has been regarded as a partially (see below) raptorial feeder (Geisler et al. 2017). It is noteworthy, however, that the inci- 
sors and canines of Mystacodon, conspicuously smaller than in basilosaurids, would indicate less efficient raptorial habits, especially in catching large and robust preys (capable of strong resistance) because of a weaker grip power. As a matter of fact, the basilosaurid Cynthiacetus peruvianus is known to have fed upon large scombrid fishes probably as large as $2 \mathrm{~m}$ long (Martínez-Cáceres et al. 2017). Such large prey may not have been suitable for Mystacodon. In this context, suctionassisted raptorial feeding on smaller prey than Cynthiacetus may have characterized Mystacodon's ecology. Raptorial feeding was probably present in Llanocetus and Aetiocetus, but poorly developed and of little efficiency because of the relative small size of their teeth combined to large diastemata. In contrast, Janjucetus, with relatively small cheek teeth but very small diastemata, has been regarded as a macrophagous raptorial predator (Fitzgerald 2010).

As mentioned above, because of its palate morphology, rostrum proportions and palate size, dental relative size, extent of diastemata, and powerful sternohyoideus muscle inferred from the great anterior width of the manubrium (see above, this section and in Tables and Figures cited there), it is likely that $M$. selenensis already acquired some degree of suction feeding ability.

Interestingly, the presence of radially oriented accessory denticles on the crowns of at least part of the cheek teeth of Mystacodon is reminiscent of the condition of Coronodon (Fig. 26). In the latter, the highly typical dentition lead to the hypothesis of a dental assisted filter-feeding strategy (Geisler et al. 2017). Considering the great degree of tooth wear observed in the holotype of Mystacodon selenensis (see below), such a strategy is at best very unlikely for the latter (Hocking et al. 2017b), although the discovery of complete, unworn teeth of Mystacodon would be necessary to confirm the morphological similarities with Coronodon.

\section{Dental wear}

The dental wear of the holotype of Mystacodon selenensis also drastically differs from the condition of basilosaurids. In the latter, dental wear is mostly subvertical as a consequence of the vertical shearing of their large and sharp teeth (attrition wear facets). The smaller teeth of Mystacodon drastically differ from those of basilosaurids and part of the other toothed mysticetes in the presence of planar and subhorizontal (or moderately sloping) dental wear surface. The condition of Mystacodon is reminiscent of the apical wear observed in Mammalodon, although, the resemblance is only partial since Mystacodon lacks any lingual wear surface and possesses only one apical wear surface, while two are observed in the former (Fitzgerald 2010: 443). The condition in Mystacodon suggests an efficient dental abrasion, resulting either from feeding upon hard or abrasive food items (such as, for instance, denticles embedded in the skin of sharks or rays [Ford et al. 2011; Fahlke et al. 2013]), or from the ingestion of sediment during prey capture. This latter condition would imply some degree of bottom feeding. A benthic feeding behavior has also been hypothesized in Mammalodon, which could explain its particular dental wear as the result of the ingestion of abrasive and benthic material such as sand grains (Fitzgerald 2010). In the extant walrus, a bottom suction feeder, heavy subhorizontal dental wear is also observed on postcanine teeth and clearly related to the ingestion of sand particles while feeding upon preys on (or below) the surface of the sea floor (Fay 1982). However, a lingual facet is also present, which is heavily polished and bears fine horizontal striae, as a result of anteroposterior movements of the tongue carrying fine microlithic particles (Fay 1982). This condition is a consequence of the piston function of the walrus tongue when extracting the siphon and foot out of bivalves (see Fay 1982: 165-169). As mentioned above, no lingual wear surfaces are observed on the teeth of Mystacodon. In this respect, the latter differs from Mammalodon, which possesses a distinct oblique lingual wear facet on the occlusal surface of the lower teeth (Fitzgerald 2010: 444).

Fitzgerald (2010: 443) pointed out the fact that the anterior four pairs of teeth of the beluga (Delphinapterus leucas) also have a planar and not polished dental wear. However, this wear surface is produced by direct occlusion of the upper teeth with their lower antagonists (tooth-tooth contact, attrition), and food ingestion (whether abrasive or not and with or without sediment particles) is likely to have a reduced effect on the development of these facets. As a matter of fact, the beluga is considered a suction feeder, and the contribution of its teeth during feeding is certainly limited (Brodie 1989). As noted by this author: "teeth do not protrude in functional numbers until at least the second and third years and all the animals seem capable of feeding by suction (Ray 1966; see Fig. 5), therefore the teeth of adults may serve an equal or greater social function" (Brodie 1989: 127). Therefore, such a pattern does not (or not only) include a tooth-sediment or a tooth-food contact, neither necessarily implies a bottom suction feeding ecology. Some anterior lower teeth in the holotype of Mystacodon selenensis (the isolated teeth) also present a planar wear surface that one could be tempted to explain with tooth-tooth contacts. However, the anterior lower teeth of Mystacodon are not directly aligned with their upper antagonists, as indicated by the presence of well-defined embrasure pits, and their wear surface is not inclined to the same extent as in the beluga. Therefore, these anterior wear surfaces in Mystacodon were most likely not formed by occlusion (tooth-tooth contact), but probably by contact with food items and/or abrasive sediment.

The absence of lingual or labial wear in Mystacodon could be explained by the fact that part of the crown was protected by gingival tissue. This explanation is supported by the pattern of the lower molars, which are the only teeth of MUSM 1917 being in situ and showing the whole wear surface. In lateral view, the wear surfaces of lower molars are located in a same anterodorsally oriented plane, parallel to the dorsal margin of the dentary. Such a pattern is hard to explain by both tooth-tooth or tooth-food contact alone, but is more easily explained by the abrasion of the whole portion of the crown exposed above the gum level by benthic sediments and abrasive food items. As for Odobenus, the edges of the unworn crown were probably protected by the gingivae and the abrasive benthic sediment (ingested with the food 
items foraged on the sea floor) may have been responsible in part for the strong subhorizontal dental abrasion in the holotype of Mystacodon selenensis. A microwear analysis would probably confirm this hypothesis, but is beyond the scope of this study. This benthic feeding behavior inferred for Mystacodon is also supported by the strong wear surface observed in anterior teeth, which were likely used to capture prey on the sea floor, thus producing an inevitable ingestion of abrasive sediment.

Therefore, although it is not possible to ascertain how the dental wear of $M$. selenensis was produced, the subhorizontal (or moderately sloping) wear surface was probably not the result of the direct occlusion of lower and upper teeth (as in Delphinapterus leucas) or by the lingual movements involved in suction generation (as in Odobenus rosmarus), but more likely the result of feeding upon abrasive organisms (such as elasmobranch denticles) or/and because of the ingestion of benthic sediment particles when feeding.

\section{Orbit morphology and orientation (Fig. 53)}

Because vision plays an important role in interactions with the environment, Muizon \& Domning (2002), Fitzgerald (2006, 2010), Marx (2011), and Debey \& Pyenson (2013) have considered the size, morphology, and orientation of the orbit as a series of factors related to feeding preferences in marine mammals. For carnivorous marine mammals that do not echolocate (mysticetes, pinnipeds, and sea otters), vision is indeed crucial for prey detection, to avoid predators, and for spatial orientation during migrations (Mass \& Supin 2017). Marx (2011) compared size and orientation of the orbit of some pelagicetes (mysticetes and basilosaurids) to that observed in pinnipedimorphs. However, because pinnipedimorphs have a drastically different cranial architecture and, generally, a different ecology from that of pelagicetes, this comparison is probably not fully adequate in deciphering their respective feeding habits. Modern pinnipeds have a remarkably large vision field with anterior, dorsal, and, in some cases, ventral binocular vision (Kastelein et al. 1993). Although the earliest cetaceans (pakicetids, ambulocetids, and remingtonocetids) have a small supraorbital process (as compared to other cetaceans) and dorsally approximated orbits in an excellent position for dorsal and anterodorsal binocular vision, especially in Pakicetus (Numela et al. 2006; Thewissen et al. 2009; Bajpai et al. 2011), in protocetids, basilosaurids, and neocetes, the supraorbital process of the frontal is greatly expanded anteroposteriorly and laterally, and forms a major barrier to dorsal vision. As a consequence, it fully overhangs the orbit and forces an almost exclusively lateral orientation of the eyes. Most extant neocetes have virtually no binocular vision, although some ventral overlapping of the visual fields is observed in dolphins in aerial vision (Mass \& Supin 2009). However, in some cases, the morphology of the supraorbital processes can very likely allow binocular vision. Indeed, in some taxa, the plane of the orbit is not oriented fully laterally but anterolaterally. This position clearly approximates the anteromedial areas of visual fields, anteriorly, and may allow for some anterior binocular vision. This character has been analyzed by Marx (2011) in relation to the relative size of the orbit in several extant and fossil cetaceans. The result of this analysis is that this character is present in four genera of toothed mysticetes: Aetiocetus, Fucaia, Janjucetus, and Mammalodon. Using Marx (2011)'s variables, in Fig. 53 we have measured (see figure caption) the following specimens: Aetiocetus cotylalveus (USNM 25210), A. weltoni (USNM 12290), Fucaia goedertorum (LACM 131146), Janjucetus hunderi (NMV P216929), and Mammalodon colliveri (NMV P1999986). Cranial material of Aetiocetus polydentatus and A. tomitai has been regarded as too incomplete or too distorted to allow for satisfactory measurements. Furthermore, we have added to the analysis the recently described toothed mysticetes Coronodon havensteini (CCNHM 108) and Mystacodon selenensis (MUSM 1917), as well as the two, unpublished toothed mysticetes from the Charleston Museum (ChM PV 5270 and 4745), which have become classical specimens of most phylogenetic analyses including toothed mysticetes. We also increased the number of archaeocetes and added some chaeomysticetes as listed in Table 14. Although comparison with pinnidepimorphs does not apply fully satisfactorily to cetaceans, as mentioned above, we have retained the taxa (and the measurements) analyzed by Marx (2011), which, in spite of their inadequacy, provide the only available ecological comparison point.

Our measurements confirm the separation of most toothed mysticetes from chaeomysticetes retrieved by Marx (2011). However, toothed mysticetes are not fully individualized from baleen-bearing mysticetes since Coronodon, ChM PV 5720, and ChM PV 4745 distinctly cluster with the chaeomysticetes. In contrast, Mystacodon clearly departs from chaeomysticetes and is included in a diffuse cluster of toothed mysticetes, which slightly overlap with the pinnipedimorphs on the other end of the diagram. Furthermore, the distribution of the archaeocetes (protocetids and basilosaurids), which is markedly superimposed to the area including chaeomysticetes, confirms the position obtained by Marx (2011) for Zygorhiza and indicates that protocetids and basilosaurids probably had a reduced anterior binocular vision.

The position of Coronodon is interesting as it departs from the other toothed mysticetes and is included in the plot of raptorial basilosaurids and filter-feeding chaeomysticetes. This may be an indication that Coronodon was probably an eclectic hunter (in part, raptorial feeder) as suggested by Geisler et al. (2017) and Hocking et al. (2017b), and was combining different feeding strategies (partly raptorial, partly suction feeder and/or partly filter feeder) as has also been suggested by Deméré \& Berta (2008) for Aetiocetus (as far as raptorial and filter feeding habits are concerned).

Another important character of the supraorbital process that impacts the extension of the vision field is the concavity of its lateral edge, which represents the dorsal edge of the orbit. Several toothed mysticetes have a deeply concave lateral edge of the supraorbital process, whereas chaeomysticetes and basilosaurids have either a slightly concave or a straight dorsal edge of the orbit. A deeply notched dorsal edge of the orbit is also present in the highly derived odontocetes (Muizon 


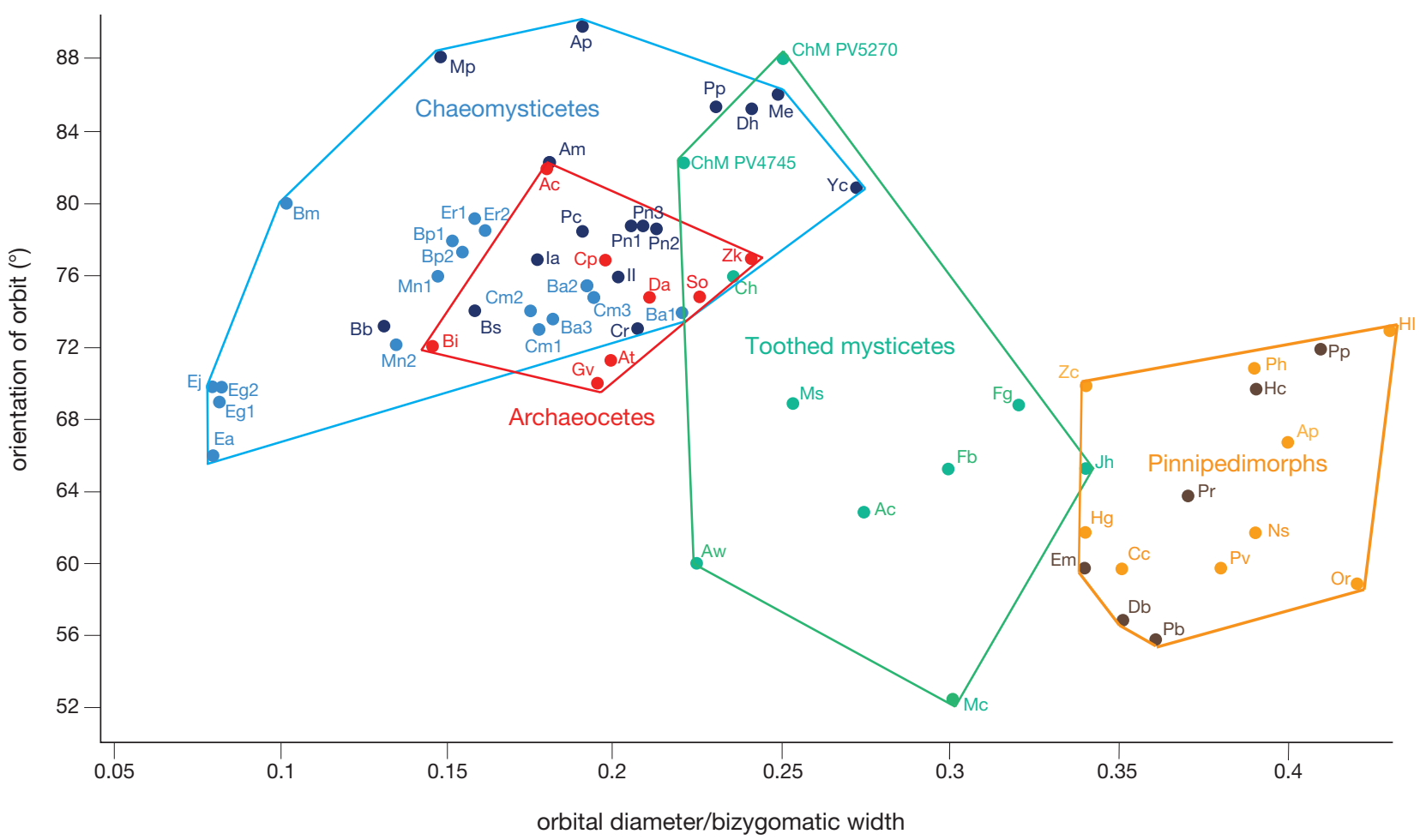

FIG. 53. - Scatter plot showing the orbit orientation (measured as the posterolateral angle of the longitudinal axis of the orbit with the transverse plane) plotted against maximum orbital diameter vs the bizygomatic width. Color code: red, archaeocetes; green, toothed mysticetes; dark blue, fossil toothless mysticetes; light blue, extant mysticetes; orange, extant pinnipedimorphs; brown, fossil pinnipedimorphs. Plot modified from Marx (2011). Abbreviations: 1) archaeocetes: Ac, Artiocetus clavis; At, Aegyptocetus tarfa; Bi, Basilosaurus isis; Cp, Cynthiacetus peruvianus; Da, Dorudon atrox; Gv, Georgiacetus vogtlensis; So, Saghacetus osiris; Zk, Zygorhiza kochii; 2) toothed mysticetes: Ac, Aetiocetus cotylalveus; Aw, Aetiocetus weltoni; ChM PV $\mathbf{4 7 4 5}$ and $\mathbf{5 7 2 0}$, undescribed specimens from the Charleston Museum; Ch, Coronodon havensteini; Fb, Fucaia buelli; Fg, Fucaia goedertorum; Jh, Janjucetus hunderi; Mc, Mammalodon colliveri; Ms, Mystacodon selenensis; 3) chaeomysticetes: Am, Aglaocetus moreni; Ap, Aglaocetus patulus; Bm, Balaena mysticetus; Bb, Balaenella brachyrhynchus; Ba, Balaenoptera acutorostrata; Bp, Balaenoptera physalus; Bs, Balaenoptera siberi; $\mathbf{C m}$, Caperea marginata; Cr, Cetotherium rathkii; Dh, Diorocetus hiatus; Ea, Eubalaena australis; Eg, Eubalaena glacialis; Ej, Eubalaena japonica; Er, Eschrichtius robustus; Ia, Incakujira anillodefuego; II, Isanacetus laticephalus; Me, Mixocetus elysius; Mm, Megaptera miocaena; Mn, Megaptera novaeangliae; Mp, Miocaperea pulchra; Pc, Pelocetus calvertensis; Pn, Piscobalaena nana; Pp, Parietobalaena palmeri; Yc, Yamatocetus canaliculatus; 4) Pinnipedimorphs: Ap, Arctocephalus philippii; Cc, Cystophora cristata; Db, Desmatophoca brachycephala; Et, Enaliarctos tedfordi; Hc, Homiphoca capensis; Hg, Halichoerus grypus; HI, Hydrurga leptonyx; Ns, Neomonachus schauinslandi; Or, Ommatophoca rossii; Pb, Pteronarctos bishopi; Ph, Phocarctos hookeri; Pp, Piscophoca pacifica; Pr, Proneotherium repenningi; Pv, Phoca vitulina; Zc, Zalophus californianus.

et al. 2002; Muizon \& Domning 2002) Odobenocetops peruvianus and $O$. leptodon (although less so in this species), two species that respectively lacked or had reduced echolocating abilities. Such a condition has been regarded as allowing for an efficient anterodorsal to anterior binocular vision when the animal was foraging on the sea floor with the body in an inferred oblique position. In aetiocetids the deeply notched lateral edge of the supraorbital process is an indication of good dorsal to anterodorsal binocular vision, a condition regarded as characteristic of benthic feeding marine mammals (Fitzgerald 2010). However, extant pinnipeds have excellent dorsal and anterodorsal binocular vision, but are not especially benthic feeders, except for the walrus.

In fact, the orientation and dorsal notching of the orbit in non-echolocating cetaceans does not appear to be strictly related to a specific type of feeding, probably because several types of feeding behavior may have been used concomitantly in some fossil taxa as is observed in the extant Gray whale (suction and filter feeding). An almost laterally oriented, small-sized orbit with a relatively straight dorsal edge is present in several chaeomysticetes, which are filter feeders, but an anterolaterally oriented orbit is also present in others, including Megaptera, some specimens of Balaenoptera acutorostrata, and Eubalaena glacialis. Extant gray whales have a small, anterolaterally oriented orbit with a notched dorsal edge and are benthic suction filter feeders. A medium-sized laterally oriented orbit with a straight dorsal edge is also present in raptorial basilosaurids. An anterolaterally oriented, but un-notched large orbit is present in the probably partly raptorial Coronodon, and in the probable benthic feeder Mystacodon (Lambert et al. 2017a), (Fig. 54). An anterolaterally oriented and deeply notched orbit is present in the essentially raptorial Janjucetus (Fitzgerald 2006) and in the archaeocete-like raptorial feeder Fucaia (Marx \& Fordyce 2015: 30). Such a condition is also present in the partly single prey raptorial feeder Aetiocetus (Deméré \& Berta 2008: 341; Marx \& Fordyce 2015), but also a possible baleen filter feeder (Deméré \& Berta 2008: $341)$; in contrast, it is also present in the benthic suction feeder Mammalodon (Fitzgerald 2010). Moreover, archeocetes and pinnipedimorphs are widely separated on Figure 54, the former with a reduced capacity of anterior and binocular vision, the latter with a very efficient one, in spite of being both characterized by single prey raptorial feeding (at least for the pinnipedimorphs plotted in Fig. 53). 
Therefore, considering that: 1) the toothed mysticete plot partially overlaps with chaeomysticetes; 2 ) chaeomysticetes and basilosaurids fully overlap in spite of having radically different feeding types, and 3) the mostly single prey feeders basilosaurids and pinnipedimorphs are widely separated, it seems that the orientation and morphology of the orbit are not fully adequate to provide, alone, information on the feeding habits of early mysticetes, but should be regarded as a useful complement to other features such as cranial structure and dental morphology, implantation, and wear. It is also noteworthy to recall that basal toothed mysticetes, at this early stage of mysticete evolution, may have been more eclectic than several hypotheses seem to indicate, and their feeding habits were probably more complex and varied than thought. This consideration is clearly (although not directly) expressed by Deméré \& Berta (2008: 341).

In the case of Mystacodon, the straight dorsal edge of the orbit would argue against benthic feeding, whereas the anterolateral orientation of the orbit, providing enhanced anterior vision, would favor such an ecology.

\section{Mandible}

The dentary of Mystacodon is clearly intermediate between that of basilosaurids and that of other toothed mysticetes. The numerous and relatively large antorbital and mental foramina of Mammalodon have been regarded as indicative of a well-developed labial musculature related to an important tactile sense for prey detection, possibly related to benthic suction feeding (Sanderson \& Wassersug 1993; Werth 2000, 2006; Fitzgerald 2010). Although the antorbital and mental foramina of Mystacodon are large, they are not as numerous and developed as in other toothed mysticetes (except Janjucetus), thus indicating that its lips were certainly not as irrigated as those of Aetiocetus, Chonecetus, and Mammalodon. Finally, the mandibular symphysis of Mystacodon is characterized by a well-developed and tightly articulated symphysis (with deep grooves and prominent ridges), as in basilosaurids (although shorter). This condition contrasts with all other mysticetes. Chaeomysticetes have no bony symphysis, but a smooth surface, which accommodates a fibrocartilage ligament that allows mandible rotation while feeding. The mobility of the symphysis in mysticetes is related to mandibular kinesis at the intramandibular joint, a feature unique to extant mysticetes and related to their specialized filter feeding system. Aetiocetids are very similar in this respect to chaeomysticetes and present a smooth symphyseal surface with longitudinal groove, which indicates a clearly mobile ligamentous symphysis (Deméré \& Berta 2008), even if such a mobility may have been limited due to the dental occlusion observed in Aetiocetus and Fucaia (Marx et al. 2016). As mentioned by Deméré \& Berta (2008: 334) for Aetiocetus weltoni, "similar and, presumably, homologous features occur on the dentaries of extant mysticetes and are associated with a fibrocartilage skeleton that loosely connects the right and left dentaries". Other toothed mysticetes (Mammalodon and Janjucetus) have a greatly shortened bony symphysis, lacking prominent ridges and deep grooves, in contrast to the long and tight symphysis of basilosaurids and
Mystacodon (Fitzgerald 2010, 2012). However, Mammalodon and Janjucetus retain a rugose symphyseal surface, indicating low mobility. A similar condition is observed in Coronodon, although in this genus the symphysis is longer and extends posteriorly until the level of the anterior edge of the canine (p1 in Mystacodon).

The absence of any mobility at the level of the mandibular symphysis in Mystacodon further supports the hypothesis that the latter was not a specialized filter feeder, but a more generalized predator.

Since Mystacodon has the most primitive cranial morphology among mysticetes, it is tempting to consider that it could occupy the initial ecological niche of the group. Both mammalodontids and aetiocetids are considered to have different ecological niches compared to that of the basilosaurids. In this context Mystacodon may represent a transitional stage between the classic piscivorous and, for the largest, mammal- or birdfeeding basilosaurids (Uhen 2004; Fahlke 2012; Snively et al. 2015; Martínez-Cáceres et al. 2017) and the more specialized suction and/or filter feeding toothed mysticetes.

In conclusion, based on dental and cranial morphology, it is likely that Mystacodon was mostly a generalized raptorial predator, probably presenting some degree of specialization towards suction feeding, but without the specializations observed in more derived mysticetes, and that, given its dental morphology and tooth wear, it probably fed upon benthic single prey items (possibly including sharks or/and rays). The rib-cage morphology with expanded distal extremity of ribs extending further posteriorly than anterior ribs and the bone structure of ribs, close to osteosclerosis, may further support this hypothesis.

\section{Forelimb}

The forelimb of the holotype of Mystacodon selenensis is well preserved and presents a characteristic morphology, which is susceptible to bring new elements to elucidate its feeding strategies. Although the forelimb of Mystacodon closely resembles that of basilosaurids, it notably differs from the basilosaurid pattern in the ankylosis of the elbow and in the protruding large radial tubercle.

In all neocetes (with one possible exception, see comments by Sanders \& Geisler 2015 on Mirocetus riabinini) the distal articular surface of the humerus is composed of two roughly flat facets, (in some cases slightly concave), and respectively oriented anterodistally and posterodistally. The anterior facet receives the proximal facet of the radius and the posterior facet is for the proximal facet of the ulna. The two facets are separated by a sharp rectilinear transverse crest and are at an angle of approximately $120^{\circ}$. This crest prevents from any flexion or extension of the forearm, and the elbow is thus ankylosed. In basilosaurids the distal articular surface is a continuous, saddle-shaped surface, which receives the radius anteriorly and the ulna posteriorly. Because of this functional trochlea, the elbow is capable of some mobility, although probably not very pronounced. The transverse crest, which prevents the elbow from any mobility is a characteristic feature and a unique synapomorphy of neocetes. 
TABLE 14. - Taxon list and measurements of Figure 53. In blue are the specimens (or casts) that have been available and directly measured during this study; in green are the specimens that have been measured from photos; in yellow, those whose data have been obtained from publications (reference given when relevant). Pinnipedimorph data (pink) refer to Marx (2011); ratios, angles, and references were kindly provided by F. G. Marx. Angle is the obtuse angle between the longitudinal axis of the orbit and the transverse plane. Abbreviations: Bz, bizygomatic width; Od, orbital diameter. The latter is measured from the anterolateral angle to the posterolateral angle of the supraorbital process for cetaceans and from the postorbital process of the jugal to the anterior edge of the orbit below the lacrimal tubercle for pinnipedimorphs; e, estimated measurements.

\begin{tabular}{|c|c|c|c|c|c|}
\hline Taxon & Angle & Bz & Od & $\mathrm{Od} / \mathrm{Bz}$ & Reference \\
\hline Artiocetus clavis (GSP-UM3458) & 82 & 308 & 57 & 0.18 & \\
\hline Aegyptocetus tarfa (MSNUP I-15459) & 71.5 & 298 & 60.8 & & \\
\hline Georgiacetus vogtlensis (GSM 350) & 70 & 310 & 60.5 & 0.195 & \\
\hline Cynthiacetus peruvianus (MNHN.F.PRU10) & 77 & 478 & 94.5 & 0.197 & \\
\hline Zygorhiza kochii (USNM 11962) & 77 & $336 \mathrm{e}$ & 80 & 0.24 & \\
\hline Saghacetus osiris (BMNH 10228) & $73.7,76.7 / X=75$ & 380 & 86 & 0.23 & Kellogg (1936) \\
\hline Dorudon atrox (Type specimen destroyed; see Kellogg 1936: pl. 24-25) & 75 & 354 & 75 & 0.21 & Kellogg (1936) \\
\hline Basilosaurus isis (CGM 42195) & 73 & 600 & 87 & 0.145 & \\
\hline Aetiocetus cotylalveus (USNM 25210) & 63 & $318 \mathrm{e}$ & 87 & 0.273 & \\
\hline Aetiocetus weltoni (UCMP 12290) & 60 & 287 & 64 & 0.209 & \\
\hline Fucaia geodertorum (LACM 131146) & 69 & $236 \mathrm{e}$ & 75 & 0.317 & \\
\hline Fucaia buelli (UWBM 84024) & 63.5 & $230 \mathrm{e}$ & 69.7 & 0.303 & Marx et al. (2015) \\
\hline Janjucetus hunderi (NMV P216929) & 65 & $332 \mathrm{e}$ & 113 & 0.34 & \\
\hline Mammalodon colliveri (NMV P199986) & 53 & $300 \mathrm{e}$ & 89.7 & 0.30 & \\
\hline ChM PV 4745 & 80 & 346 & 76 & 0.22 & \\
\hline ChM PV 5720 & 88 & 359 & 91 & 0.25 & \\
\hline Coronodon havensteini (CCNHM 108) & 76 & 463 & 109 & 0.235 & \\
\hline Mystacodon selenensis (MUSM 1917) & 69 & 399.6 & 100.7 & 0.254 & \\
\hline Yamatocetus canaliculatus (KMNH VP 000,017) & 81 & 427 & 115 & 0.27 & Okazaki (2012) \\
\hline Piscobalaena nana 1 (MNHN.F.SAS1617) & 79 & 403 & 82.9 & 0.205 & \\
\hline Piscobalaena nana 2 (MNHN.F.SAS1618) & 78.5 & 418 & 88.5 & 0.212 & \\
\hline Piscobalaena nana 3 (MNHN.F.SAS1623) & 79 & 432 & 90.1 & 0.208 & \\
\hline Cetotherium rathkii (PIN1840/1) & 74 & 330 & 70 & 0.212 & \\
\hline Mixocetus elysius (LACM 882) & 86 & 1000 & 254 & 0.287 & Kellogg (1934a) \\
\hline Parietobalaena palmeri (USNM 10677) & 85 & $442 e$ & 101 & 0.229 & Kellogg (1968) \\
\hline Aglaocetus moreni (FMNH P 13407) & 78 & $468 \times 2=936 e$ & 169 & 0.18 & Kellogg (1934b) \\
\hline Aglaocetus patulus (USNM 23690) & 90 & 760 & 145 & 0.19 & Kellogg (1968) \\
\hline Diorocetus hiatus (USNM 23494) & 85 & 635 & 152 & 0.24 & Kellogg (1968) \\
\hline Pelocetus calvertensis (USNM 11976) & 79 & 945 & 178 & 0.188 & Kellogg (1965) \\
\hline Isanacetus laticephalus (MFM 28501) & 76 & $250 \times 2=500 e$ & 104 & 0.208 & Kimura \& Ozawa (2002) \\
\hline Incakujira anillodefuego (GNHM Fs-098-12) & 77 & 1000 & 175 & 0.175 & Marx \& Kohno (2016) \\
\hline Megaptera miocaena (USNM 10300) & 83 & 1216 & 190 & 0.156 & Kellogg (1922) \\
\hline Megaptera novaeangliae 1 (USNM 21492) & 72 & 1809 & 238 & 0.131 & True (1904) \\
\hline Megaptera novaeangliae 2 (USNM 16252) & 76 & 1421 & 203 & 0.143 & True (1904) \\
\hline Eschrichtius robustus (AMNH 34260) & $80 \& 78 / X=79$ & 1110 & 172 & 0.155 & Andrews (1914) \\
\hline Eschrichtius robustus (USNM 13803) & $76 \& 80 / X=78$ & 1041 & 165 & 0.158 & Andrews (1914) \\
\hline Balaenoptera siberi (Holotype, SMNK uncat) & 74.5 & 1110 & $185 / 5$ & 0.167 & Pilleri (1989) \\
\hline Balaenoptera acutorostrata 1 (USNM 20931) & 74 & 587 & 130 & 0.221 & True (1904) \\
\hline Balaenoptera acutorostrata 2 (USNM 13877) & 75 & 877 & 169 & 0.192 & True (1904) \\
\hline Balaenoptera acutorostrata 3 (USNM 12177) & 73 & 910 & 174 & 0.191 & True (1904) \\
\hline Balaenoptera physalus 1 (USNM 16045) & 78 & 1620 & 239 & 0.147 & True (1904) \\
\hline Balaenoptera physalus 2 (USNM 16039) & 77.5 & 1531 & 229 & 0.150 & True (1904) \\
\hline Miocaperea pulchra (SMNS 46978) & 88 & 560 & 83 & 0.148 & Bisconti (2012) \\
\hline Caperea marginata 1 (MNHN-ZM-AC-1879-259) & 73 & 860 & 156 & 0.181 & \\
\hline Caperea marginata 2 (USNM 550146) & 74 & 711 & 122 & 0.171 & \\
\hline Caperea marginata 3 (UO A 81.2) & 74.5 & 793 & 156 & 0.196 & \\
\hline Balaenella brachyrhynchus (NMB 42001) & 73 & 525 & 69.5 & 0.13 & Bisconti (2005) \\
\hline Eubalaena glacialis 1 (USNM 23077) & 69 & 2153 & 178 & 0.083 & True (1904) \\
\hline Eubalaena glacialis 2 (measurements from drawing: Allen 1908: pl. 20) & 70 & “88.8” & “7.5” & 0.084 & Allen (1908) \\
\hline Eubalaena japonica (Kirittapu whale of Omura (1958) & 70.5 & 1950 & 162 & 0.083 & Omura (1958) \\
\hline Eubalaena australis (MNHN-ZM-AC-1921-123) & 66 & 2810 & 223 & 0.079 & \\
\hline Balaena mysticetus (Osaka whale of Nishiwaki \& Kasuya (1970) & 80 & 1021 & 108 & 0.106 & Nishiwaki \& Kasuya (1970) \\
\hline Enaliarctos tedfordi & 60 & - & - & 0.34 & Berta 1991 \\
\hline Pinnarctidion bishopi & 56 & - & - & 0.36 & Barnes 1979 \\
\hline Pteronarctos goedertae & 70 & - & - & 0.34 & Barnes 1989 \\
\hline Desmatophoca brachycephala & 57 & - & - & 0.35 & Barnes 1987 \\
\hline Proneotherium repenningi & 64 & - & - & 0.37 & Deméré \& Berta 2001 \\
\hline Piscophoca pacifica & 72 & - & - & 0.41 & Muizon 1981 \\
\hline Homiphoca capensis & 70 & - & - & 0.39 & Muizon \& Hendey 1980 \\
\hline Halichoerus grypus & 62 & - & - & 0.34 & Bonner 1981b \\
\hline Phoca vitulina & 60 & - & - & 0.38 & Bigg 1981 \\
\hline Cystophora cristata & 60 & - & - & 0.35 & Reeves \& King 1981 \\
\hline Neomonachus schauinslandi & 62 & - & - & 0.39 & Kenyon 1981 \\
\hline Hydrurga leptonyx & 73 & - & - & 0.43 & MVC 25039 \\
\hline Ommatophoca rossii & 59 & - & - & 0.42 & Ray 1981 \\
\hline Zalophus californianus & 70 & - & - & 0.34 & Odell 1981 \\
\hline Phocarctos hookeri & 71 & - & - & 0.39 & Walker \& Ling 1981 \\
\hline Arctocephalus philippii & 67 & - & - & 0.4 & Bonner 1981a \\
\hline
\end{tabular}

In Mystacodon the anterior radial crest bears a remarkably salient and long radial process. The process is approximately $25 \%$ of the total radial length and c. $75 \%$ the width of the diaphysis. In lateral view the radial process is distinctly asymmetrical: the proximal end forms a steep edge, which is at c. $90^{\circ}$ with the proximal anterior border of the radius, while 
the distal half of the process gently slopes distally. This morphology clearly indicates that the traction forces exerted on this structure were essentially proximal. Because of the size of the process, it is likely that a strong muscle inserted on it, and because of the ankylosis of the elbow, this muscle did not act as a flexor of the latter articulation and consequently did most likely not originate on the humerus. Therefore, this muscle had to originate on the scapula, acting, then, as an extensor of the shoulder.

In basilosaurids the anterior radial crest is generally well developed and forms a distinct angle (Uhen 2004; MartínezCáceres et al. 2017), but no process or tubercle is observed. Uhen (2004) suggested that it received the insertion of the brachialis muscle, a flexor of the elbow, which originates on the lateral edge of the humerus, just distal to the head, and inserts on the anterior border of the radius, just distal to the head. This interpretation makes sense in the case of a basilosaurid, characterized by a mobile elbow, but poses a problem with the ankylosed elbow of Mystacodon. The brachialis muscle is notably absent in extant neocetes (Cooper et al. 2007a). A major extensor of the shoulder is the deltoideus muscle, which, in the dog (Evans \& de Lahunta 2013), originates on the spine and acromion of the scapula and inserts on the deltoid tuberosity, on the lateral side of the humerus. In Balaenoptera, the deltoideus originates on the anterior two fifth of the outer surface of the scapula, extending on the whole surface of the acromion, with an insertion on the anterior side and distolateral region of the humerus (Schulte 1916: pl. 46, 1). Noteworthy is the extension of the insertion on the anterior and anterolateral edge of the proximal third of the radius (Schulte 1916). Because of this distal extension of the deltoideus insertion in extant balaenopterids, we hypothesize that the robust radial anterior tubercle of Mystacodon may have been the insertion site for the same muscle. However, a question remains about the fact that the anterior radial tubercle of Mystacodon is in the same position as the anterior angulation of the radius of Dorudon, regarded by Uhen (2004) as the insertion of the brachialis muscle. A speculative interpretation may be provided by the forelimb musculature of the pygmy hippo, Choeropsis liberiensis. As illustrated by Fischer et al. (2007: pl. 2, B), in this species, the insertion of the deltoideus is adjacent and posterodistal to the lateral part of the origin of the brachialis. Therefore, it seems reasonable to hypothesize that, given the ankylosis of the elbow in Mystacodon and the consecutive uselessness of the brachialis, the two muscles may have fused to form a large deltobrachialis muscle, which inserted on both the humerus and the anterior edge of the radius. Of course, this hypothesis cannot be tested. However, the very large (wide and long) and distally shifted acromion on the scapula of Mystacodon and the great distal extension of the deltopectoral crest indicate strong distal tractions and perfectly combines with the large, massive, and proximally distorted (most likely because of traction) anterior radial process. Whether the muscle joining these two structures is the deltoideus alone or the deltoideus partially fused to the brachialis, it is clear that this muscle was very strong, which indicates that Mystacodon was capable of powerful extensions of the shoulder. Furthermore, the powerful extension abilities of the shoulder are corroborated by the powerful flexion abilities, as suggested by the width and the massiveness of the olecranon of the ulna. The olecranon receives the insertion of the triceps brachii caput longum, a flexor muscle of the shoulder, which originates on the posterodistal edge of the scapula and which was therefore probably powerful in Mystacodon. Therefore, the morphology of the scapula, humerus, ulna, and radius advocates for powerful movements of the shoulder, to a greater extent than in basilosaurids.

Interpreting the functional context in which such movements occurred is not easy because of the transitional morphology of the forelimb of Mystacodon. In extant cetaceans, the main locomotor functions of the forelimb are stabilization, rotation of the body on itself, and steering (Benke 1993). Extant cetaceans do not present a distally shifted acromion and a massive anterior tubercle of the radius, which indicates that the condition of Mystacodon may suggest another function besides stabilization and steering. As suggested by Lambert et al. (2017a) and above, different observations suggest that Mystacodon was probably a bottom feeder, and the inferred power of the shoulder extension and flexion could be related to that ecology. However, 1) because the forelimb of other basal toothed mysticetes for which benthic feeding has been suggested is unknown, and 2) because the morphology of the forelimb of Mystacodon radically differs from that of extant mysticetes, its interpretation is difficult. Extension of the shoulder projects the forelimb anteriorly or, if the limb is fixed, projects the body posteriorly. Because the latter use is unlikely it is possible that Mystacodon used its forelimb with active flexions and extensions of the shoulder to turn over the sand of the sea floor in order to locate and flush the mimetic fishes living on the bottom (e.g. rays, pleuronectiforms) and to capture them. Such an interpretation may also explain the relative robustness of the phalanges of Mystacodon as compared to those of basilosaurids. In the former, the phalanges possibly played an active role in the aforementioned hypothesis, which requires stout, but not necessarily long phalanges; in the latter, the phalanges being more involved in steering and stabilization of the body when swimming, require a greater length in order to extend the length of the forelimb and increase efficiency.

In this hypothesis of a bottom foraging behaviour in Mystacodon, it is likely that the predator would have ingested some sea floor sediment because of the need of a rapid reaction to catch its prey. This would explain the strong abrasion observed on the teeth of the holotype of $M$. selenensis, which would thus be rather related to sediment ingestion than to feeding on abrasive organisms. However, if Mystacodon effectively preyed upon rays on the sea floor, it is noteworthy that the skin of these selacians is also very abrasive and could also be, in part, responsible for the strong dental wear. We certainly admit that this scenario is highly intuitive and speculative, and may even be simplistic. Furthermore, it may only represent one of the possible functions of the forelimb of M. selenensis, other than stabilizer and steering hydrofoil. However, it provides an ecofunctional interpretation of the powerful capacities of 
shoulder extension and flexion inferred from the anatomy of the forelimb of Mystacodon. In addition, as suggested by Lambert et al. (2017a), this morphology may also have been related to some kind of assistance of the forelimb for moving along the sea floor, or for maintaining a static position as hypothesized on the life reconstruction of Figure 54.

Another possible function of the forelimb in relation to the powerful capacities of shoulder extension could be related to a resistance to flexion (which is biomechanically identical to an extension). In this case, the forelimbs could have been used as hydrodynamic organs, acting as laterally extended flaps, which according to their orientation would have forced the body up or down in the water mass, while propulsion was powered by the fluke. During this vertical hydrofoil function the flipper had to resist the strong anteroposterior force of the water flow with a powerful extension of the shoulder.

Be that as it may, given the fact that such an ecomorphotype as that of Mystacodon (i.e., partly raptorial, partly suction feeder, and possibly bottom feeder) is unknown in extant or other fossil cetaceans, any intent of interpretation obviously remains highly speculative, which does not mean that hypotheses should not be proposed.

\section{ON THE REDUCTION OF THE PELVIC BONES WITHIN THE NEOCETI}

As mentioned in the description above, the reduced innominate of Mystacodon resembles that of basilosaurids more than any other cetacean. Basilosaurids and Mystacodon still retained a well-developed (although small) hind limb. In the case of Mystacodon, the femur is ascertained, because of the presence of a deep and functional acetabulum, and a tibia was also probably present based on the condition in basilosaurids. The innominate of extant cetaceans is even more atrophied than that of Mystacodon and basilosaurids, and is rarely associated with vestigial femur and tibia (only observed in a few large species, such as for instance Balaena mysticetus, Balaenoptera musculus, and Megaptera novaeangliae). Therefore, the drastic reduction of the pelvis involves a major change of both hind limb and lumbar musculature. In consequence to this architectural modification, previous works (e.g. Struthers 1881; Andrews 1921; Howell 1930a, b; Simóes-Lopes \& Gutstein 2004; Tajima et al. 2004) have pointed out the difficulty in establishing homologies between the pelvis of modern cetacean and that of terrestrial mammals. Depending of its anatomical relationships, it has been proposed that the pelvis is formed by the ischium (Struthers 1881, 1888, 1893; Simóes-Lopes \& Gutstein 2004); by both ilium and ischium (Lönnberg 1910; Howell 1930a); by both pubis and ischium (Tajima et al. 2004); by the fusion of the ilium, pubis and ischium (Lönnberg 1938; Omura 1957; Gol'din 2014); or even by a sesamoid bone different from the classic pelvic bones (Arvy 1979).

Moreover, the pelves of both odontocetes and mysticetes present some important differences (Beneden \& Gervais 1880; Howell 1930a) and it has been proposed that the odontocete pelvis includes only one single or two pelvic bones (Howell 1930b; Ogama \& Kamiya 1957; Nemoto 1963; Berzin 1972;
Simôes-Lopes \& Gutstein 2004; Tajima et al. 2004). As a matter of fact, the only case of an odontocete pelvis formed by the three pelvic bones (Lönnberg 1938; in Stenella atenu$a t a$ ) is regarded as an atavistic condition (Simóes-Lopes \& Gutstein 2004)

Since Mystacodon still has a pelvis formed by the three well-differentiated pelvic bones, it is much likely that the reduction of the pelvis (and thus the disappearance of one or two pelvic bones) has been achieved independently in both groups. Moreover, ontogenetic studies suggested that the reduction of the hind limb in odontocetes takes place in an earlier ontogenetic stage as compared to the mysticetes (Kükenthal 1914 and references cited herein).

A crest or notch can occasionally be observed on the ventral margin of the pelvis in some juvenile specimens of Balaena mysticetus (Fig. 51). As compared to Mystacodon, this feature is interpreted here as being the posterior end of a relict of the obturator foramen. Using the relative position of the obturator foramen in Mystacodon, the posterior portion of the pelvis in extant mysticetes (body of the pelvis in Struthers 1881) should be regarded as homologous to the ischial ramus. In this context, the anterodorsal expansion of the pelvis (beak of the pelvis in Struthers 1881) is the homologous of the iliac process, and the short and massive expansion corresponds to the acetabular portion of the pubis (Fig. 50). However, this interpretation needs to be confirmed by an ontogenetic study of the pelvis, since only one center of ossification has been reported in the foetus of extant mysticetes (Eschricht, Reinhardt, and Struthers in Hosokawa 1951).

Moreover, Howell (1930b), Simóes-Lopes \& Gutstein (2004), and Tajima et al. (2004) have pointed out that the ischium forms most of the innominate in odontocetes. This condition is also observed in basilosaurids (Martínez-Cáceres et al. 2017), balaenids (Fig. 51B-D), and Mystacodon, and is regarded as plesiomorphic. In contrast, in various specimens of Balaenoptera musculus and B. physalus the illium is 50\% longer than the ischium (Fig. 50).

Similarly to basilosaurids, the pelvis of Mystacodon most likely played an important role in the suspension and the anchoring of the reproductive organs. As a matter of fact, in extant cetaceans, strong sexual dimorphism is noted for the shape and length of the pelvic body (Struthers 1881, 1893; Dines et al. 2014).

\section{CONCLUSIONS}

Mystacodon selenensis is a unique taxon of toothed mysticete and, so far, the oldest and most basal representative of the suborder. The study of its skull, dentition and postcranial skeleton (including the innominate) reveals numerous primitive and unique characters. Morphological comparison with other neocetes and basilosaurids indicates that it could represent one of the most archaic mysticetes.

Although definitely a mysticete, Mystacodon selenensis shares numerous similarities with basilosaurids. Its skull resembles basilosaurids in the concave lateral margin of 
the rostrum, the anteriorly located bony nares, the anteriorly located antorbital foramina of the maxilla, the long and wide supraorbital process of the frontal, the thin and long zygomatic process of the squamosal, the conspicuous intertemporal constriction, the thyrohyal being unfused to the basihyal, and the dental formula $(3 \mathrm{I} / 3 \mathrm{i}, \mathrm{C} / \mathrm{c}, 4 \mathrm{P} / 4 \mathrm{p}$, $2 \mathrm{M} / 3 \mathrm{~m})$. On the postcranial skeleton, it shares with basilosaurids the distally expanded (pestle-like) osteosclerotic ribs, the massive morphology of the manubrium, the scapula almost as long as high, the elongated humerus, the short ulna and radius, the carpals, metacarpals, and phalanges all bearing articular facets, and the well-developed pelvis with a distinct acetabulum.

However, in many respects Mystacodon clearly departs from basilosaurids and exhibits neocete and mysticete characters. Mystacodon resembles the early neocetes in the following features: mesorostral groove open dorsally, premaxillae loosely contacting anteriorly, antorbital process of the maxilla present, $\mathrm{P} 3$ and $\mathrm{P} 4$ separated by a diastema, posterior apex of nuchal crest anterior to occipital condyle, occipital shield facing posterodorsally, and ankylosed elbow. Furthermore, Mystacodon is included within the mysticetes essentially because of the distinct dorsoventral flattening of the rostrum, the presence of an infraorbital plate of the maxilla, which extends the palate posteriorly, the zygomatic process of the squamosal, which is closely apposed to the postorbital process of the frontal, the triangular occipital shield, the external occipital crest restricted to the anterodorsal half of the occipital shield, the thick basioccipital crest, and the humeral head being oriented more proximally than posteriorly. Mystacodon also differs from basilosaurids in its long nasal and in lacking a sagittal crest.

Given the phylogenetic relationships of Mystacodon retrieved in our analysis, it is noteworthy that the oldest known mysticete $(36.4 \mathrm{Ma})$ is, at the least, contemporaneous of many basilosaurids, and even older than some of them. As a matter of fact, in the Ica desert of the Peruvian coast, Cynthiacetus peruvianus is a basilosaurid from the Otuma Formation (late Priabonian - early Rupelian), which overlies the Yumaque Member of the Paracas Formation (Bartonian-Priabonian), in which the holotype of $M$. selenensis was discovered. $M$. selenensis is slightly older than the mysticete Llanocetus denticrenatus, from the La Meseta Formation of Seymour Island (Antarctica), for which mollusk based ${ }^{87} \mathrm{Sr} / 86 \mathrm{Sr}$ dating suggests an age of $34.2 \pm 0.87 \mathrm{Ma}$. As retrieved in our phylogenetic analysis, Mystacodon is not closely related to Llanocetus (contra Fordyce \& Marx 2018), and is the earliest diverging mysticete of our tree. Not surprisingly Mystacodon is, so far, the most archaic and the most basilosaurid-looking mysticete, markedly differing from all the other mysticetes in the overall morphology of the skull.

The dental morphology of Mystacodon is unfortunately poorly known because most the teeth of the holotype are either strongly weathered or extensively worn. However, as seen in Table 8 the cheek teeth of Mystacodon were comparable in relative length to those of basilosaurids, and were proportionally larger than in the other toothed mysticetes except Coronodon and the Charleston Museum specimens (ChM PV 4745 and 5720). Because of its large cheek teeth separated by moderate diastemata, Mystacodon was probably a raptorial feeder, although less efficient than basilosaurids because of the smaller size of its incisors and canines. Its palate, larger than in basilosaurids and posteriorly extended by the infraorbital plate suggests suctionassisted raptorial feeding. Furthermore, the dental wear observed on the holotype, subhorizontal on anterior teeth and sloping in posterior premolars and molars (not subvertical as in basilosaurids), indicates feeding upon abrasive organisms or/and ingestion of benthic sediment particles when feeding. Therefore, our analysis of Mystacodon dental and cranial anatomy suggests that it was a benthic suction assisted raptorial feeder.

Furthermore, the peculiar morphology of the forelimb (distally projected acromion of the scapula, very long distally extended deltopectoral crest of the humerus, very strong anterior tubercle of the radius, massive acromion of the ulna indicating a powerful triceps, and short and stout phalanges - as compared to basilosaurids) suggests that the forelimb of Mystacodon was not only used as a steering and stabilizing organ, as in extant cetaceans and probably basilosaurids. Capacity of powerful movements of the shoulder joint and robustness of the digits could be explained by an active use of the forelimbs on the sea floor, for example during foraging for benthic organisms, such as flat fishes, rays, or crustaceans.

Although resembling basilosaurids more than any other toothed mysticete Mystacodon selenensis clearly features major modifications also present in the other toothed mysticetes, especially concerning the lengthening of the posterior region of the rostrum (between posterior edge of bony nares and antorbital process) and corresponding lengthening of the nasals, the posterior extension of the palate, the dorsoventral flattening of the rostrum, and the reduction of the length of the premaxillary region of the rostrum and anterior teeth (Table 7 ). These features clearly predispose Mystacodon as early as in the middle Priabonian (36.4 Ma) for the morphology observed $10 \mathrm{Ma}$ later in the late Oligocene aetiocetids, which are probably the most chaeomysticete-looking toothed mysticetes. Even if the hypothesized feeding behaviours of Mystacodon are not drastically different from those of basilosaurids they most likely added to the raptorial feeding of the latter an important component of suction feeding, probably associated to bottom feeding. Such a proposed feeding strategy is clearly far from the filter feeding of chaeomysticetes, for which Mystacodon did not have the indispensable organ, the baleen, but is also different from the inferred feeding strategies of most later toothed mysticetes. Because of the great functional gap between the basilosaurid and chaeomysticete feeding strategies, it is not surprising that several attempts characterized the evolution of feeding adaptations among early mysticetes, until the appearance of baleen. During this transitional period, feeding adaptations in mysticetes were 


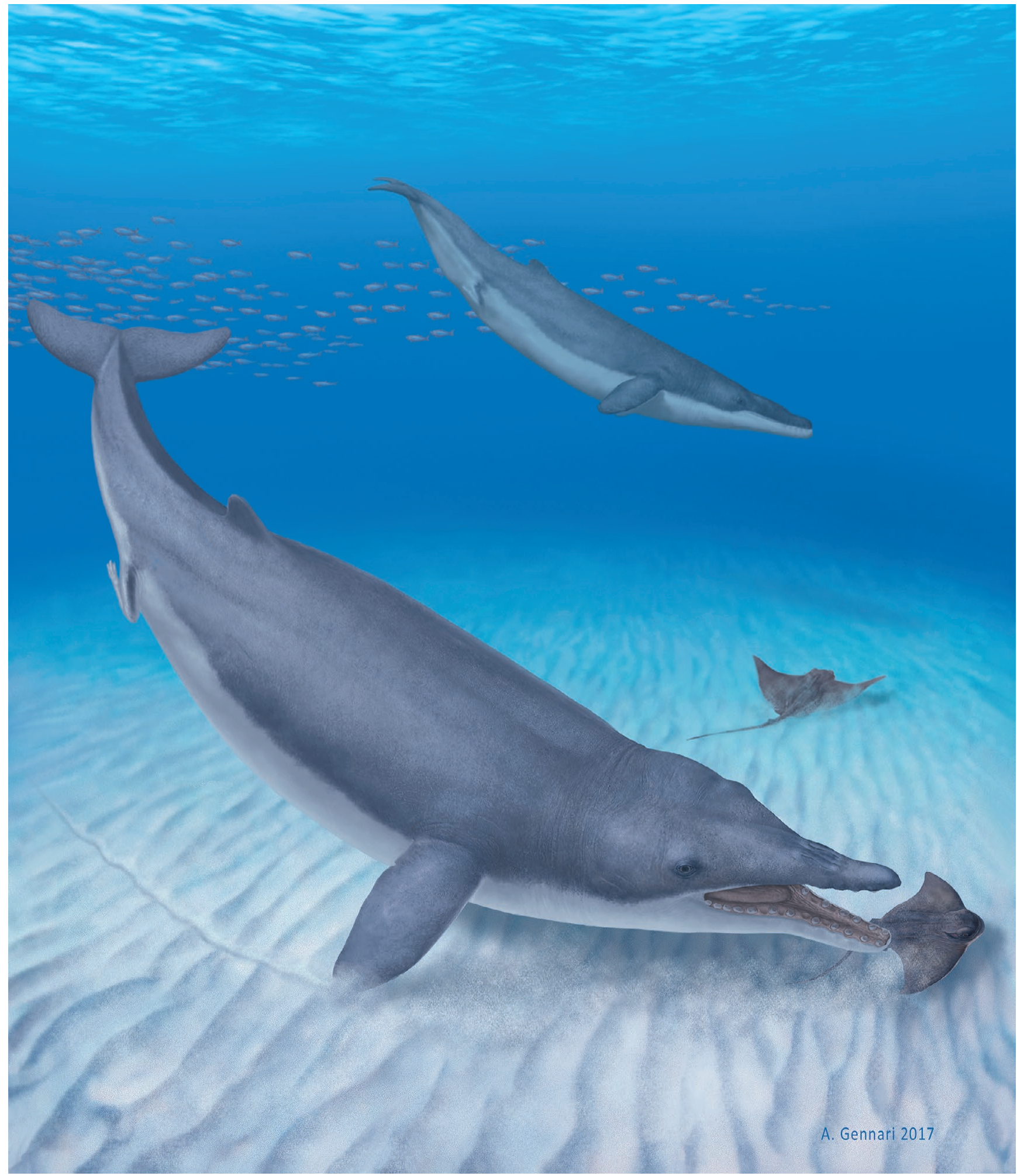

FIG. 54. - Life reconstruction of Mystacodon selenensis (painting by Alberto Gennari), showing this early toothed mysticete feeding along the seafloor off the coast of nowadays southern Peru.

probably numerous and these animals were probably eclectic, considering the high morphological disparity observed among toothed mysticetes. Given our poor knowledge of toothed mysticete diversity, the elaboration of a stepwise and straightforward scenario for the evolutionary history of feeding strategies among toothed mysticetes is probably far from the, mosaic-like actual sequence, which is likely to have been more complex. 


\section{Acknowledgements}

The holotype of Mystacodon selenensis was discovered by M. Urbina, who collected the skull and mandible. The field expedition, during which the postcranial skeleton of the holotype of Mystacodon selenensis has been collected, was funded by the Muséum national d'Histoire naturelle, Paris (Action Transversale "Biodiversité actuelle et fossile" 2010). Geological and stratigraphical field investigations were supported by a grant of the Italian Ministero dell'Istruzione dell'Università e della Ricerca (PRIN Project 2012YSBMK). We thank R. Salas-Gismondi, M. Urbina, W. Aguirre, E. Díaz, and R. Varas-Malca for their help during the fieldwork campaign of November 2010, when the postcranial skeleton was collected, W. Aguirre for the careful preparation of MUSM 1917, R. Salas-Gismondi and R. Varas-Malca for giving access to the MUSM collection, and C. Di Celma, K. Gariboldi, E. Malinverno, and E. Steurbaut for their help in defining the geological context of Playa Media Luna and the chronostratigraphic age of the level where the holotype of $M$. selenensis was found. Special thanks are due to R. E. Fordyce and F. G. Marx for sending us photographs of the holotype of Llanocetus denticrenatus, F. G. Marx for providing extensive access to his photographs of other fossil and extant mysticetes as well as for fruitful discussions on several aspects of the manuscript, J. H. Geisler for providing photographs of Coronodon havensteini, M. D. Uhen for providing many photographs of Dorudon atrox, P. D. Gingerich for providing photographs of Basilosaurus and Rodhocetus, and V. de Buffrénil and R. Salas-Gismondi for fruitful discussions. A. Gennari prepared the life reconstruction of $M$. selenensis. We are indebted to C. Buell for giving permission to reproduce the reconstructions of Aetiocetus, Caperea, Eomysticetus, Eubalaena, Janjucetus, Physeter, and Tursiops of Figure 52 and to F. G. Marx for providing them; warm thanks also to A. Gennari (and J. Geisler for Coronodon) for his permission to use the reconstructions of Balaenoptera, Coronodon, Cynthiacetus, Piscobalaena, and Squalodon reproduced in Figure 52. Our special thanks to the reviewers R. W. Boessenecker and T. Kimura for their constructive comments, which greatly improved our manuscript. Thin sections illustrated on Figure 40 have been processed by S. Morel (CR2P - CNRS, MNHN Sorbonne Université).

\section{REFERENCES}

Agnini C., Fornaciari E., Raffi I., Catanzariti R., Pälike H., BACKMAN J. \& RIO D. 2014. - Biozonation and biochronology of Paleogene calcareous nannofossils from low and middle latitudes. Newsletters on Stratigraphy 47: 131-181. https://doi. org/10.1127/0078-0421/2014/0042

AlleN J. A. 1908. - The North American right whale and its near allies. Bulletin of the American Museum of Natural History 24: 277-322. http://hdl.handle.net/2246/1957

Allen G. M. 1921. - A new fossil cetacean. Bulletin of the Museum of Comparative Zoology 65 (1): 1-14. https://biodiversitylibrary.org/page/4774154
ANDREWS R. C. 1911. - A new porpoise from Japan. Bulletin of the American Museum of Natural History 30: 31-51. http:// hdl.handle.net/2246/1786

ANDrews R. C. 1914. - Monographs of the Pacific Cetacea - the California gray whale (Rhachianectes glaucus Cope). Memoirs of the American Museum of Natural History 1 (5-6): 229-287. http://hdl.handle.net/2246/5730

ANDREWS R. C. 1921. - A remarkable case of external hindlimbs in a humpback whale. American Museum Novitates 9: 1-6. http://hdl.handle.net/2246/4849

ARVY L. 1979. - The abdominal bones of cetaceans. Investigations on Cetacea 10: 215-227.

Bajpai S., Thewissen J. G. M. \& Conley R. W. 2011. - Cranial anatomy of middle Eocene Remingtonocetus (Cetacea, Mammalia) from Kutch, India. Journal of Paleontology 85: 703-718. https://doi.org/10.1666/10-128.1

BARNES L. G. 1979. - Fossil enaliarctine pinnipeds (Mammalia: Otariidae) from Pyramid Hill, Kern County, California. Contributions in Science, Los Angeles County Museum 318: 1-41. http://www.biodiversitylibrary.org/page/52102709

BARNES L. G. 1987. - An early Miocene pinniped of the genus Desmatophoca (Mammalia: Otariidae) from Washington. Contributions in Science, Los Angeles County Museum 382: 1-20. http://www.biodiversitylibrary.org/page/52108135

BARNES L. G. 1989. - A new enaliarctine pinniped from the Astoria Formation, Oregon, and a classification of the Otariidae (Mammalia: Carnivora). Contributions in Science, Los Angeles County Museum 403: 1-26. http://www.biodiversitylibrary.org/page/52138685

Barnes L. G. 2008. - Miocene and Pliocene Albireonidae (Cetacea, Odontoceti), rare and unusualfossil dolphins from the eastern North Pacific Ocean, in WANG X. \& BARNES L. G. (eds), Geology and vertebrate paleontology of Western and Southern North America, contributions in honor of David P. Whistler. Science Series 41: 100-152.

Barnes L. G., Kimura M., Furusawa H., \& Sawamura H. 1994. - Classification and distribution of Oligocene Aetiocetidae (Mammalia; Cetacea; Mysticeti) from western North America and Japan. The Island Arc 3 (4): 392-431. https:// doi.org/10.1111/j.1440-1738.1994.tb00122.x

Barnes L. G. \& SAnders A. E. 1996. - The transition from archaeocetes to mysticetes: late Oligocene toothed mysticetes from near Charleston, South Carolina. Paleontological Society Special Publication 8: 24. https://doi.org/10.1017/ S2475262200000265

BARONE R. 1976. - Anatomie comparée des mammiferes domestiques. Tome 1, fascicule 2 (Atlas), Ostéologie. Vigot, Paris, 428 p.

Bebej R. M., Zalmout I. S., El-Aziz A.A., Antar M. S., \& GingERICH P. D. 2016. — First remingtonocetid archaeocete (Mammalia, Cetacea) from the middle Eocene of Egypt with implications for biogeography and locomotion in early cetacean evolution. Journal of Paleontology 89: 882-893. https:// doi.org/10.1017/jpa.2015.57

Beatty B. L. \& Dooley A. C. 2009. - Injuries in a mysticete skeleton from the Miocene of Virginia, with a discussion of buoyancy and the primitive feeding mode in the Chaeomysticeti. Jeffersoniana 20: 1-28.

BenEDEN P. J. VAN \& GeRVAIS P. 1880. - Ostéographie des cétacés vivants et fossiles, comprenant la description et l'iconographie du squelette et du système dentaire de ces animaux; ainsi que des documents relatifs à leur histoire naturelle. Arthus Bertrand, Paris VIII, 634 p. https://doi.org/10.5962/bhl.title.50302

BENKE H. 1993. - Investigations on the osteology and the functional morphology of the flipper of whales and dolphins (Cetacea). Investigations on Cetacea 24: 9-252.

BERTA A. 1991. - New Enaliarctos* (Pinnipedimorpha) from the Oligocene and Miocene of Oregon and the role of "enaliarctids" in pinniped phylogeny. Smithsonian Contribution in Paleobiology 69: 1-33. https://doi.org/10.5479/si.00810266.69.1 
Berzin A. A. 1972. - The Sperm Whale. Pacific Scientific Research Institute of Fisheries and Oceanography. Israel Program for Scientific Translations, Jerusalem. US Dept. of Commerce, National Technical Information Service, Springfield, VA, 394 p.

BianucCi G. \& Gingerich P. D. 2011. - Aegyptocetus tarfa, n. gen. et sp. (Mammalia, Cetacea), from the middle Eocene of Egypt: clinorhynchy, olfaction, and hearing in a protocetid whale. Journal of Vertebrate Paleontology 31 (6): 1173-1188. https://doi.org/10.1080/039.031.0610

BIGg M. A. 1981. - Harbour Seal Phoca vitulina Linnaeus, 1758 and Phoca largha Pallas, 1811, in RIDGWAY S. H., HARRISON R. J. (eds), Handbook of Marine Mammals. Vol. 2. Seals. London Academic Press, London: 1-27.

BisCONTI M. 2005. - Skull morphology and phylogenetic relationships of a new diminutive balaenid from the lower Pliocene of Belgium. Palaeontology 48: 793-816. https://doi. $\mathrm{org} / 10.1111 / \mathrm{j} .1475-4983.2005 .00488 . \mathrm{x}$

BisCONTI M. 2012. - Comparative osteology and phylogenetic relationships of Miocaperea pulchra, the first fossil pygmy right whale genus and species (Cetacea, Mysticeti, Neobalaenidae). Zoological Journal of the Linnean Society 166: 876-911. https:// doi.org/10.1111/j.1096-3642.2012.00862.x

BisConti M. \& Bosselaers M. 2016. - Fragilicetus velponi: a new mysticete genus and species and its implications for the origin of Balaenopteridae (Mammalia, Cetacea, Mysticeti). Zoological Journal of the Linnean Society 177 (2): 450-474. https://doi.org/10.1111/zoj.12370

BisCONTI M., LAMBERT O. \& BOSSElaERS M. 2013. - Taxonomic revision of Isocetus depawi (Mammalia, Cetacea, Mysticeti) and the phylogenetic relationships of archaic 'cetothere' mysticetes. Palaeontology 56: 95-127. https://doi.org/10.1111/j.14754983.2012.01168.x

Bisconti M., Lambert O. \& Bosselaers M. 2017. - Revision of "Balaena" belgica reveals a new right whale species, the possible ancestry of the northern right whale, Eubalaena glacialis, and the ages of divergence for the living right whale species PeerJ 5: e3464. https://doi.org/10.7717/peerj.3464

BoesSENECKER R. W. \& FordyCE R. E. 2015a. - Anatomy, feeding ecology, and ontogeny of a transitional baleen whale: a new genus and species of Eomysticetidae (Mammalia: Cetacea) from the Oligocene of New Zealand. PeerJ 3: e1129. https:// doi.org/10.7717/peerj.1129

Boessenecker R. W. \& Fordyce R. E. 2015b. - A new genus and species of eomysticetid (Cetacea: Mysticeti) and a reinterpretation of 'Mauicetus' lophocephalus Marples, 1956: Transitional baleen whales from the upper Oligocene of New Zealand. Zoological Journal of the Linnean Society 175: 607660. https://doi.org/10.1111/zoj.12297

Boessenecker R. W. \& Fordyce R. E. 2017. — A new eomysticetid from the Oligocene Kokoamu Greensand of New Zealand and a review of the Eomysticetidae (Mammalia, Cetacea). Journal of Systematic Palaeontology 15: 429-469. https://doi. org/10.1080/14772019.2016.1191045

Boessenecker R. W., Fraser D., Churchill M. \& Geisler J. H. 2017. - A toothless dwarf dolphin (Odontoceti: Xenorophidae) points to explosive feeding diversification of modern whales (Neoceti). Proceeding of the Royal Society B 284: 20170531. https://doi.org/10.1098/rspb.2017.0531

BonNer W. N. 1981a. - Grey Seal Halichoerus grypus Fabricius, 1791, in Ridgway S. H., Harrison R. J. (eds), Handbook of Marine Mammals. Vol. 2. Seals. London Academic Press: 111-144.

BONNER W. N. 1981b. - Southern Fur Seals Arctocephalus (Geoffroy Saint-Hilaire \& Cuvier, 1826), in RIDGWAY S. H. \& HARrison R. J. (eds), Handbook of Marine Mammals. Vol. 2. Seals. London Academic Press, London: 161-208.

Bouetel V. \& Muizon C. DE 2006. - The anatomy and relationships of Piscobalaena nana (Cetacea, Mysticeti), a Ceto- theriidae s.s. from the early Pliocene of Peru. Geodiversitas 28 (2): 319-395.

BRANDT J. F. 1843. - De cetotherio, novo balaenarum familiae genre in Rossia Meridionali ante aliquot annos effoso. Bulletin de la Classe physico-mathématique de l'Académie impériale des Sciences de Saint-Pétersbourg 2 (1): 145-148. https://biodiversitylibrary.org/page/45977835

Brodie P. F. 1989. - The white whale - Delphinapterus leucas (Pallas, 1776), in RidgWaY S. H. \& HARRISON R. J. (eds), Handbook of Marine Mammals. Vol. 4. River Dolphins and the Larger Toothed Whales. Academic Press, London: 119-144.

Buffrénil V. De, Ricqlès A. De, Ray C. E. \& Domning D. P. 1990. - Bone histology of the ribs of the archaeocetes (Mammalia: Cetacea). Journal of Vertebrate Paleontology 10 (4): 455-466. https://www.jstor.org/stable/4523344

Buffrénil V., Canoville A., D’Anastasio R. \& Domning D. P. 2010. - Evolution of sirenian pachyosteosclerosis, a model-case for the study of bone structure in aquatic tetrapods. Journal of Mammalian Evolution 17: 101-120. https://doi. org/10.1007/s10914-010-9130-1

CARPENTER K. \& White D. 1986. - Feeding in the archaeocete whale Zygorhiza kochii (Cetacea: Archaeoceti). Mississippi Geology 7: 1-15.

Cooper L. N., Dawson S. D., Reidenberg J. S. \& Berta A. 2007a. - Neuromuscular anatomy and evolution of the cetacean Forelimb. The Anatomical Record 290: 1121-1137. https://doi.org/10.1002/ar.20571

Cooper L. N., Berta A., Dawson S. D. \& Reidenberg J. S. 2007b. - Evolution of hyperphalangy and digit reduction in the cetacean manus. The Anatomical Record 290: 654-672. https://doi.org/10.1002/ar.20532

Debey L. B. \& Pyenson N. D. 2013. - Osteological correlates and phylogenetic analysis of deep diving in living and extinct pinnipeds: What good are big eyes? Marine Mammal Science 29: 48-83. https://doi.org/10.1111/j.1748-7692.2011.00545.x

DEMÉré T. A. 1994. - Two new species of fossil walruses (Pinnipedia: Odobenidae) from the Upper Pliocene San Diego Formation, California. Proceedings of the San Diego Society of Natural History 29: 77-98. http://www.biodiversitylibrary. org/page/2887947

DEMÉRÉ T. A. \& BERTA A. 2001. - A re-evaluation of Proneotherium repenningi from the Miocene Astoria Formation of Oregon and its position as a basal odobenid (Pinnipedia: Mammalia). Journal of Vertebrate Paleontology 21: 279-310. https://doi. org/10.1671/0272-4634(2001)021[0279:AROPRF]2.0.CO;2

DEMÉRÉ T. A. \& BERTA A. 2008. - Skull anatomy of the Oligocene toothed mysticete Aetiocetus weltoni (Mammalia, Cetacea): implications for the mysticete evolution and functional anatomy. Zoological Journal of the Linnean Society 154: 308-352. https://doi.org/10.1111/j.1096-3642.2008.00414.x Deméré T. A., McGowen M., Berta A. \& Gatesy J. 2008. Morphological and molecular evidence for a stepwise evolutionary transition from teeth to baleen in mysticete whales. Systematic Biology 57: 15-37. https://doi.org/10.1080/10635150701884632

DeVries T. J. 1998. - Oligocene deposition and Cenozoic sequence boundaries in the Pisco Basin (Peru). Journal of South American Earth Sciences 11 (3): 217-231. https://doi. $\mathrm{org} / 10.1016 /$ S0895-9811(98)00014-5

DeVries T. J. 2004. - Eocene mollusks from the Pisco Basin (Southern Peru): evidence for re-evaluating the age of the Otuma Formation. XII Congreso Peruano de Geologia. Resumenes Extendidos 615-618.

DEVRIES T. J. 2017. - Eocene stratigraphy and depositional history near Puerto Caballas (East Pisco Basin, Peru). Boletín de la Sociedad Geológica del Perú 112: 39-52.

DeVries T. J., Narváez Y., Sanfilippo A., Malumian N. \& TAPIA P. 2006. - New microfossil evidence for a late Eocene age of the Otuma Formation (Southern Peru). XIII Congreso Peruano de Geologia, Resúmenes Extendidos: 615-618. 
Dines J. P., Otárola-Castillo E., Ralph P., Alas J., Daley T., Smith A. D. \& Dean M. D. 2014. - Sexual selection targets cetacean pelvic bones. Evolution 68: 3296-3306. https://doi. org/10.1111/evo.12516

Dunbar R. B., Marty R. C. \& Baker P. A. 1990. - Cenozoic marine sedimentation in the Sechura and Pisco basins, Peru. Palaeogeography, Palaeoclimatology, Palaeoecology 77: 235-261. https://doi.org/10.1016/0031-0182(90)90179-B

Ekdale E. G., Deméré T. A. \& Berta A. 2015. - Vascularization of the gray whale palate (Cetacea, Mysticeti, Eschrichtius robustus): soft tissue evidence for an alveolar source of blood to baleen. The Anatomical Record 298: 691-702. https://doi. org/10.1002/ar.23119

El Adli J. J., Deméré T. A. \& Bossenecker R. W. 2014. Herpetocetus morrowi (Cetacea: Mysticeti), a new species of diminutive baleen whale from the Upper Pliocene (Piacenzian) of California, USA, with observations on the evolution and relationships of the Cetotheriidae; Zoological Journal of the Linnean Society 170: 400-466. https://doi.org/10.1111/zoj.12108

EMLONG D. 1966. - A new archaic cetacean from the Oligocene of Northwest Oregon. Bulletin of the Museum of Natural History, University of Oregon 3: 1-51. http://hdl.handle. net/1794/19998

Evans H. E. \& De Lahunta A. 2013 - Miller's Anatomy of the Dog. Saunders, St Louis, 850 p.

FAHLKE J. M. 2012. — Bite marks revisited - evidence for middleto-late Eocene Basilosaurus isis predation on Dorudon atrox (both Cetacea, Basilosauridae). Palaeontologia Electronica 15 (3): 32A, 16 p. https://doi.org/10.26879/341

FahlKe J. M., Bastl K. A., Semprebon G. M. \& Gingerich P. D. 2013. - Paleoecology of archaeocete whales thorough the Eocene: dietary adaptations revealed by microwear analysis. Palaeogeography, Plaeoclimatology, Palaeoecology 386 :690-701. https://doi.org/10.1016/j.palaeo.2013.06.032

FaY F. H. 1982. - Ecology and Biology of the Pacific Walrus, Odobenus rosmarus divergens Illiger. US Department of Interior, Fish and Wildlife Service, North American fauna 74: 1-279. https://doi.org/10.3996/nafa.74.0001

Fischer R. E., SCOTT K. M. \& NAPles V. L. 2007. — Forelimb myology of the pygmy hippopotamus (Choeropsis liberiensis). The Anatomical Record 290: 673-693. https://doi.org/10.1002/ar.20531

FitzGERAlD E. M. G. 2006. - A bizarre new toothed mysticete (Cetacea) from Australia and the early evolution of baleen whales. Proceedings of the Royal Society Biological Sciences 273 (1604): 2955-2963. https://doi.org/10.1098/rspb.2006.3664

FitzGerald E. M. G. 2010. - The morphology and systematics of Mammalodon colliveri (Cetacea: Mysticeti), a toothed mysticete from the Oligocene of Australia. Zoological Journal of the Linnean Society 158: 367-476. https://doi.org/10.1111/ j.1096-3642.2009.00572.x

FitZGerald E. M. G. 2012. - Archaeocete-like jaws in a baleen whale. Biology Letters 8: 94-96. https://doi.org/10.1098/ rsbl.2011.0690

FLOWER W. H. 1864. - Notes on the skeletons of whales in the principal museums of Holland and Belgium, with descriptions of two species apparently new to science. Proceedings of the Zoological Society of London 1864: 384-420. https:// biodiversitylibrary.org/page/28500709

Ford J. K. B., Ellis G. M., MatKin C. O., Wetklo M. H., Barrett-Lennard L. G. \& Withler R. E. 2011. - Shark predation and tooth wear in a population of northeastern Pacific killer whales. Aquatic Biology 11: 213-224. https:// doi.org/10.3354/ab00307

FORDYCE R. E. 1994. - Waipatia maerewhenua, new genus and new species (Waipatiidae, new family), an archaic late Oligocene dolphin (Cetacea: Odontoceti: Platanistoidea) from New Zealand. Proceedings of the San Diego Society of Natural History 29: 147-176. https://doi.org/10.5962/bhl.part.10662
FORDYCE R. E. 2002. - Simocetus rayi (Odontoceti, Simocetidae, new family); a bizarre new archaic Oligocene dolphin from the eastern North Pacific. Smithsonian Contributions to Paleobiology 93: 185-222.

FORDYCE R. E. 2003. - Early crown-group Cetacea in the Southern Ocean: the toothed archaic mysticete Llanocetus. Journal of Vertebrate Paleontology 23 (3): 50A-51A.

FORDYCE R. E. 2004. - The transition from Archaeoceti to Neoceti: Oligocene archaeocetes in the southwest Pacific. Journal of Vertebrate Paleontology 24 (supplement 3): 258-259.

FORDYCE R. E. 1982. - A review of Australian fossil Cetacea. Memoirs of the National Museum Victoria 43: 43-59. https:// doi.org/10.24199/j.mmv.1982.43.04

FORDYCE R. E. 1989. - Problematic early Oligocene toothed whale (Cetacea, Mysticeti) from Waikari, North Canterbury, New Zealand. New Zealand Journal of Geology and Geophysics 32: 395-400. https://doi.org/10.1080/00288306.1989. 10425719

FordyCE R. E. \& MARX F. G. 2018. - Gigantism precedes filter feeding in baleen whale evolution. Current Biology 28 (10): 1670-1676.e2. https://doi.org/10.1016/j.cub.2018.04.027

FordyCE R. E. \& MUIZON C. DE 2001. - Evolutionary history of Cetaceans: a review, in MAZIN J. M \& BUfFréNIL V. DE (eds), Secondary Adaptation of Tetrapods to Life in the Water. Pfeil Verlag, Munich: 169-233.

Fourtanier E. \& Macharé J. 1988. — Late Eocene to Pliocene marine diatoms from Peru, in Round F. E. (ed.), Proceedings of the Ninth International Diatom Symposium, Bristol, August 24-30, 1986. Biopress, Bristol: 151-163.

FranTZ R. L. 1993. - Sedimentological and Geochemical Study of the Late Eocene to Early Oligocene Yumaque Formation, East Pisco Basin, Peru. Ms. A. Unpublished thesis, Rice University, Houston, 203, p.

GEISLER J. H. \& SANDERS A. E. 2003. - Morphological evidence for the phylogeny of Cetacea. Journal of Mammalian Evolution 10 (1/2): 23-129. https://doi.org/10.1023/A:1025552007291

Geisler J. H., Boessenecker R. W., Brown M. \& Beatty B. L. 2017. - The origin of filter feeding in whales. Current Biology 27: 1-7. https://doi.org/10.1016/j.cub.2017.06.003 Gingerich P. D. 2005. - Cetacea, in Rose L. D. \& ArChibald J. D. (eds), The Rise of Placental Mammals. Johns Hopkins University Press, Baltimore, MD: 234-252.

GingERICH P. D. 2008. - Early evolution of whales. A century of research in Egypt, in Fleagle J. G. \& GilberT C. C. (eds), Elwyn Simons: A Search for Origins. Springer, New York: 107124. https://doi.org/10.1007/978-0-387-73896-3_10

Gingerich P. D., Smith B. H. \& Simons E. L. 1990. - Hindlimbs of Eocene Basilosaurus: evidence of feet in whales. Science 249: 154-157. https://doi.org/10.1126/science.249.4965.154 Gingerich P. D, RaZa M. S., Arif M. Anwar M. \& Zhou X. 1994. - New whale from the Eocene of Pakistan and the origin of cetacean swimming. Nature 368: 844-847. https:// doi.org/10.1038/368844a0

Gingerich P. D., Ul-HaQ M., Zalmout I., Khan I. H. \& MaLKANi M. S. 2001. - Origin of whales from early artiodactyls: hands and feet of Eocene Protocetidae from Pakistan. Science 293 (5538): 2239-2242. https://doi.org/10.1126/ science. 1063902

Gingerich P. D., Al-Haq M., Koenigswald W. von, Sanders W. J., Smith, B. H. \& Zalmut I. S. 2009. - New protocetid whale from the Middle Eocene of Pakistan: birth on land, precocial development, and sexual dimorphism. PLoS One 4 (2): 1-20. https://doi.org/10.1371/journal.pone.0004366

Girondot M. \& Laurin M. 2003. - Bone Profiler: a tool to quantify, model, and statistically compare bone-section compactness profiles. Journal of Vertebrate Paleontology 23: 458461. https://doi.org/10.1671/0272-4634(2003)023[0458:BPA TTQ]2.0.CO;2 
GOL'DIN P. 2014. - Naming an innominate: pelvis and hindlimbs of Miocene whales give an insight into evolution and homology of cetacean pelvic girdle. Evolutionary Biology 41: 473-479. https://doi.org/10.1007/s11692-014-9281-8

Gol'din P., Startsev D. \& Krakhmalnaya T. 2014. - The anatomy of the Late Miocene baleen whale Cetotherium riabinini from Ukraine. Acta Palaeontologica Polonica 59 (4): 795-814. https://doi.org/10.4202/app.2012.0107

Hocking D. P., Marx F. G., Park T., Fitzgerald E. M. G. \& EvANS A. R. 2017a. - A behavioural framework for the evolution of feeding in predatory aquatic mammals. Proceedings of the Royal Society Biological Sciences 284: 20162750. https:// doi.org/10.1098/rspb.2016.2750

Hocking D. P., Marx F. G., Fitzgerald E.M.G. \& Evans A.R. 2017 b. - Ancient whales did not filter feed with their teeth. Biology Letters 13: 20170348. https://doi.org/10.1098/ rsbl.2017.0348

Hocking D. P., Marx F. G., Park T., Fitzgerald E. M. G. \& Evans A. R. 2017c. - Reply to comment by Kienle et al. 2017. Proceedings of the Royal Society Biological Sciences 284: 20171836. https://doi.org/10.1098/rspb.2017.1836

HoSOKAWA H. 1951. - On the extrinsic eye muscles of the whale, with special remarks upon the innervation and function of the musculus retractor bulbi. The Scientific Reports of the Whale Research Institute 6: 1-33.

Houssaye A., Tafforeau P. Muizon C. De \& Gingerich D. P. 2015. - Transition of Eocene whales from land to sea: evidence from bone microstructure. Plos ONE 10 (2): e0118409. https://doi.org/10.1371/journal.pone.0118409

Howell A. B. 1927. - Contribution to the anatomy of the Chinese finless porpoise Neomeris phocaenoides. Procedings of the United States National Museum 70 (13): 1-43. https://doi. org/10.5479/si.00963801.70-2662.1

Howell A. B. 1930a. - Myology of the narwhal (Monodon monoceros). American Journal of Anatomy 46 (2): 187-215. https://doi.org/10.1002/aja.1000460202

Howell A. B. 1930b. - Aquatic Mammals: their Adaptations to Life in the Water. C. C. Thomas Publisher, Springfield and Baltimore, 338 p. https://doi.org/10.5962/bhl.title.6582

HulberT R. C. JR 1998. - Postcranial osteology of the North American middle Eocene protocetid Georgiacetus, in THEWISSEN J. G. M. (ed.), The Emergence of Whales: Evolutionary Patterns in the Origin of Cetacea. Plenum press, New York and London: 235-267. https://doi.org/10.1007/978-1-4899-0159-0_8

Hulbert R. C. JR, Petkewich R. M., Bishop G. A., Burky D. \& Aleshire D. P. 1998. - A new middle Eocene protocetid whale (Mammalia: Cetacea: Archaeoceti) and associated biota from Georgia. Journal of Paleontology 72: 905-925. https:// doi.org/10.1017/S0022336000027232

INTERNATIONAL COMMITTEE ON VETERINARY GrosS ANATOMICal Nomenclature 2012. - Nomina Anatomica Veterinaria. Fifth edition. Hannover (Germany), Columbia, MO (USA), Ghent (Belgium, Sapporo (Japan), 177 p.

Johnston C. \& Berta A. 2011. - Comparative anatomy and evolutionary history of suction feeding in cetaceans. Marine Mammal Science 27 (3): 493-513. https://doi.org/10.1111/ j.1748-7692.2010.00420.x

Kastelein R. A., Zweypfenning R. C. V. J., Spekreijse H., DubBELDAM J. L. \& BORN E. W. 1993. - The anatomy of the walrus head (Odobenus rosmarus). Part 3: the eyes and their function in walrus ecology. Aquatic Mammals 19 (2): 61-92.

KellogG R. 1922. - Description of the skull of Megaptera miocaena, a fossil humpback whale from the Miocene diatomaceous earth of Lompoc, California. Procedings of the United States National Museum 61: 1-18. https://doi.org/10.5479/ si.00963801.61-2435.1

KellogG R. 1923. - Description of two squalodonts recently discovered in the Calvert Cliffs, Maryland; and notes on the shark-toothed dolphins. Proceedings of the United States National Museum 62 (6): 1-69. https://doi.org/10.5479/ si.00963801.62-2462.1

KELLOGG R. 1924. -- Description of a new genus and species of whalebone whale from the Calvert Cliffs Maryland. Proceedings of the United States National Museum 63: 1-14. https:// doi.org/10.5479/si.00963801.63-2483.1

KeLlogG R. 1934a. - The patagonian fossil whalebone whale Cetotherium moreni (Lydekker). Carnegie Institution of Washington Publication 447: 64-81.

KellogG R. 1934b. - A new cetothere from the Modelo Formation at Los Angeles, California. Carnegie Museum of Washington Publications 447: 83-104.

KellogG R. 1936. - Review of the Archaeoceti. Carnegie Institution of Washington Publications 482: 1-366.

KELLOGG R. 1965. - Fossil marine mammals from the Miocene Calvert Formation of Maryland and Virginia. Bulletin of the United States National Museum 247 (1-2): 1-63. https://biodiversitylibrary.org/page/32795711

KeLLOGG R. 1968. -- Fossil marine mammals from the Miocene Calvert Formation of Maryland and Virginia. Bulletin of the United States National Museum 247 (5-8): 103-201. https:// biodiversitylibrary.org/page/32795812

KellogG R. 1969. - Cetothere skeletons from the Miocene Choptank Formation of Maryland and Virginia. Bulletin of the United States National Museum 294: 1-40. https://doi. org/10.5479/SI.03629236.294.1

KeNYON K. W. 1981. — Monk Seals Monachus Fleming, 1822, in RIDGWAY S. H. \& HARRISON R. J. (eds), Handbook of Marine Mammals. Vol. 2. Seals. Academic Press, London: 195-220.

Kienle S. S., Law C. J., Costa D. P., Berta A. \& Mehta R. S. 2017. - Revisiting the behavioural framework of feeding in predatory aquatic mammals. Procedings of the Royal Society Biological Science 284: 20171035. https://doi.org/10.1098/ rspb.2017.1035

Kimura T. \& OZAWA T. 2002. - A new cetothere (Cetacea: Mysticeti) from the early Miocene of Japan. Journal of Vertebrate Paleontology 22: 684-702. https://doi.org/10.1671/02 72-4634(2002)022 [0684:ANCCMF]2.0.CO;2

Ksepka D. T., Clarke J. A., DeVries T. J. \& Urbina M. 2008. - Osteology of Icadyptes salasi, a giant penguin from the Eocene of Peru. Journal of Anatomy 213: 131-147. https:// doi.org/10.1111/j.1469-7580.2008.00927.x

KÜKENTHAL W. G. 1914. - Untersuchungen an Walen (Zweiter Teil). Jenaische Zeitschrift für Naturwissenschaft 51: 1-122. https://biodiversitylibrary.org/page/29105022

Lambert O., Martínez-CÁceres M., Bianucci G., Di Celma C., Salas-Gismondi R., Steurbaut E., Urbina M. \& Muizon C. DE 2017a. - Earliest mysticete from the Late Eocene of Peru sheds new light on the origin of baleen whales. Current Biology 27 (10): 1535-1541.e2. https://doi.org/10.1016/j. cub.2017.04.026

Lambert O., Muizon C. de, Malinverno E., Di Celma C., Urbina M. \& BianuCCI G. 2017b. - A new odontocete (toothed cetacean) from the Early Miocene of Peru expands the morphological disparity of extinct heterodont dolphins. Journal of Systematic Palaeontology: 1-36. https://doi.org/10. 1080/14772019.2017.1359689

LeÓN W. \& Aleman A. 2002. — Forearc extension: tectonics, sedimentologic and stratigraphic evolution of the East Pisco Basin. XI Congreso Peruano de Geología: 9-12.

LÖNNBERG E. 1910. - The pelvic bones of some Cetacea. Arkiv för Zoology 7 (10): 1-15. https://biodiversitylibrary. org/page/6457138

LÖNNBERG E. 1938. - Notes on the skeleton of Prodelphinus graffmani Lönnb. Arkiv för Zoology 30A (20): 1-21.

LUCAS F. A. 1900. - The pelvic girdle of zeuglodon Basilosaurus cetoides (Owen), with notes on other portions of the skeleton. 
Proceedings of the United States National Museum 23: 327-331. https://doi.org/10.5479/si.00963801.23-1211.327

Madar S. I., Thewissen J. G. M. \& Hussain S. T. 2002. Additional holotype remains of Ambulocetus natans (Cetacea, Ambulocetidae), and their implications for locomotion in early whales. Journal of Vertebrate Paleontology 22 (2): 405422. https://www.jstor.org/stable/4524232

Marocco R. \& Muizon C. DE 1988. — Los vertebrados del Neogeno de La Costa Sur del Perú: ambiente sedimentario y condiciones de fosilización. Bulletin de l'Institut français des Études andines 17 (2): 105-117.

Martínez-CÁCeres M. \& Muizon C. De 2011. - A new basilosaurid (Cetacea, Pelagiceti) from the late Eocene to early Oligocene Otuma Formation of Peru. Comptes Rendus Palevol 10 (7): 517-526. https://doi.org/10.1016/j.crpv.2011.03.006

Martínez-CÁCeres M., LamberT O. \& Muizon C. De 2017. - The anatomy and phylogenetic affinities of Cynthiacetus peruvianus, a large Dorudon-like basilosaurid (Cetacea, Mammalia) from the late Eocene of Peru. Geodiversitas 39 (1): 7-163. https://doi.org/10.5252/g2017n1a1

MARTINI E. 1971. — Standard Tertiary and Quaternary calcareous nannoplankton zonation. Proceedings of Second Planktonic Conference, Roma, 1970, 2: 739-785.

MARTY R. C. 1989. - Statigraphy and Chemical Sedimentology of Cenozoic Biogenic Sediments from the Pisco and Sechura Basins, Peru. PhD Dissertation, Rice University, Houston, 268 p.

MARX F. 2011. - The more the merrier? A large cladistic analysis of mysticetes, and comments on the transition from teeth to baleen. Journal of Mammalian Evolution 18 (2): 77-100. https://doi.org/10.1007/s10914-010-9148-4

MarX F. G. \& FordyCE R. E. 2015. - Baleen boom and bust: a synthesis of mysticete phylogeny, diversity and disparity. Royal Society Open Science 2: 140434. https://doi.org/10.1098/ rsos. 140434

MarX F. G. \& Kohno N. 2016. - A new Miocene baleen whale from the Peruvian desert. Royal Society Open Science 3: 160542. https://doi.org/10.1098/rsos.160542

Marx F. G., Hocking D. P., Park T., Ziegler T., Evans A. R., \& FitzGerald E. M. G. 2016. - Suction feeding preceded filtering in baleen whale evolution. Memoirs of Museum Victoria 75: 71-82. https://doi.org/10.24199/j.mmv.2016.75.04

Marx F. G., Tsai C.-H. \& Fordyce R. E. 2015. - A new Early Oligocene toothed 'baleen'whale (Mysticeti: Aetiocetidae) from western North America: one of the oldest and the smallest. Royal Society Open Science 2: 150476. https://doi. org/10.1098/rsos.150476

Marx F. G., Collareta A., Gioncada A., Post K., Lambert O., Bonaccorsi E., Urbina M. \& Bianucci G. 2017. How whales used to filter: exceptionally preserved baleen in a Miocene cetotheriid. Journal of Anatomy 231: 212-220. https://doi.org/10.1111/joa.12622

Mass A. M. \& SupIN A. Y. 2017. — Vision, in WÜrsig B., TheWISSEN J. G. M. \& Kovacs K. M. (eds), Encyclopedia of Marine Mammals, Third Edition. Academic Press, Cambridge (MA): 1035-1044. https://doi.org/10.1016/B978-0-12804327-1.00266-1

Mass A. M. \& Supin A. Y. 2009. - Vision, in Perrin W. F., Thewissen J. G. M. \& Kovacs K. M. (eds), Encyclopedia of Marine Mammals, Second Edition. Academic Press, Cambridge (MA): 1200-1211. https://doi.org/10.1016/B978-012-373553-9.00275-3

MEAD J. G. \& FORDYCE R. E. 2009. —The therian skull: a lexicon with emphasis on the odontocetes. Smithsonian Contributions to Zoology 627: 1-216. https://doi.org/10.5479/si.00810282.627

Mitchell E. D. 1989. - A new cetacean from the late Eocene La Meseta formation, Seymour Island, Antarctic Peninsula. Canadian Journal of Fisheries and Aquatic Sciences 46 (12): 2219-2235. https://doi.org/10.1139/f89-273
Muizon C. DE 1981. — Les Vertébrés fossiles de la Formation Pisco (Pérou). Première partie: deux nouveaux Monachinae (Phocidae, Mammalia) du Pliocène de Sud-Sacaco. Travaux de l'Institut français d'Études andines 22: 1-160.

Muizon C. DE 1991. - A new Ziphiidae (Odontoceti, Mammalia) from the Early Miocene of Washington state (USA) and a phylogenetical analysis of the major groups of odontocetes. Bulletin du Muséum national d'Histoire naturelle, Paris, 4e série, section C, 12: 279-326. https://biodiversitylibrary. org/page/55749938

MuIZON C. DE 1993. - Walrus-like feeding adaptation in a new cetacean from the Pliocene of Peru. Nature 365: 745-748. https://doi.org/10.1038/365745a0

MuizOn C. DE \& Hendey Q. B. 1980. - Late Tertiary Seals of the South Atlantic Ocean. Annals of the South African Museum. 82 (3): 91-128. https://biodiversitylibrary.org/page/40752149

Muizon C. De \& DeVries T. J. 1985. - Geology and paleontology of late Cenozoic marine deposits in the Sacaco area (Peru). Geologische Rundschau 74 (3): 547-563. https://doi. org/10.1007/BF01821211

Muizon C. De, Domning D. P. \& Ketten D. R. 2002. Odobenocetops peruvianus, the walrus-convergent delphinoid (Mammalia: Cetacea) from the early Pliocene of Peru. Smithsonian Contributions to Paleobiology 93: 223-261.

Muizon C. DE \& Domning D. P. 2002. - The anatomy of Odobenocetops (Delphinoidea, Mammalia), the walrus-like dolphin from the Pliocene of Peru and its palaeobiological implications. Zoological Journal of the Linnean Society 134: 423-452. https://doi.org/10.1046/j.1096-3642.2002.00015.x

Nummela S., Hussain S. T. \& Thewissen J. G. M. 2006. - Cranial anatomy of Pakicetidae (Cetacea, Mammalia). Journal of Vertebrate Paleontology 26: 746-759. https://doi. org/10.1671/0272-4634(2006)26[746:CAOPCM]2.0.CO;2

Nemoto T. 1963. - New records of sperm whales with protruded rudimentary hind-limbs. Scientific Reports of the Whales Research Institute 17: 79-81.

NishiwaKi M. \& KasuYa T. 1970. — A Greenland right whale caught at Osaka Bay. Scientific Reports of the Whales Research Institute 22: 45-62.

ODELl D. K. 1981. - California Sea Lion Zalophus californianus (Lesson, 1828), in Ridgway S. H. \& HarRison R. J. (eds), Handbook of Marine Mammals. Vol. 1. The Walrus, Sea Lions, Fur Seals and Sea Otter. Academic Press, London: 67-97.

Ogama T. \& KamiYa T. 1957. - A case of the cachalot with protruded rudimentary hind limbs. Scientific Reports of the Whales Research Institute 12: 197-208.

OKAZAKI Y. 2012. - A new mysticete from the upper Oligocene Ashiya group, Kyushu, Japan and its significance to mysticete evolution. Bulletin of the Kitakyushu Museum of Natural History and Human History, Series A (Natural History) 10: 129-152.

OMURA H. 1957. - Osteological study of the little piked whale from the coast of Japan. Scientific Reports of the Whales Research Institute 12: 1-21.

Omura H. 1958. - North Pacific right whale. Scientific Reports of the Whales Research Institute 13: 1-52.

Peredo C. M., Pyenson N. D. \& Boersma. A. T. 2017. Decoupling tooth loss from the evolution of baleen in whales. Frontiers in Marine Science 4: 67. https://doi.org/10.3389/ fmars.2017.00067

Peredo C. M. \& Pyenson N. D. 2018. - Salishicetus meadi, a new aetiocetid from the late Oligocene of Washington State and implications for feeding transitions in early mysticete evolution. Royal Society Open Science 5: 172336. https://doi. org/10.1098/rsos.172336

Pilleri G. 1989. - Balaenoptera siberi, ein neuer spätmiozäner Bartenwal aus der Pisco-Formation Perus, in Pilleri G. (ed.), Beiträge zur Paläontologie der Cetaceen Perus. Hirnanatomisches Institut Ostermundingen, Bern: 63-84. 
Pledge N. S. 2005. - A new species of early Oligocene cetacean from Port Willunga, South Australia. Memoirs of the Queensland Museum 51: 123-133. http://www.biodiversitylibrary.org/ page/55834547

Pritchard B. G. 1939. - On the discovery of a fossil whale in the older Tertiaries of Torquay, Victoria. The Victorian Naturalist 55 (9): 151-159. http://www.biodiversitylibrary.org/page/40653535

RAY G. C. 1966. - Round table: practical problems, in NorRIS K. S. (ed.), Whales, Dolphins, and Porpoises. University of California Press, Berkeley: 671.

RaY G. C. 1981. - Ross Seal Ommatophoca rossii Gray, 1844, in RidgWaY S. H. \& HaRrison R. J. (eds), Handbook of Marine Mammals. Vol. 2. Seals. Academic Press, London: 275-296.

Reeves R. R. \& King J. K. 1981. - Hooded Seal Cystophora cristata Erxleben, 1777, in RIDGWAY S. H. \& HARRISON R. J. (eds), Handbook of Marine Mammals. Vol. 2. Seals. Academic Press, London: 171-194.

Rogers T. 2017. — Leopard seal: Hydrurga leptonyx, in WÜRSIG B., Thewissen J. G. M. \& Kovacs K. M. (eds), Encyclopedia of Marine Mammals, Third Edition. Academic Press, Cambridge (MA): 550-552. https://doi.org/10.1016/B978-0-12-804327$1.00163-1$

RUSSELL L. S. 1968. - A new cetacean from the Oligocene Sooke Formation of Vancouver Island, British Columbia. Canadian Journal of Earth Sciences 5: 929-933. https://doi.org/10.1139/ e68-089

SAnders A. E. \& Barnes L. G. 2002. - Paleontology of the late Oligocene Ashley and Chandler Bridge formations of South Carolina, 3: Eomysticetidae, a new family of primitive mysticetes (Mammalia: Cetacea). Smithsonian Contributions to Paleobiology 93: 313-356.

SAnders A. E. \& Geisler J. H. 2015. - A new basal odontocete from the upper Rupelian of South Carolina, USA, with contributions to the systematics of Xenorophus and Mirocetus (Mammalia, Cetacea). Journal of Vertebrate Paleontology 35: e890107. https://doi.org/10.1080/02724634.2014.890107

SANDERSON S. L. \& WASSERSUG R. 1993. - Convergent and alternative designs for vertebrate suspension feeding, in HANKEN J. \& Hall B. K. (eds), The Skull. University of Chicago Press, Chicago: 37-112.

SAWAMURA H. 2008. - The origin of baleen whale - Comparative morphology of the toothed Mysticetes and the minke whale fetuses. Journal of Fossil Research 40 (2): 120-130.

SAWAMURA H., ICHISHIMA H., ITO H. \& ISHIKAWA H. 2006. Features implying the beginning of baleen growth in aetiocetids. Journal of Vertebrate Paleontology 26 (Suppl. 3): 120A.

SCHUlte H. W. VON 1916. - Anatomy of a foetus Balaenoptera borealis. Memoirs of the American Museum of Natural History 1: 389-502. https://doi.org/10.5962/bhl.title.31424

SChulte H. W. vON \& DE Forest SMith 1918. — The external charactrers, skeletal muscles, and peripheral nerves of Kogia breviceps (Blainville). Bulletin of the American Museum of Natural History 38: 7-72. http://hdl.handle.net/2246/1348

Simôes-Lopez P. C. \& GuTstein C. S. 2004. - Notes on the anatomy, positioning and homology of the pelvic bones in small cetaceans (Cetacea, Delphinidae, Pontoporiidae). Latin American Journal of Aquatic Mammals 3 (2): 1-6.

Snively E., FAHLKe J. M. \& Welsh R. C. 2015. — Bone-breaking bite force of Basilosaurus isis (Mammalia, Cetacea) from the Late Eocene of Egypt estimated by Finite Element Analysis. PLoS ONE 10: e0118380. https://doi.org/10.1371/journal. pone. 0118380

STEEMAN M. E. 2007. - Cladistic analysis and a revised classification of fossil and recent mysticetes. Zoological Journal of the Linnean Society of London 150: 875-894. https://doi. org/10.1111/j.1096-3642.2007.00313.x

STRUTHERS J. 1881. - The bones, articulations, and muscles of the rudimentary hind-limb of the Greenland right whale
(Balaena mysticetus). Journal of Anatomy and Physiology 15: 141-321. https://www.ncbi.nlm.nih.gov/pubmed/17231384

STRUTHERS J. 1888. - On some points in the anatomy of a Megaptera longimana: Part II. Journal of Anatomy and Physiology 22: 237-282. https://www.ncbi.nlm.nih.gov/pubmed/17231740

STRUTHERS J. 1893. - On the rudimentary hind-limb of a great fin-whale (Balaenoptera musculus) in comparison with those of the humpback whale and the Greenland right-whale. Journal of Anatomy and Physiology 27 (3): 291-335. https://www.ncbi. nlm.nih.gov/pubmed/17232044

SwOFFORD D. L. 2002. — PAUP*. Phylogenetic Analysis Using Parsimony (*and Other Methods). Version 4. Sinauer Associates, Sunderland, Massachusetts.

Szewciw L. J., Kerckhove D. G. De, Grim G. W. \& Fudge D. S. 2010. - Calcification provides mechanical reinforcement to whale baleen alpha-keratin. Proceedings of the Royal Society B 277: 2597-2605. https://doi.org/10.1098/rspb.2010.0399

Tajima Y., Hayashi Y. \& Yamada T. K. 2004. - Comparative anatomical study on the relationships between the vestigial pelvic bones and the surrounding structures of finless porpoises (Neophocaena phocaenoides). Journal of Veterinary Medical Science 66 (7): 761-766. https://doi.org/10.1292/jvms.66.761

Thewissen J. G. M., Cooper L. N., Georges J. C. \& Bajpai S. 2009. - From land to water: the origin of whales, dolphins and porpoises. Evo Edu Outreach 2: 272-288. https://doi. org/10.1007/s12052-009-0135-2

TruE F. W. 1904. - The whalebone whales of the Western North Atlantic compared with those occurring in European waters with some observations on the species of the North Pacific. Smithsonian Contribution to Knowledge 33: 1-332. https:// doi.org/10.5962/bhl.title. 25586

UHEN M. D. 1999. - New species of protocetid archaeocete whale, Eocetus wardii (Mammalia: Cetacea) from the Middle Eocene of North Carolina. Journal of Paleontology 73 (3): 512 528. https://doi.org/10.1017/S002233600002802X

Uhen M. D. 2004. - Form, function, and anatomy of Dorudon atrox (Mammalia, Cetacea): an archaeocete from the middle to late Eocene of Egypt. University of Michigan Papers on Paleontology 34: 1-222. http://hdl.handle.net/2027.42/48670

Uhen M. D. 2008. - New protocetid whale from Alabama and Mississippi, and a new cetacean clade, Pelagiceti. Journal of Vertebrate Paleontology 28 (3): 589-593. https://doi. org/10.1671/0272-4634(2008)28[589:NPWFAA]2.0.CO;2

UHEN M. D. 2014. - New material of Nachitochia jonesi and a comparison of the innominata and locomotor capabilities of Protocetidae. Marine Mammal Science 30: 1029-1066. https://doi.org/10.1111/mms.12100

Uhen M. D. \& Gingerich P. D. 2001. - New genus of dorudontine archaeocete (Cetacea) from the Middle-to-Late Eocene of South Carolina. Marine Mammal Science 17 (1) 1-34. https://doi.org/10.1111/j.1748-7692.2001.tb00979.x

Uhen M. D., Fordyce R. E. \& Barnes L. G. 2008a. - 35. Mysticeti, in Janis C. M., Gunnell G. F. \& Uhen M. D. (eds), Evolution of Tertiary Mammals of North America. Vol. 2. Small Mammals, Xenarthrans and Marine Mammals. Cambridge University Press, Cambridge: 607-628.

Uhen M. D., Pyenson N., DeVries T. \& Urbina M. 2008b. The oldest cetaceans from the Southern hemisphere: new archaeocetes from the Pisco Basin of Southern Peru. Journal of Vertebrate Paleontology 28 (3): 154A.

VAN VALEN L. 1968. - Monophyly or diphyly in the origin of whales. Evolution 22:37-41. https://doi.org/10.1111/j.1558-5646.1968. tb03446.x

Walker G. E. \& Ling J. K. 1981. - New Zealand Sea Lion Phocarctos hookeri (Gray, 1844), in RIDGWAY S. H. \& HARRISON R. J. (eds), Handbook of Marine Mammals. Vol. 1. The Walrus, Sea Lions, Fur Seals and Sea Otter. Academic Press, London: 25-38 
Werth A. J. 2000. — Feeding in marine mammals, in SCHWENK K. (ed.), Feeding: Form, Function, and Evolution in Tetrapods. Academic Press, San Diego: 487-526.

Werth A. J. 2006. - Mandibular and dental variation and the evolution of suction feeding in Odontoceti. Journal of Mammalogy 87 (3): 579-588. https://doi.org/10.1644/05MAMM-A-279R1.1
Werth A. J. 2007. - Adaptations of the cetacean hyolingual apparatus for aquatic feeding and thermoregulation. Anatomical Record 290: 546-568. https://doi.org/10.1002/ar.20538 Whitmore F. C. \& BARnes L. G. 2008. - The Herpetocetinae, a new subfamily of extinct baleen whales (Mammalia, Cetacea, Cetotheriidae). Virginia Museum of Natural History Special Publication 14: 141-180.

Submitted on 3 December 2018; accepted on 20 February 2019; published on 30 May 2019. 


\section{APPENDICES}

APPENDIX 1. - List of genus and species names cited in the text with authorship and date of publication.

Aegyptocetus Bianucci \& Gingerich, 2011

Aegyptocetus tarfa Bianucci \& Gingerich, 2011

Aetiocetus cotylalveus Emlong, 1966

Aetiocetus Emlong, 1966

Aetiocetus polydentatus Barnes, Kimura, Furusawa \& Sawamura, 1995

Aetiocetus tomitai Barnes, Kimura, Furusawa \& Sawamura, 1995 Aetiocetus weltoni Barnes, Kimura, Furusawa \& Sawamura, 1995

Aglaocetus Kellogg, 1934

Aglaocetus moreni Kellogg, 1934

Aglaocetus patulus Kellogg, 1968

Agorophius Muller, 1849

Archaeodelphis Allen, 1921

Archaeodelphis patrius Allen, 1921

Arctocephalus E Geoffroy Saint-Hilaire \& F. Cuvier, 1826

Arctocephalus philippii (Petters, 1866)

Artiocetus Gingerich, Haq, Zalmout, Khan \& Malkani, 2001

Artiocetus clavis Gingerich, Haq, Zalmout, Khan \& Malkani, 2001

Balaena Linnaeus, 1758

Balaena mysticetus Linnaeus, 1758

Balaenella Bisconti, 2005

Balaenella brachyrhynchus Bisconti, 2005

Balaenoptera Lacépède, 1804

Balaenoptera acutorostrata Lacépède, 1804

Balaenoptera musculus (Linnaeus, 1758)

Balaenoptera physalus (Linnaeus, 1758)

Basilosaurus Harlan, 1834

Basilosaurus cetoides (Owen, 1839)

Basilosaurus isis (Beadnell in Andrews, 1904)

Caperea Gray, 1846

Caperea marginata Gray, 1846

Cetotherium Brandt, 1843

Cetotherium rathkii Brandt, 1843

Cetotherium riabinini Gol'din, Startsev \& Krakhmalnaya, 2014

Chonecetus Russell, 1968

Chonecetus sookensis Russell, 1968

Chrysocetus Uhen \& Gingerich, 2001

Chrysocetus healyorum Uhen \& Gingerich, 2001

Coronodon Geisler, Boessenecker, Brown \& Beatty, 2017

Coronodon havensteini Geisler, Boessenecker, Brown \& Beatty, 2017

Cynthiacetus Uhen, 2005

Cynthiacetus peruvianus, Martínez-Cáceres \& Muizon, 2011

Cystophora Nilsson, 1820

Cystophora cristata Erxleben, 1777

Delphinapterus Lacépède, 1804

Delphinapterus leucas Pallas, 1776

Desmatophoca Condon, 1906

Desmatophoca brachycephala Barnes, 1987

Diorocetus Kellogg, 1968

Diorocetus hiatus Kellogg, 1968

Dorudon Gibbes, 1845
Dorudon atrox (Andrews, 1906)

Echovenator Churchill, Martínez-Cáceres, Muizon, Mnieckowski \& Geisler, 2016

Enaliarctos Mitchell \&Tedford, 1973

Enaliarctos tedfordi Berta, 1991

Eomysticetus Sanders \& Barnes, 2002

Eomysticetus whitmorei Sanders \& Barnes, 2002

Eschrichtius Gray, 1864

Eschrichtius robustus (Lilljeborg, 1861)

Eubalaena Gray, 1864

Eubalaena australis (A. Desmoulins, 1822)

Eubalaena glacialis (Müller, 1776)

Eubalaena japonica (Lacépède, 1818)

Fucaia Marx, Tsai \& Fordyce, 2015

Fucaia buelli Marx, Tsai \& Fordyce, 2015

Fucaia goedertorum (Barnes, Kimura, Furusawa \& Sawamura, 1995)

Georgiacetus Hulbert, Petkewich, Bishop, Bukry \& Aleshire, 1998

Georgiacetus vogtlensis: Hulbert, Petkewich, Bishop, Bukry \& Aleshire, 1998

Halichoerus Nillson, 1820

Halichoerus grypus (Fabricius, 1791)

Herpetocetus Van Beneden, 1872

Herpetocetus bramblei Whitmore \& Barnes, 2008

Herpetocetus morrowi El Adli, Deméré \& Boessenecker, 2014

Herpetocetus transatlanticus Whitmore \& Barnes, 2008

Homiphoca Muizon \& Hendey, 1980

Homiphoca capensis (Hendey \& Repenning, 1972)

Hydrurga Gistel, 1848

Hydrurga leptonyx (Blainville, 1820)

Incakujira Marx \& Kohno, 2016

Incakujira anillodefuego Marx \& Kohno, 2016

Isanacetus Kimura \& Ozawa, 2002

Isanacetus laticephalus Kimura \& Ozawa, 2002

Janjucetus Fitzgerald, 2006

Janjucetus hunderi Fitzgerald, 2006

Llanocetus Mitchell, 1989

Llanocetus denticrenatus Mitchell, 1989

Maiacetus Gingerich, Ul-Haq, Koenigswald, Sanders, Smith \& Zalmout, 2009

Maiacetus inuus Gingerich, Ul-Haq, Koenigswald, Sanders,

Smith \& Zalmout, 2009

Mammalodon Pritchard, 1939

Mammalodon colliveri Pritchard, 1939

Megaptera Gray, 1846

Megaptera miocaena Kellogg, 1922

Megaptera novaeangliae (Borowski, 1781)

Micromysticetus Sanders \& Barnes, 2002

Micromysticetus rothauseni Sanders \& Barnes, 2002

Miocaperea Bisconti, 2012

Miocaperea pulchra Bisconti, 2012

Mixocetus Kellogg, 1934 
Mixocetus elysius Kellogg, 1934

Morawanocetus Barnes, Kimura, Furusawa \& Sawamura, 1995

Neomonachus Scheel, Slater, Kolokotronis, Potter, Rotstein,

Tsangaras, Greenwood \& Helgen, 2014

Neomonachus schauinslandi (Matschie, 1905)

Odobenocetops Muizon, 1993

Odobenocetops peruvianus Muizon, 1993

Odobenocetops leptodon Muizon, Domning \& Parrish, 1993

Odobenus Brisson, 1762

Odobenus rosmarus (Linnaeus, 1758)

Ommatophoca Gray, 1844

Ommatophoca rossii Gray, 1844

Pakicetus Gingerich \& Russell, 1981

Parietobalaena Kellogg, 1924

Parietobalaena campiniana Bisconti, Lambert \& Bosselaers, 2013

Parietobalaena palmeri Kellogg, 1924

Pelocetus Kellogg, 1965

Pelocetus calvertensis Kellogg, 1965

Phoca Linnaeus, 1758

Phoca vitulina Linnaeus, 1758

Phocarctos Petters, 1866

Phocarctos hookeri (Gray, 1844)

Physeter Linnaeus, 1758

Physeter macrocephalus Linnaeus, 1758

Pinnarctidion Barnes, 1979

Pinnarctidion bishopi Barnes, 1979

Piscobalaena Pilleri, 1989

Piscobalaena nana Pilleri, 1989

Piscophoca Muizon, 1981
Piscophoca pacifica Muizon, 1981

Proneotherium Kohno, Barnes \& Hirota, 1995

Proneotherium repenningi Kohno, Barnes \& Hirota, 1995

Protocetus Fraas, 1904

Protocetus atavus Fraas, 1904

Pteronarctos Barnes, 1989

Pteronarctos goedertae Barnes, 1989

Rodhocetus Gingerich, Raza, Arif, Anwar, \& Zhou, 1994

Rodhocetus kasrani Gingerich, Raza, Arif, Anwar, \& Zhou, 1994

Saghacetus Gingerich, 1992

Saghacetus osiris Dames, 1894

Salishicetus Peredo \& Pysenson, 2018

Simocetus Fordyce, 2002

Simocetus rayi Fordyce, 2002

Squalodon Grateloup, 1840

Squalodon bariensis Jourdan, 1861

Squalodon calvertensis Kellogg, 1923

Thinocetus Kellogg, 1969

Thinocetus arthritus Kellogg, 1969

Tursiops Gervais, 1855

Tursiops truncatus (Montagu, 1821)

Waipatia Fordyce, 1994

Waipatia maerewhenua Fordyce, 1994

Yamatocetus Okazaki, 2012

Yamatocetus canaliculatus Okazaki, 2012

Zalophus Gill, 1866

Zalophus californianus (Lesson, 1828)

Zygorhiza True, 1908

Zygorhiza kochii (Reichenbach, 1847) 


\section{PROTOCETIDAE}

Georgiacetus vogtlensis: GSM 350 holotype, Hulbert et al. (1998);

Maiacetus inuus: Gingerich et al. (2009).

Aegyptocetus tarfa: MSNTUP I-15459 (holotype), Bianucci \& Gingerich (2011), original and cast.

BASILOSAURIDAE

Basilosaurus cetoides: Lucas (1900); Kellogg (1936);

Basilosaurus isis: UM 93231, Kellogg (1936), Gingerich et al. (1990);

Chrysocetus healyorum: SCSM87.195 (holotype); Uhen \& Gingerich (2001);

Cynthiacetus peruvianus: MNHN.F.PRU10 (holotype); Martínez-Cáceres et al. (2017), personal observations;

Dorudon atrox: UM101222, UM93220, Uhen (2004) and original photos;

Saghacetus osiris (BMNH 10228; MNHN.F.LBE695; UM 97550); Kellogg (1936);

Zygorhiza kochii: USNM 11962; Kellogg (1936), personal observations and original photos.

\section{ODONTOCETI}

Agorophius spp.: ChM PV4256, ChM PV5852;

Archaeodelphis patrius: MCZ 15749 (holotype); Allen (1921), cast; Physeter macrocephalus: MNHN-ZM-AC-1886-601, MNHNZM-AC-1886-602, MNHN-ZM-AC-1877-381;

Simocetus rayi: USNM 256517 (holotype); Fordyce (2002), personal observations and cast;

Squalodon bariensis: MHNL Dr15; Muizon (1991), personal observations and original photos;

Squalodon calvertensis: USNM 10484 (holotype), Kellogg (1923), personal observations and original photos;

Tursiops truncatus: MNHN-ZM-AC-1979-273, MNHNZM-AC-1882-103, MNHN-ZM-AC-1878-314;

Waipatia maerewhenua: OU 22095 (holotype); Fordyce (1994), personal observations, original photos, and cast.

\section{MYSTICETI}

Aetiocetus cotylalveus: USNM 25210 (holotype); Emlong (1966) and original photos;

Aetiocetus weltoni: UCMP 122900 (holotype); Barnes et al. (1994), Deméré \& Berta (2008) and original photos;

Aetiocetus polydentatus: AMP: 12 (holotype); Barnes et al. (1994) and original photos;

Aglaocetus moreni: FMNH P13407 (holotype); Kellogg (1934); Aglaocetus patulus: USNM 23690 (holotype); Kellogg (1968); personal observations;

Balaena mysticetus: MNHN-ZM-AC-1869-758, LACM 0722490, LACM 072472; Struthers (1881);

Balaenoptera acutorostrata: MNHN-ZM-AC-1886-758, MNHN-ZM-AC-1881-1225, MNHN-ZM-AC-A9130;
Balaenoptera musculus: MNHN-ZM-AC-1882-17; Struthers (1893);

Balaenoptera physalus: MNHN-ZM-AC-1894-36;

Caperea marginata: USNM DM 340, OM VT 227, MNHN-ZM-AC-1879-259, MNHN-ZM-AC-1880-1279;

Cetotherium rathkii: PIN 1840/1 (holotype); Brandt (1843), Beneden \& Gervais (1880) and original photos;

Cetotherium riabinini: NMHN-P 668/1 (holotype); Gol'din et al. (2014);

Choenecetus sookensis: Russell (1968) and original photos;

Coronodon havensteini: CCNHM 108 (holotype); Geisler et al. (2017) and original photos;

Diorocetus hiatus: USNM 16783 (holotype); 23494; Kellogg (1968) and personal observations;

Eubalaena australis: MNHN-ZM-AC-1921-123, MNHNZM-AC-A2937;

Eomysticetus whitmorei: ChM PV4253 (holotype); Sanders \& Barnes (2002);

Fucaia goedertorum: LACM 131146 (holotype); Barnes et al. (1994) and cast;

Fucaia buelli: UWBM 84024 (holotype), Marx et al. (2015);

Herpetocetus bramblei: UCMP 82465 (holotype); Whitmore \& Barnes (2008);

Herpetocetus morrowi: UCMP 124950 (holotype); El Adli et al. (2014);

Herpetocetus transatlanticus: USNM 182962 (holotype); Whitmore \& Barnes (2008);

Isanacetus laticephalus MFM 28501 (holotype); Kimura \& Ozawa (2002)

Incakujira anillodefuego GNHM Fs-098-12 (holotype); Marx \& Kohno (2016);

Janjucetus hunderi: NMV P216929 (holotype); Fitzgerald (2006) and cast;

Mammalodon colliveri: NMV P199986 (holotype); Fitzgerald (2010) and cast;

Megaptera novaeangliae: MNHN-ZM-AC-A2931, MNHNZM-AC-1885-729; Struthers (1888);

Micromysticetus rothauseni: ChM PV 4844 (holotype); Sanders \& Barnes (2002);

Miocaperea pulchra: SMNS 46978 (holotype); Bisconti (2012);

Parietobalaena campiniana: IRSNB M.399; Bisconti et al. (2013);

Parietobalaena palmeri: USNM 10668, 10677, 16119, 16570, 23022; Kellogg (1924, 1968);

Piscobalaena nana: MNHN.F.SAS892, SAS1616, SAS1617, SAS1618, SAS1623; SMNK Pal 4050 (holotype); Bouetel \& Muizon (2006) and personal observations;

Pelocetus calvertensis: USNM 11976; Kellogg (1965);

Undescribed toothed mysticetes: ChM PV5720; 4745; original photos;

Yamatocetus canaliculatus: KMNH VP 000,017 (Okazaki 2012) and original photos. 
1. - Length of rostral portion of maxilla anterior to antorbital notch: (0) less than bizygomatic width; (1) equal to or greater than bizygomatic width; (2) more than one and a half times the bizygomatic width.

2. - Portion of rostrum anterior to nasals in lateral view: (0) below the level of the supraoccipital; (1) raised to or above the supraoccipital.

3. - Mesorostral groove (new character): (0) closed dorsally; (1) partly opened dorsally.

4. - Orientation of dorsal surface of maxilla: (0) subvertical or strongly erected laterally (angle of more than 45 degrees); (1) subhorizontal or gently sloping laterally (angle of less than 45 degrees).

Comment: this character corresponds to a revisited version of Character 3 of Marx \& Fordyce (2015) and Fordyce \& Marx (2018). It has been complemented with the two following characters.

5. - Height of the maxilla relative to width at transverse midpoint of a section anteroposteriorly located at the level of posterior third of the bone length but anterior to antorbital process (new character): (0) higher than wide; (1) roughly as high as wide or lower.

6. - Alveolar border (or lateral edge if teeth are absent) of maxilla in posterior region of rostrum (new character): (0) rounded or subvertical (i.e., rather ventrally directed); (1) crest-like and sharp (i.e., rather laterally directed).

7. - Lateral border of maxilla anterior to antorbital notch or homologous point on rostrum in dorsal view: (0) concave; (1) straight or slightly convex; (2) broadly convex. Change in Fordyce \& Marx (2018) coding: Llanocetus, ? > 1

Comment: although the lateral border of the maxilla of the holotype of Llanocetus is partly damaged, a large part of it is preserved and it is clear that the edge was not concave. At the least, it was straight or slightly convex. We therefore coded this character (1) in Llanocetus.

8. - Transverse width of maxilla (in dorsal view) at midpoint of the rostrum: (0) distinctly less than that of the premaxilla;

(1) roughly equal to or up to twice the width of the premaxilla;

(2) more than twice the width of the premaxilla (2). Change

in Fordyce \& Marx (2018) coding: Llanocetus, ? > 1.

Comment: concerning Llanocetus, because the anterior part of the rostrum is missing this character has been coded (?) by Fordyce o Marx (2018). However, in this matrix we made an approximation. Considering that the midpoint of the rostrum in Mystacodon is slightly anterior to the anterior point of the nasals, we estimated that the midpoint of the rostrum in Llanocetus was probably not anterior to the anterior most preserved part of the rostrum, and probably slightly more posterior. At the anterior point of the rostrum of the holotype of Llanocetus, as preserved, the transverse width of the premaxilla (in dorsal view) is at least equal to that of the maxilla. Therefore, this character is codded (1) for Llanocetus in our matrix. In fact, at midpoint of the rostrum of Llanocetus the maxilla is probably much wider than the premaxilla.

9. - Premaxilla in dorsal view: (0) widens at anterior end; (1) portion anterior to nasal opening narrows or remains the same width anteriorly.

10. - Premaxilla adjacent to and anterior to narial fossa: (0) elevated above the maxilla and forming a distinct lateral face; (1) continuous or nearly continuous with the maxilla.

11. - Premaxilla adjacent to and at posterior edge of narial opening: (0) does not clearly overhang maxilla, its lateral edge being distinctly oblique; (1) premaxilla overhangs maxilla, its lateral edge being sub-vertical. Change in Fordyce \& Marx (2018) codings: Waipatia, Coronodon $0>1$; Llanocetus ? $>0$.

Comment: the lateral edge of the premaxilla of Llanocetus clearly does not overhangs the maxilla as it does in Fucaia or Aetiocetus. It is distinctly oblique and in this respect more resembles the condition of state $(0)$.

12. - Anterior portions of premaxillae: (0) firmly contact each other; (1) premaxillae are separated or only loosely contact along their entire length. Change in Fordyce \& Marx (2018) coding: Mystacodon $0>1$

13. - Suture between maxilla and premaxilla on rostrum: (0) firmly articulated; (1) loose. Change in Fordyce \& Marx (2018) coding: Coronodon $0>1$ (Geisler et al. 2017)

14. - Antorbital process: (0) absent; (1) present as a distinct anterior to anterolateral projection lateral to antorbital notch.

Comment: the states (1) and (2) of Fordyce \& Marx (2018) are comparing different aspects of the antorbital process: their state (1) rather describes the morphology of the process, whereas their state (2) describes its position. In fact, in both states the process is lateral to the antorbital notch. Therefore, we rather restrict this character to two states (absent and present) and displace the steep face evoked in state (1) of Fordyce o Marx (2018) to character 15, below.

15. - Medial extension of the antorbital process (new character): (0) absent: posterior region of maxilla and contact with anterior edge of the supraorbital process is smooth and flat; (1) extension as a sharp crest or smooth ridge directed antero- or posteromedially or medially in the posterior region of maxilla and forming a sloping or subvertical wall.

Comment: the condition in Llanocetus is poorly developed but it is regarded as incipiently developed. It clearly differs from that of Mystacodon. 
16. - Antorbital notch morphology (new character): (0) absent; (1) notch subvertical; (2) notch oblique to subhorizontal.

17. - Distinct posterolaterally open cavity between the ascending process of the maxilla, which markedly overhangs the anteromedial region of the supraorbital process ventrally: (0) absent; (1) present.

18. - Lateral process of maxilla underlapping lacrimal: absent (0); present (1) Change in Fordyce \& Marx (2018) coding: Fucaia $0>1$.

19. - Palatal keel formed by vomer and medial edges of maxillae and bordered laterally by wide troughs: (0) absent; (1) present. Changes in Fordyce \& Marx (2018) codings: Aetiocetus weltoni, A. cotylalveus, Fucaia $0>1 ;$ A. polydentatus, $0>$ ?; Llanocetus, ? > 1 .

Comment: this character is character 15 of Marx \& Fordyce (2015) which has been deleted by Fordyce \& Marx (2018). We have retained it here but have merged the states (1) and (2). A distinct elevation (palatal keel) of the median region of the palate is present in Aetiocetus and Fucaia and is bordered laterally by wide anteroposteriorly oriented depressions (troughs). Although the condition in these genera is less developed than in chaeomysticetes, this character is regarded as incipiently present. State (1) also appears to be present in Llanocetus. Because the palate of A. polydentatus is damaged and distorted we coded this character as (?) for this taxon.

20. - Exposure of premaxilla on palate: (0) exposed along at least one third of the medial border of the maxilla; (1) limited in extent to less than one third of the medial border of the maxilla. Change in Fordyce \& Marx (2018) coding: Coronodon? $>0$

21. - Palatal window exposing vomer: (0) present; (1) narrow and variable exposure of vomer along most or all of the midline of the rostrum; (2) vomer broadly exposed along the midline of the rostrum. Change in Fordyce \& Marx (2018) coding: Coronodon? $>0$

Comment: because a palatal window is clearly present in Coronodon this character is coded (0) for this taxon

22. - Palatal nutrient foramina and sulci: (0) absent; (1) present.

Comment: although we have mentioned above some shallow grooves on the palate of Mystacodon, these grooves are distinctly shallower than in chaeomysticetes. It is therefore, probable that these structures are homologous to those observed in baleen-bearing mysticetes. For that reason, we rather coded this character as absent in Mystacodon.

23. - Outline of suture between maxillae and palatines: (0) roughly straight transversely or bowed anteriorly; (1) forms a posteriorly pointing V shape; (2) anterior margins of palatines form two separate and posteriorly pointing $U$ shapes.

24. - Anteriormost point of palatine: (0) located in line with or posterior to the level of the antorbital notch or equivalent point on rostrum; (1) located anterior to the level of the antorbital notch.

25. - Anterior portion of palatine distinctly concave transversely and forming a sharp median crest: (0) absent; (1) present.

26. - Premaxillae abruptly depressed just anterior to the nasals: (0) present (step-like); (1) absent (smooth transition to the post narial part of the premaxillae; (2) intermediate (part of the premaxillae bordering the narial fossa, gently concave. (Steeman 2007, modified)

Comment: concerning this character, we rather use here the formulation of Steeman 2007, than that of Fordyce \& Marx (2018) but with addition of state 2 of the latter. We therefore follow the codings of Elstrup-Steeman for Llanocetus (1) and Eomysticetus (1). Furthermore, the condition of the holotype of Janjucetus in which the anterior edge of the nasals and the prenarial part of the premaxillae are damaged appears uncertain, although the slight elevation of the right premaxilla in the median region of the narial fossa could indicate that state (0) was present in this taxon. Nevertheless, we coded Janjucetus (?) for this character.

27. - Rostrum width: (0) width at antorbital notches or equivalent point on rostrum less than $80 \%$ the length of the rostrum as measured from its tip to the antorbital notches; (1) width at antorbital notches or equivalent point more than $80 \%$ the length of the rostrum.

28. - Teeth in adult individuals: (0) present; (1) absent or vestigial.

29. - Upper dentition: (0) comprises 10 teeth including M2;

(1) includes 11 teeth including M3 or is polydont.

30. - Large diastemata between posterior upper cheek teeth: (0) absent; (1) present. Change in Fordyce \& Marx (2018) coding: Mystacodon $1>0$.

31. - Large diastema between P3 and P4: (0) absent; (1) present and shorter than one tooth length; (2) present and equal to or longer than one tooth length.

32. - Enamel ornamentation on postcanines: (0) vertical striations present on both lingual and labial surfaces; (1) vertical striations present on lingual surface only; (2) vertical striations are poorly developed or absent; (3) enamel is absent. 
Change in Fordyce \& Marx (2018) codings: Mystacodon $1>$ 0 ; Coronodon, $0>2$.

Comments: we retained the formulation of this character as in Marx \& Fordyce 2015 because vertical striations are poorly developed or absent on both sides of postcanines teeth in Coronodon.

We changed the coding of Fordyce of Marx (2018) for Mystacodon $(1>0)$ because on the tooth referred to a p1 (Fig. 27 G-I) striae are absent on the labial side.

33. - Shape of upper molars in lingual or labial view: (0) crown base distinctly wider than crown height; (1) crown base is shorter than or roughly equal to crown height.

34. - Ectocingulum on P3 and P4: (0) present; (1) absent. 35. - Entocingulum on P3 and P4: (0) present; (1) absent.

36. - Posterior premolar and molar roots: (0) separate along their entire length; (1) fused proximally but separate distally; (2) fused or closely apposed along their entire length. Change in Fordyce \& Marx (2018) coding: Coronodon $0>1$.

37. - Posteriormost upper tooth: (0) situated below anterior portion of orbit (including antorbital process); (1) situated anterior to anterior border of orbit. Change in Fordyce $\&$ Marx (2018) coding: Coronodon $0>1$.

38. - Heterodonty: (0) present with clear distinctions between anterior teeth, premolars and molars; (1) present but reduced with molars and premolars being of comparable size and shape; (2) absent or greatly reduced with accessory denticles on postcanines absent or tiny compared to main cusp.

39. - Skull length: about one third of total body length: (0) absent; (1) present.

40. - Facial asymmetry: (0) absent; (1) present.

41. - Diameter of orbit as measured between the distalmost points of the preorbital and postorbital processes: (0) less than $25 \%$ of bizygomatic width;(1) $25 \%$ or more. Change in Fordyce \& Marx (2018) coding: Coronodon $0>1$.

42. - Anterior edge of supraorbital process lateral to ascending process of maxilla: (0) pointing posteriorly (i.e., anteromedially-posterolaterally oriented); (1) oriented transversely or pointing anteriorly (i.e., anterolaterally-posteromedially oriented); (2) linguiform and tapering to a point.

Comment: the anterior edge of the supraorbital process mentioned in this character corresponds to the Frontal-lacrimal suture in dorsal view.
43. - Outline of anterior edge of supraorbital process in dorsal view: (0) roughly straight or concave; (1) distinctly sinusoidal.

44. - Posterior border of supraorbital process in dorsal view: (0) concave; (1) straight. Change in Fordyce \& Marx (2018) coding: Mystacodon $0>1$

45. - Supraorbital process of frontal in anterior view: (0) horizontal or nearly horizontal; (1) gradually slopes away lateroventrally from the skull vertex; (2) abruptly depressed to a level noticeably below the vertex with the lateral skull wall above the supraorbital formed by both parietal and frontal.

46. - Anterior and posterior borders of supraorbital process in dorsal view: (0) roughly parallel or converging medially; (1) converging laterally.

47. - Width of supraorbital process as measured in a straight line from the lateralmost point of the postorbital process to the intertemporal constriction: (0) equal to or shorter than the anteroposterior length of the supraorbital process above the orbit; (1) up to twice the length above the orbit; (2) more than twice the length above the orbit.

48. - Postorbital process in lateral view: (0) pointed or rounded; (1) forms and anteroposteriorly elongate triangle with a flattened posterior face.

49. - Orbital rim of supraorbital process of frontal in lateral view: (0) dorsoventrally thin; (1) thickened with a flat lateral surface; (2) thickened with a rounded lateral surface. Change in Fordyce \& Marx (2018) coding: Mystacodon, $0>1$.

50. - Position of anteriormost point of supraorbital process in dorsal view: (0) in line with the posterior extremity of the nasals or passing through the nasals; (1) at the same level as the anterior extremity of the nasals; (2) anterior to the anterior extremity of the nasals.

51. - Dorsalmost point of orbit relative to lateral edge of rostrum in lateral view, with skull resting on a horizontal surface: (0) elevated above or roughly in line with the lateral edge of the rostrum; (1) located well below the lateral edge of the rostrum.

52. - Lacrimal modified into a thin elongated blade which extends medially between the frontal and maxilla and separates the anterolateral edge of the supraorbital process of the frontal from lateral part of the posterior edge of the maxilla, dorsally: (0) absent; (1) present.

Comment: This character is a modified version of the character 53 of (Marx \& Fordyce 2015): "Lacrimal in dorsal view situated entirely lateral to the ascending process of the maxilla (0); 
lacrimal extends medially and separates the lateral corner of the ascending process from the more anterior portion of the maxilla (1). "In fact, this character is very confusing because it is not possible to define precisely the "lateral corner" of the ascending process of the maxilla.

53. - Contact of jugal with zygomatic process of squamosal: (0) the two bones overlap dorsoventrally; little or no overlap (1).

54. - Anteriormost portion of jugal broadly underlapped by maxilla: (0) absent; (1) present. Change in Fordyce \& Marx (2018) coding: Mystacodon, ? > 1 .

55. - Optic canal in ventral view: (0) ventrally open; (1) medial portion is enclosed by anterior and/or posterior bony laminae.

56. - Postorbital ridge along medial portion of optic canal: (0) absent or anteroposteriorly thin, with the optic canal running adjacent to the posterior border of the supraorbital process; (1) well developed and thickened, thus resulting in the displacement of the optic canal away from the posterior border of the supraorbital process.

57. - Maxillary infraorbital plate: (0) absent; (1) present. Change in Fordyce \& Marx (2018) coding: Coronodon $0>1$.

58. - Maxillary window originating from posterior border of infraorbital plate: (0) absent; (1) present.

59. - Anteromedial corner of supraorbital process extending to a point markedly medial to antorbital notch: (0) absent; (1) present.

60. - Preorbital region of frontal in lateral view: (0) thickened compared to more central portions of the orbit; (1) dorsoventrally flat.

61. - Primary dorsal infraorbital foramen on ascending process of maxilla opening into a posterodorsally directed sulcus: (0) absent; (1) present. Change in Fordyce \& Marx (2018) coding: Waipatia $0>1$.

62. - Premaxillary sac fossa: (0) absent; (1) present.

63. - Premaxillary foramen: (0) absent; (1) present.

64. - Suture between maxilla and frontal: (0) contact between the bones is straight or maxilla overrides anteromedial corner of the frontal; (1) maxilla overrides half or more of the frontal.

65. - Morphology of ascending process of maxilla: (0) lateral edges convergent with the process tapering to a point; $(0)$ lateral edges parallel or divergent posteriorly; (2) ascending process wide with a rounded apex.
66. - Triangular parasagittal wedge of frontal separating ascending process of maxilla from nasal or/and premaxillae or/and maxillae premaxilla: (0) absent; present.

67. - Posterior end of ascending process of premaxilla: (0) no contact with frontal or contacts the frontal with the posteriormost tip only; (1) forms a transversely wide contact with the frontal level with posterior end of nasal.

68. - Posterior ends of ascending processes of maxillae in dorsal view contact each other medially with nasal being compressed between them into a thin sheet: (0) Absent; (1) Present. (modified from Fordyce \& Marx 2018, K66)

Comment: because of the great deal of individual variation of in the bones separating the ascending processes of the maxillae (as for example in Zygorhiza) and because we have retained above the character 67 of Marx \& Fordyce (2015), we have modified the character 66 of Fordyce \& Marx (2018) as above.

69. - Relative position of posteriormost edge of ascending process of maxilla in dorsal view: (0) approximately in transverse line with or posterior to posterior edge of nasal; (1) anterior to posterior edge of nasal (1). Change in Fordyce \& Marx (2018) coding: Coronodon, $1>0$.

Comment: we changed the coding of Coronodon $(1>0)$ because its condition is similar to that of Janjucetus and Mammalodon which are coded (0) in Fordyce \& Marx (2018).

70. - Lateral profile of cranium along exposure of parietals on vertex: (0) dorsal edge of parietal is low to flat with an angle of less than 10 degrees; (1) dorsal edge of parietal ascends steeply towards posterior edge of skull at an angle of 10 degrees or more measured relative to the lateral edge of rostrum.

Comment: this character is character 72 of Marx \& Fordyce (2015). It was deleted by Fordyce \& Marx (2018), but we retain it here.

71. - Length of nasal relative to bizygomatic width: (0) less than $50 \%$ of bizygomatic width; (1) more than $50 \%$ of bizygomatic width.

72. - Shape of nasal: (0) medial and lateral margins parallel; (1) medial and lateral margins posteriorly convergent.

73. - Anterior margins of nasals: (0) roughly straight or U shaped; (1) form a distinct, posteriorly pointing W shape; (2) with point on midline and a gap on each side between premaxilla and nasal; (3) form an anteriorly pointing W shape.

74. - Dorsal surface of nasals: (0) flattened; (1) developed into a sagittal keel; (2) medial portion raised into a nasal scoop. 
75. - Anterior edge of the nasals upturned and elevated (new character): (0) absent; (1) present.

Comment: in lateral view the nasals are distinctly higher anteriorly than posteriorly. Although the anterior edge of the nasals of the holotype Fucaia are damaged, we coded the taxon (1) for this character because the height of the nasal appears to increase anteriorly.

Coronodon is coded (0) for this character because the elevation of the nasal is not at the anterior edge of the bones but forms a median keel, a condition different from that observed, for instance, in Aetiocetus.

76. - Separation of posterior portions of nasals along sagittal plane by narial process of frontal: (0) present; (1) absent. Change in Fordyce \& Marx (2018) codings: Archaeodelphis, $1>0$; Fucaia, $0>1$; Aetiocetus polydentatus, A. weltoni, ? > 1 .

77. - Zygomatic process of squamosal and exoccipital in dorsal view: (0) clearly separated by an angle; (1) posterior border of zygomatic process and lateral edge of exoccipital are confluent forming a continuous or nearly continuous lateral skull border.

78. - Orbitotemporal crest: (0) positioned along posterior border of supraorbital process with the origin of the temporal muscle facing posteriorly or posteroventrally; (1) absent or positioned on the dorsal surface of the supraorbital process with the origin of the temporal muscle facing posterodorsally or dorsally.

79. - Area enclosed by orbitotemporal crest on supraorbital process of frontal: (0) forms less than half of the dorsal surface of the supraorbital process; (1) covers half or more of the dorsal surface of the supraorbital process.

80. - Outline and orientation of orbitotemporal crest: (0) subparallel to posterior border of supraorbital process; (0) distal half oriented distinctly posterolaterally and approaching the posterolateral corner of the supraorbital process; (2) as state 1 but with the crest terminating halfway along the posterior border of the supraorbital process; (3) as state 1 but with the crest being distinctly U-shaped.

81. - Shape of temporal fossa: (0) longer anteroposteriorly than wide transversely or as wide as long; (1) wider than long. Change in Fordyce \& Marx (2018) coding: Waipatia, $1>0$.

82. - Intertemporal constriction: (0) longer than wide; (1) as long as wide or wider than long.

83. - Exposure of frontal on skull vertex: (0) broadly exposed; (1) anteroposteriorly compressed or absent.
84. - Parietal and interparietal anteriormost point: (0) located no further forward than postorbital process; (1) anteriormost point in line with supraorbital process.

85. - Sagittal median trough on anterior portion of parietals and/or posterior region of frontal vertex: (0) present; (1) absent. Changes in Fordyce \& Marx (2018) codings: Janjucetus, $0>$ 1; Coronodon, Diorocetus, Aglaocetus patulus, A. moreni, Parietobalaena palmeri, P. calvertensis $0>-$.

Comments: the sagittal trough is not observable in taxa with a conspicuous sagittal crest. In this case, it is coded as inapplicable (e.g. Coronodon). In Janjucetus a small trough is present on the posterior sagittal region of the frontals but it is absent on the parietals because of the presence of a small sagittal crest. Therefore, the character is coded present (1) in this taxon.

86. - Fronto-parietal suture forms an elevated ridge or tuberosity dorsally or dorsolaterally (formulation modified from Fordyce \& Marx, 2018): (0) absent; (1) present.

87. - On fronto-parietal suture, frontals projects posteriorly along the sagittal plane and separate the left and right parietal anteriorly: (0) absent; (1) present. Modified from character 83 of Fordyce \& Marx (2018). Changes in Fordyce \& Marx (2018) codings: Micromysticetus, Yamatocetus, Eomysticetus, $2>1$.

Comment: because we regard the definition of state (2) of Fordyce \& Marx (2018) (highly irregular) as poorly identified, this new formulation includes their state (2) in our state (1).

88. - Orbitotemporal crest extends posteriorly on the parietal forming parasagittal crest: (0) absent; (1) present. Change in Fordyce \& Marx (2018) coding: Fucaia, $1>0$.

89. - Parietal in lateral view: (0) as long as high or longer; (1) higher than long.

90. - Spreading of anterolateral portion of parietal on to posteromedial corner of supraorbital process of frontal: (0) absent; (1) present. Changes in Fordyce \& Marx (2018) codings: Mystacodon selenensis, Coronodon, Llanocetus, Mammalodon, Janjucetus, Fucaia, Aetiocetus cotylalveus, A. polydentatus, A. weltoni, Yamatocetus, Eomysticetus, Cetotherium rathkii, C. riabinini, Herpetocetus morrowi, Piscobalaena, - > 0.

91. - Anteriormost point of parietal and interparietal: (0) more posterior than the posterior border of the ascending process of the maxilla; (1) more anterior than or in line with the posterior border of the ascending process of the maxilla; (2) as state 1 but the parietal being dorsoventrally concave and undercutting the maxilla and associated frontal. 
92. - Anteriormost point of supraoccipital in dorsal view: (0) located posterior to or in line with the anterior border of the squamosal fossa; (1) in line with temporal fossa, but posterior to the apex of the zygomatic process of the squamosal; (2) in line with or located anterior to the level of the apex of the zygomatic process of the squamosal; (3) in line with the anterior half or anterior edge of the supraorbital process. Change in Fordyce \& Marx (2018) coding: Mystacodon, $1>0$.

93. - Anteroposterior position of posterior apex of nuchal crest: (0) posterior to the occipital condyle; (1) anterior to or in line with the posteriormost point of the occipital condyle. Change in Fordyce \& Marx (2018) coding: Llanocetus, $0>1$.

94. - Mediolateral position of posterior apex of nuchal crest: (0) aligned with the medial half or halfway point of the temporal fossa; (1) approaching the level of the lateral border of the temporal fossa.

95. - Distinct nuchal tubercle at junction of parietosquamosal suture and supraoccipital: (0) absent; (1) present.

96. - Exposure of alisphenoid in or at ventral border of temporal fossa: (0) exposed on temporal wall of skull and contributing to orbital fissure; (1) alisphenoid separated from orbital fissure or not exposed on temporal skull wall. Change in Fordyce \& Marx (2018) coding: Archaeodelphis, ? > 0.

97. - Postparietal foramen located at junction of parietal and squamosal: (0) absent; (1) present.

98. - Zygomatic process of squamosal extremely well developed and robust in dorsal view: (0) absent; (1) present.

99. - Orientation of zygomatic process of squamosal in dorsal view: (0) directed anteriorly or slightly anteromedially or anterolaterally; (1) directed distinctly laterally or anterolaterally.

Comment: we have merged the states ( 0 ) and (1) of Fordyce of Marx (2018) because of the very slight difference in the orientation of the zygomatic process in both cases. In fact, the taxa with a medially directed zygomatic process state ( 0 ) have a long process, of which only the anterior half is directed medially and the taxa with anteriorly or anterolaterally directed process have a much shorter one (i.e., probably corresponding to the posterior part of the taxa with a long processes). Furthermore, the difference in the between the anterior, slightly lateral or slightly medial orientation is sometimes very subtle, whereas the lateral orientation observed in the Balaenidae is conspicuous.

100. - Zygomatic process of squamosal in lateral or ventral view: (0) tapering anteriorly; (1) expanded anteriorly, thus forming a central constriction. Change in Fordyce \& Marx (2018) codings: Waipatia, Coronodon? $>0$.
101. - Twisting of zygomatic process of squamosal: (0) partially twisted anticlockwise on the left and clockwise on the right; (1) absent; (2) partially twisted clockwise on the left and anticlockwise on the right; (3) as state 1 but with the process twisted almost 90 degrees. Change in Fordyce \& Marx (2018) coding: Waipatia $1>2$.

102. - Position of apex of zygomatic process of squamosal: (0) situated well posterior to the postorbital process; (1) closely apposed to the postorbital process or situated ventral to the latter.

Comment: this character is character 101 of Marx \& Fordyce (2015), which has been deleted by Fordyce \& Marx (2018). It has been retained in this list.

103. - Apex of zygomatic process of squamosal deflected anteroventrally: (0) absent; (1) present.

104. - Supramastoid crest of zygomatic process of squamosal: (0) present; (1) present on posterior portion of zygomatic process only; (2) absent. Change in Fordyce \& Marx (2018) coding: Physeter, $0>1$.

105. - Size of squamosal including zygomatic and postglenoid processes: (0) longer anteroposteriorly than high dorsoventrally or about as high as long; (0) distinctly higher than long.

106. - Parieto-squamosal suture shaped like a crest or ridge: (0) absent or low; (1) present and distinctly elevated.

107. - Squamosal prominence: (0) present as a projection on the crest delimiting the lateral or posterolateral edge of the squamosal fossa; (1) absent. Change in Fordyce \& Marx (2018) codings: Archaeodelphis, ? > 1; Mammalodon, ? > 1; Fucaia, $0>$ ?

108. - Transverse width of squamosal lateral to exoccipital: (0) width equal to or greater than $15 \%$ of the distance between the sagittal plane and the lateral edge of the exoccipital; (1) exposed portion of squamosal is less than $15 \%$ of that distance.

109. - Length of squamosal fossa relative to maximum transverse width of temporal fossa as measured in a straight line from the posteriormost point of the temporal fossa to the posteriormost point of the nuchal crest: (0) length of squamosal fossa is three quarters the width of the temporal fossa or longer; (1) length of squamosal fossa is less than three quarters the width of the temporal fossa.

110. - Squamosal cleft: (0) absent; (1) present.

111. - Squamosal crease: (0) absent; (1) present. 
112. - Paired tubercles on supraoccipital: (0) absent; (1) limited to low ridges forming the lateral edges of a medial fossa; (2) present.

113. - Lateral edge of supraoccipital in dorsal view: (0) convex; (1) straight; (2) concave; (3) sigmoidal. Changes in Fordyce \& Marx (2018) codings: Mystacodon, $3>1$; Coronodon, $0>1$.

114. - Anterior border of supraoccipital shield: (0) rounded or pointed; (1) squared.

115. - Overall outline of supraoccipital in dorsal view: (0) rounded; (1) triangular.

116. - Anterior half of dorsal surface of supraoccipital: (0) concave; (1) flat or convex. Change in Fordyce \& Marx (2018) coding: Fucaia, $1>0$.

117. - External occipital crest: absent or faint (0); restricted to anterodorsal half of supraoccipital shield (1); present and running all the way along the supraoccipital shield (2). Changes in Fordyce \& Marx (2018) coding: Coronodon, $1 \& 2>2$.

118. - Tip of postglenoid process in lateral view: (0) curving anteriorly; (1) pointing ventrally; (2) pointing posteriorly.

119. - Ventral edge of postglenoid process in lateral view: (0) approximately in line with or dorsal to ventral edge of exoccipital; (1) extending well ventral to ventral edge of exoccipital.

120. - Orientation of postglenoid process in posterior view: (0) ventrolateral; (1) ventral; (2) ventromedial. Change in Fordyce \& Marx (2018) coding: Archaeodelphis, ? > 1.

121. - Outline of postglenoid process in anterior or posterior view: (0) parabolic; (1) as state 0 but with lateral and medial edges parallel or concave; (2) as state 1 but distinctly wider transversely than high dorsoventrally; (3) triangular; (4) trapezoidal with a ventrally directed medial border.

122. - Twisting of postglenoid process in ventral view, clockwise on the left side and anticlockwise on the right side so that the glenoid cavity faces anteromedially: (0) absent; (1) present.

123. - Position of base of postglenoid process in ventral or posterior view: (0) in line with the lateral edge of the skull; (1) shifted away medially from the lateral edge of the skull.

124. - Medial border of postglenoid process in ventral view: (0) confluent with more medial portion of squamosal; (1) offset from remainder of squamosal by a distinct ridge.
125. - Choanal margin of palatine in ventral view: (0) absent; (1) straight or convex; (2) concave; (3) forms a longitudinal notch. Change in Fordyce \& Marx (2018) coding: Archaeodelphis, $1>0$.

126. - Pterygoid in ventral view: (0) partially or entirely exposed; (1) palatine almost completely covers pterygoid and extends on to the hamular process.

127. - Anteriomost point of pterygoid sinus fossa: (0) located anterior to foramen pseudovale (or path of mandibular branch of trigeminal nerve); (1) approximately in line with anterior edge of foramen pseudovale; (2) located posterior to anterior edge of foramen pseudovale.

128. — Lateral lamina of pterygoid: (0) located entirely anterior to the anterior process of the periotic; (1) extending on to the anterior process of the periotic.

129. - Superior lamina of pterygoid: (0) absent or restricted to anteromedial quarter of pterygoid sinus fossa; (1) present and covering half or more of ventral exposure of alisphenoid within pterygoid sinus fossa.

Comment: this character, present in Marx \& Fordyce (2015), was deleted in Fordyce \& Marx (2018). We have retained it in this matrix because state (1), which is present (when observable) in all the chaeomysticetes of the matrix is also present in some basal mysticetes.

130. - Shape of pterygoid Hamulus: (0) finger-like; (1) expanded into a dorsoventrally flattened plate flooring the pterygoid sinus fossa; (2) triangular and wing-like; (3) reduced in size or almost absent.

131. - Position of pterygoid hamuli in ventral view: (0) located directly adjacent to the sagittal plane and almost contacting each other; (1) well separated from each other.

132. - Position of foramen pseudovale: (0) foramen located within squamosal or between squamosal and pterygoid and opening anterolaterally or laterally; (1) as state 0 but with foramen opening posteriorly; (2) foramen lies within pterygoid.

133. - Foramen pseudovale raised above more lateral portions of squamosal in ventral view: (0) absent; (1) present.

134. - Fossa on squamosal for reception of sigmoid process of tympanic bulla: (0) present; (0) absent or poorly defined. Change in Fordyce \& Marx (2018) coding: Physeter, ? > 1

135. - Base of postglenoid process in ventral view: (0) in transverse line with or located posterior to the posterior half of the tympanic bulla; (1) in transverse line with or located anterior to the anterior half of the tympanic bulla; (2) in 
transverse line with the anteroposterior center of the tympanic bulla. Change in Fordyce \& Marx (2018) codings: Waipatia, ? > 2; Llanocetus, ? > 0 .

136. - Ventral border of sagittal part of vomer (nasal septum) in ventral view: (0) posteriormost portion projects beyond the posterior border of the palatines and is visible in ventral view; (1) completely covered by palatines.

137. — Basioccipital crest: (0) narrow transversely; (1) wide and bulbous.

138. - Lateral border of basioccipital crest in ventral view: (0) straight; (1) concave.

139. - Orientation of basioccipital crests in ventral view: (0) diverging posteriorly; (1) parallel or subparallel with no angle formed.

Comment: This character is character 137 of Marx \& Fordyce (2015), which has been deleted in the matrix of Fordyce o Marx (2018). However, we have retained it in our present matrix because it has the same coding in the three balaenids (0), which differs from most other chaeomysticetes and therefore provides significant information.

140. - Supraoccipital shield: (0) subvertical; (1) inclined (i.e., facing posterodorsally) (Deméré \& Berta 2008).

141. - Ventromedial corner of paroccipital process in posterior view: (0) located more ventrally than the basioccipital crest; (1) level with or more dorsal than the basioccipital crest. Change in Fordyce \& Marx (2018) coding: Llanocetus, 0 > ?

Comment: we coded this character (?) for Llanocetus because the ventromedial corners of the paraoccipital processes are reconstructed on the holotype and only known specimen.

142. - Posteriormost point of exoccipital in dorsal view: (0) located more anteriorly than posterior edge of occipital condyle; (1) level with or posterior to posterior edge of condyle.

143. - Outline of stylohyal in cross section: (0) cylindrical; (1) flattened into a plate.

144. - Orientation of thyrohyal in dorsal or ventral view: (0) oriented posterolaterally; (1) oriented laterally. Change in Fordyce \& Marx (2018) coding: Mystacodon, ? > 0 .

145. - Shape of thyrohyal: (0) cylindrical; (1) flattened.

Comment: we have merged the states (1) and (2) of Fordyce $\&$ Marx (2018) [(1) flattened and wing-like; (2) plate-like], which are similar.
146. - Distal end of thyrohyal expanded relative to shaft: (0) absent; (1) present.

147. - Posterior projections on basihyal for attachment of sternohyoid muscle: (0) absent; (1) present.

148. - Ankylosed basihyal and thyrohyals: (0) absent; (1) present. Change in Fordyce \& Marx (2018) coding: Mystacodon, ? > 0 .

149. - Tympanohyal: (0) indistinct; (1) clearly differentiated trumpet-shaped element fused to crista parotica. Change in Fordyce \& Marx (2018) coding: Coronodon, ? > 0.

150. - Dorsomedial (cranial) elongation of pars cochlearis towards cranial cavity: (0) absent; (1) present; (2) as state 1, but with only the anterior side of the pars cochlearis being elongated.

151. - Attachment of anterior process to pars cochlearis: (0) absent; (1) present.

152. - Anterior process of periotic in lateral view: (0) squared off or rounded; (1) triangular; (2) anterior border of process is two-bladed and L-shaped.

153. - Shape of anteroventral angle of anterior process of periotic in medial or lateral view: (0) rounded or forms a relatively blunt angle; (1) slender and tapering to a point.

154. - Ventral edge of anterior process of periotic in medial view: (0) at the same level or dorsal to ventral edge of pars cochlearis; (1) ventral to ventral profile of pars cochlearis. Change in Fordyce \& Marx (2018) coding: Coronodon, $0>1$.

155. - Anterior process transversely compressed and bladelike: (0) absent; (1) present.

156. - Length of anterior process of periotic: (0) shorter than the anteroposterior length of the pars cochlearis, as measured from the anterior border of the pars cochlearis to the medial border of the fenestra rotunda; (1) same length or longer than the pars cochlearis.

157. - Anteroexternal sulcus: (0) forms an oblique or vertical groove on lateral side of anterior process, immediately anterior to lateral tuberosity; (1) absent (1.

158. - Pyramidal process: (0) absent; (1) present.

159.- Articulation of anterior process of periotic and tympanic bulla: (0) accessory ossicle of tympanic bulla contacts fovea epitubaria on the anterior process of the periotic; (1) accessory ossicle or homologous region fused to periotic (1). 
160. - Anterior bullar facet: (0) present; (1) flattened and not clearly distinguishable from fovea epitubaria; (2) absent. Change in Fordyce \& Marx (2018) coding: Coronodon, $2>0$

161. - Shape of lateral tuberosity of anterior process: (0) absent or poorly developed; (1) well-defined tubercle; (2) broadly triangular and longer than wide; (3) hypertrophied; (4) forms a distinct shelf.

162. — Position of lateral tuberosity: (0) situated posterolateral to anterior pedicle of tympanic bulla or fovea epitubaria; (1) situated lateral or anterolateral to anterior pedicle of tympanic bulla or fovea epitubaria.

163. - Body of periotic lateral to pars cochlearis: (0) hypertrophied: absent; (1) present laterally and ventrally; (2) present laterally only.

164. - Mallear fossa: (0) well excavated and possessing a clearly defined rim; (1) present only as a depression with diffuse edges.

165. - Distinct ridge delimiting insertion surface of tensor tympani on medial side of anterior process: (0) absent; (1) absent but insertion surface distinctly excavated; (2) present.

Comment: because no taxon in our sample is coded (1) we have deleted this state. Therefore, the state (2) of Fordyce \& Marx (2018) becomes state (1) of this character.

166. - Dorsal extension of attachment area for tensor tympani on medial side of anterior process: (0) absent or indistinct; (1) present as a deeply excavated groove.

Comment: we reformulated this character replacing canal by groove.

167. - Anteromedial corner of pars cochlearis in ventral view: (0) developed as a rounded, anteroposterior ridge; (1) angular and projecting medially, resulting in a flattened ventral surface of the pars cochlearis; (2) smooth and rounded.

168. - Promontorial groove on medial side of pars cochlearis: (0) present, but relatively shallow; (1) present and deeply excavated; (2) present and forming a distinct constriction, separating a smooth and rounded ventral portion of the pars cochlearis from a flattened and striated dorsal one; (3) absent.

169. - Caudal tympanic process (=posterior cochlear crest) in posteromedial view: (0) well separated from crista parotica; (1) narrow separation or contact.

170. - Posteromedial corner of pars cochlearis: (0) medial to fenestra rotunda rounded and level with fenestra rotunda; (1) inflated and projecting posteriorly beyond fenestra cochleae appears recessed into the posterior face of pars cochlearis.
171. - Morphology of caudal tympanic process ( = posterior cochlear crest): (0) developed as a posteriorly extending triangular shelf; (1) as state 0 , but with the crest appearing sigmoidal in ventral view; (2) as state 0 , but with the ventral border bulging ventrally; (3) as state 0 , but pointing posterodorsally; (4) developed as a robust, ventrally directed projection; (5) absent or poorly developed. Change in Fordyce \& Marx (2018) coding: Micromysticetus, $5>0$.

172. - Anteroposterior alignment of proximal opening of facial canal, internal acoustic meatus and aperture for cochlear aqueduct: (0) present; (1) absent.

173. - Anteroposterior alignment of aperture for cochlear aqueduct and aperture for vestibular aqueduct: (0) absent; (1) present.

174. - Prominent septum dividing foramina for vestibular and cochlear nerves within internal acoustic meatus (dividing foramen singulare from spiral cribriform tract): (0) present; (1) absent.

175. - Sharp cranial rim surrounding proximal opening of facial canal: (0) absent; (1) present.

176. - Shape of aperture for cochlear aqueduct: (0) round with sharply defined dorsal margins; (1) slit-like.

177. - Size of aperture for cochlear aqueduct: (0) smaller than aperture for vestibular aqueduct; (1) approximately the same size.

178. - Aperture for cochlear aqueduct and fenestra rotunda: (0) separate; (1) confluent.

179. - Superior process: (0) present as a distinct crest forming the lateral wall of the suprameatal fossa; (1) the lateral border of the suprameatal fossa is low and not clearly defined; (2) absent. Change in Fordyce \& Marx (2018) codings: Micromysticetus, Eomysticetus, Morenocetus, $1>0$.

Comment: we changed the codings of the three taxa mentioned above because their condition more resemble that of Zygorhiza and Cynthiacetus (state 0) than that of Waipatia, Squalodon, Coronodon, and ChM5720 (state 1).

180. - Suprameatal area hypertrophied: (0) absent; (1) present.

181. - Development of crista transversa: (0) depressed well below the rim of the internal acoustic meatus; (1) well developed and reaching the cerebral surface of the pars cochlearis.

182. - Morphology of crista transversa: (0) developed as a septum of varying thickness; (1) proximal opening of facial 
canal is widely separated from internal acoustic meatus and connected to the latter via a distinct sulcus.

183. — Hiatus Fallopii: (0) absent or small opening located anterior or anteroventral to proximal opening of facial canal; (1) as state 0 , but with the hiatus Fallopii being well developed and large; (2) anterior border of proximal opening of facial canal is continuous with the hiatus Fallopii and shaped like a fissure.

184. - Size of proximal opening of facial canal: (0) no more than half the size of the internal acoustic meatus; (1) more than half the size of the internal acoustic meatus.

185. - Tympanal recess of scala tympani: (0) absent; present (1).

186. - Squamosal flange located posterior to lateral tuberosity: (0) absent; (1) present.

187. - Articulation surfaces on posterior processes of tympanic bulla and periotic: (0) unfused; (1) fused in adults to form compound posterior process.

188. - Morphology of facial sulcus on compound posterior process: (0) absent or shallow with equally defined anterior and posterior borders; (1) deep groove with elevated anterior and/or posterior borders; (2) as state 1, but with the facial sulcus being partially or entirely floored.

Comment: we have retained the formulation of Marx \& Fordyce (2015), but we have merged their states 1 and 2.

189. - Position of facial sulcus on compound posterior process in ventral view: (0) facial sulcus runs close to or along the posterior border of the compound posterior process; (1) facial sulcus located centrally on the ventral surface of the compound posterior process. Change in Fordyce \& Marx (2018) coding: Piscobalaena, $0>1$.

190. - Orientation of compound posterior process in ventral view, with periotic being in situ: (0) oriented posterolaterally with respect to the longitudinal axis of the anterior process of the periotic; (1) oriented at a right angle to the axis of the anterior process.

191. - Shape of posterior processes (periotic + tympanic whether fused or not): (0) cylindrical or slightly conical; (1) short and stocky; (2) flattened anteroposteriorly; (3) tetrahedral plug, widening at apex. Change in Fordyce \& Marx (2018) coding: Waipatia, ? > 1.

192. - Exposure of posterior processes (periotic + tympanic whether fused or not) on lateral skull wall: (0) external surface absent or poorly defined; (1) external surface present but distinct from lateral skull wall (i.e., faces ventrolaterally and not conspicuously laterally); (2) lateral surface is expanded and firmly integrated into the lateral skull wall; (3) as state 2, but with the exposed lateral surface being flat to concave and defined by a distinct ridge separating it from its ventral surface. Change in Fordyce \& Marx (2018) coding: Waipatia, ? > 0

193. - Bony texture of ventral surface of compound posterior process: (0) massive; (1) spongy; (2) fibrous.

Comment: we added a new state to this character to acknowledge for the spongy nature of the posterior processes of periotic and tympanic (whether fused or not). Consequently, we have changed the codings of Fordyce \& Marx (2018) accordingly.

194 - Neck of compound posterior process markedly constricted: (0) absent; (1) present.

195. - Anterior border of bulla in dorsal or ventral view: (0) obliquely truncated; (1) squared; (2) rounded; (3) pointed.

196. - Anterior portion of bulla transversely wider than posterior portion in ventral view: (0) absent; (1) present.

197. - In situ orientation of main axes of tympanic bullae in ventral view: (0) diverging posteriorly; (1) parallel; (2) diverging anteriorly.

198. - Position of dorsal origin of lateral furrow: (0) located along posterior two thirds of the anteroposterior length of the bulla; (1) located at roughly one third of the anteroposterior length of the bulla.

199. - Orientation of lateral furrow in lateral view: (0) ventral; (1) distinctly anteroventral.

200. - Orientation of ventral keel of lateral lobe of bulla: (0) faces ventrally; (1) faces ventromedially or medially.

201. - Anteroposterior outline of lateral lobe or main ridge of bulla in lateral view: concave (0); straight or convex (1).

202. - Position of involucral ridge in dorsal view: (0) coincident with medial edge of the bulla; (1) laterally retracted.

203. - Position of involucral ridge relative to posterior margin of bulla: (0) coincident with posterior margin; (1) retracted anteriorly.

204. - Sigmoid process deflected laterally in anterior or posterior view: (0) absent; (1) present; (2) as state 1, but with the sigmoid process being nearly horizontal. 
205. - Dorsomedial corner of sigmoid process in anterior view: (0) separated from the pedicle of the malleus; (1) confluent with the pedicle of the malleus.

206. - Ventral margin of sigmoid process in lateral view: (0) present; (1) absent, with the lateral margin of the sigmoid process turning smoothly into a sulcus on the lateral side of the bulla.

207. - Shape of conical process in lateral view: (0) well developed and dorsally convex; (1) reduced to a low ridge or absent.

208. - Elliptical foramen: (0) present; (1) absent.

209. - Inner posterior prominence (medial lobe of tympanic bulla): (0) present as distinct lobe and transversely wider than its lateral counterpart; (1) present but subequal in width to the lateral lobe or smaller; (2) absent or indistinct.

210. - Interprominential ridge (crest connecting medial and lateral lobes of tympanic bulla) in posterior view: (0) present; (1) absent.

211 - Transverse creases on dorsal surface of involucrum: (0) poorly developed or absent; (1) well defined and deep.

212. - Ridge on inside of bulla extends laterally from involucrum and partially divides cavum tympani into anterior and posterior portions: (0) present; (1) absent.

213. - Tympanic sulcus: (0) developed as a faint line; (1) forms a distinct crest or sulcus.

214. - Outline and position of tympanic sulcus: (0) forms a semicircular and ventrally curved line well separated from the intersection of the conical and sigmoid processes; (1) forms a roughly horizontal line at or close to the level of the intersection of the conical and sigmoid processes.

215. - Anteromedial portion of ventral surface of tympanic bulla: (0) transversely convex; (1) distinctly flattened or slightly concave. Change in Fordyce \& Marx (2018) coding: Coronodon, $0>1$

216. - Anterolateral corner of bulla: (0) broadly rounded; (1) inflated and forming a distinct lobe; (2) flattened.

217. — Anterolateral ridge or shelf: (0) absent; (1) present.

218. - Position of posterior pedicle of tympanic bulla in dorsal view: (0) situated at or near the posterior border of the bulla; (1) located far anterior to the posterior end of the bulla.
219. - Posterior mandibular cheek teeth: (0) oriented vertically or anteriorly; (1) reclined posteriorly.

220. - Medial surface of central part of mandible: (0) similar to lateral surface; (1) distinctly flattened relative to lateral surface.

221. - Dorsomedial surface of posterior portion of mandibular body: (0) flat or convex; (1) distinctly excavated.

222. - Mandibular symphysis: (0) sutured or fused; (1) unfused.

223. - Outline of posterior portion of mandible in dorsal or ventral view: (0) follows a straight line or simple curve; (1) sigmoidal owing to a laterally reflexed neck and condyle.

224. - Mandibular body in dorsal view: (0) bowed medially; (1) straight; (2) bowed laterally, but with curvature mainly confined to anterior portion of mandible; (3) evenly bowed laterally.

225. - Anterior extremity of mandible: (0) vertical or slightly twisted, with the ventral edge shifted medially; (1) apex of mandible shifted to an almost horizontal position.

226. - Height of dentary at anterior extremity along the mandibular symphysis or symphyseal groove: (0) tapering dorsoventrally anteriorly; (1) not tapering.

227. - Mandibular body (horizontal ramus, from apex of dentary to posterior edge of last molar) in medial or lateral view: (0) height of ramus remains roughly constant throughout; (1) arched dorsally; (2) increases in height anteroposteriorly;

(3) dorsoventrally constricted near the center; (4) decreasing in height anteroposteriorly, with the anteriormost portion being distinctly expanded. Changes in Fordyce \& Marx (2018) codings: Waipatia, $0>2$; Physeter, $0>0 \& 2$; Coronodon, $0>2$

228. - Height of mandibular foramen: (0) dorsoventral height approximately that of the mandibular body, thus forming a mandibular fossa; (1) dorsoventral height about half that of the mandibular body or less.

229. - Anterior border of mandibular foramen: (0) rounded; (1) sharply triangular.

230. - Dorsal border of mandibular foramen: (0) projected medially and developed into a roof absent; (1) present.

231. - Satellite process: (0) absent or limited to a low rugosity; (1) present. 
232. - Ridge on posteromedial portion of coronoid process: (0) running close and parallel to its posterior border: absent; (1) present.

233. - Relative position of anterior border of mandibular foramen: (0) in line with coronoid process; (1) posterior to coronoid process.

234. - Subcondylar furrow: (0) absent or extremely shallow; (1) present as a well-defined groove medially only; (2) as state 1 , but with the dorsal border of the furrow being accentuated by a medially well-developed condyle; (3) extends across the posterior surface of the condyle, separating it from the angular process both medially and laterally. Change in Fordyce \& Marx (2018) coding: Coronodon, ? > 0 .

235. - Coronoid process in lateral or medial view: (0) forms a broad elevated plate; (1) distinctly triangular and low; (2) shaped like a finger and pointing posteriorly.

236. - Shape of coronoid process (if triangular) in lateral or medial view: (0) sharply triangular and about as high dorsoventrally as long anteroposteriorly; (1) bluntly triangular and considerably longer than high.

237. - Outline of coronoid process in anterior view: (0) vertical; (1) bent laterally.

238. — Postcoronoid elevation: (0) absent; (1) present.

239. - Angular process in medial view: (0) hollowed out; (1) solid.

240. - Position of angular process relative to mandibular condyle: (0) located anterior to mandibular condyle; (1) located approximately below the condyle; (2) projects posteriorly beyond the condyle.

241. - Height of mandibular condyle relative to angular process: (0) lower than angular process; (1) as high or higher. Change in Fordyce \& Marx (2018) codings: Coronodon, Janjucetus, Fucaia, ? > 0; Mammalodon, 1 > ?.

242. - Angular process deflected ventrally: (0) absent; (1) present.

243. - Fossa on medial side of angular process: (0) absent; (1) present. Change in Fordyce \& Marx (2018) coding: Janjucetus, $0>$ ?.

244. - Orientation of articular surface of mandibular condyle: (0) posterior; (1) posterodorsal; (2) dorsal, with the condyle being confluent with a dorsoventrally expanded angular process; (3) dorsal, with the condyle being larger than and clearly offset from the angular process.

245. - Sulcus for attachment of mylohyoid muscle (mylohyoid sulcus) on ventromedial surface of mandible: (0) absent; (1) present.

246. - Foramen transversarium (vertebrarterial foramen) in axis: (0) absent; (1) present.

247. - Development of parapophysis and diapophysis on axis in anterior or posterior view: (0) parapophysis considerably more robust than diapophysis; (1) parapophysis and diapophysis are similar in size. Change in Fordyce \& Marx (2018) coding: Piscobalaena $1>0 \& 1$.

248. - Cervical vertebrae: (0) separate; (1) partially fused starting from the axis; (2) completely fused.

249. - Parapophysis on seventh cervical vertebra: (0) present; (1) absent.

250. - Centra of cervical vertebrae in anterior or posterior view: (0) rounded; (1) squared.

251. - Orientation of transverse processes of anterior lumbar vertebrae in anterior or posterior view: $(0)$ oriented distinctly ventrolaterally; (1) oriented slightly ventrolaterally or subhorizontally; (2) oriented laterally and horizontally.

252. - Outline of transverse processes of lumbar vertebrae in anterior or posterior view: (0) flattened or slightly thickened; (1) robust and triangular, with a dorsoventrally thickened base reaching up to the ventral border of the neural arch.

253. - Apices of neural spines of posterior thoracic and anterior lumbar vertebrae anteroposteriorly: (0) expanded and squared off absent; (1) present.

254. - Number of lumbar vertebrae: (0) more than 12; (1) 10 to 12 ; (2) fewer than 10.

255. - Zygapophyses (= metapophyses) on posterior thoracic and anterior lumbar vertebrae in lateral view: (0) oriented dorsally to anterodorsally; (1) sub-horizontal. Changes in Fordyce \& Marx (2018) coding, Physeter, $0>1$.

Comment: the formulation of character 249 of Fordyce \& Marx (2018) has been slightly modified but this change does not modify the codings.

256. - Sternum: (0) composed of several bones; (1) composed of one bone. 
257. - Manubrium of sternum: (0) roughly rectangular, massive and thick (thickness is at least $50 \%$ of anterior width) with cylindrical anterior edge; (1) cordiform or plate-like; (2) cruciform or T-shaped; (3) hourglass-shaped (strongly constricted in its median region with median width less than 50\% anterior width) and dorsoventrally thin (less than 50\% anterior width). Changes in Fordyce \& Marx (2018) codings: Physeter, Mammalodon, $0>1$; Fucaia, Aetiocetus cotylalveus, A. polydentatus $0>3$.

Comments: the formulation of states (0) and (2) of this character has been modified, and a fourth state (3) had been added, which required some changes in the codings of Fordyce \& Marx (2018).

258. - Anterior (but not anteriormost) ribs expanded and pestle-like at distal extremity and pachyosteosclerotic: (0) present; (1) absent.

259. - Proportions of scapula: (0) length of scapula is less than 150 percent its maximum dorsoventral height; (1) length equals 150 percent of height or more.

260. _ Coracoid process of scapula: (0) present; (1) absent. 261. - Acromion process of scapula: (0) present; (1) absent.

262. - Supraspinous fossa of scapula: (0) present; (1) absent or nearly absent, with acromion process located near anterior edge of scapula.

263. - Deltoid crest of humerus: (0) present as a distinct crest; (1) absent or reduced to a variably developed rugosity.

264. - Relative length of humerus: (0) longer than or roughly the same length as radius and ulna; (1) distinctly shorter than radius and ulna.

Comment: this character has been slightly re-formulated with no incidence on the codings of Fordyce \& Marx (2018).

265. - Orientation of humeral head in medial or lateral view: (0) proximal to posteroproximal (with the posterior component much smaller than the proximal one); (1) Posterior to posteroproximal (with the posterior component equal to or much greater than the proximal one. Change in Fordyce \& Marx (2018) codings: Waipatia, 1 > 0; Eschrichtius, Megaptera, $0>1$.

Comment: this character has been slightly re-formulated with some incidence on the codings of Fordyce \& Marx (2018).

266. - Posterior notch on distal portion of humeral shaft in medial or lateral view: (0) present; (1) absent.

267. - Articulation facet for radius on humerus in medial or lateral view: (0) radial and ulnar facets are subequal in size;
(1) radial facet is distinctly larger than ulnar facet, excluding the olecranon.

268. - Shaft of radius in medial or lateral view: (0) roughly as wide as that of the ulna; (1) markedly more robust and up to twice as wide as that of the ulna; (2) twice the width of that of the ulna or wider.

269 - Functional humeral trochlea: (0) present; (1) absent. Comment: the presence of a humeral trochlea indicates that the elbow was articulated (state 0). In state the radial and ulnar articulation are separated by a conspicuous crest, which interrupts the trochlea; in this case, the elbow articulation is ankylosed.

270. — Radial crest: (0) present as a distinct tubercle or crest; (1) absent or reduced to a low angle.

271. - Proximal epihysis of radius in medial or lateral view: (0) narrower than radial shaft or approximately equal in width; (1) proximal epiphysis is slightly flared.

272. - Olecranon process: (0) present as a distinct process; (1) absent.

273. - Manus: (0) pentadactyl; (1) tetradactyl.

274. - Femur: (0) present as a relatively well-developed bone; (1) absent or reduced to a barely recognisable lump with an extremely rough surface texture.

275. — Tibia: (0) present; (1) absent.

276. - Ventral throat grooves: (0) absent; (1) present and terminate well anterior to umbilicus; (2) present and extend to umbilicus.

277. — Ventral throat pouch: (0) absent; (1) present.

278. - Tongue: (0) muscular; (1) reduced and predominantly connective tissue.

279. - Temporomandibular joint: (0) synovial; (1) fibrocartilagenous mass originates in the glenoid fossa and envelopes the mandibular condyle.

280. - Longitudinal ridges on rostrum: (0) absent or indistinct; (1) single median ridge; (2) three longitudinal ridges.

281. - Dorsal fin: (0) present as fin or dorsal hump; (1) absent (1).

282. - Chromosome number: (0) 42; (1) 44. 


\section{CHARACTERS OF FORDYCE \& MARX (2018)'S DATA MATRIX, WHICH HAVE NOT BEEN RETAINED IN THE CHARACTER LIST OF OUR ANALYSIS.}

Character 12 of Fordyce \& Marx (2018). — ("Anterior border of supraorbital process lateral to ascending process of the maxilla bordered by lacrimal only, 0 ; bordered by lacrimal and maxilla, 1") is confusing because it relies on the lateral limit of the ascending process of the maxilla, which is continuous with the remaining lateral part of the maxilla. Therefore, this "lateral limit" is very difficult to determine. The only precise definition of the anterolateral limit of the ascending process could be where the maxilla contacts the medial edge of the lacrimal. But in this case all the taxa would be coded as state 0 of Fordyce \& Marx (2018) or state 1 of Marx \& Fordyce (2015) and the character would be useless. The fact that these authors drastically changed their mind in the definition and coding of the states of this character between 2015 and 2018 is revealing. For example, Zygorhiza was coded with an anterior edge of the supraorbital process bordered by the lacrimal and maxilla by Marx \& Fordyce (2015), whereas Fordyce \& Marx (2018) considered that it was bordered by the lacrimal only. Because of these difficulties to define this character, we therefore rather delete it from the matrix.

Character 22 of Fordyce \& Marx (2018). — ("Anterior edge of narial fossa located in posterior three quarters of rostrum (0); located in anterior quarter of rostrum (1)") has been deleted because the identification of the anterior edge of the narial fossa is in many cases very subjective. In fact, it has been coded 1 by Fordyce \& Marx (2018) in Mammalodon and Janjucetus when the anterior region of the rostrum is missing in Mammalodon and sufficiently damaged in Janjucetus to prevent a satisfactory identification of the anterior edge of the narial opening. Furthermore, in Fucaia goedertorum and Coronodon havensteini, in which the rostrum is complete, the anterior edge of the narial fossa is continuous with the mesorostral groove. This condition makes the identification of the anterior edge of the narial fossa extremely improbable. The only taxon in which the anterior edge of the narial fossa is probably located in the anterior quarter of the rostrum is Mystacodon, but again, in this taxon, the narial fossa in continuous anteriorly with the mesorostral groove and the precise anterior edge of the narial fossa is uncertain. Therefore, because on taxon only is could be coded (1) this character is not relevant to our matrix.
Character 34 of Fordyce \& Marx (2018). — ("Heavy planar occlusal wear resulting in loss of most or all of tooth crown absent (0); present (1)") has been deleted because it is a behavioral and not a morphological character. Furthermore, this character is misleading in the case of a young adult specimen with unworn teeth.

Character 45 of Fordyce \& Marx (2018). — ("Postorbital process in dorsal view: oriented posteriorly $(0)$; oriented laterally, 1; oriented posterolaterally, 2; short and not markedly projecting in any direction, 3 ") has been deleted because we regard it as too subjective in the definition of the four states. In fact, the postorbital process is always oriented posterolaterally in all the cases. For example, in Llanocetus and Coronodon Fordyce \& Marx code it as oriented posteriorly while it is clearly oriented posterolaterally.

Character 64 of Fordyce \& Marx 2018. — ("Lateral flange at base of ascending process of maxilla absent (0); present (1)") was coded (1) in one taxon only (Cetotherium rathkii). Therefore, this character is uninformative and has been deleted.

Character 95 of Fordyce \& Marx (2018). — (“Zygomatic process of squamosal dorsoventrally expanded in lateral view: absent (0); present with the zygomatic process being distinctly higher dorsoventrally than wide transversely (1)") has been deleted from our matrix because of the great variety of morphologies of the zygomatic process and because of the difficulty to evaluate the degree of dorsoventral expansion of the process according to the anteroposterior position of the measurement. In these conditions, we regard the evaluation of this character as very subjective.

Character 166 of Fordyce \& Marx (2018). — ("Elongate lobe and fossa extending posteromedially from fenestra ovalis in ventral view absent (0); present (1)") has been deleted because state (1) was not present in our taxon sample.

Character 252 of Fordyce \& Marx (2018). — ("Posterior ribs transversely expanded absent (0); present (1)") has been deleted because state (1) is coded by in two taxa only (Caperea marginata and Cetotherium riabinini) and the expansion of the posterior ribs is very different in the two species. In the former the ribs are expanded anteroposteriorly and are flat; in the later the ribs appear to be heavily pachyosteosclerotic and are expanded in all directions (as observed in sirenians). Therefore, these two conditions are probably not homologous. 